\title{
MEANLINE ANALYSIS OF RADIAL INFLOW TURBINES AT DESIGN AND OFF-DESIGN CONDITIONS
}

\author{
by
}

\section{Zicheng Wei}

A thesis submitted to the Faculty of Graduate and Postdoctoral Affairs in partial fulfillment of the requirements for the degree of

\section{Master of Applied Science}

in

\author{
Aerospace Engineering
}

Ottawa-Carleton Institute for Mechanical \& Aerospace Engineering

Department of Mechanical \& Aerospace Engineering

Carleton University

Ottawa, Ontario, Canada

CZicheng Wei 


\begin{abstract}
Two codes have been developed for use in the preliminary aerodynamic design of radial inflow turbines. Both use a one-dimensional approximation for the flow through the machine along with empirical correlations for estimating the losses. This is known as meanline analysis. The first code, known as RITMLD (for Radial Inflow Turbine Meanline Design Operating Point), is used to obtain the main geometric parameters of the turbine based on the required performance at the design operating point. The second code, RITMLO (for Radial Inflow Turbine Meanline Off-Design Operating Point), is then used to predict the performance at off-design values of mass flow rate and rotational speed.
\end{abstract}

The codes were intended for use in designing the turbines for closed-cycle gas turbine engines employing super-critical carbon dioxide $\left(\mathrm{S}-\mathrm{CO}_{2}\right)$ as the working fluid. Since $\mathrm{S}-\mathrm{CO}_{2}$ behaves as a non-ideal gas, the codes use real gas properties throughout the analysis. The codes can be used for any other ideal or non-ideal gas by substituting calls to the appropriate fluid property subroutines from the National Institute for Standards and Technology (NIST).

After a specific turbine was designed using RITMLD, the flow was analyzed in detail using ANSYS-CFX, a three-dimensional Computational Fluid Dynamics (CFD) code. The goal was to assess how accurately the performance is predicted by the simple meanline analysis. Furthermore, since it is novel to predict the full off-design characteristics using the meanline approach, CFX was also used to calculate the off-design performance. The comparison of results between meanline and CFD analyses show that the general trends of full turbine characteristics are similar for both prediction methods. 


\section{Acknowledgements}

First and foremost, I would like to thank my supervisor, Professor S. A. Sjolander. His guidance and constructive comments have contributed greatly to the completion of this thesis.

I would like to thank my co-supervisor Professor H. Saari, who spent a considerable portion of his time to make useful suggestions for further revisions.

I would also appreciate the opportunity, which is provided by Professor Sjolander and Professor Saari, to write this thesis and access the field in which I am very interested.

The financial support of the Government of Canada through the Natural Resources Canada (NRCan) ecoEnergy Innovation Initiative is also gratefully acknowledged.

Finally, I would like to express my gratitude to my parents and family for their immense love and support in my life. 


\section{Table of Contents}

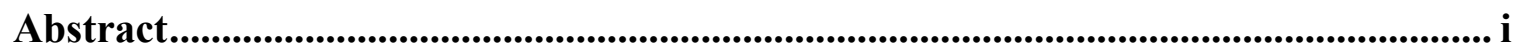

Acknowledgements ................................................................................................................ ii

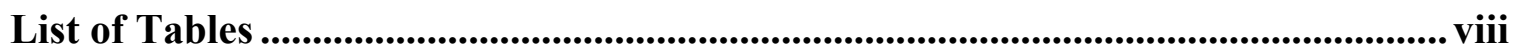

List of Figures...................................................................................................................... ix

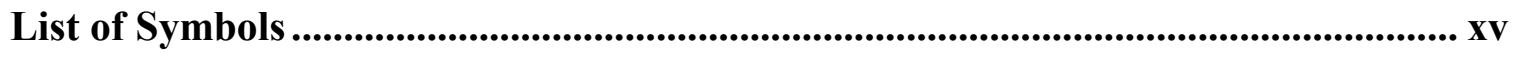

Chapter 1 Introduction................................................................................................................... 1

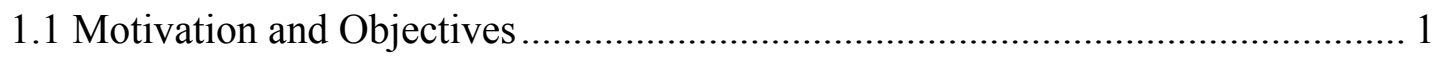

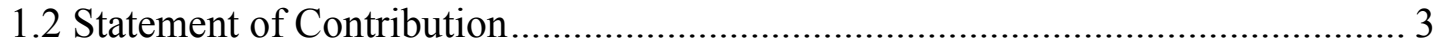

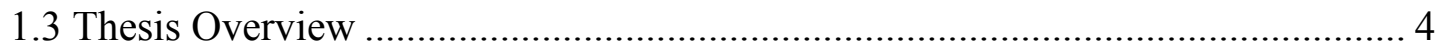

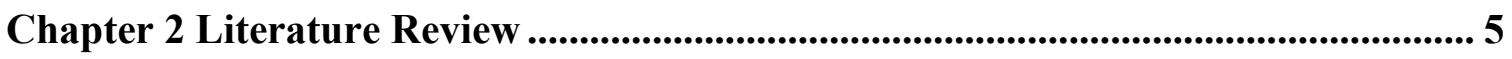

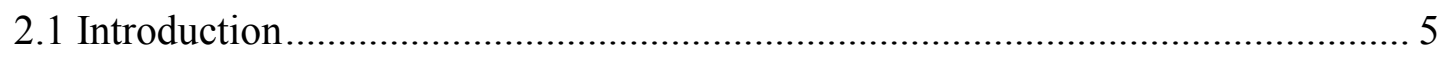

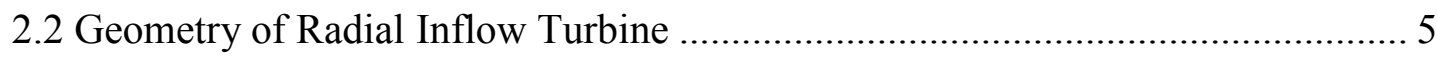

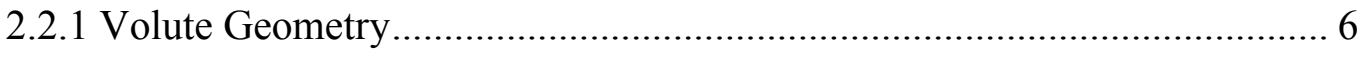

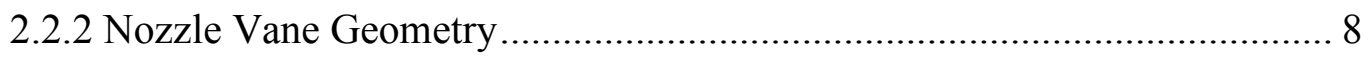

2.2.3 Rotor Blade Geometry ................................................................ 9

2.3 Nomenclature and Flow Angle Definition of Radial Inflow Turbine................. 10

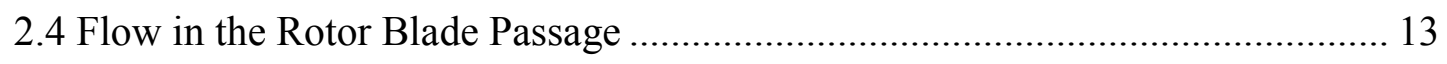




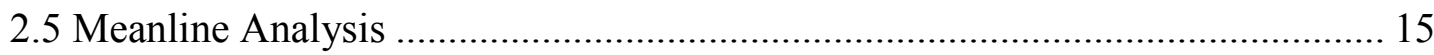

2.5.1 Meanline Analysis at the Design Operating Point ..................................... 16

2.5.2 Meanline Analysis at the Off-Design Operating Point............................... 25

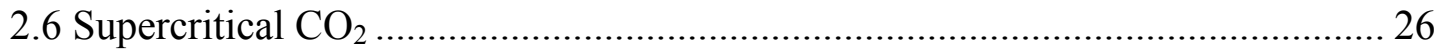

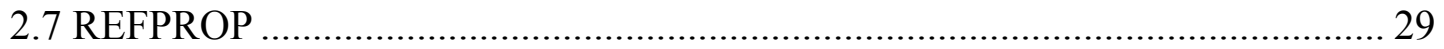

Chapter 3 Meanline Analysis Codes .......................................................................... 30

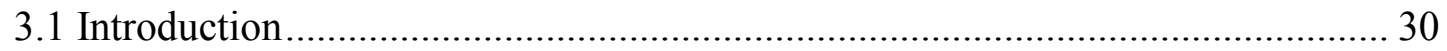

3.2 Loss Correlations for Meanline Analysis of Radial Inflow Turbines................... 31

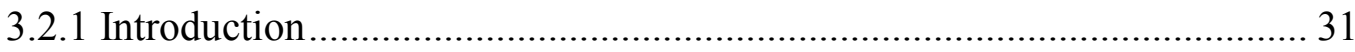

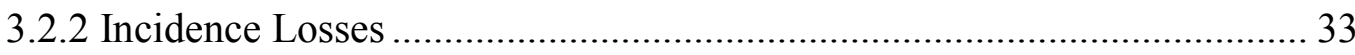

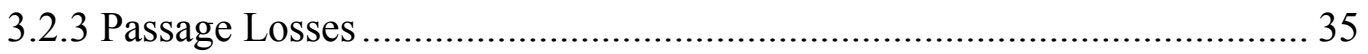

3.2.4 Tip Clearance Losses ............................................................................. 39

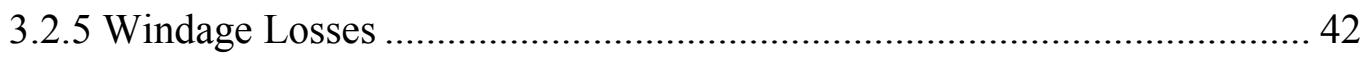

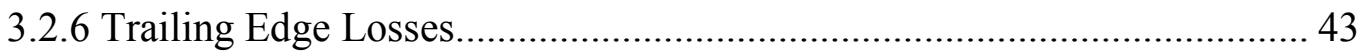

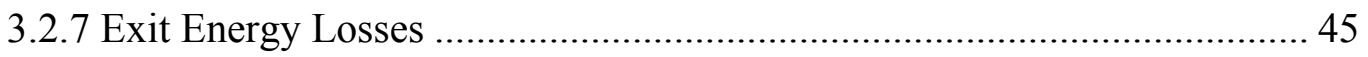

3.3 Development of the Radial Inflow Turbine Meanline Design Operating Point

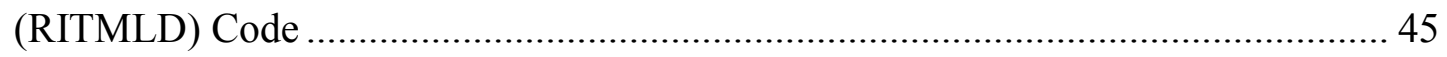

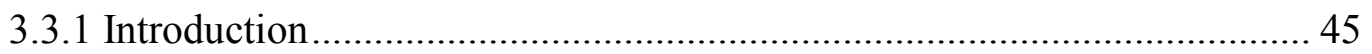

3.3.2 Development of Rotor Design in RITMLD ............................................... 46

3.3.3 Development of Nozzle Design in RITMLD............................................ 50 
3.3.4 Development of Volute Design in RITMLD 51

3.3.5 Calculation of Loss Correlations in RITMLD ........................................... 53

3.3.6 Update of Turbine Stage Pressure Ratio in RITMLD ................................. 53

3.3.7 Development of Additional Functions for RITMLD ................................... 55

3.4 Development of the Radial Inflow Turbine Meanline Off-Design Operating Point

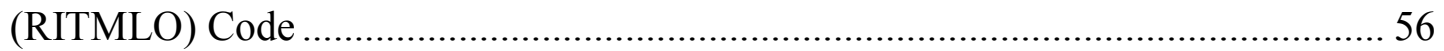

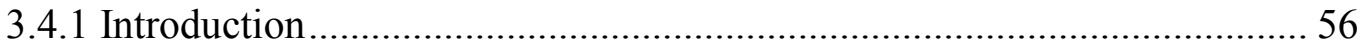

3.4.2 Development of the Radial Inflow Turbine Meanline Off-Design Operating

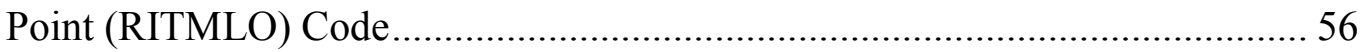

Chapter 4 CFD Model ........................................................................................................... 62

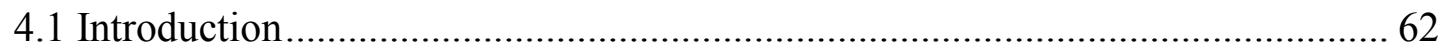

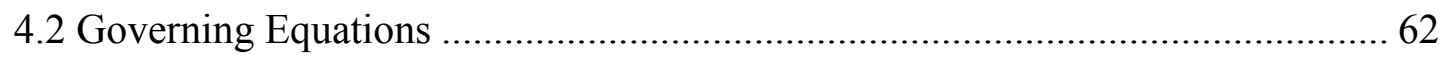

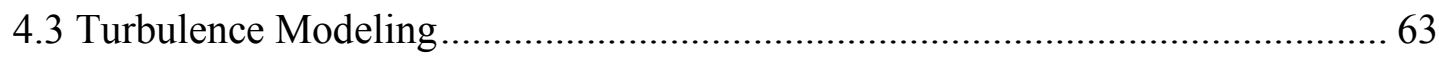

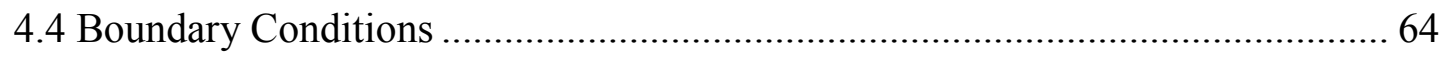

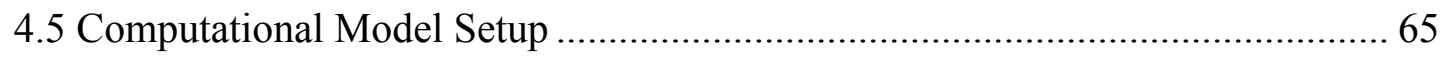

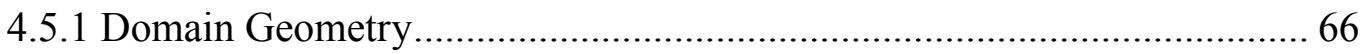

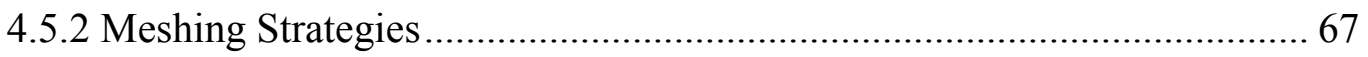

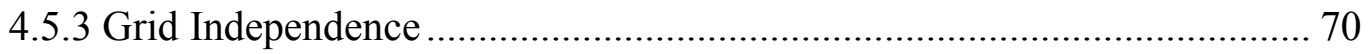

4.5.4 Solution Convergence ............................................................................... 71 
5.1 Introduction 73

5.2 Results of Meanline Analysis at the Design Operating Point. 73

5.3 CU-BCL Radial Inflow Turbine Characteristics from RITMLO ...................... 83

5.4 Result of CFD Analysis for the CU-BCL Radial Inflow Turbine ..................... 90

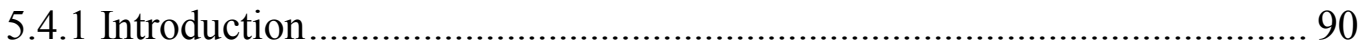

5.4.2 Result of CFD Analysis at Design Operating Point................................. 90

5.4.3 Result of CFD Analysis at Off-Design Operating Points ........................ 93

5.5 The Comparison of Results from Meanline and CFD Analyses....................... 102

5.5.1 The Comparison of Results from Meanline and CFD Analyses at Design

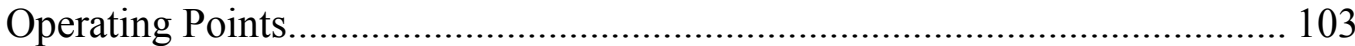

5.5.2 The Comparison of Results from Meanline and CFD Analyses at Off-Design Operating Points ....................................................................... 105

Chapter 6 Conclusions and Recommendations........................................................... 114

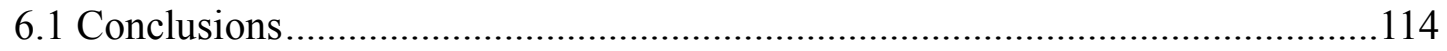

6.2 Recommendations for Future Work.............................................................116

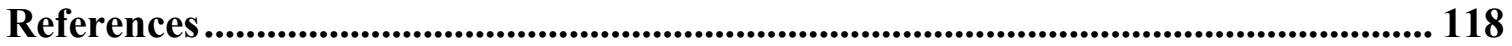

Appendix $A$.............................................................................................................................. 123

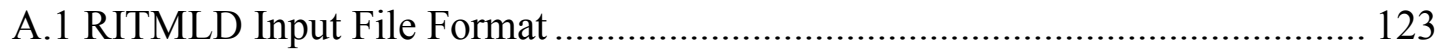


B.1 RITMLO Input File Format ........................................................................... 129

B.2 Example of Input Files for RITMLO ……………......................................... 131

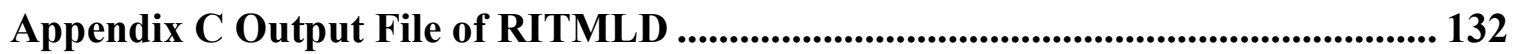

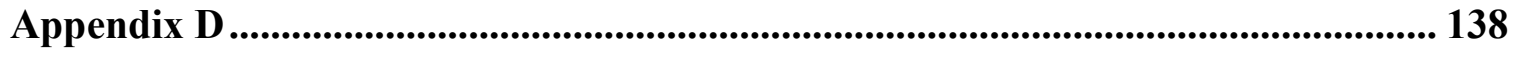

D.1 Rotor Design Procedures in RITMLD .......................................................... 138

D.2 Nozzle Design Procedures in RITMLD ......................................................... 143

D.3 Volute Design Procedures in RITMLD .......................................................... 145

Appendix E Results Comparison for Off-Design Rotational Speed between Meanline and CFD Analyses............................................................................................................. 147 


\section{List of Tables}

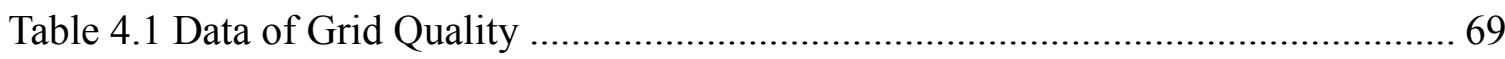

Table 4.2 Comparison between the Coarse and Fine Meshes ..................................... 70

Table 5.1 Design Operating Point for the CU-BCL Radial Inflow Turbine..................... 74

Table 5.2 The CU-BCL Radial Inflow Turbine Stage Dimensions............................... 76

Table 5.3 Feasibility Checks for the Meanline Analysis of the CU-BCL Radial Inflow

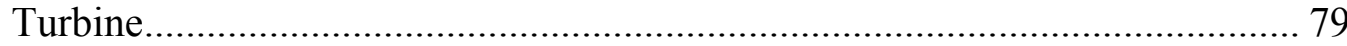

Table 5.4 Stage Performance of the CU-BCL Radial Inflow Turbine .......................... 83

Table 5.5 Results Comparison of CFD Analysis at Design and Off-Design Points........ 99

Table 5.6 Results Comparison of Meanline and CFD analyses at Design Operating Point

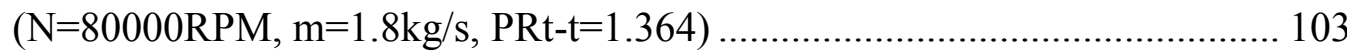

Table 5.7 Deviation of the CU-BCL Radial Inflow Turbine Rotor Blade..................... 105 


\section{List of Figures}

Figure 1.1 Schematic of the 2013-2014 Carleton University Fourth-Year Engineering

Project Power Plant......................................................................................... 1

Figure 2.1 Radial Turbine Stage Cross Section (Aungier, 2005) .................................. 6

Figure 2.2 Volute Geometry (Baines, 2003) …............................................................ 7

Figure 2.3 Nozzle Vanes (Baskharone, 2006) .......................................................... 8

Figure 2.4 Radial Turbine Rotor Geometry (Baskharone, 2006) ................................. 9

Figure 2.5 Nomenclature of Radial Turbine (a) Volute (b) Nozzle Vane and (c) Rotor Blade (Adapted from Aungier 2005) .........................................................11

Figure 2.6 Flow Angle Definition of Radial Inflow Turbine Rotor (Adapted from

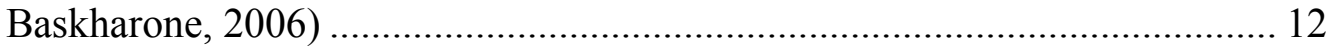

Figure 2.7 Recirculation in the Inlet Region of a Radial Turbine Rotor Passage (Baines,

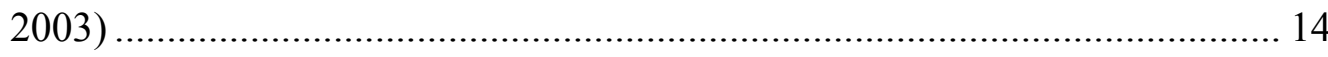

Figure 2.8 Mean Kinetic Energy Loss Profiles at Several Typical Locations of a Radial Turbine Rotor Passage (Baskharone, 2006)............................................. 15

Figure 2.9 Example of a Radial Turbine Mean Radius and Velocity Triangles at Meanline Design Point Analysis (Adapted from Baskharone, 2006)........................... 17

Figure 2.10 Correlation of Blade Loading and Flow Coefficients for Radial Inflow Turbines. Data Points and Contours Show Total to Static Efficiency (Chen and Baines, 1994) ...................................................................................... 19

Figure 2.11 A Generalized Stage Performance Chart (Aungier, 2005) .......................... 22

Figure 2.12 Example of Radial Turbine Mean Radius and Velocity Triangles at Meanline Off-Design Point Analysis (Adapted from Baskharone, 2006) 26 
Figure 2.13 Carbon Dioxide Pressure-Temperature Phase Diagram (Adapted from Taylor, 1996) 27

Figure 2.14 Generalized Compressibility Factor (Z) Diagram (Adapted from Holman, 1988) 28

Figure 3.1 Predicted Distribution of Radial Turbine Losses along Curve of Maximum Total to Static Efficiency (Rohlik, 1968) ................................................. 32

Figure 3.2 Tip Clearance of a Radial Turbine Rotor (Baines, 2003)............................. 39

Figure 3.3 Windage Loss due to Rotor Backflow (Baines, 2003) ................................ 42

Figure 3.4 An External Elliptical Volute (Baines, 2003)............................................ 52

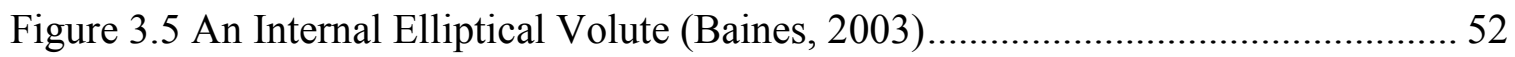

Figure 3.6 The $\mathrm{h}_{0}$-s Diagram for Compressible-Flow Turbines (adapted from Sjolander, 2013) 54

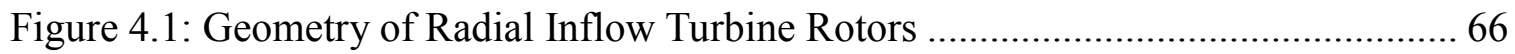

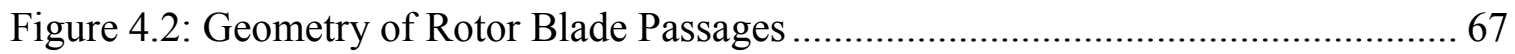

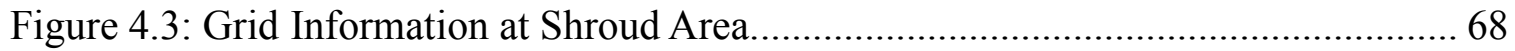

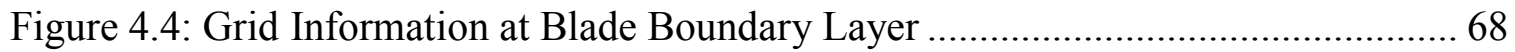

Figure 4.5 (a) Normalized RMS Residuals at Design Operating Point ......................... 72

Figure 4.5 (b) Normalized MAX Residuals at Design Operating Point ......................... 72

Figure 5.1 The CU-BCL Turbomachinery Arrangement (CU-BCL 2013-14 Design Team,

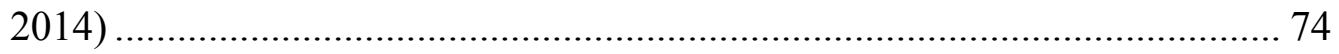

Figure 5.2 Nomenclature for Radial Inflow Turbine Stage Cross Section ..................... 75

Figure 5.3 Velocity Triangles of the CU-BCL Radial Inflow Turbine at Design Operating Point (Adapted from Baskharone, 2006) ..................................................... 76 
Figure 5.4 Correlation of Blade Loading and Flow Coefficients for Radial Inflow Turbines. Data Points and Contours Show Total to Static Efficiency (Chen and Baines, 1994) 78

Figure 5.5 Distribution of Enthalpy Losses at the CU-BCL Radial Inflow Turbine Rotor

Figure 5.6 Comparison of Nozzle and Rotor Enthalpy Losses of the CU-BCL Radial Inflow Turbine 82

Figure 5.7 Characteristics of Total-to-Static Efficiency of the CU-BCL Radial Inflow Turbine 84

Figure 5.8 Characteristics of Total-to-Total Efficiency of the CU-BCL Radial Inflow Turbine 85

Figure 5.9 Corrected Mass Flow Rate of the CU-BCL Radial Inflow Turbine. 86

Figure 5.10 Characteristics of the Rotor Inlet Relative Flow Angle of the CU-BCL Radial Inflow Turbine.

Figure 5.11 Characteristics of the Rotor Outlet Absolute Flow Angle of the CU-BCL Radial Inflow Turbine 88

Figure 5.12 Characteristics of the Rotor Inlet Absolute Mach Number of the CU-BCL Radial Inflow Turbine

Figure 5.13 Velocity Vectors at 50\% Span of the CU-BCL Radial Inflow Turbine Rotor Blade Passages 91

Figure 5.14 Contour of Entropy at 50\% Span of the CU-BCL Radial Inflow Turbine Rotor Blade Passages

Figure 5.15 Velocity Streamlines at the CU-BCL Radial Inflow Turbine Rotor Blade Passages.

Figure 5.16 Velocity Vectors at 50\% Span of the CU-BCL Radial Inflow Turbine Rotor Blade Passages $(\mathrm{N}=80000, \mathrm{PR}=2.20)$ 93

Figure 5.17 Contour of Entropy at 50\% Span of the CU-BCL Radial Inflow Turbine Rotor Blade Passages $(\mathrm{N}=80000, \mathrm{PR}=2.20)$ 
Figure 5.18 Velocity Streamlines at the CU-BCL Radial Inflow Turbine Rotor Blade Passages $(\mathrm{N}=80000, \mathrm{PR}=2.20)$

Figure 5.19 Velocity Vectors at 50\% Span of the CU-BCL Radial Inflow Turbine Rotor Blade Passages $(\mathrm{N}=40000, \mathrm{PR}=1.87)$ 96

Figure 5.20 Contour of Entropy at 50\% Span of the CU-BCL Radial Inflow Turbine Rotor Blade Passages $(\mathrm{N}=40000, \mathrm{PR}=1.87)$........................................ 96

Figure 5.21 Velocity Streamlines at the CU-BCL Radial Inflow Turbine Rotor Blade Passages $(\mathrm{N}=40000, \mathrm{PR}=1.87)$ 97

Figure 5.22 Velocity Vectors at 50\% Span of the CU-BCL Radial Inflow Turbine Rotor Blade Passages $(\mathrm{N}=104000, \mathrm{PR}=2.41)$ 97

Figure 5.23 Contour of Entropy at 50\% Span of the CU-BCL Radial Inflow Turbine Rotor Blade Passages $(\mathrm{N}=104000, \mathrm{PR}=2.41)$ 98

Figure 5.24 Velocity Streamlines at the CU-BCL Radial Inflow Turbine Rotor Blade Passages $(\mathrm{N}=104000, \mathrm{PR}=2.41)$.

Figure 5.25 Velocity Vectors at 50\% Span of the CU-BCL Radial Inflow Turbine Rotor Blade Passages $(\mathrm{N}=40000, \mathrm{PR}=1.14)$ 101

Figure 5.26 Contour of Entropy at 50\% Span of the CU-BCL Radial Inflow Turbine Rotor Blade Passages $(\mathrm{N}=40000, \mathrm{PR}=1.14)$ 101

Figure 5.27 Velocity Streamlines at the CU-BCL Radial Inflow Turbine Rotor Blade Passages $(\mathrm{N}=40000, \mathrm{PR}=1.14)$ 102

Figure 5.28 Results Comparison for Total-to-Total Efficiency between Meanline and CFD Analyses ( $\mathrm{N}=80000 \mathrm{RPM})$

Figure 5.29 Results Comparison for Total-to-Static Efficiency between Meanline and CFD Analyses ( $\mathrm{N}=80000 \mathrm{RPM})$

Figure 5.30 Results Comparison for Mass Flow Rate between Meanline and CFD Analyses (N=80000RPM).

Figure 5.31 Results Comparison for Rotor Inlet Relative Flow Angle between Meanline and CFD Analyses ( $\mathrm{N}=80000 \mathrm{RPM})$. .110 
Figure 5.32 Results Comparison for Rotor Outlet Absolute Flow Angle between Meanline

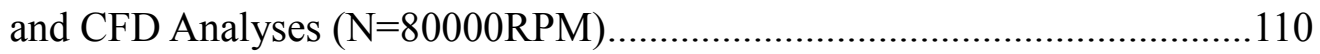

Figure 5.33 Results Comparison for Rotor Inlet Absolute Mach Number between Meanline and CFD Analyses ( $\mathrm{N}=80000 \mathrm{RPM})$

Figure 5.34 Results Comparison for Rotor Outlet Absolute Mach Number between Meanline and CFD Analyses (N=80000RPM) 111

Figure E-1 Results Comparison for Total-to-Total Efficiency between Meanline and CFD Analyses ( $\mathrm{N}=40000 \mathrm{RPM})$.

Figure E-2 Results Comparison for Total-to-Static Efficiency between Meanline and CFD Analyses $(\mathrm{N}=40000 \mathrm{RPM})$........................................................... 148

Figure E-3 Results Comparison for Mass Flow Rate between Meanline and CFD Analyses $(\mathrm{N}=40000 \mathrm{RPM})$ 148

Figure E-4 Results Comparison for Rotor Inlet Relative Flow Angle between Meanline and CFD Analyses (N=40000RPM)..................................................... 149

Figure E-5 Results Comparison for Rotor Outlet Absolute Flow Angle between Meanline and CFD Analyses (N=40000RPM).

Figure E-6 Results Comparison for Rotor Inlet Absolute Mach Number between Meanline and CFD Analyses (N=40000RPM) 150

Figure E-7 Results Comparison for Rotor Outlet Absolute Mach Number between Meanline and CFD Analyses (N=40000RPM) 150

Figure E-8 Results Comparison for Total-to-Total Efficiency between Meanline and CFD Analyses (N=60000RPM).

Figure E-9 Results Comparison for Total-to-Static Efficiency between Meanline and CFD Analyses ( $\mathrm{N}=60000 \mathrm{RPM})$.

Figure E-10 Results Comparison for Mass Flow Rate between Meanline and CFD Analyses $(\mathrm{N}=60000 \mathrm{RPM})$

Figure E-11 Results Comparison for Rotor Inlet Relative Flow Angle between Meanline and CFD Analyses ( $\mathrm{N}=60000 \mathrm{RPM})$ 152 
Figure E-12 Results Comparison for Rotor Outlet Absolute Flow Angle between Meanline and CFD Analyses ( $\mathrm{N}=60000 \mathrm{RPM})$

Figure E-13 Results Comparison for Rotor Inlet Absolute Mach Number between Meanline and CFD Analyses (N=60000RPM)

Figure E-14 Results Comparison for Rotor Outlet Absolute Mach Number between Meanline and CFD Analyses ( $\mathrm{N}=60000 \mathrm{RPM})$

Figure E-15 Results Comparison for Total-to-Total Efficiency between Meanline and CFD Analyses (N=104000RPM) 154

Figure E-16 Results Comparison for Total-to-Static Efficiency between Meanline and CFD Analyses ( $\mathrm{N}=104000 \mathrm{RPM})$

Figure E-17 Results Comparison for Mass Flow Rate between Meanline and CFD Analyses (N=104000RPM). 155

Figure E-18 Results Comparison for Rotor Inlet Relative Flow Angle between Meanline

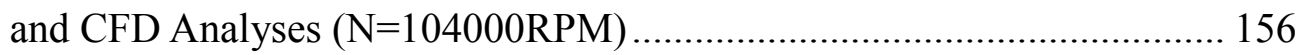

Figure E-19 Results Comparison for Rotor Outlet Absolute Flow Angle between Meanline and CFD Analyses ( $\mathrm{N}=104000 \mathrm{RPM})$. 156

Figure E-20 Results Comparison for Rotor Inlet Absolute Mach Number between Meanline and CFD Analyses (N=104000RPM)

Figure E-21 Results Comparison for Rotor Outlet Absolute Mach Number between Meanline and CFD Analyses (N=104000RPM) 


\section{List of Symbols}

A $\quad=$ area; ellipse axial semiaxis

$\begin{array}{ll}\mathrm{AR} & =\text { aspect ratio } \\ \mathrm{b} & =\text { rotor passage width } \\ \mathrm{B} & =\text { ellipse radial semiaxis } \\ \mathrm{c} & =\text { absolute velocity } \\ \mathrm{C} & =\text { specific heat at constant pressure } \\ \mathrm{c}_{\mathrm{P}} & =\text { discharge spouting velocity } \\ C_{0 s} & \\ \mathrm{CFD} & \text { Computational Fluid Dynamics }\end{array}$

CU-BCL = Carleton University Brayton Cycle Loop

$D_{h} \quad=\frac{1}{2}\left[\left(\frac{4 \pi r_{4} b_{4}}{2 \pi r_{4}+N_{R} \cdot b_{4}}\right)+\left(\frac{2 \pi \cdot\left(\left(r_{s 5}\right)^{2}-\left(r_{h 5}\right)^{2}\right)}{\pi\left(r_{s 5}-r_{h 5}\right)+N_{R} \cdot b_{5}}\right)\right]=$ mean passage hydraulic

diameter
$\Delta h_{0} \quad=$ total enthalpy change
$\mathrm{H}=$ static enthalpy
$\mathrm{H}_{0} \quad=$ stagnation enthalpy
$\Delta H_{i d} \quad=$ total-to-static ideal enthalpy drop 


$$
\begin{aligned}
& \mathrm{i} \quad=\text { incidence, in degrees } \\
& K_{a} \quad=\text { discharge coefficients for axial tip clearances } \\
& K_{r} \quad=\text { discharge coefficients for radial tip clearances } \\
& K_{a r}=\text { a cross-coupling coefficient for both axial and radial tip clearance } \\
& L \quad=\text { enthalpy losses for each loss mechanism } \\
& L_{h} \quad=\frac{\pi}{4}\left[\left(Z_{R}-\frac{b_{4}}{2}\right)+\left(r_{4}-r_{t}-\frac{b_{t}}{2}\right)\right]=\text { mean passage hydraulic length } \\
& \dot{\mathrm{m}} \quad=\text { mass flow rate } \\
& \text { M = Mach number } \\
& \mathrm{M}_{\mathrm{rel}} \quad=\text { relative Mach number } \\
& \mathrm{N}=\text { rotational speed, in RPM } \\
& n_{s} \quad=\text { specific speed } \\
& N_{R} \quad=\text { number of rotor blades } \\
& \text { NIST = National Institute for Standards and Technology } \\
& o_{t} \quad=\text { mean throat width } \\
& \mathrm{P} \quad=\text { static pressure } \\
& \mathrm{P}_{0} \quad=\text { total pressure } \\
& \mathrm{P}_{\mathrm{c}}=\text { static pressure at critical point } \\
& \mathrm{P}_{\mathrm{R}} \quad=\mathrm{P} / \mathrm{P}_{\mathrm{c}}=\text { reduced pressure } \\
& \mathrm{PR}_{\mathrm{t}-\mathrm{s}}=\text { total-to-static pressure ratio } \\
& \mathrm{PR}_{\mathrm{t}-\mathrm{t}}=\text { total-to-total pressure ratio }
\end{aligned}
$$




$$
\begin{aligned}
& q_{5} \quad=\text { rotor outlet mean blade pitch } \\
& Q \quad=\text { volume flow rate } \\
& \mathrm{r} \quad=\text { mean radius } \\
& r_{\max } \quad=\text { maximum radius of turbine stage } \\
& \Delta r \quad=\text { distance between nozzle exit and rotor inlet } \\
& \text { R }=\left(H_{4}-H_{5}\right) /\left(H_{01}-H_{05}\right)=\text { degree of reaction } \\
& \operatorname{Re} \quad=\text { Reynolds number } \\
& \text { RGP }=\text { Real Gas Properties } \\
& \text { REFPROP }=\text { REFerence Fluid PROPerties } \\
& \text { RITMLD = Radial Inflow Turbine Meanline Design Operating Point } \\
& \text { RITMLO = Radial Inflow Turbine Meanline Off-Design Operating Point } \\
& \mathrm{s} \quad=\text { entropy } \\
& \mathrm{S}-\mathrm{CO}_{2}=\text { supercritical carbon dioxide } \\
& \text { SST } \quad=\text { Shear Stress Transport } \\
& \mathrm{t} \quad=\text { blade passage throat; blade thickness } \\
& \mathrm{T}=\text { static temperature } \\
& \mathrm{T}_{0} \quad=\text { total temperature } \\
& \text { Tc }=\text { static temperature at the critical point } \\
& \mathrm{T}_{\mathrm{R}} \quad=\mathrm{T} / \mathrm{T}_{\mathrm{c}}=\text { reduced temperature } \\
& t_{\text {leading }}=\text { blade leading edge thickness } \\
& t_{\text {trailing }}=\text { blade trailing edge thickness }
\end{aligned}
$$




$$
\begin{array}{ll}
\mathrm{U} & =\text { blade speed } \\
v_{s} & =\text { velocity ratio } \\
\mathrm{W} & =\text { relative velocity } \\
\dot{W} & =\dot{m} \Delta h_{0}=\text { output power } \\
\mathrm{y}^{+} & =\text {non-dimensional wall distance } \\
\mathrm{Z} & =\text { compressibility factor } \\
\mathrm{Z}_{\mathrm{R}} & =\text { axial length of the rotor } \\
\Delta Z & =\text { stage axial length } \\
\alpha & =\text { absolute flow angle, in degrees } \\
\beta & =\text { blade angle, in degrees } \\
\beta^{\prime} & =\text { relative flow angle } \\
\gamma & =\text { ratio of the constant volume and constant pressure heat capacity } \\
\rho_{a} & =\text { deviation, in degree } \\
\delta & =\text { total-to-static efficiency } \\
\eta_{t-s} &
\end{array}
$$




$$
\begin{array}{ll}
\varepsilon_{r} & =\text { radial clearance } \\
\varepsilon_{b} & =\text { back face clearance } \\
\tau_{f r i c} & =\text { torque coefficient } \\
& =\frac{C_{m 5}}{U_{4}}=\text { flow coefficient } \\
\phi & =\frac{C_{m 4}}{C_{m 5}}=\text { rotor meridional velocity ratio } \\
\xi & =1+5\left(\frac{b_{4}}{r_{4}}\right)^{2}=\text { Anugier's correlation of rotor meridional velocity ratio } \\
\Gamma & =\frac{\Delta h_{0}}{U_{4}^{2}}=\text { stage loading or work coefficient } \\
\psi & =\text { rotational speed, in rad/s } \\
\omega
\end{array}
$$

\section{Subscripts}

$$
\begin{array}{ll}
1 & =\text { volute inlet parameter } \\
2 & =\text { volute exit and nozzle inlet parameter } \\
3 & =\text { nozzle exit parameter } \\
4 & =\text { rotor inlet parameter } \\
5 & =\text { rotor exit parameter } \\
6 & =\text { diffuser exit parameter } \\
\mathrm{h} & =\text { hub at rotor outlet }
\end{array}
$$




$\begin{array}{ll}\mathrm{S} & =\text { shroud at rotor outlet } \\ \mathrm{m} & =\text { meridional component of velocity } \\ \mathrm{u} & =\text { tangential component of velocity } \\ \mathrm{i} & =\text { incidence losses } \\ \mathrm{p} & =\text { tip clearance losses } \\ \mathrm{c} & =\text { windage losses } \\ \mathrm{W} & =\text { trailing edge losses } \\ \mathrm{t} & =\text { exit energy losses } \\ \mathrm{e} & \end{array}$




\section{Chapter 1 Introduction}

\subsection{Motivation and Objectives}

One of the fourth year capstone engineering projects in the Department of Mechanical and Aerospace Engineering is the Carleton University Brayton Cycle Loop (CU-BCL). It is a closed-loop, indirectly-fired pilot-scale power plant under development through funding from Natural Resources Canada. A schematic of the plant is shown in Figure 1.1.

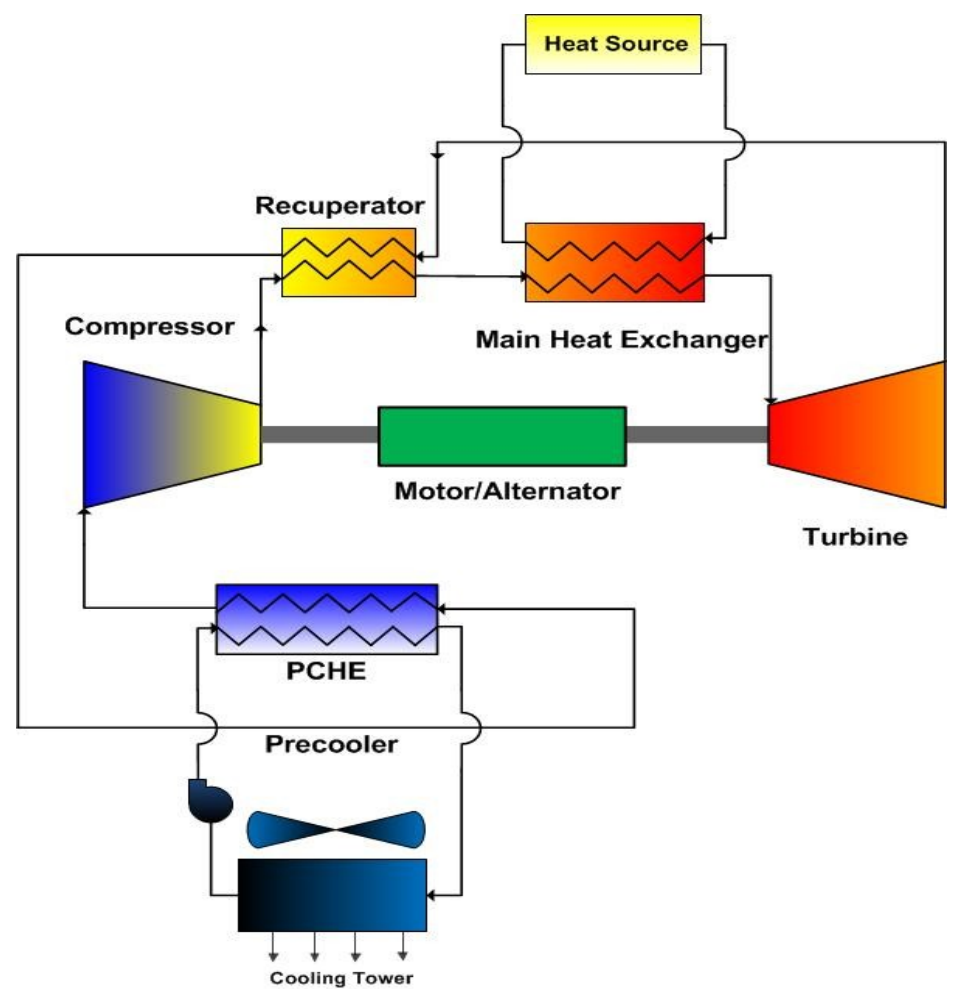

Figure 1.1 Schematic of the CU-BCL Fourth-Year Project Power Plant. 
The objective of this project is to construct a $250 \mathrm{~kW}$ pilot-scale supercritical carbon dioxide $\left(\mathrm{S}-\mathrm{CO}_{2}\right)$ Brayton Cycle Demonstration Loop for use in future, high-efficiency fossil fuel-based or renewable energy-based electricity generation systems. It is essentially a closed cycle gas turbine engine with a recuperator. The Brayton cycle using $\mathrm{S}-\mathrm{CO}_{2}$ as the working fluid is one of the potential options being developed as the power module for next generation cleaner coal systems. The choice of working fluid, among other advantages, provides for more efficient compression due to the unique properties of S-CO2 near its critical point. However, the need to account for the real gas properties of the fluid, especially near the critical point, poses certain challenges in the design of the thermodynamic cycle and the turbomachinery. As part of this project, a radial inflow turbine has been designed to drive the compressor and produce power from the pilot-scale loop. Due to the scale of the loop, a radial turbine (and also a centrifugal compressor) was the appropriate choice of turbomachinery type. Due to the limited available heat input to power the cycle, certain compromises in the aerodynamic design of the turbine (and of the compressor) were made early in the development of the overall thermodynamic cycle design. These were necessary to allow for practical turbomachinery size and rotational speed, while attempting to maximize the aerodynamic and cycle thermal efficiencies. Due to the fact that the turbine and compressor are mechanically connected, and thus rotate at the same speed, it was challenging to optimize and balance their efficiencies and performances.

The present work concentrates on the preliminary aerodynamic design of the radial inflow turbine for the pilot-scale loop turbomachinery. In order to design the turbine stage geometry and analyze the flow conditions at each critical location, a program named Radial Inflow Turbine Meanline Design Operating Point (RITMLD) was developed in this thesis. Meanline design has been widely used in the preliminary design stages for turbomachinery. In meanline analysis, the working fluid is essentially treated as one-dimensional flow at the mean radius of the turbomachinery stage and the fluid parameters at the mean radius are assumed as reasonable average values for the flow across the full blade span. 
After RITMLD was developed successfully, it was used as the basis to develop the second code, called RITMLO (Radial Inflow Turbine Meanline Off-Design Operating Point), to predict the radial inflow turbine characteristics when the machine runs at off-design rotational speeds and mass flow rates. As mentioned above, $\mathrm{S}-\mathrm{CO}_{2}$ was employed as the working fluid for this power plant, thus the codes of RITMLD and RITMLO were developed based on that working fluid. In view of the fact that the behavior of $\mathrm{S}-\mathrm{CO}_{2}$ is different from an ideal gas, the codes use real gas properties throughout the analysis. The database of real fluid properties in REFPROP 9.0, which has been developed by the National Institute for Standards and Technology (NIST), was incorporated in the codes of RITMLD and RITMLO. Also, by substituting calls to the appropriate fluid property subroutines, the codes can be used for any other ideal or non-ideal gas.

In order to analyze more aspects of the flow through the rotor blade passages, a full viscous three-dimensional Computational Fluid Dynamics (CFD) model has been developed based on the turbomachinery geometry that was designed by RITMLD. Due to fact that the aerodynamics analysis of radial inflow turbines is relatively poorly supported by a body of experimental work, and that the corresponding database of experimental data is also quite limited, CFD was also used to calculate the turbine performance over the full operating range, in order to assess the performance of the meanline codes. As one of the available CFD codes, ANSYS-CFX was used to analyze the flow through the rotor blade passages at the corresponding operating points. Since CFD predictions are considered more reliable than the meanline analysis, if the results show that the general trends of the full turbine characteristics are similar for both prediction methods, it can demonstrate that the meanline approach is able to make reasonable estimates of the full machine characteristics early in the design process. Finally, after the corresponding results and data are given by the meanline and CFD analyses, the CU-BCL radial inflow 
turbine characteristics at design and off-design operating points will be presented by Tecplot.

\subsection{Statement of Contribution}

The prediction of turbine characteristics at full off-design points using one-dimensional meanline analysis code is a novel application in the field of turbomachinery. It is a potential method to provide the information on the overall turbine characteristics at an early point in the turbomachinery design. Furthermore, in order to ensure the most accurate predictions and make it more comparable with the future experimental data, real fluid property subroutines are incorporated in the meanline design and off-design codes.

\subsection{Thesis Overview}

The literature review, which includes the background of the geometry of radial inflow turbine, is given in Chapter 2. It also describes what is meant by meanline analysis. Chapter 3 describes the loss correlation system that was used in the meanline analysis. The essential correlations employed in RITMLD and RITMLO are described in this chapter as well. Chapter 4 describes the setup information as well as the choice of governing equation and turbulence model for the CFD model. The CU-BCL radial inflow turbine characteristics from the meanline and CFD analyses at design and off-design operating points are presented in Chapter 5, as well as, the results comparison between the two methods. Finally, conclusions and recommendations for future work are given in Chapter 6. 


\section{Chapter 2 Literature Review}

\subsection{Introduction}

In this chapter, the fundamental background about radial inflow turbines and the design methods of turbine stages are described. The basic geometry model of a radial inflow turbine is described in Section 2.2. Section 2.3 introduces the definition of velocity triangles of radial inflow turbine. Section 2.4 describes the flow through the rotor blade passages of radial inflow turbines. The meaning and significance of meanline analysis for the radial inflow turbine design and off-design analysis are summarized in Section 2.5. Section 2.6 describes some general features and benefits of the Supercritical $\mathrm{CO}_{2}$ cycle loop. The program REFPROP, which accounts for the real gas properties of supercritical $\mathrm{CO}_{2}$, was incorporated in the codes of the meanline design and off-design analysis and will be described in Section 2.7.

\subsection{Geometry of Radial Inflow Turbine}

The fundamental components of a radial inflow turbine include the inlet volute, nozzle row, rotor and exhaust diffuser, as shown in Figure 2.1. Vaneless annular passages exist between the volute exit and nozzle inlet as well as the nozzle exit and rotor inlet (Aungier, 2005). 


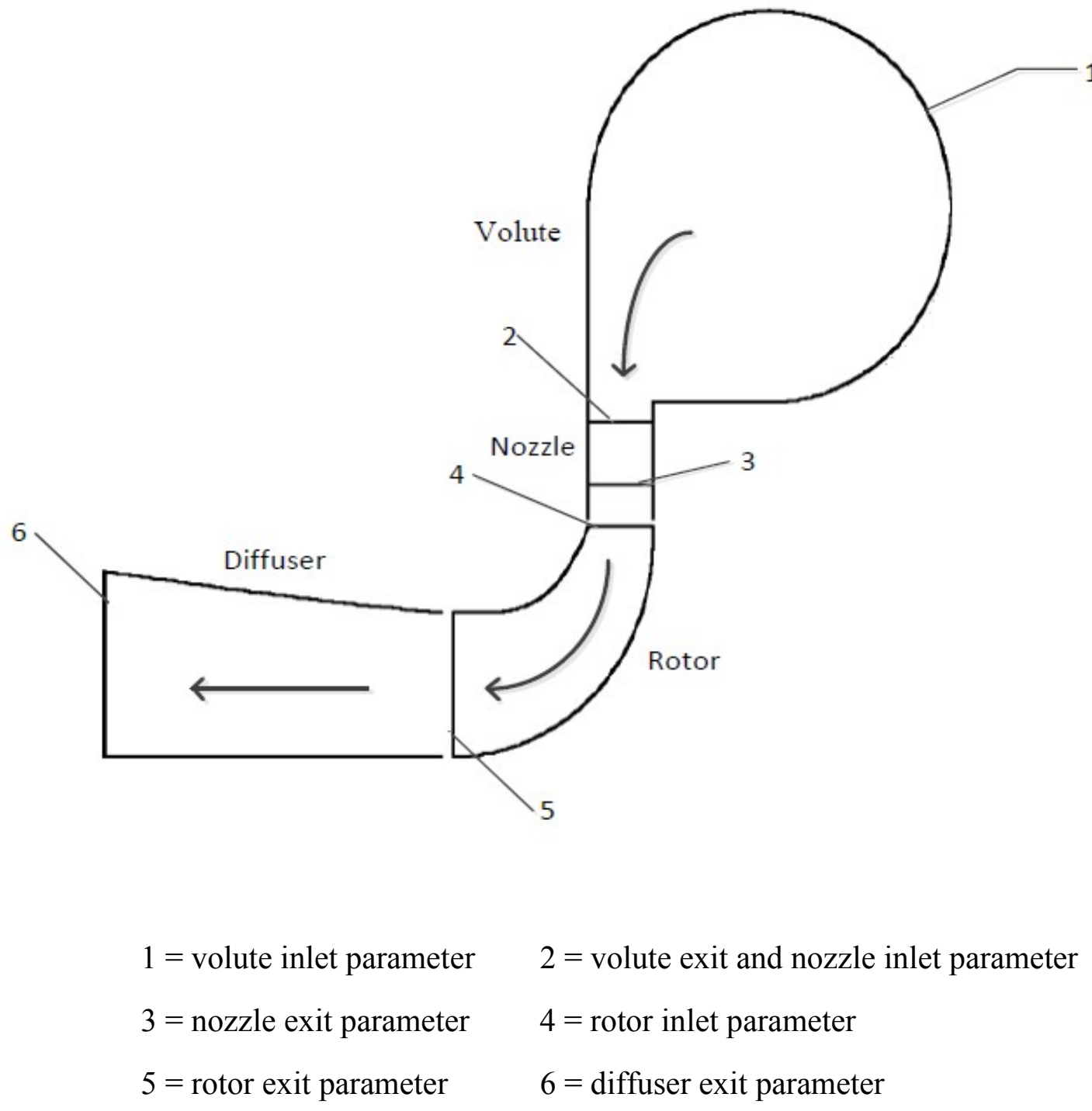

Figure 2.1 Radial Turbine Stage Cross Section (Aungier, 2005).

\subsubsection{Volute Geometry}

At the inlet station of the radial inflow turbine stage, the flow enters the volute in a direction tangential to the rotor. The volute turns the flow from the tangential direction to one with a large swirl component of velocity relative to the rotor. Also, if a radial inflow turbine operates at the design point, the volute is intended to distribute the flow to a 
circumferentially uniform flow in terms of mass flow rate and pressure at the exit of volute. The goal of the volute is to provide a flow that approaches the leading edge of the nozzles and rotors with a uniform distribution.

An example of the volute geometry is shown in Figure 2.2. The volute geometry has a three-dimensional curved shape. For design purposes, a series of radial sections can be defined along the periphery. As shown, an inlet section, where an area is dominated by linear flow, and a scroll region, where a vortex flow exists, has been separated in the volute (Baines, 2003)*.

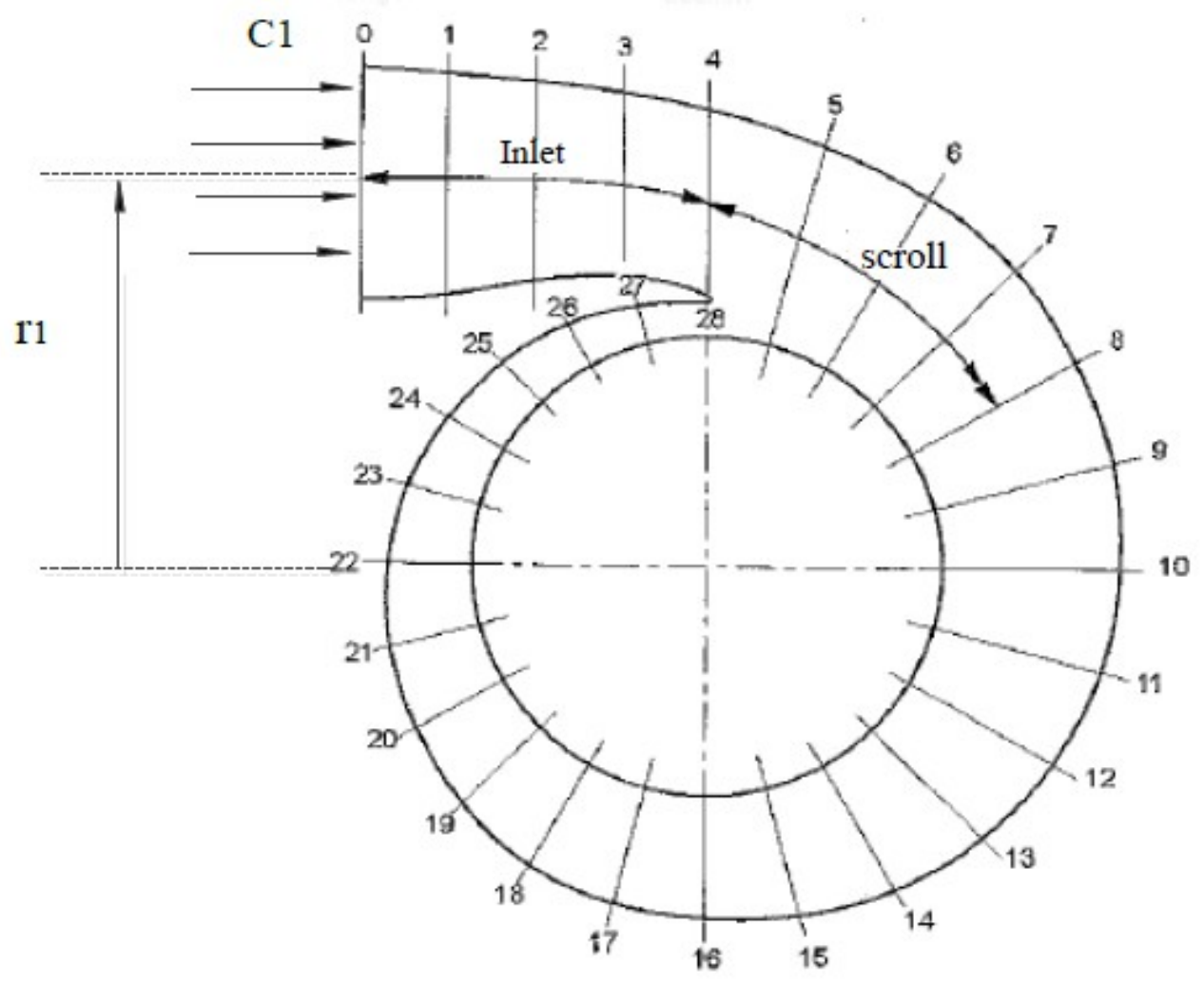

Figure 2.2 Volute Geometry (Baines, 2003).

* The reference (Baines, 2003) refers specifically to the chapters written by N.C. Baines in the textbook "Axial and Radial Turbines" by Moustapha, Zelesky, Baines, and Japikse. 


\subsubsection{Nozzle Vane Geometry}

When the flow arrives at the volute exit, the next component of the non-rotating assembly is the nozzle ring. The type of the nozzle vanes depends on whether the nozzle ring is preceded by a volute. As mentioned above, the volute has given the flow a large swirl component before the inlet of the nozzles for the turbine. This might be sufficient in itself to present the fluid to the rotor inlet at an appropriate incidence. In this case, the function of the nozzle is simply to remove any non-uniformity in the flow and further accelerate it (Baines, 2003). Thus, the nozzle will not be required to do some additional turning and the form of a straight vane is more appropriate for the nozzle section of the turbine. In order to reduce the losses incurred by the incidence, the nozzle vanes must be set to an appropriate blade angle to make the swirl flow approach the leading edge of the nozzle vanes and rotor blades smoothly at the same time. An example of a nozzle section is presented in Figure 2.3.

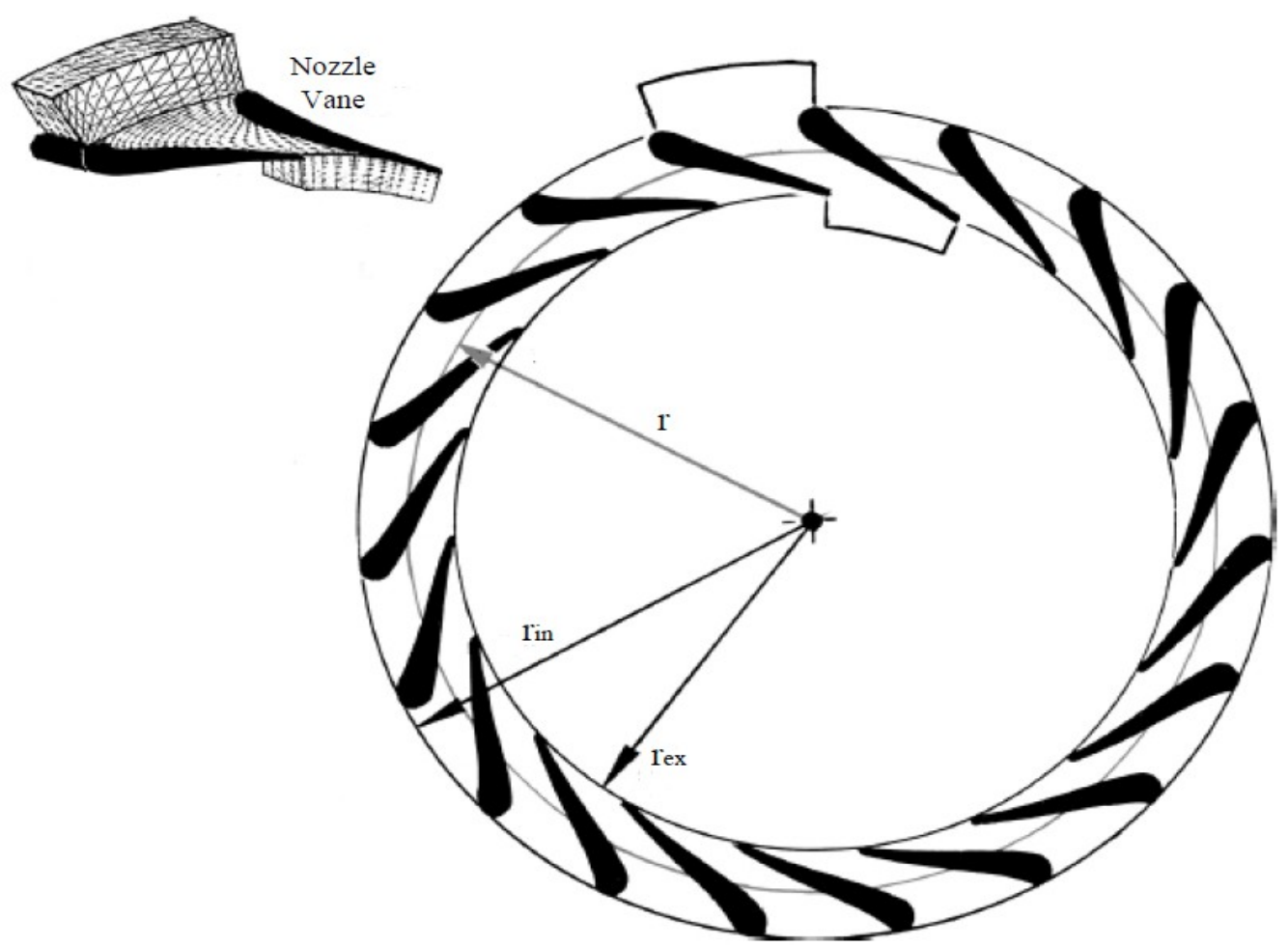

Figure 2.3 Nozzle Vanes (Baskharone, 2006). 


\subsubsection{Rotor Blade Geometry}

After the flow exits from the nozzle vanes, a radial gap exists between the nozzle exit and rotor inlet, between location 3 and 4 in Figure 2.1. This radial gap is a vaneless section and it is also a part of the non-rotating assembly. The main function of this component is to accelerate the flow, with very low losses before the rotor inlet station. After that, the flow goes through the rotor blade passages, which is the most important section to determine the overall performance of a radial inflow turbine. For radial inflow turbines, the inlet section of the rotor blades is generally radial, as shown in Figure 2.4. The purpose of this is to avoid the bending stress that would be caused by the centrifugal force on the rotor blades if they were swept (Baines, 2003). Therefore, the rotor inlet blade angle is zero for radial inflow turbine geometry. After the flow passes through the rotor blade passages, it comes to the rotor exit. In order to achieve zero outlet swirl flow in the absolute frame when the turbine is running at the design operating point, the rotor outlet must be curved, as indicated in Figure 2.4.
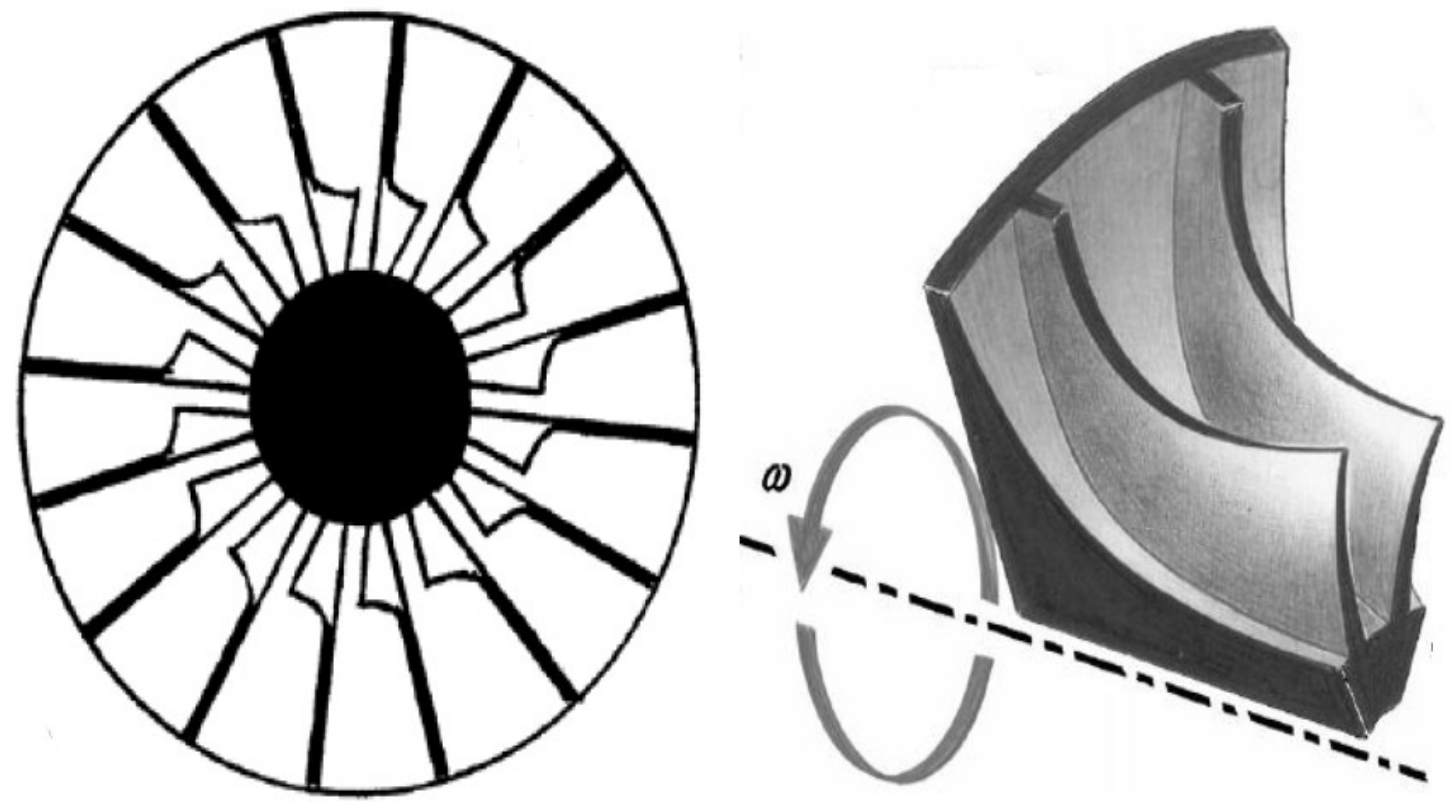

Figure 2.4 Radial Turbine Rotor Geometry (Baskharone, 2006). 


\subsection{Nomenclature and Flow Angle Definition of Radial Inflow Turbine}

The nomenclature for the geometry of different sections of the radial inflow turbine is shown in Figures 2.5 (a), (b) and (c) respectively.

(a)

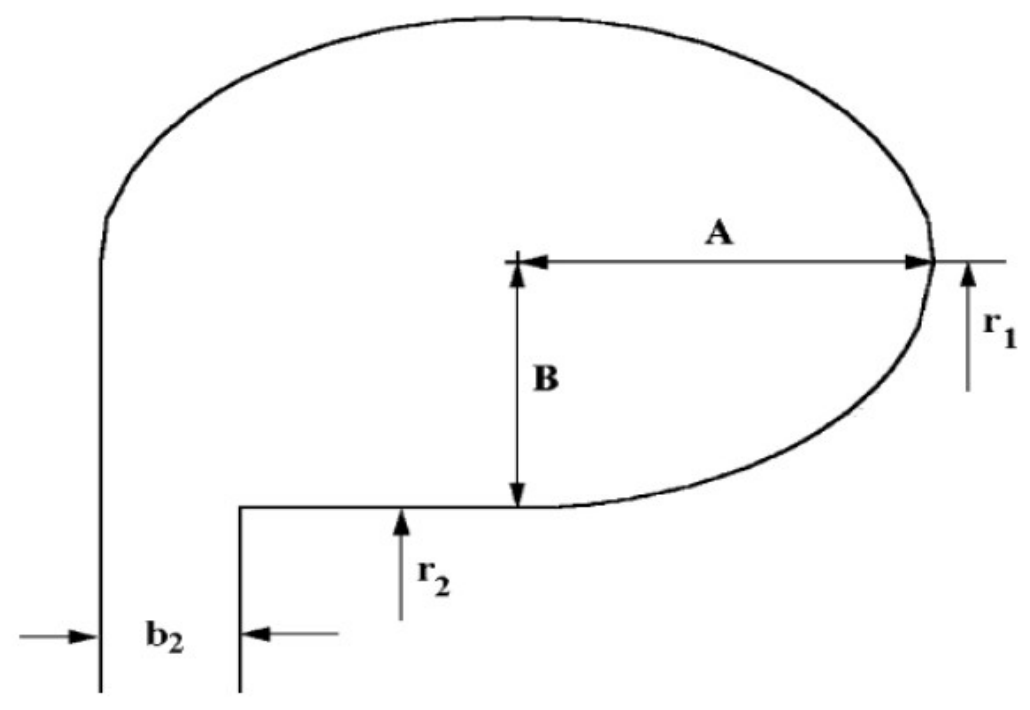

(b)

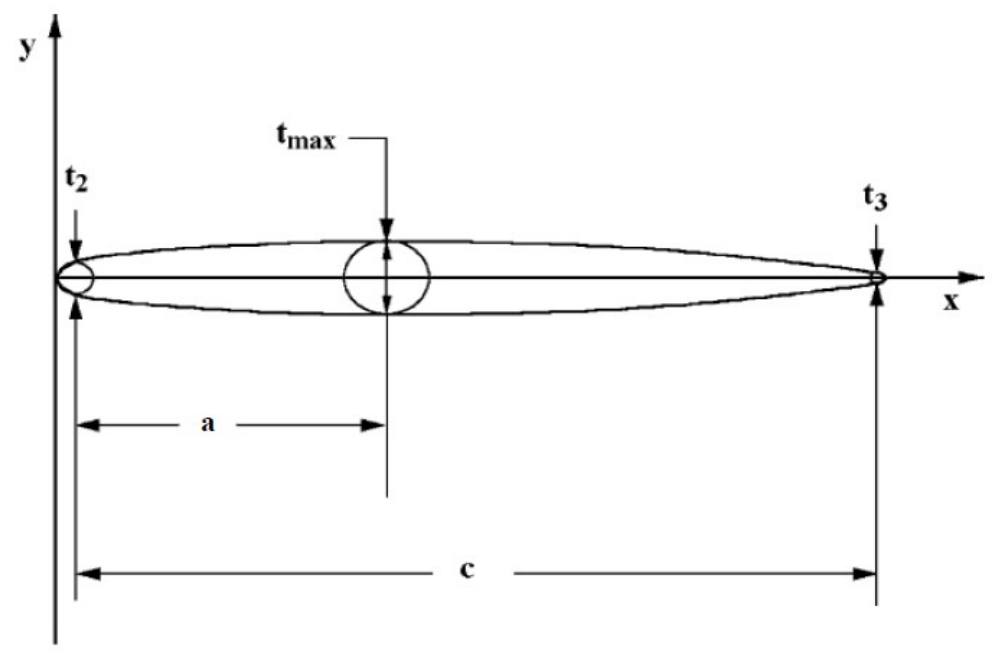


(c)

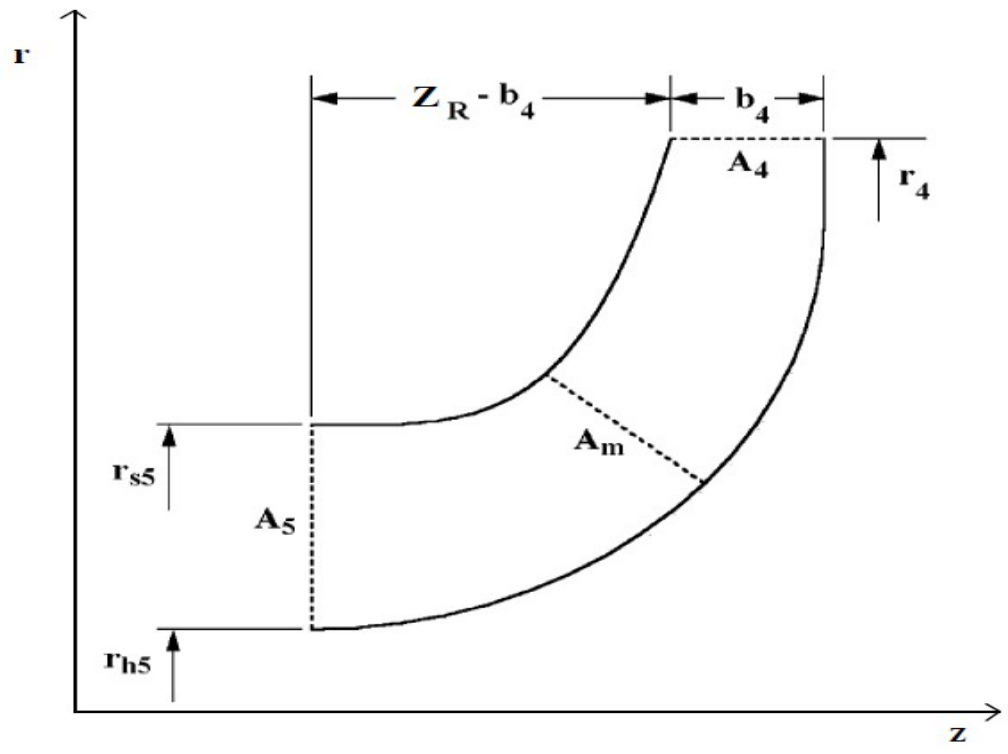

A: ellipse axial semiaxis

B: ellipse radial semiaxis

$r_{1}$ : inlet radius of volute

$\mathrm{r}_{2}$ : inlet radius of nozzle

$\mathrm{b}_{2}$ : passage width of nozzle vane

$t_{\max }$ : the maximum nozzle vane thickness

a: location of the maximum blade thickness

c: chord length

t2: nozzle inlet blade thickness

t3: nozzle exit blade thickness

r4: rotor inlet radius

b4: rotor inlet passage width

$\mathrm{r}_{\mathrm{h}}$ : rotor exit hub radius

$\mathrm{r}_{\mathrm{S} s}:$ rotor exit shroud radius

A4: rotor inlet area

As: rotor exit area

Am: mean value of rotor inlet and exit area

$Z_{R}$ : axial length of the rotor

Figure 2.5 Nomenclature of Radial Turbine (a) Volute (b) Nozzle Vane and (c) Rotor Blade (Adapted from Aungier 2005).

The definition of flow angles in the radial inflow turbine rotor are shown in Figure 2.6. The rotor exit blade metal angle is in the opposite direction for the rotational speed, so it is defined as a negative angle. 
(2) Nozzle Inlet
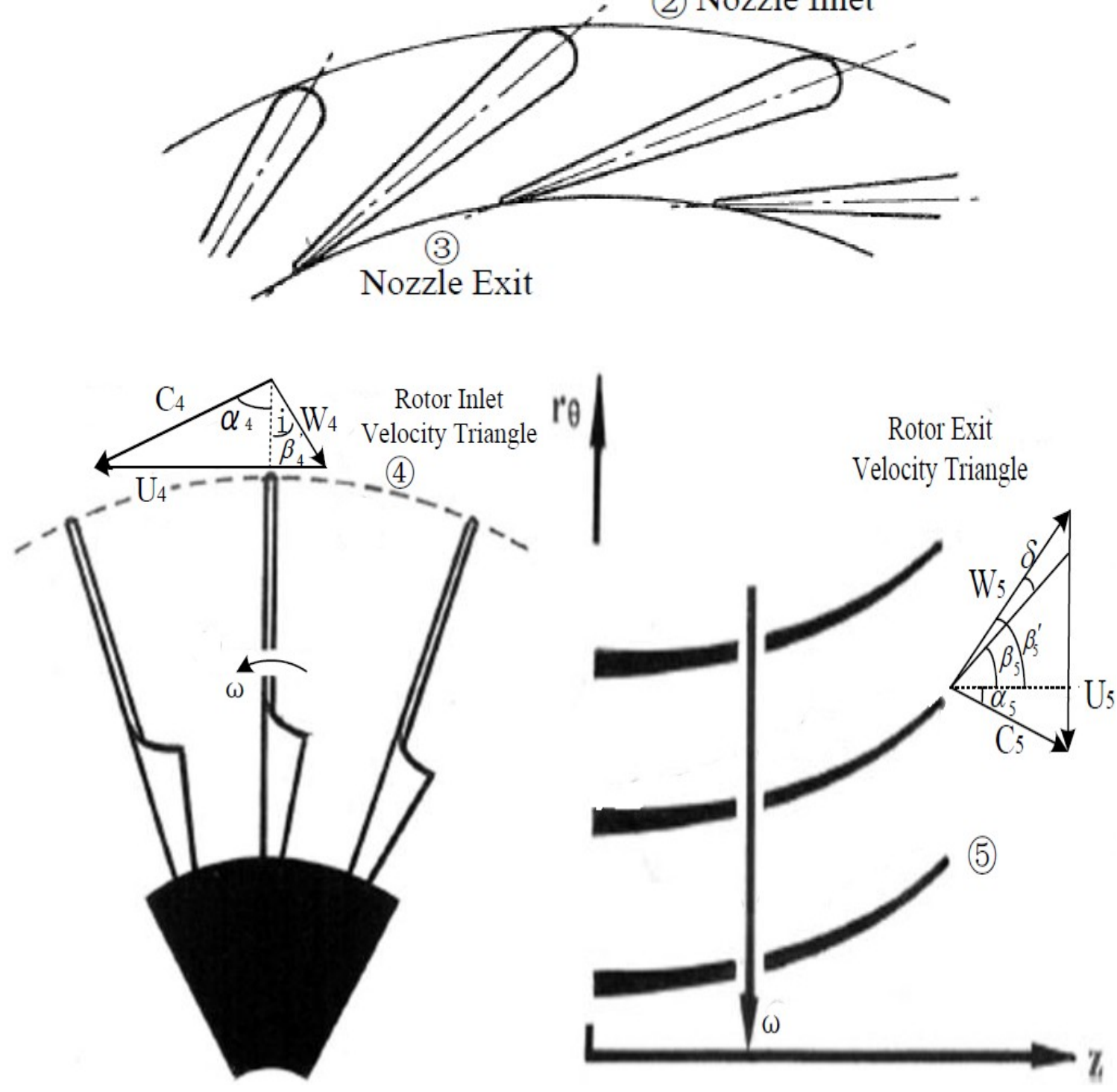

$\alpha_{4}$ : rotor inlet absolute flow angle

$\alpha_{5}$ : rotor outlet absolute flow angle

$\beta_{4}$ : rotor inlet metal angle

$\beta_{4}^{\prime}$ : rotor inlet relative flow angle

$\beta_{5}$ : rotor exit metal angle

$\beta_{5}{ }^{\prime}$ : rotor exit relative flow angle

i: rotor incidence angle

$\delta$ : rotor deviation angle

Figure 2.6 Flow Angle Definition of Radial Inflow Turbine Rotor (Adapted from Baskharone, 2006). 
The incidence, $i$, is defined as the difference between the inlet relative flow angle and the blade metal angle. For a radial inflow turbine rotor, incidence is equal to the inlet relative flow angle, $\beta_{4}{ }^{\prime}$, because the inlet blade metal angle, $\beta_{4}$, is radial as indicated in Figure 2.6. The deviation, $\delta$, is the difference between exit relative flow angle, $\beta_{5}^{\prime}$, and exit blade metal angle, $\beta_{5}$. At the design operating point, the deviation is normally intended to be zero.

As shown in Figure 2.6, the inlet relative flow angle is not equal to the zero blade metal angle but has a certain degree of negative incidence. The reasons for this will be described in more detail in connection with the incidence loss correlation, which is discussed in Chapter 3.

\subsection{Flow in the Rotor Blade Passage}

The flow field in the radial inflow turbine rotor blade passages is highly complicated because the flow enters the rotor in the radial direction and leaves in the axial direction, with a significant radius change during the 90 degrees of flow turning, as shown in Figure 2.4.

At the inlet region, if the flow direction is not appropriate as it approaches the leading edge of rotor blades, flow separation and recirculation can occur either near the suction surface or pressure surface of the rotor blades. The reason for flow separation and the formation of recirculation is that the magnitude of cross passage force at the blade leading edge is different from the force at the lower radius. Therefore, secondary flow is generated and exists as circulation flow in direction opposite to the rotational speed, as shown in Figure 2.7. If the magnitude of circulation is sufficiently large, it will cause 
flow separation (Baines, 2003).

Due to the combined effects of cross passage force and tip leakage flow, a complex secondary flow occurs in the passages from the inlet region to the trailing edge of the rotor blade (Baines, 2003). The main form of secondary flow is a vortex in the inlet region. Since there is no reliable method to separate the passage loss into profile loss and secondary flow loss and measure it separately (Baines, 2003), the mean kinetic energy loss profiles generated within the blade passages are important to understand. As shown by Figure 2.8, the majority of losses are generated within the passages near the shroud corner, due to the influence of tip leakage flow. Therefore, the radius and direction shift, as well as tip leakage flow, are the main factors that shape the flow phenomena in the blade passages of radial inflow turbine rotors.

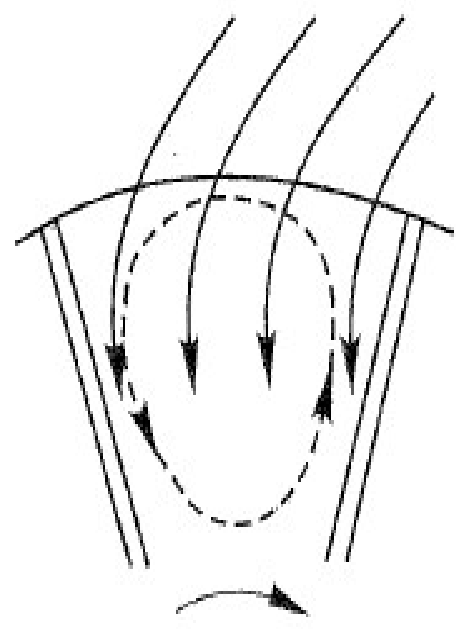

Figure 2.7 Recirculation in the Inlet Region of a Radial Turbine Rotor Passage (Baines, 2003). 


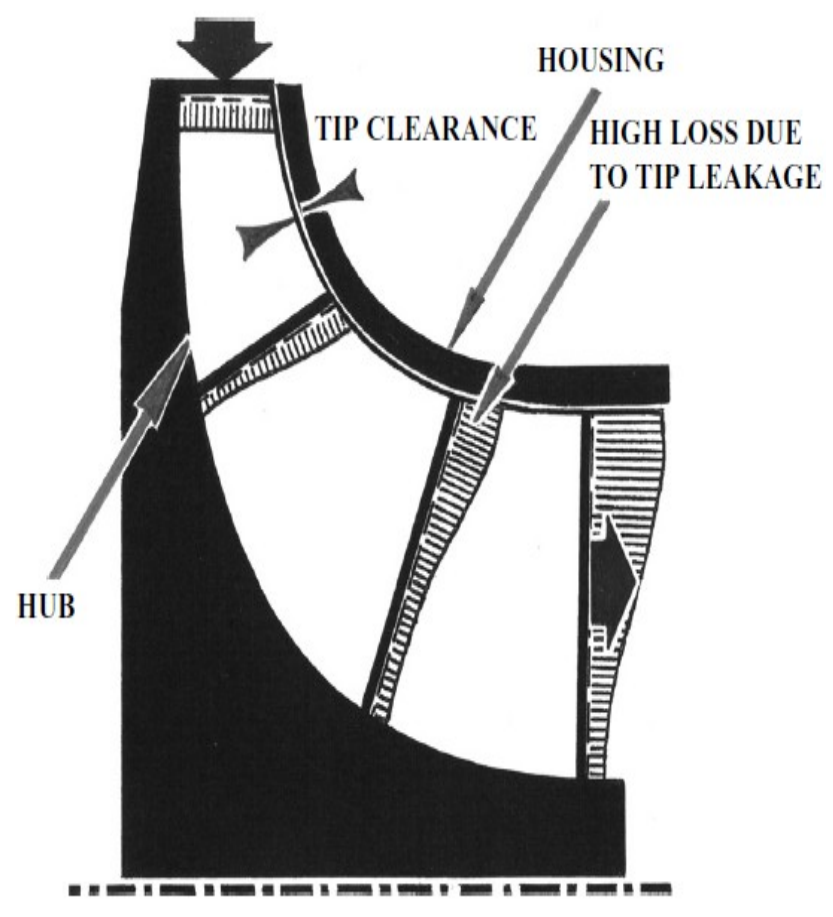

Figure 2.8 Mean Kinetic Energy Loss Profiles at Several Typical Locations of a Radial Turbine Rotor Passage (Baskharone, 2006).

\subsection{Meanline Analysis}

Meanline analysis is a one-dimensional flow approximation based at the mean radius of a turbomachinery stage. This analysis can provide reasonable estimates of the geometry and flow parameters through a turbomachine. Through the meanline analysis process, a good overall estimate of the performance of radial inflow turbine stages can be obtained. More detailed aerodynamic performance analysis can then be accomplished by CFD once appropriate turbine geometry and other parameters have been established through the meanline analysis. 


\subsubsection{Meanline Analysis at the Design Operating Point}

Generally, the basic parameters in terms of mass flow rate, rotational speed, inlet total pressure and temperature as well as output power will be specified as known parameters at the design operating point of the meanline analysis. Because the flow at the mean radius is assumed to be an average of the full span, the definition of the mean radius is important. For radial inflow turbines, only the exit mean radius, $\mathrm{r}_{5}$, needs to be defined to evaluate the exit velocity triangle because the fluid enters in the radial direction and leaves in the axial direction. There are generally two ways to define the mean radius: the arithmetic and the root-mean-square (RMS) methods. The RMS radius method divides the gas path area in two halves, which is suitable for simple radial equilibrium of flow along with uniform total pressure as most suitable for the axial turbines (Baines, 2003). The arithmetic radius definition, as shown in Equation 2.1, was chosen for simplicity of the radial inflow turbine meanline analysis,

$$
r_{5}=\frac{r_{5 s}+r_{5 h}}{2}
$$

where $r_{s}, r_{s}$, and $r_{s h}$ are the mean radius, shroud radius and hub radius at the exit of the rotor, respectively.

Figure 2.9 shows an example of a radial inflow turbine nozzle and rotor geometry with the outlet mean radius indicated. The absolute velocity, relative velocity and blade speed are represented by $\mathrm{C}, \mathrm{W}$ and $\mathrm{U}$ respectively. Subscripts $\mathrm{m}$ and $\mathrm{u}$ represent meridional and tangential velocity components, respectively. The locations 3, 4 and 5 indicate the location of nozzle exit, rotor inlet and rotor exit, respectively. 


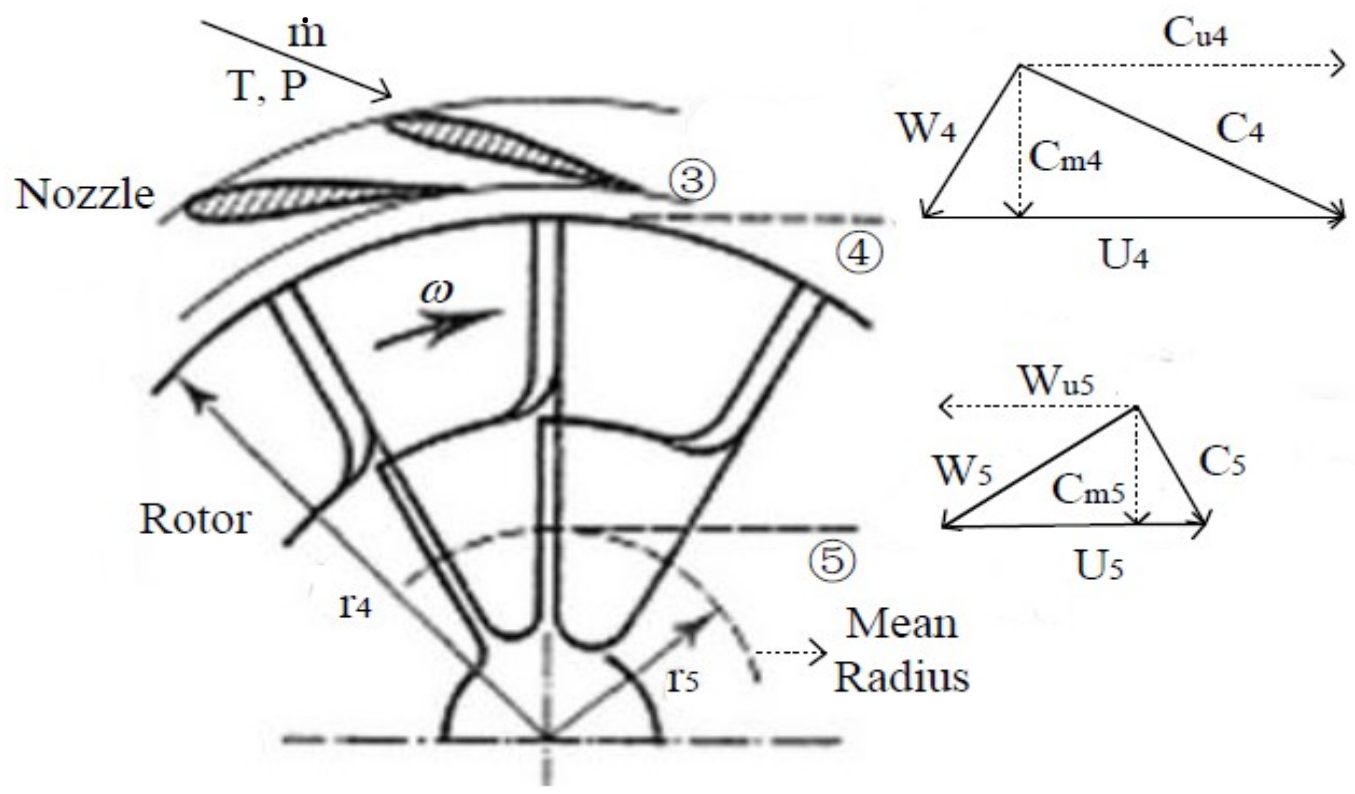

Figure 2.9 Example of a Radial Turbine Mean Radius and Velocity Triangles at Meanline Design Point Analysis (Adapted from Baskharone, 2006).

As shown in Figure 2.9, some angularity exists between $\mathrm{C}_{5}$ and $\mathrm{C}_{\mathrm{m}}$ indicating that there is some swirl at the rotor exit. Generally, the designer will aim for zero swirl flow at the turbine exit to avoid high levels of exit kinetic energy losses at the rotor outlet. In Figure 2.9, the directions of rotation and exit blade metal angle are reversed from Figure 2.6. From the two examples in Figures 2.6 and 2.9, it indicates that, in order to achieve the zero swirl, the direction of rotor exit blade metal angle should be opposite to the direction of rotation.

In order to establish the complete meanline design, some significant parameters need to be estimated at the early stages of the design process. Non-dimensional parameters of flow and stage loading coefficients as well as degree of reaction are widely used in turbomachinery meanline design. Normally, the rotor inlet blade speed, $\mathrm{U}_{4}$, is chosen to define the stage loading and flow coefficients for a radial inflow turbine. The stage loading or work coefficient, $\psi$, is defined as: 


$$
\psi=\frac{\Delta h_{0}}{U_{4}^{2}}=\frac{C_{u 4}}{U_{4}}-\varepsilon \frac{C_{u 5}}{U_{4}}
$$

where $\varepsilon=\frac{r_{5}}{r_{4}}$ is the rotor radius ratio, $C_{u 4}$ and $C_{u 5}$ are the tangential component of the absolute velocity at rotor inlet and outlet. Because the exit tangential component of absolute velocity, $C_{u 5}$, and flow angle are quite small or even zero at the design operating point, the term of $\varepsilon \frac{C_{u 5}}{U_{4}}$ is fairly small compared to the term of $\frac{C_{u 4}}{U_{4}}$, and thus the stage loading coefficient can be approximated as:

$$
\psi=\frac{\Delta h_{0}}{U_{4}^{2}} \simeq \frac{C_{u 4}}{U_{4}}
$$

The simplified stage loading coefficient is fairly useful in radial inflow turbine meanline design operating point analysis. The total enthalpy change, $\Delta h_{0}$, in Equation 2.3 , is given by the steady flow energy equation as:

$$
\Delta h_{0}=\frac{\dot{W}}{\dot{m}}
$$

where $\dot{W}$ is output power and $\dot{m}$ is mass flow rate. Therefore, the inlet blade speed, $\mathrm{U}_{4}$, and tangential velocity component, $\mathrm{Cu} 4$, can be determined after choosing a reasonable value of stage loading coefficient. The stage loading coefficient is chosen based on experimental data such as that shown in Figure 2.10.

The exit meridional velocity and inlet blade speed are used to define the flow coefficient, $\phi$, for a radial inflow turbine: 


$$
\phi=\frac{C_{m 5}}{U_{4}}
$$

Because the inlet blade speed, $\mathrm{U}_{4}$, has been determined from the stage loading coefficient and the total enthalpy drop, the exit meridional velocity can be obtained after the flow coefficient value is chosen. The values of $\phi$ and $\psi$ can be selected together from Figure 2.10 to give good total to static efficiency.

The data presented in Figure 2.10 were taken from about forty different radial turbine stages from a variety of sources (Baines, 2003). As shown, the optimum value of total to static efficiency corresponding to the stage loading coefficient lies within the range of 0.9-1.0 and the flow coefficient is between 0.2 and 0.3 . The contours of total to static efficiency indicate that a reasonable value of efficiency is applicable for a fairly wide range of stage loading and flow coefficients. A good meanline design point analysis should ensure that the two coefficients and efficiency are within, or fairly close to, the optimum ranges of the coefficient values.

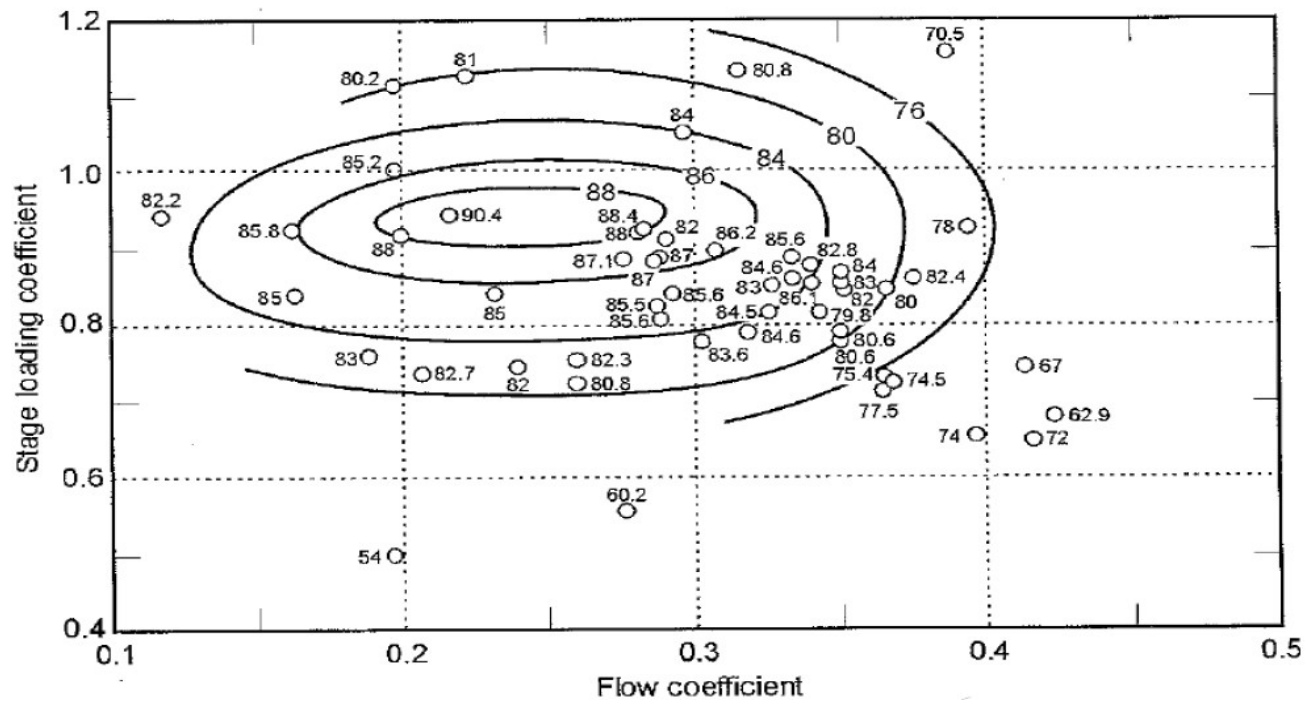

Figure 2.10 Correlation of Blade Loading and Flow Coefficients for Radial Inflow Turbines.

Data Points and Contours Show Total to Static Efficiency (Chen and Baines, 1994). 
In order to establish the complete velocity triangles at the rotor inlet and outlet, a third non-dimensional parameter, the rotor meridional velocity ratio for radial inflow turbine, is typically needed and it is defined as:

$$
\xi=\frac{C_{m 4}}{C_{m 5}}
$$

The inlet meridional velocity and the inlet velocity triangle can be determined by this ratio. The value of rotor meridional velocity ratio should be close to unity, especially at the design operating point. If the rotor inlet radius was fixed, through adjusting the value of meridional velocity ratio, the rotor inlet area and inlet blade height can be related to the mass flow rate from the continuity equation:

$$
\dot{m}=2 \cdot \pi \cdot r_{4} \cdot b_{4} \cdot \rho_{4} \cdot C_{m 4}
$$

As discussed above, because the rotor exit flow will be designed to have zero swirl at the design point, the absolute exit velocity, $\mathrm{C}_{5}$, is equal to exit meridional velocity, $\mathrm{C}_{\mathrm{m}}$. Then the static density can be determined from the static pressure and static enthalpy at the rotor exit. Based on the continuity equation, the rotor outlet area, A5, can then be obtained. The ratio of hub radius to inlet radius is generally limited to avoid the overcrowding of the rotor blades at the hub. A reasonable value of this ratio is recommended by Baines (2003). Thus the tip radius and blade height as well as the mean radius at rotor exit can be determined. Finally, the rotor exit velocity triangle is obtained.

There is another approach that can be used for the initial sizing of a radial turbine. This approach is described by Aungier (2005) and it is based on different parameters: specific speed, $n_{s}$, and velocity ratio, $v_{s}$. The total to static efficiency, $\eta_{s}$, again 
correlates with those two parameters. The specific speed is defined as:

$$
n_{s}=\frac{\omega \sqrt{Q_{5}}}{\left(\Delta H_{i d}\right)^{0.75}}
$$

where $\omega$ is the rotational speed and $Q_{5}$ is the volume flow rate at the rotor exit, which is determined from continuity:

$$
Q_{5}=\frac{\dot{m}}{\rho_{05}}
$$

In Equation 2.8, $\Delta H_{i d}$ is defined by Aungier (2005) as total-to-static ideal enthalpy drop:

$$
\Delta H_{i d}=\frac{H_{01}-H_{05}}{\eta_{s}}
$$

where $H_{01}$ is the total enthalpy at the stage inlet, $H_{05}$ is the total enthalpy at the stage outlet, and $\eta_{s}$ is the stage total-to-static efficiency.

Equation 2.11 gives a curve fit of total-to-static efficiency with specific speed for radial inflow turbines as given by Aungier (2005):

$$
\eta_{s}=0.87-1.07\left(n_{s}-0.55\right)^{2}-0.5\left(n_{s}-0.55\right)^{3}
$$

This curve is shown in Figure 2.11. The initial choice for the velocity ratio, $v_{s}$, is selected based on the generalized performance correlation given by Aungier (2005) and 
shown in Figure 2.11. The chart gives the expected total to static efficiency and recommended values of velocity ratio as a function of specific speed. This chart also includes two sets experimental data for radial turbines.

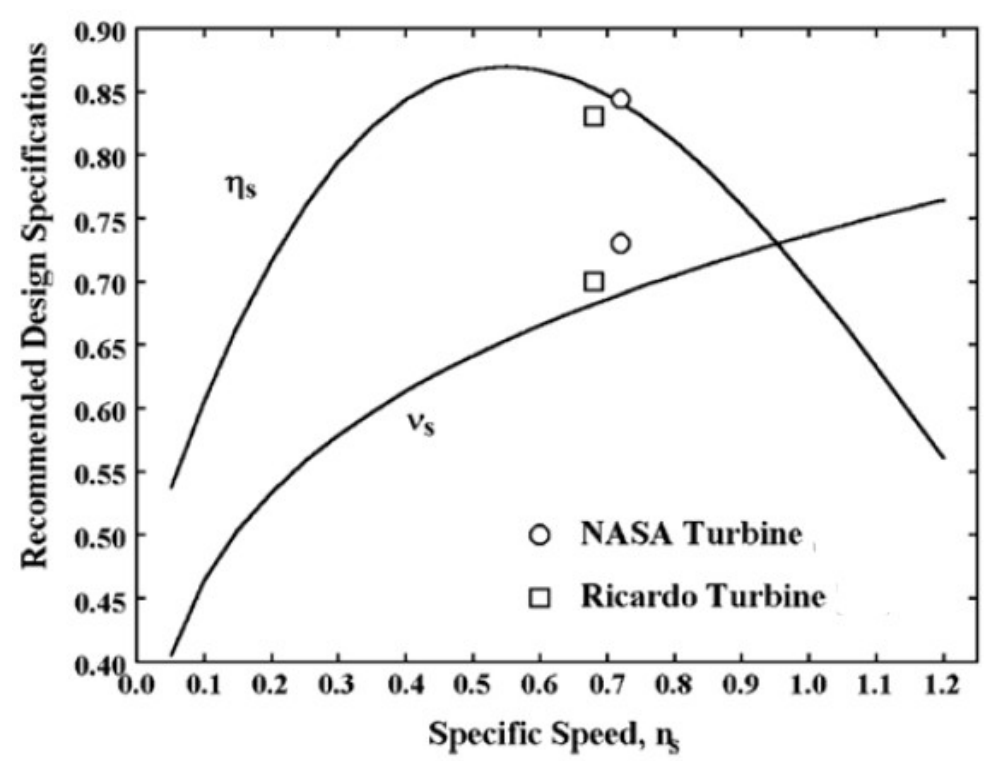

Figure 2.11 A Generalized Stage Performance Chart (Aungier, 2005).

Based on the value of $n_{s}$, the value of $\eta_{s}$ and $v_{s}$ can be obtained from Figure 2.11. As shown, the best efficiency corresponds to a velocity ratio within the range of 0.6 and 0.7 . However, for a specific radial turbine, if the value of $v_{s}$ deviates from the optimum range based on a specific value of $n_{s}$, the turbine stage may still achieve a reasonably good performance, due to the fact that these generalized correlations curves are not based on actual performance, which would need to be examined. In this case, the user may still choose a value from 0.6-0.7 to design the turbine stage but not have to follow the corresponding curve in Figure 2.11. Furthermore, based on the evaluation of the turbine stage performance, the velocity ratio could be revised subsequently to pursue the optimum efficiency point. 
Once the basic parameters of specific speed, $n_{s}$, velocity ratio, $v_{s}$, and total-to-static efficiency, $\eta_{s}$, are available, the rotor inlet velocity triangle and geometry dimensions can be defined. The definition of discharge spouting velocity is:

$$
C_{0 s}=\sqrt{2 \Delta H_{i d}}
$$

and then the rotor tip speed is given by:

$$
U_{4}=v_{s} C_{0 s}
$$

As mentioned, the outlet flow is normally designed to have zero swirl at the meanline analysis. Then the rotor inlet tangential absolute velocity is given by:

$$
C_{u 4}=\frac{U_{4} \eta_{S}}{2 v_{s}^{2}}
$$

The initial values of rotor inlet absolute flow angle can be estimated by Rohlik's (1968) correlation as a function of specific speed as:

$$
\alpha_{4}=10.8+14.2 n_{s}^{2}
$$

where $\alpha_{4}$ is in degrees. Thus the inlet velocity triangle and the main geometry dimensions can be determined from the above parameters. The rotor exit velocity triangle can be formed by the conventional coefficient parameters as discussed in connection with the first method. Alternatively, the designer can use the correlation of Equation 2.16, which was recommended by Aungier, to supply a reasonable initial estimation value for 
rotor meridional velocity ratio as:

$$
\frac{C_{m 5}}{C_{m 4}}=1+5\left(\frac{b_{4}}{r_{4}}\right)^{2}
$$

After completing the meanline analysis by using the second method, the values of the stage loading and flow coefficients can be calculated as well. The values of these two coefficients may then be used to evaluate the meanline design by comparison with the data in Figure 2.10. If the corresponding efficiency lies within the optimum area, it suggests that the preliminary design is acceptable and reasonable.

For the CU-BCL radial inflow turbine, the meanline analysis process is based on Aungier's method at design and off-design points. The feature of this approach is that it is based on an automatic calculation process and does not selects values for the stage loading and flow coefficients as in the first method. This feature supplies a significant advantage for the meanline off-design analysis, which is a process to predict the turbine characteristics over the full operating range. Also, when the machine is operating away from the design point, the values of stage loading and flow coefficients in Figure 2.10 cannot be chosen to determine the velocity triangles. Thus, in order to maintain consistency, Aungier's approach is used for the design and off-design meanline analyses, although the first method is eligible for the design point analysis as well. However, this does not mean that the conventional non-dimensional parameters of stage loading and flow coefficients are abandoned in the design process. Figure 2.10 is also used as an important criterion to evaluate the performance of a designed turbine.

No matter which method is used, some fundamental non-dimensional parameters such as stage loading and flow coefficients, specific speed as well as efficiency are 
estimated based on the generalized performance chart. It is then necessary to introduce the loss correlation system to obtain more accurate estimates of the efficiency and therefore performance results for turbine characteristics. The loss correlation system will be introduced in Chapter 3, where the detailed procedures of meanline analysis are described.

\subsubsection{Meanline Analysis at the Off-Design Operating Point}

The turbine will not always operate at the design point if the mass flow rate or rotational speed are different from the design values. Off-design operation will cause the pressure ratio, incidence and velocity triangle to deviate from the design values. Hence, the turbine will have a different overall performance, i.e. different output power and efficiency, than at the turbine running at the design point.

After the geometric model of the radial inflow turbine has been obtained from the results of meanline design point analysis, the off-design performance will be analyzed using the meanline approach. Although meanline analysis is not the standard procedure to predict turbine off-design characteristics, the accuracy of this approach can be examined by comparing the results with those produced by CFD analysis of the off-design operating points. By changing the input values of pressure ratio and rotational speed, turbine characteristics corresponding to the full operating range can be generated. As with the design point analysis, the turbine characteristics over the full operating range are determined from the predicted velocity triangles at the rotor inlet and outlet, as well as off-design loss correlations. In Figure 2.12, the inlet velocity triangle at the reduced mass flow and the outlet velocity triangle at the reduced rotational speed off-design operating points are presented. The dotted and solid lines represent the velocity triangles at the design point and at off-design, respectively. As shown, as the turbine operates at a reduced mass flow rate at off-design, the incidence deviates from the designed angle at 
the inlet velocity triangle.

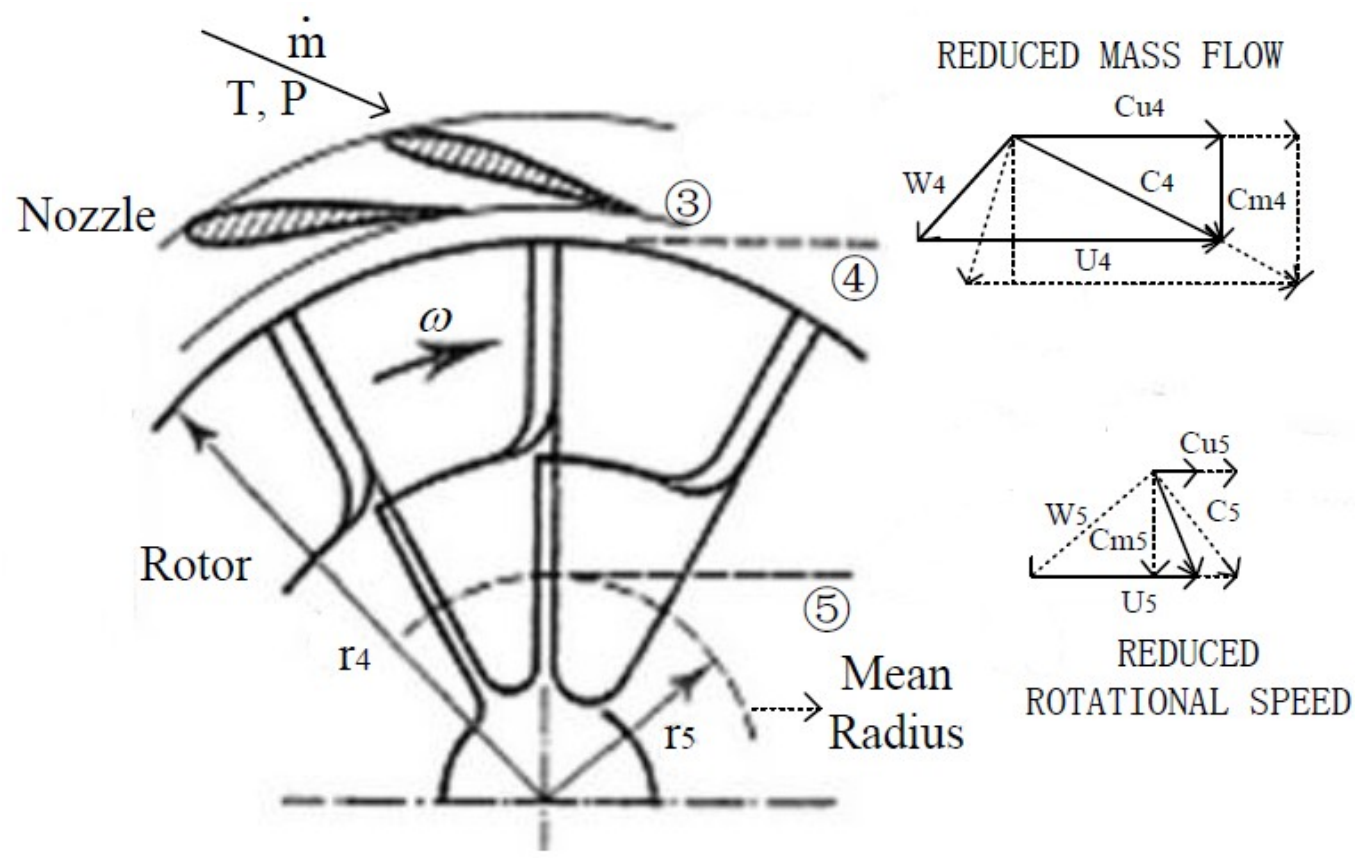

Figure 2.12 Example of Radial Turbine Mean Radius and Velocity Triangles at Meanline Off-Design Point Analysis (Adapted from Baskharone, 2006).

\subsection{Supercritical $\mathrm{CO}_{2}$}

The supercritical carbon dioxide $\left(\mathrm{S}-\mathrm{CO}_{2}\right)$ Brayton cycle is a recently proposed technology for advanced power cycles due to good thermal efficiency for relatively low turbine inlet temperatures and compactness of the turbomachinery as compared to other plants. The reason for these benefits is that the compressor inlet condition is near the critical point. Near the critical point, the $\mathrm{S}-\mathrm{CO}_{2}$ density is high and the fluid, although a gas, behaves much like a liquid. As a result, the compressor power for a given pressure ratio and mass flow is reduced relative to the turbine output power. Therefore, the net output power as well as the overall cycle efficiency of the plant increases substantially.

The definition of the supercritical region is that the fluid is above the critical temperature and pressure (Taylor, 1996). The critical temperature is $304 \mathrm{~K}$ and the 
critical pressure is 73.9 bar for $\mathrm{S}-\mathrm{CO}_{2}$ (Moran and Shapiro, 2004). The carbon dioxide pressure-temperature phase diagram is presented in Figure 2.13. The critical point and supercritical region are identified.

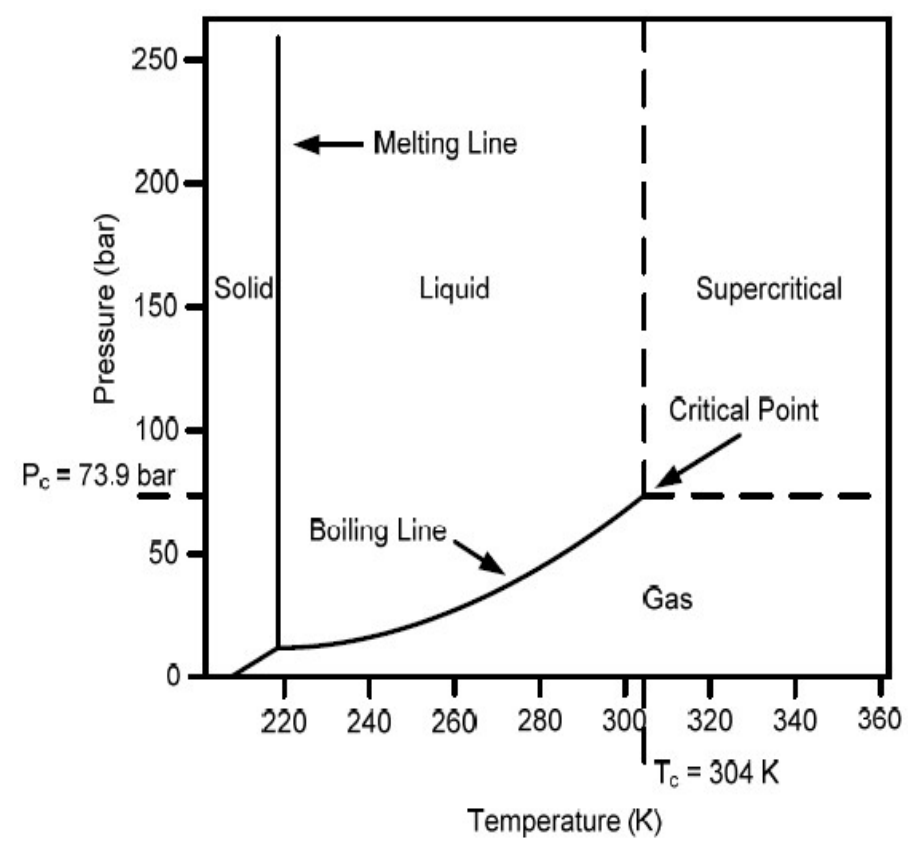

Figure 2.13 Carbon Dioxide Pressure-Temperature Phase Diagram (Adapted from Taylor, 1996).

At the compressor inlet conditions of typical S- $\mathrm{CO}_{2}$ Brayton cycles, the temperature and pressure are close to the critical point of $\mathrm{S}_{-} \mathrm{CO}_{2}$. As a result, the behavior of the $\mathrm{S}-\mathrm{CO}_{2}$ is significantly different from ideal gas behavior. However, at the turbine inlet, where the temperature and pressure are far away from the critical point, the behavior of $\mathrm{S}-\mathrm{CO}_{2}$ is much closer to that of an ideal gas. The compressibility factor is an important parameter to characterize whether or not the fluid behaves as an ideal gas. The definition of the compressibility factor is:

$$
Z=\frac{P}{\rho R T}
$$

where $\mathrm{R}$ is the gas constant. $\mathrm{Z}=1.0$ indicates that the fluid behaves as an ideal gas. Figure 
2.14 shows the variation of the generalized compressibility factor in terms of reduced temperature $T_{R}=T / T_{c}$ and reduced pressure $P_{R}=P / P_{c}$ where $T_{c}$ and $P_{c}$ represent the critical point of temperature and pressure respectively.

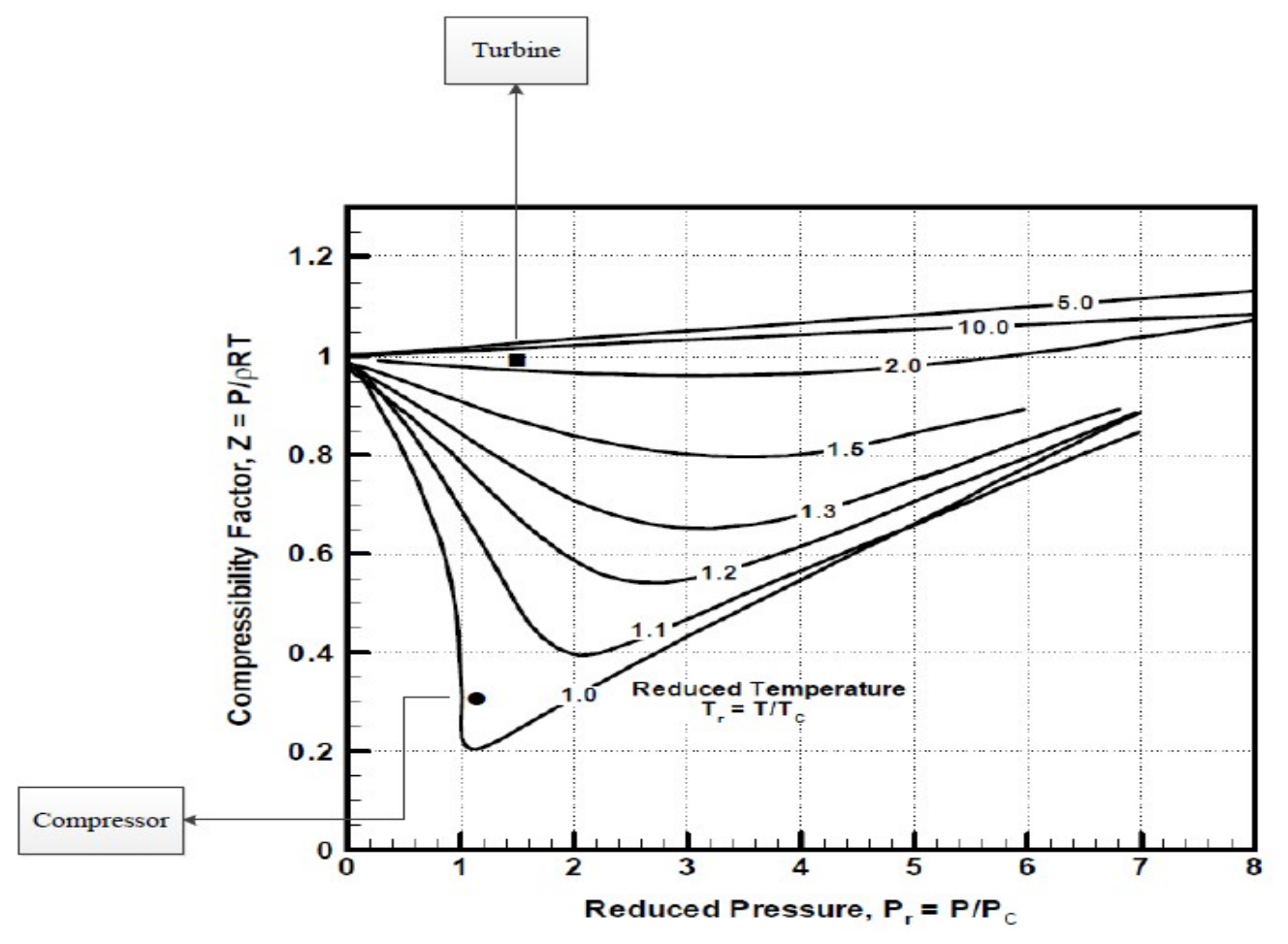

Figure 2.14 Generalized Compressibility Factor (Z) Diagram (Adapted from Holman, 1988).

As shown, the black circle and square spot represent the compressibility factors at the inlets of the compressor and turbine for the 2013-2014 CU-BCL power plant. The behavior of the working fluid is very different from that of an ideal gas at the compressor inlet, where $T_{R}$ and $P_{R}$ are close to 1.0. Thus it creates a big challenge during the compressor design process. Although Figure 2.14 shows that the turbine inlet conditions result in behavior that is reasonably close to ideal gas behavior, including the capability to deal with real gas properties in the meanline codes would allow for flexibility of use for design at conditions where the real gas properties must be considered. Furthermore, for the best level of accuracy, it was decided to incorporate real gas properties in both the meanline codes, as well as the corresponding CFD analyses. 


\subsection{REFPROP}

As discussed above, ideal gas properties were not used in the design and analysis procedures. The program REFerence Fluid PROPerties (REFPROP) which includes the most accurate data and equations to calculate thermodynamic and transport properties of real fluids and their mixtures, was incorporated in the codes for the meanline analysis process. REFPROP was developed by National Institute of Standards and Technology (NIST), which is an agency of the United States Department of Commerce. NIST is engaged in advancing measurement science, standards and technology. The fluid property database of REFPROP is updated regularly and incorporates the most recent available data (NIST, 2014).

The state equations of fluid property that are used in REFPROP are based on a large number of correlations for many different working fluids. These correlations are able to capture the changes of the working fluid properties over a wide range of state points (Span and Wagner, 1994). Therefore, REFPROP can return accurate fluid property data based on different sets of state points, either temperature and pressure or enthalpy and entropy are specified by the user.

The program of REFPROP has been widely used in the fields of turbomachinery design as a fluid property database or as a reference standard to examine the accuracy of results. The version of REFPROP 9.0, which was updated in 2013 by NIST, along with the FORTRAN source code for the working fluids of $\mathrm{S}-\mathrm{CO}_{2}$ were incorporated in the codes of the meanline design and off-design points analyses. 


\section{Chapter 3 Meanline Analysis Codes}

\subsection{Introduction}

This chapter describes the detailed steps in the development of the radial inflow turbine meanline design operating point (RITMLD) and off-design operating point (RITMLO) codes based on real fluid properties. The codes were implemented using the FORTRAN programming language.

As introduced in Chapter 2, an accurate estimate of turbomachinery efficiency requires the use of a loss correlation system. Section 3.2, therefore, will introduce the loss correlation system used in the meanline design and off-design analysis. After the loss correlation system is described, the development of the detailed codes for the turbine meanline analysis at design operating points (RITMLD) will be described in Section 3.3. In Section 3.3, the method of obtaining the real fluid properties of the working fluid is discussed as well. In order to obtain the turbine characteristics over the full operating range, the radial inflow turbine meanline analysis at off-design operating point (RITMLD) was developed. The majority of the RITMLD code was reused in RITMLO, but the logic in the developing process was changed and many new iteration loops needed to be added. All of the methods and code changes from RITMLD to RITMLO are described in Section 3.4 . 


\subsection{Loss Correlations for Meanline Analysis of Radial Inflow Turbines}

\subsubsection{Introduction}

As the flow passes through the radial inflow turbine stage, losses occur along with entropy generation. The major contributions to the entropy generation are the incidence, passage (friction, secondary flow and flow separation), tip leakage flow and trailing edge losses, which occur in the internal rotor blade passages. The windage and exit losses are the major contributions to the losses generated outside the blade passages. The various mechanisms are strongly inter-related in the loss generation processes. For instance, incidence losses have to account for a part of the passage losses that the deviation from optimum incidence will cause due to the resulting disturbances of the fluid field in the passages. However, the benefit of dividing the loss model into various categories is that the highly complex loss process is simplified to manageable components. These components are sensitive to variations of the parameters, and therefore may be used to calculate the losses over the full operating range (Baines, 2003). In view of the fact that the entropy generation cannot be estimated in a one-dimensional meanline analysis directly, the enthalpy losses are typically used as an indirect method to estimate the losses corresponding to the entropy generation in the turbine stage. The definition of total to static isentropic efficiency can be expressed in terms of the enthalpy losses as:

$$
\eta_{t-s}=\frac{\Delta h_{0}}{\Delta h_{0}+\sum \Delta h_{\text {loss }}}
$$

where $\Delta h_{0}$ and $\Delta h_{\text {loss }}$ represent the total enthalpy drop and total enthalpy losses in the radial inflow turbine stage, respectively. The loss correlation system involves many aspects of the flow in the radial inflow turbine stage. The turbine geometry, 
thermodynamic parameters of the working fluid, as well as the velocity triangles are all used within the system. In the design process, with a loss correlation system, the turbine efficiency can be optimized by varying the parameters of velocity ratio or incidence to minimize the predicted losses. In the off-design analysis, the converged result for efficiency can be calculated by an updated loss correlation system for off-design analysis, after an initial value of efficiency is guessed.

Due to the lack of high quality data in the open literature with sufficient detail to develop loss correlations for stators (Baines, 2003), which are the vanes of the nozzle ring, the data from Figure 3.1 were used to predict the losses in the nozzle section. Figure 3.1 illustrates the division of losses in the radial turbine stage. The rotor and rotor-related losses (clearance, windage and exit velocity) relative to the nozzle losses as a function of specific speed are emphasized in this figure as well.

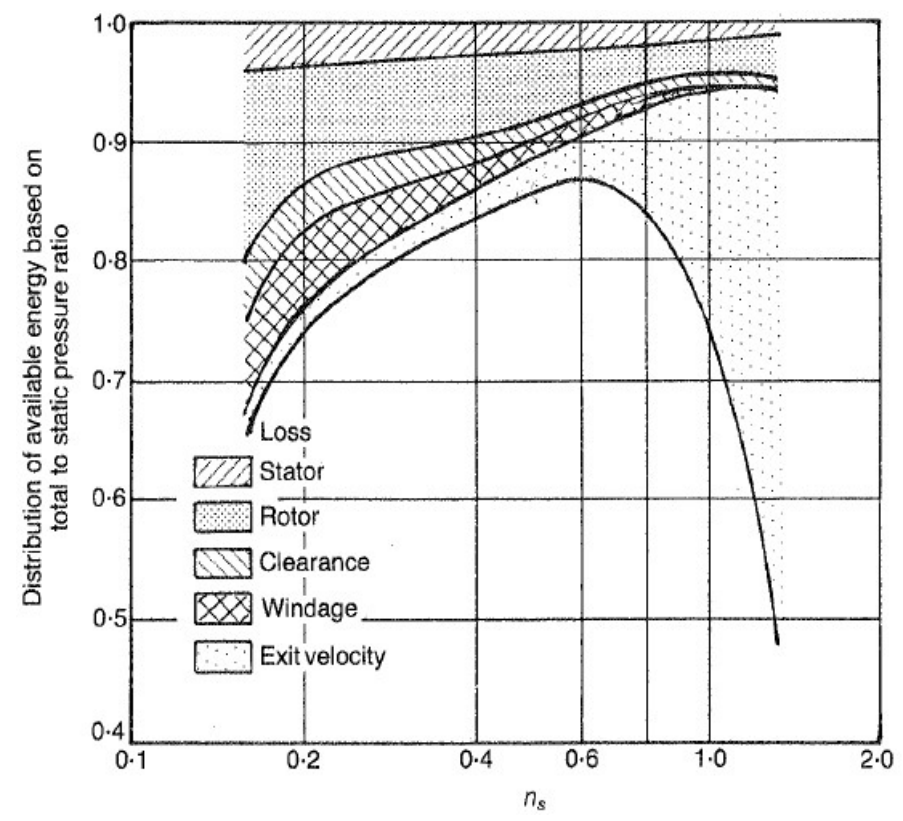

Figure 3.1 Predicted Distribution of Radial Turbine Losses along Curve of Maximum Total to Static Efficiency (Rohlik, 1968). 
This loss breakdown is only an indication of the generalized trends in losses, and not definitive to for any particular radial inflow turbine. For the rotor section, the loss prediction is still based on the loss correlation system that will be described next.

\subsubsection{Incidence Losses}

The incidence losses refers to the losses that occur at the inlet region of the radial inflow turbine rotor blade passages when the turbine is operating away from the design incidence and the flow does not enter the passage in the optimum direction. The main form of the loss process in the rotor blade passage is by the creation of secondary flows,

and these are considerably affected by the deviation from optimum incidence. A reasonable estimate of the optimum incidence can be deduced from the well-established meanline design operating point analysis. It is found that the optimum incidence should lie within the range of about $-20^{\circ}$ to $-40^{\circ}$ (Baines, 2003).

Wallace (1958) introduced an early incidence loss model that was based on an assumption that the turning of the fluid took place in a constant pressure process of infinitely small extent. Based on the Wallace model, and experience with a similar model for axial turbine stages, Futral and Wasserbauer (1965) proposed that the enthalpy losses due to the deviation from optimum incidence are equal to the kinetic energy change in the tangential component. Their incidence loss estimate, which is also known as the NASA model, is given by:

$$
L_{i}=\frac{1}{2} W_{4}^{2} \sin ^{2} \beta_{4}
$$

As mentioned above, the enthalpy losses are used to estimate the corresponding entropy generation and define the total to static efficiency. Thus, all of the loss 
correlations are defined in terms of the enthalpy losses and the term $L$ represents the enthalpy losses $\sum \Delta h_{\text {loss }}$. In the early incidence losses model, the optimum incidence was assumed equal to the zero inlet blade angle for a radial inflow turbine, so $\beta_{4}$ represents the deviation from optimum incidence.

However, as discussed above, the optimum incidence for radial turbine is not equal to the inlet blade angle but lies within the range of $-20^{\circ}$ to $-40^{\circ}$. Yeo and Baines (1990) conducted experiments to measure the value of optimum incidence for a particular radial inflow turbine and found it to be equal to about $-30^{\circ}$, corresponding to the maximum efficiency point. Moreover, later results proved that the incidence loss model of a constant pressure process is not suitable for finite blade thickness and non-zero inlet blade angle. Therefore, Wasserbauer and Glassman (1975) rewrote the incidence loss equation for non-zero optimum incidence as:

$$
L_{i}=\frac{1}{2} W_{4}^{2} \sin ^{2}\left(\beta_{4}-\beta_{4, o p t}\right)
$$

Equation 3.3 is generally used as the incidence loss correlation for current radial inflow turbine design and, as such, it was selected to be used in this thesis. Equation 3.3 is only required to be used in RITMLO for off-design analysis because the flow enters the rotor blade passage at the specified optimum incidence at the design point. However, although Equation 3.3 would not account for the incidence loss in RITMLD, it does not mean that there is no loss generation at the design point due to the incidence. In order to account for the incidence losses at the design point, Balje (1952) introduced an incidence losses correlation as:

$$
L_{i}=\frac{0.75}{2\left(1-M_{4}^{2}\right)}\left(\frac{C_{m 4}}{C_{m 5}} \frac{C_{m 4}}{U_{4}} \tan \alpha_{4}-1\right)^{2} U_{4}^{2}
$$


As seen, Balje's correlation was introduced in 1952, which predates Wasserbauer and Glassman's (1975) non-zero optimum incidence correlation as well as Yeo and Baines's (1990) corresponding experiment. However, Balje's correlation is mainly constituted by the component of absolute flow velocity, and not the relative flow, as in Equation 3.3. Thus, even though the optimum range of incidence angle has been introduced and tested after 1952, Balje's correlation is not in conflict with the updated incidence loss correlation. Finally, in RITMLD, Equation 3.4 was used as the incidence loss correlation. In RITMLO, incidence loss correlations were comprised by Equations 3.3 and 3.4 to account for the incidence losses when the turbine is operating away from the design point.

\subsubsection{Passage Losses}

The passage losses refer to all of the losses occurring in the internal blade passage. For a radial inflow turbine rotor, the main forms of passage losses include secondary flow, blockage, kinetic energy losses due to the growth of boundary layers, as well as flow separation in extreme cases (Baines, 2003). As discussed in Section 2.4, a reliable method does not exist for radial turbines to separate the passage loss into profile losses and secondary flow losses. Therefore, the secondary flow losses and friction losses due to the viscous shear effects on the blade surfaces constitute the passage loss model for radial inflow turbines. Initially, Futral and Wasserbauer (1965) proposed a simple correlation for secondary flow losses based on the mean kinetic energy of the fluid in the blade passage. This correlation was examined by Benson (1970) and he found that the same accuracy of efficiency prediction as other more complicated correlations can be achieved based on this correlation. This correlation was developed further by Wasserbauer and Glassman (1975) as: 


$$
L_{p}=\frac{1}{2} K\left(W_{4}^{2} \cos ^{2} i+W_{5}^{2}\right)
$$

where $\mathrm{K}$ is a coefficient that was determined through comparison with experiment (Baines, 2003). Wasserbauer and Glassman (1975) suggested that reliable results can be obtained when $K=0.3$. However, Benson (1970) suggested that the value of $K$ is not constant and should be varied with the nozzle exit blade angle to a small extent.

Another part of the passage loss model is a friction loss correlation as:

$$
L_{f}=C_{f}\left(L_{h} / D_{h}\right) \frac{1}{2}\left(\frac{W_{4}+W_{5}}{2}\right)^{2}
$$

where $C_{f}$ is the friction coefficient, and $L_{h}$ and $D_{h}$ are the hydraulic length and diameter of blade passage respectively. The Moody chart or the Colebrook-White equation is generally used to calculate the friction coefficient but it is only suitable for fully developed turbulent flow in straight pipes. For a radial inflow turbine rotor, a higher value of friction coefficient is found to be needed to account for the fact that flow is developing in a strongly-curved passage (Baines, 2003).

Equations 3.5 and 3.6 are also known as the NASA passage loss model for radial inflow turbines. A comparison of the results of measured and predicted efficiencies was conducted for a number of experiments for radial inflow turbines. The results show that, overall, a much lower accuracy of efficiency prediction based on NASA model than other loss models (Baines, 2003). For this reason, an improved passage loss model, namely the CETI model, was developed to estimate more realistically the losses due to the secondary flow and friction in the rotor passages. In this model, secondary flow and friction loss formulations are combined into one correlation as: 


$$
L_{p}=m_{f} \cdot 0.11 \cdot\left[\left(\frac{L_{h}}{D_{h}}\right)+0.68 \cdot\left(1-\left(\frac{r_{t}}{r_{4}}\right)^{2}\right) \cdot \frac{\cos \left(\beta_{t}\right)}{\left(\frac{b_{t}}{c}\right)}\right] \cdot \frac{W_{4}^{2}+W_{t}^{2}}{2}
$$

where $m_{f}=1$ for $\frac{r_{4}-r_{t}}{b_{t}} \geq 0.2$ and $m_{f}=2$ for $\frac{r_{4}-r_{t}}{b_{t}}<0.2$. This accounts for the effect of secondary losses greatly increasing and probable flow separation happened near the blade tip due to the very small radius of curvature on the shroud line of the rotor (Baines, 2003). Subscript t represents the rotor throat where the location separates from the rotor exit. In view of the fact that there is no correlation to predict the fluid information at the rotor throat in the open literature for preliminary meanline analysis, the corresponding terms are approximated by: $r_{t}=r_{5}, \beta_{t}=0.8 \beta_{5}, W_{t}=0.7 W_{5}, b_{t}=o_{t}$ where $o_{t}$ is the mean throat width and determined by:

$$
o_{t}=\frac{q_{5} C_{m 5}}{W_{5}}
$$

where $q_{5}$ is the rotor outlet mean blade pitch and determined by:

$$
q_{5}=\frac{2 \pi r_{5}}{N_{R}}
$$

The above approximated parameters at the rotor throat are determined based on a series of results compared between the RITMLD and the other existing models, which is developed by Ventura et al. (2012), to predict the percentage of different loss mechanisms in the overall losses process along with the stage efficiency. The terms 
$\left(\frac{L_{h}}{D_{h}}\right)$ and $0.68 \cdot\left(1-\left(\frac{r_{t}}{r_{4}}\right)^{2}\right) \cdot \frac{\cos \left(\beta_{t}\right)}{\left(\frac{b_{t}}{c_{t}}\right)}$ account for the friction and secondary flow losses respectively. The second term also includes an element for the blade loading as a result of the mean radius change and an element for the flow turning in the tangential component. $L_{h}$ and $D_{h}$ are the mean passage hydraulic length and diameter. $L_{h}$ is approximated as the mean of two quarter circle distances based on the rotor inlet and exit (Equation 3.8) and $D_{h}$ is the mean of the inlet and exit hydraulic diameters (Equation 3.9) (Baines, 2003),

$$
\begin{gathered}
L_{h}=\frac{\pi}{4}\left[\left(Z_{R}-\frac{b_{4}}{2}\right)+\left(r_{4}-r_{t}-\frac{b_{t}}{2}\right)\right] \\
D_{h}=\frac{1}{2}\left[\left(\frac{4 \pi r_{4} b_{4}}{2 \pi r_{4}+N_{R} \cdot b_{4}}\right)+\left(\frac{2 \pi \cdot\left(\left(r_{s 5}\right)^{2}-\left(r_{h 5}\right)^{2}\right)}{\pi\left(r_{s 5}-r_{h 5}\right)+N_{R} \cdot b_{5}}\right)\right]
\end{gathered}
$$

where $N_{R}$ refers to the number of rotor blades and $c$ is the chord of rotor blade which is approximated by:

$$
c=\frac{Z_{R}}{\cos \beta} \text { where } \tan \beta=\frac{1}{2}\left(\tan \beta_{4}+\tan \beta_{5}\right)
$$

Equation 3.7 was used as the passage loss correlation in RITMLD and RITMLO. 


\subsubsection{Tip Clearance Losses}

In a radial inflow turbine, a clearance gap exists between the rotor blade and shroud. It can be separated into axial and radial clearances as shown in Figure 3.2.

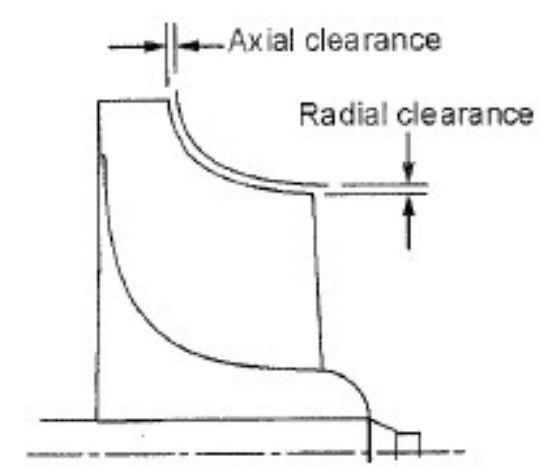

Figure 3.2 Tip Clearance of a Radial Turbine Rotor (Baines, 2003).

The effects of tip clearance on the performance of radial inflow turbines were studied by Krylov and Spunde (1963), Futral and Holeski (1970) as well as Wantanabe et al. (1971). The results show that radial turbine efficiency was significantly affected by the leakage flow due to the existence of the tip clearance. Also, Futral and Holeski (1970) demonstrated that the leakage flow influences flow conditions at the rotor exit area to a large extent. The radial clearance was found to make a larger contribution to the effects of secondary flow formation and deviation of exit flow angle than the axial clearance.

After a series of experiments, Krylov and Spunde (1963), proposed a simple expression to account for efficiency losses due to the effect of tip clearance as follows:

$$
\Delta \eta_{t c}=0.1 \varepsilon_{r} / b_{5}
$$


Rodgers (1968) gave the following alternative expression:

$$
\Delta \eta_{t c}=2 \frac{\varepsilon_{r}}{b_{5}}\left(\frac{r_{5}}{r_{4}}-0.275\right)
$$

where $\varepsilon_{r}$ and $b_{5}$ refer to the radial clearance and the exit blade height respectively. However, a flaw exists in these simple expressions in that no flow parameters, only geometry dimensional parameters, were considered, as noted by Baines (2003).

An improved model was developed by Spraker (1987). This model is based on the leakage flow rate as estimated from:

$$
\dot{m}_{L}=\frac{1}{2} \rho U \varepsilon_{r} L N_{R} K
$$

where $\mathrm{L}$ is the length of the gap and $\mathrm{K}$ is a coefficient equal to 1.5 based on experiment. The tip clearance losses are then given by:

$$
L_{c}=\frac{1}{2}\left(\dot{m}_{L} / \dot{m}\right) U_{4}^{2}
$$

where $\dot{m}$ is the total mass flow rate through the stage and $\mathrm{U}_{4}$ is the blade speed at the rotor inlet. However, the effect of axial clearance on the tip clearance losses was not considered in Spraker's model. This shortcoming caused the accuracy of the efficiency prediction to be poor when this model was checked against experimental data (Baines, 2003). Accordingly, an improved model, which included both of the axial and radial influences, was developed. The leakage flow rate for this separate leakage gaps improved model is expressed as:

$$
\dot{m}_{L}=\frac{1}{2}\left[\rho_{4} U_{4} K_{a} \varepsilon_{a}\left(r_{4}-r_{s 5}\right)+\rho_{5} U_{s 5} K_{r} \varepsilon_{r}\left(Z_{R}-b_{4}\right)\right] N_{R}
$$


where $K_{a}$ and $K_{r}$ are discharge coefficients for the axial and radial tip clearances respectively. The total mass flow rate through the turbine is:

$$
\dot{m}=\rho_{4} C_{m 4} 2 \pi r_{4} b_{4}=\rho_{5} C_{m 5} 2 \pi r_{5} b_{5}
$$

Using Equations 3.15 and 3.16, the expression for the losses given by Equation 3.14 is then replaced by:

$$
L_{c}=\frac{U_{4}^{3} N_{R}}{8 \pi}\left(K_{a} \varepsilon_{a} C_{a}+K_{r} \varepsilon_{r} C_{r}\right)
$$

where

$$
C_{a}=\frac{1-\left(r_{s 5} / r_{4}\right)}{C_{m 4} \cdot b_{4}} \quad \text { and } \quad C_{r}=\left(\frac{r_{s 5}}{r_{4}}\right) \frac{Z_{R}-b_{4}}{C_{m 5} \cdot r_{5} \cdot b_{5}}
$$

Dambach et al (1998) proposed that the motion of the blade relative to the casing also has an effect on the leakage flow losses. In order to account for this effect, a cross-coupling coefficient, $K_{a r}$, was introduced to an improved model:

$$
L_{c}=\frac{U_{4}^{3} N_{R}}{8 \pi}\left(K_{a} \varepsilon_{a} C_{a}+K_{r} \varepsilon_{r} C_{r}+K_{a r} \sqrt{\varepsilon_{a} \varepsilon_{r} C_{a} C_{r}}\right)
$$

where $K_{a}=0.4, K_{r}=0.75$ and $K_{a r}=-0.3$ were determined by experimental results. A good agreement with other measured data for two different turbines was achieved based on these values (Baines, 2003).

The comparison of experimental results between predicted and measured efficiency for different radial inflow turbines using Equation 3.18 was shown by Baines (2003) to 
be reasonable. Therefore, Equation 3.18 was used in RITMLD and RITMLO to account for the tip clearance losses.

\subsubsection{Windage Losses}

Windage losses are frictional losses occurring on the back face of the turbine disk. The fluid leaks between the rotor disk and the backplate, as shown in Figure 3.3.

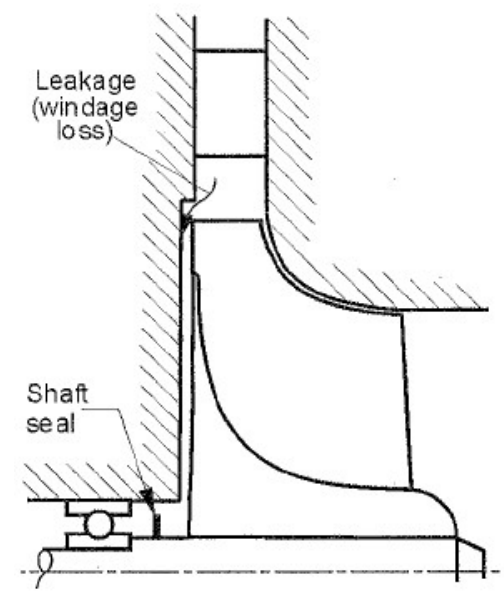

Figure 3.3 Windage Loss due to Rotor Backflow (Baines, 2003).

Generally, windage losses have been calculated based on a torque coefficient, $\tau_{\text {fric }}$, which was developed by Daily and Nece (1960) as:

$$
\tau_{\text {fric }}=K_{f} \frac{1}{4} \rho \omega^{2} r_{4}^{2}
$$

where $K_{f}$ is a function of Reynolds number as:

$$
K_{f}=\frac{3 \cdot\left(\frac{\varepsilon_{b}}{r_{4}}\right)^{0}}{\operatorname{Re}^{0.5}}\left(\operatorname{Re}<10^{5}\right) \quad \text { and } \quad K_{f}=\frac{0.102\left(\frac{\varepsilon_{b}}{r_{4}}\right)^{0}}{\operatorname{Re}^{0.2}}\left(\operatorname{Re}>10^{5}\right)
$$


where $\varepsilon_{b}$ represents the clearance between the back face of the rotor disk and the turbine backplate and $\mathrm{Re}$ is defined as:

$$
\operatorname{Re}=\frac{\bar{\rho} \cdot \bar{C} \cdot r_{4}}{\bar{\mu}}
$$

where $\bar{\rho}, \bar{C}$ and $\bar{\mu}$ are the average fluid density, velocity and viscosity between rotor inlet and outlet.

The expression for windage losses in terms of enthalpy change was developed by Ghosh et al. (2011):

$$
L_{w}=K_{f} \frac{\bar{\rho} \cdot U_{4}^{3} \cdot r_{4}^{2}}{2 \cdot m \cdot W_{5}^{2}}
$$

This is the expression used to estimate the windage losses in RITMLD and RITMLO.

\subsubsection{Trailing Edge Losses}

The passage loss correlation presented in Equation 3.7, accounts for the loss process between the inlet and the throat of the rotor. Thus, a trailing edge loss correlation is necessary to account for the losses due to the effect of the sudden expansion from the rotor throat to a plane just downstream of the trailing edge (Baines, 2003). Glassman (1995) developed a trailing edge loss model based on the relative pressure losses: 


$$
\Delta P_{0, r e l}=\frac{\rho_{5} \cdot W_{5}^{2}}{2 \cdot g}\left(\frac{N_{R} \cdot t_{\text {trailing }}}{\pi\left(r_{s 5}+r_{h 5}\right) \cdot \cos \beta_{5}}\right)^{2}
$$

where $t_{\text {trailing }}$ is trailing edge thickness. Ghosh et al. (2011) developed the corresponding enthalpy loss expression as:

$$
L_{t}=\frac{2}{\gamma \cdot M_{5, r e l}^{2}} \cdot \frac{\Delta P_{0 . r e l}}{P_{5} \cdot\left(1+\frac{W_{5}^{2}}{2 \cdot T_{5} \cdot c_{p}}\right)^{\left(\frac{\gamma}{\gamma-1}\right)}}
$$

As seen, due to the existence of the parameters of heat capacity at constant pressure $c_{p}$ and the ratio of the constant volume and constant pressure heat capacity $\gamma$, the ideal gas assumption is used in Equation 3.22. Although this correlation conflicts with the calculation process that is based on real gas properties, the error only exists in the expression transformation process, in which the relative pressure losses converts to the corresponding enthalpy losses, since the relative pressure loss in Glassman's correlation does not use the ideal gas assumption. Also, the trailing edge losses only have a very limited impact on the overall enthalpy losses for radial turbines at design and off-design points, which will be discussed in Chapter 5. The effect of the ideal gas assumption in terms of the enthalpy losses expression on the accuracy of meanline analysis is fairly small. Furthermore, since the compressibility factor of $\mathrm{S}-\mathrm{CO}_{2}$ is fairly close to 1.0 for the CU-BCL radial inflow turbine, as presented in Figure 2.14, the characteristics of the CU-BCL radial inflow turbine over the full operating range almost avoid being influenced by the ideal gas assumption. Therefore, until a reliable correlation, which is based on real gas effects, to predict the trailing edge losses in terms of enthalpy change for the radial turbine, is developed, Equation 3.22 is eligible to be used in RITMLD and RITMLO. 


\subsubsection{Exit Energy Losses}

For a single stage radial turbine, the kinetic energy in the outlet flow is treated as the exit energy loss. At the design operating point, in order to reduce these losses, the working fluid has been designed to have zero swirl since the magnitude of exit flow velocity is a deciding factor in the exit energy losses. However, a part of the velocity in the kinetic energy can be converted into static pressure through a diffuser component, thus reducing these losses. Suhrmann et al. (2010) presented the exit energy loss correlation as follows:

$$
L_{e}=\frac{C_{5}^{2}}{2}
$$

Finally, Equations 3.3, 3.4, 3.7, 3.18, 3.20, 3.22, 3.23 were chosen as the loss correlations for the loss correlation system for the meanline design (RITMLD) and the off-design (RITMLO) operating point analyses.

\subsection{Development of the Radial Inflow Turbine Meanline Design Operating Point (RITMLD) Code}

\subsubsection{Introduction}

As discussed in Section 2.7, the behavior of the working fluid differs from the ideal gas behavior when the compressibility factor, $\mathrm{Z}$, is different from 1.0. In order to account for this effect, REFPROP 9.0 was incorporated into RITMLD and RITMLO. For the

design requirements of the Carleton University Brayton Cycle Loop (CU-BCL), the 
working fluid is supercritical carbon dioxide $\left(\mathrm{S}-\mathrm{CO}_{2}\right)$.

One of the objectives of RITMLD is to obtain the main geometric dimensions of the radial inflow turbine. The mass flow rate $(\dot{\mathrm{m}})$, rotational speed $(\mathrm{N})$, inlet total pressure and total temperature $\left(\mathrm{P}_{01}, \mathrm{~T}_{01}\right)$ as well as the output power $(\mathrm{W})$ for the radial inflow turbine were used as known parameters to design the geometry. These parameters are specified from the design point for CU-BCL. Also, a reasonable value of total-to-total pressure ratio $\left(\mathrm{PR}_{\mathrm{t}-\mathrm{t}}\right)$ is specified based on an assumed efficiency and then an initial value of outlet total pressure $\left(\mathrm{P}_{05}\right)$ is obtained. The value of $\mathrm{PR}_{\mathrm{t}-\mathrm{t}}$ and $\mathrm{P}_{05}$ will be updated along with the value of updated efficiency. In order to obtain a reasonable geometric model of the radial inflow turbine from RITMLD, the calculated turbine efficiency should lie within the optimum range based on the design parameters. In some cases, the output power with the outlet static pressure instead of the outlet total pressure was specified as a design requirement for outlet conditions. In order to account for this condition, the option of setting different outlet conditions was included and tested in RITMLD. Although RITMLD is a highly automatic program for radial inflow turbine design, the user still has the option to input parameters such as the velocity ratio, stage loading and flow coefficients manually within a reasonable range to design the turbine stage. The user manual for RITMLD is presented in Appendix A, along with the input file format and examples of input files.

\subsubsection{Development of Rotor Design in RITMLD}

As discussed in Section 2.5, Aungire's method was chosen for use in the meanline analysis. Thus, the specific speed becomes a significant parameter for radial inflow turbine meanline design operating point analysis, since many correlations are a function of specific speed, which will be determined initially by RITMLD. The specific speed as 
shown in Equation 3.24 was defined by Balje (1981) in dimensionless form as:

$$
n_{s}=\frac{\omega \sqrt{Q_{5}}}{\left(\Delta H_{i d}\right)^{0.75}}
$$

The ideal enthalpy drop, $\Delta H_{i d}$, corresponds to an isentropic expansion from the stage inlet total conditions to the rotor exit static condition, $\omega$ is rotational speed, and $Q_{5}$ is volume flow rate at rotor exit. $Q_{5}$ is obtained from:

$$
Q_{5}=\frac{\dot{m}}{\rho_{05}}
$$

where $\rho_{05}$ is the total density of working fluid at the exit of turbine. The value of $\rho_{05}$ is obtained from REFPROP subroutine based on the outlet total enthalpy, $H_{05}$, and the initial estimated value of outlet total pressure, $\mathrm{P}_{05}$. Based on the specified value of output power, $\dot{W}$, the total enthalpy change, $\Delta h_{0}$, can be obtained from Equation 2.4 . Also, the value of inlet total enthalpy, $H_{01}$, can be returned from REFPROP based on the inlet total pressure and total temperature, $\mathrm{P}_{01}$ and $\mathrm{T}_{01}$. Then the value of $H_{05}$ is the result of $H_{01}-\Delta h_{0}$. In order to obtain the value of total-to-static ideal enthalpy drop, $\Delta H_{i d}$, the inlet and outlet total enthalpy as well as the total-to-static efficiency must be specified. Then:

$$
\Delta H_{i d}=\frac{H_{01}-H_{05}}{\eta_{t-s}}
$$

where $\eta_{t-s}$ is the total-to-static efficiency of turbine stage and the value of $H_{01}-H_{05}$ is 
the total-to-total enthalpy drop. The initial value of $\eta_{t-s}$ in Equation 3.26 is guessed and it will be updated in the following iteration. Based on this estimated value of $\Delta H_{i d}$, the initial value of $n_{s}$ is obtained. In order to improve the accuracy of $\eta_{t-s}$ and the corresponding parameters early in the design stage, the value of $\eta_{t-s}$ is updated based on Aungier's correlation. Aungier (2005) introduced a generalized correlation of total-to-static efficiency as a function of specific speed:

$$
\eta_{t-s}=0.87-1.07\left(n_{s}-0.55\right)^{2}-0.5\left(n_{s}-0.55\right)^{3}
$$

An updated total-to-static efficiency is obtained from the result of Equation 3.27 and then it is used as the updated efficiency for Equation 3.26 until the total-to-static efficiency reached convergence. During this iterative process, the corresponding values of $\Delta H_{i d}$ and $n_{s}$ are also updated. However, even though a more accurate efficiency along with other corresponding parameters is obtained after this iterative procedure, the result is still based on a generalized estimation by Aungier (2005). Therefore, the final total-to-static efficiency will be determined after the actual losses are estimated as part of the iterative procedure.

As discussed in Section 2.5, the velocity ratio, $v_{s}$, is another non-dimensional parameter to determine the quality of the meanline design. The choice of velocity ratio will affect the flow incidence directly and the stage efficiency. Although the optimum value of velocity ratio is determined case by case, a general initial choice of this value lies within the range of 0.6-0.7. The optimum range of flow incidence lies between $-20^{0}$ and $-40^{\circ}$, as reported by Baines (2003) and observed by Woolley and Hatton (1973). Thus the velocity ratio can be optimized based on the result of flow incidence since it is 
affected by the velocity ratio directly. The final choice of the velocity ratio has to ensure the incidence lies within the optimum range. Also, because the choice of velocity ratio will have an effect on the enthalpy losses and turbine stage efficiency, the value of velocity ratio can be varied to pursue the optimum efficiency. If the optimum efficiency is achieved, the corresponding velocity ratio is also the optimum value. After the fundamental non-dimensional parameters are determined, the velocity triangles, geometry dimensions, and working fluid properties through the stage will be obtained through the following procedures.

The rotor section of the turbine stage is the most significant part that determines the performance of machine. Thus, it will be designed first at the meanline. The flow chart and equations of rotor design in RITMLD are listed in Appendix D.

A feasibility check (Ventura et al., 2012), which evaluates the quality of the rotor design, is included in RITMLD. It examines many different parameters of the geometry and flow to constrain them to a reasonable range. If the result of the rotor design meet these constraints simultaneously, it will be considered reasonable. These constraints are described as follows.

- The rotor inlet relative flow angle (incidence) should lie between $-20^{\circ} \mathrm{deg}$ and $-40^{0}$ degree (Baines, 2003).

- The Mach number at the rotor inlet and outlet should be smaller than 1.0 to avoid supersonic losses and choking condition occurring at the nozzle and rotor throats.

- Aungier (2005) recommends that $Z_{R} \geq 1.5 b_{4}$. 
- Balje (1981) suggests that limitations on the outlet meridional velocity and shroud radius are $0.2 \leq C_{m 5} / U_{4} \leq 0.4$ and $r_{s 5} / r_{4} \leq 0.78$

- Wood (1963) recommends that the ratio of meridional velocities be limited to $1 \leq C_{m 5} / C_{m 4} \leq 1.5$

- Aungier (2005) recommends that $0.45 \leq R \leq 0.65$ where $\mathrm{R}$ is the stage reaction. The degree of reaction is defined as $R=\left(H_{4}-H_{5}\right) /\left(H_{01}-H_{05}\right)$ and is known to influence the performance.

The above parameters comprise the feasibility check portion of the code, and specific warning messages for each constraint condition that is violated are presented in the output file of RITMLD. An example of the output file for RITMLD is presented in Appendix C. Also, as discussed in Section 2.5, Figure 2.10 (correlation of efficiency as a function of blade loading and flow coefficients) can be used as a basis for evaluating the design.

\subsubsection{Development of Nozzle Design in RITMLD}

This section describes the design procedures for the nozzle blade geometry. As described in Section 2.2.2, straight vanes were chosen for the nozzle ring of the CU-BCL radial inflow turbine. Because the flow is not supersonic at the blade trailing edge when the machine is operating at the design point, the blade angle of the nozzle vane, is set to be the same as the rotor inlet absolute flow angle:

$$
\beta_{2}=\beta_{3}=\alpha_{4}
$$


The blade height at the inlet and outlet of the nozzle was assumed to be equal to the rotor inlet blade height. Thus:

$$
b_{2}=b_{3}=b_{4}
$$

As discussed in Section 2.2.3, a radial gap exists between the nozzle exit and rotor inlet. Watanabe et al. (1971) introduced a correlation to estimate a suitable distance for this gap:

$$
\Delta r=2 \cdot b_{4} \cdot \cos \alpha_{4}
$$

Thus, the radius at the nozzle exit can be calculated from:

$$
r_{3}=r_{4}+\Delta r
$$

Since the nozzle section is non-rotating, it is unnecessary to consider the relative velocity component in the velocity triangle for the nozzle blade. Conservation of angular momentum and mass flow equations were used in the design procedure to relate conditions at the inlet and outlet of the radial gap. The design procedures for the velocity components at the nozzle inlet and outlet are presented in Appendix D.

\subsubsection{Development of Volute Design in RITMLD}

This section describes the types of volute and the choice of volute in RITMLD. There are two types of volute design for radial turbines. The external volute lies completely above the exit radius of the volute, as shown in Figure 3.4, and the internal volute is designed to the same radius of the volute inlet and exit, as shown in Figure 3.5. The external volute type was selected in RITMLD since the flow will be accelerated to a 
higher tangential velocity for the same inlet velocity by the change of radius (Baines, 2003).

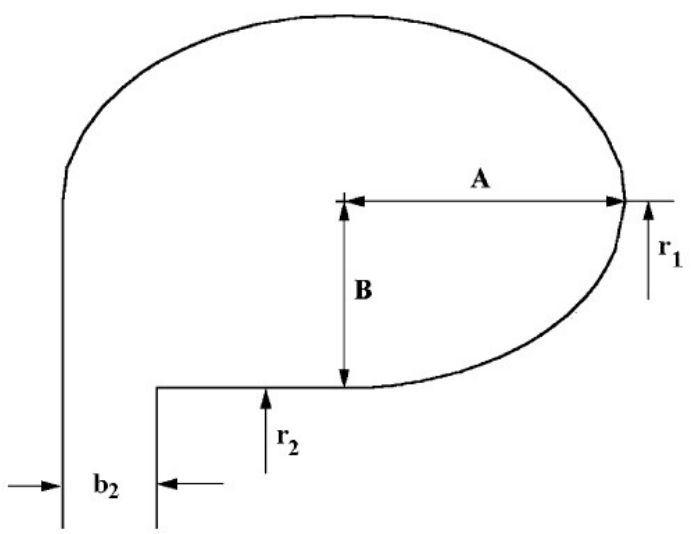

Figure 3.4 An External Elliptical Volute (Baines, 2003).

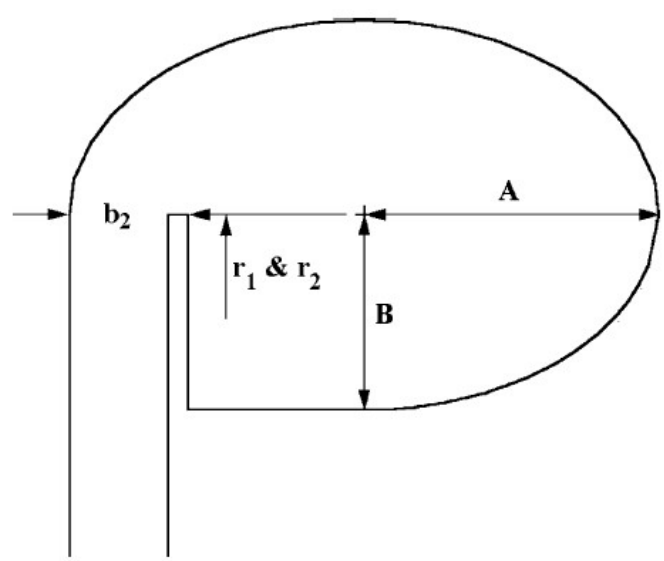

Figure 3.5 An Internal Elliptical Volute (Baines, 2003).

The design procedures for the preliminary volute design in terms of the volute passage area, $A_{1}$, and the volute mean radius, $r_{1}$, are presented in Appendix D. The overall size of the radial turbine stage in terms of the maximum axial and radial dimensions can be determined after the volute design has been finished. 


\subsubsection{Calculation of Loss Correlations in RITMLD}

In order to update the stage efficiency, the following section in the code development of RITMLD is the loss correlations calculation. The loss correlation system used in RITMLD has been described in Section 3.2. Although the nozzle and volute preliminary design have been finished before the loss correlation calculation, these correlations only account for the losses occurring in the rotor section due to the lack of reliable loss correlations for the nozzle and volute in the open literature. Thus, Figure 3.1 (predicted distribution of radial turbine losses as a function of specific speed) is used to estimate the efficiency losses incurred by the nozzle section based on the corresponding stage specific speed. After the stage enthalpy losses are calculated from the loss correlations, a new efficiency was estimated based on Equation 3.1 and Figure 3.1. This updated efficiency will be returned to Equation 3.26 and then all of the following parameters will be recalculated based on the updated efficiency. This iterative process is repeated until the value of efficiency has converged to within 0.00001 .

\subsubsection{Update of Turbine Stage Pressure Ratio in RITMLD}

As described at the beginning of Section 3.3, the initial value of stage total-to-total pressure ratio $\left(\mathrm{PR}_{\mathrm{t}-\mathrm{t}}\right)$ is based on an assumed efficiency. Thus, an updated value of $\mathrm{PR}_{\mathrm{t}-\mathrm{t}}$

and corresponding parameters can be obtained based on the converged efficiency. In order to make sure the calculation process of information update is based on real gas properties, Figure 3.6 is used as a way to understand which parameters are essential to obtain the corresponding parameters from the REFPROP subroutine. 


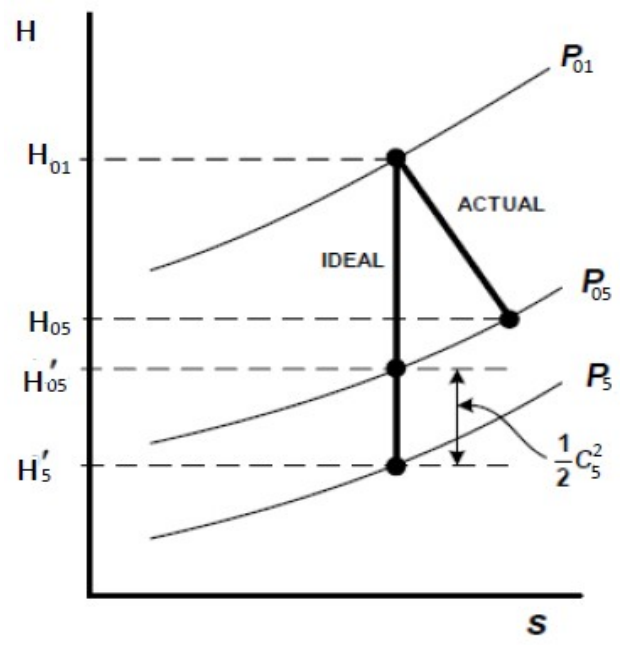

Figure 3.6 The H-s Diagram for Compressible-Flow Turbines (adapted from Sjolander, 2013).

The H-s diagram shows that the ideal and actual expansion processes needed to go through the same pressure ratio, $\mathrm{P}_{01} / \mathrm{P}_{05}$. Although the outlet entropy, $\mathrm{s}_{5}$, can be determined by the outlet total pressure, $\mathrm{P}_{05}$, or static pressure, $\mathrm{P}_{5}$, at this step, the value of these two parameters are still based on an assumed total-to-total pressure ratio $\mathrm{PR}_{\mathrm{t}-\mathrm{t}}$. Thus, the outlet total pressure or static pressure has to be updated first. As shown, the inlet (ideal) entropy, $\mathrm{s}_{1}$, and the outlet ideal static enthalpy, $H_{5}^{\prime}$, locate in the line of outlet static pressure, $\mathrm{P}_{5}$. The value of $H_{5}^{\prime}$ is the result of $H_{01}-H_{i d}$ and $\mathrm{s}_{1}$ can be obtained based on the inlet total pressure, $\mathrm{P}_{01}$, and total temperature, $\mathrm{T}_{01}$. Then an updated value of $\mathrm{P}_{5}$ is obtained from REFPROP subroutine based on the parameters of $H_{5}^{\prime}$ and $\mathrm{s}_{1}$. As mentioned above, the value of $s_{5}$ can be obtained from REFPROP subroutine based on the outlet static enthalpy, $\mathrm{H}_{5}$, and the updated outlet static pressure, $\mathrm{P}_{5}$. Finally, an updated outlet total pressure ratio, $\mathrm{P}_{05}$, is returned by the REFPROP subroutine as well based on the outlet total enthalpy, $\mathrm{H}_{05}$, and outlet entropy, $\mathrm{s}_{5}$. At the same time, an updated value of $\mathrm{PR}_{\mathrm{tt} t}$ is obtained and then all of the calculation process will be repeated based on this updated $\mathrm{PR}_{\mathrm{t}-\mathrm{t}}$. This iterative procedure is repeated until the convergence target of $0.0001 \mathrm{kPa}$ is achieved for outlet total pressure $\mathrm{P}_{05}$. 


\subsubsection{Development of Additional Functions for RITMLD}

Although the outlet pressure is not specified by the CU-BCL design point, the value of total-to-static pressure ratio $\mathrm{PR}_{\mathrm{t}-\mathrm{s}}$ will be given as a design requirement with the output power in many cases. To allow for these cases, a function calling the REFPROP subroutine to return the working fluid properties at the stage outlet based on static pressure and output power is added in RITMLD. First, the outlet static pressure, $\mathrm{P}_{5}$, is assumed equal to the outlet total pressure, $\mathrm{P}_{05}$, since the exit velocity is designed to be fairly small at the design operating point. Thus, the corresponding thermodynamic information at the stage outlet can be obtained from the REFPROP subroutine based on the parameters of $\mathrm{H}_{05}$ and $\mathrm{P}_{05}$. The following calculation procedures are based on the assumed outlet total pressure, $\mathrm{P}_{05}$, until the result of outlet absolute flow velocity, $\mathrm{C}_{5}$, is obtained. Then the outlet static enthalpy, $\mathrm{H}_{5}$, can be calculated from Equation D.21 and the outlet entropy can be obtained from the REFPROP subroutine based on the value of $\mathrm{H}_{5}$ and $\mathrm{P}_{5}$. Thus, an updated value of $\mathrm{P}_{05}$ can be returned from the REFPROP subroutine based on the parameters of $\mathrm{H}_{05}$ and $\mathrm{s}_{5}$. This updated $\mathrm{P}_{05}$ is used as a new outlet state point to call the REFPROP subroutine with the $\mathrm{H}_{05}$ for the overall calculation process. This iterative procedure is repeated until the result of outlet total pressure $\mathrm{P}_{05}$ reaches convergence.

Therefore, through the above additional calculation procedures, the parameter of total-to-static pressure ratio becomes an option of outlet condition for RITMLD to design the radial inflow turbine. 


\subsection{Development of the Radial Inflow Turbine Meanline Off-Design Operating Point (RITMLO) Code}

\subsubsection{Introduction}

In order to account for off-design points operation, the program RITMLO was developed. The objective of RITMLO is to predict the performance of radial turbines in off-design operation based on the designed geometry, as determined using RITMLD. In RITMLO, the off-design pressure ratio and rotational speed are specified as the known parameters for which to predict the turbine characteristics. After a series of iterations and the convergence target has been achieved, the final result of efficiency and mass flow rate corresponding to each different operating point is obtained. The characteristics of the radial inflow turbine can be plotted once a sufficient number of performance data have been obtained for each constant speed line.

Although the logic is different between RITMLD and RITMLO, some code sections from RITMLD could be reused in RITMLO since the correlations and flow analysis are similar. The detailed development method for RITMLO and the major modifications from RITMLD are described in the following. Also, the input file format for RITMLO is presented in Appendix B, along with an example input file.

\subsubsection{Development of the Radial Inflow Turbine Meanline Off-Design Operating Point (RITMLO) Code}

The ideal enthalpy drop is a critical parameter to determine the overall performance of the turbine. In RITMLD, it was calculated based on the real gas properties and actual 
total enthalpy drop as well as predicted total-to-static efficiency. However, the properties of the working fluid at the outlet are unknown at the beginning of the off-design calculations. Therefore, ideal gas relationships are used in the initial analysis using RITMLO. An iterative process to account for the real fluid effects was added to RITMLO,

$$
\Delta H_{i d}=C_{p} T_{01}\left[1-\left(\frac{1}{P R}\right)^{\frac{\gamma-1}{\gamma}}\right]
$$

where PR is the pressure ratio based on the ratio of inlet total pressure to outlet static pressure, $C_{p}$ is the specific heat capacity at constant pressure and $\gamma$ is the specific heat ratio. These thermodynamic parameters are returned from REFPROP based on the inlet total pressure and temperature. Thus an ideal gas approximation to the total-to-static ideal enthalpy drop was obtained. It can then be used in the same flow analysis equations as used in RITMLD. In RITMLO, the outlet static pressure is constant and user can alter the inlet total pressure to change the operating point of pressure ratio. In the CFD model, the outlet static pressure was held constant as a boundary condition as well, so this measure made the results of meanline and CFD more comparable. The outlet total pressure can be obtained based on the method described in Section 3.3.6. Thus, the map of turbine characteristic was plotted based on the variation of total pressure ratio at constant rotational speed.

After calculation of the ideal enthalpy drop, a value of total-to-static efficiency is estimated for the following flow analysis. However, Equation 3.27 cannot be used to refine the estimated efficiency since the turbine specific speed is unknown. The loss correlation system is used to calculate a new value of total-to-static efficiency and it will be compared with the original estimated efficiency. If the difference is larger than the 
convergence target of 0.001 , the original estimate efficiency was increased by 0.0002 and then the same calculation process was repeated until the convergence target was achieved. The original efficiency estimate should be conservative to ensure that the value of the final convergent efficiency was not overestimated. As seen, the convergence criterion in RITMLD is more conservative than RITMLO. This is due to the fact that RITMLO is less stable, especially when the operating point is far from the design point.

As described in section 2.5, due to the fact that the exit tangential component of absolute velocity, $C_{u 5}$, and flow angle are quite small or even zero at the design operating point, the effect of the term which accounts for the rotor outlet condition is negligible, a simplified correlation (Equation 2.3 or Equation 2.14) was used to calculate the tangential component of absolute velocity at rotor inlet, $C_{u 4}$, in RITMLD. At the off-design condition, the absolute outlet flow angle is not necessarily zero. The outlet absolute velocity can become very large at high pressure ratio off-design points. Then $C_{u 4}$ is calculated from:

$$
C_{u 4}=\frac{U_{4} \eta_{t-s}}{2 v_{s}^{2}}+\frac{r_{5}}{r_{4}} C_{u 5}
$$

which accounts for the rotor outlet swirl velocity, $C_{u 5}$. Since $C_{u 5}$ is unknown at the first iteration, $C_{u 4}$ is still calculated by Equation 2.14 until a new value of $C_{u 4}$ can be obtained from Equation 3.33. Thus, an iterative calculation for $C_{u 4}$ had to be added to RITMLO to account for the effect of the swirl at the rotor outlet.

After the rotor inlet tangential velocity, $C_{u 4}$, has been calculated, the inlet velocity 
triangle will be determined if the inlet absolute flow angle, $\alpha_{4}$, is known. In RITMLD, $\alpha_{4}$ was predicted by Aungier's correlation (Equation 2.15). However, it was found that the characteristic trend of mass flow rate with rotational speed was not predicted appropriately by using Aungier's correlation. From the subsequent CFD predictions, the trend in $\alpha_{4}$ was different for that predicted using Augier's correlation. Thus Aungier's correlation was abandoned in RITMLO. After a series of tests in RITMLO, Equations $3.34,3.35,3.36$ and 3.37 were used to calculate the inlet absolute flow angle, $\alpha_{4}$. Different correlations were developed in order to account for the effect of different rotational speeds. The value of $\alpha_{4}$ from the result of RITMLD as well as the rate of change of $\alpha_{4}$ with the varying of unit total pressure ratio from the CFX-Post results was used as reference in the development process of these correlations. Although these correlations are usable for the CU-BCL turbine design, they are clearly not generally applicable. Therefore, research is necessary in order to develop a general correlation to predict deviation at the outlet of radial turbine nozzles. Although the variation of $\alpha_{4}$ is very limited, it has been proved that this variation actually has a great effect on the turbine performance.

Inlet absolute flow angle $(\mathrm{N}=40000): \quad \alpha_{4}=90-\{12+[(P R-1) \cdot 0.3 \cdot 10]\} \quad 3.34$

Inlet absolute flow angle $\left.(\mathrm{N}=60000): \quad \alpha_{4}=90-\{13+\$ P R(-\quad 1.4 \cdot)\rangle\right\} .3 .35$

Inlet absolute flow angle $\left.(\mathrm{N}=80000): \quad \alpha_{4}=90-\{13+\beta P R(-\quad 1.4) \cdot 0]\right\}: 3.36$

Inlet absolute flow angle $(\mathrm{N}=104000): \quad \alpha_{4}=90-\{12+[(P R-1.4) \cdot 0.2 \cdot 10]\} \quad 3.37$ 
In RITMLD, the meridional component of absolute velocity at rotor outlet, $C_{m 5}$, was calculated from Aungier's correlation as given by Equation 2.16. However, it was found that Aungier's correlation is not satisfactory for this analysis either. The outlet static density, $\rho_{5}$, of working fluid was calculated from the conservation of mass flow Equation 3.38:

$$
\rho_{5}=\frac{\dot{m}}{2 \cdot \pi \cdot r_{5} \cdot b_{5} \cdot C_{m 5}}
$$

REFPROP will return the value of $\rho_{5}$ based on the outlet static enthalpy and entropy. However, the results of $\rho_{5}$ from the above two methods are not in agreement. Therefore, an iterative process instead of Aungier's correlation was used to predict the outlet static density of $\rho_{5}$ in RITMLO. Equation 3.38 was used with a reasonable estimated value of $\rho_{5}$ to calculate an initial value for $C_{m 5}$. The rotor outlet velocity triangle as well as the properties of the working fluid was obtained based on this $C_{m 5}$. Then REFPROP was called to return a new value of $\rho_{5}$. This updated $\rho_{5}$ was used in Equation 3.38 to calculate a new value of $C_{m 5}$. This updated $C_{m 5}$ not only affects the outlet velocity triangle but also the inlet velocity triangle since the inlet tangential component of absolute velocity, $C_{u 4}$, is determined by Equation 3.33 which is the Euler equation including the rotor outlet swirl velocity. Therefore, after the inlet and outlet velocity triangles were recalculated based on the updated $C_{m 5}$, a new value of $\rho_{5}$ was obtained again. This calculation procedure was repeated until the convergence target of $0.1 \mathrm{~kg} / \mathrm{m}^{3}$ was achieved for $\rho_{5}$ and then an appropriate value of $C_{m 5}$ was obtained. 
As discussed at the beginning of this section, real fluid effects were added to RITMLO in order to compensate for the effect of ideal gas calculation process, as shown in Equation 3.32. After the convergence target of the final value of total-to-static efficiency has been achieved, the ideal enthalpy drop, $H_{i d}$, based on the real fluid method can be calculated by Equation 3.26. Then the following calculations were repeated based on using the real fluid ideal enthalpy drop in RITMLO. This calculation procedure was repeated until the change in the value of $H_{i d}$ was less than $0.1 \%$. 


\section{Chapter 4 CFD Model}

\subsection{Introduction}

As described in Chapter 3, meanline analysis is a preliminary design method that assumes one-dimensional flow and depends on empirical correlations to estimate many aspects of the flow. In order to examine the flow in more detail, a full viscous three-dimensional Computational Fluid Dynamics (CFD) code, ANSYS-CFX, was used to solve the complex flow in the rotor blade passages of the radial inflow turbine.

One of the objectives of this thesis is to compare results from the meanline analysis at design and off-design operating points with CFD results. By performing a three-dimensional CFD analysis of the turbine, the degree of accuracy of the codes in meanline analysis can be investigated.

\subsection{Governing Equations}

The application of CFD to solve complex flows is based on the solution of the partial differential equations (PDE) of motion: the continuity equation for the conservation of mass, the three momentum equations and the conservation of energy equation. Taking into account the viscous effect, these equations are known as the Navier-Stokes equations and are used to solve for the velocity, pressure and temperature associated with a moving fluid.

In addition to the Navier-Stokes equations, approximate models are used to account for the turbulence in the flow. The most common approach is the Reynolds's Averaged 
Navier Stokes (RANS) equations which are solved to obtain the time-averaged properties of the flow (ANSYS, 2012).

The ANSYS CFX-v-14.5 solver was used for both design and off-design predictions. ANSYS CFX uses a finite-volume method to solve the governing equations. In view of the fact that flow conditions, between the rotor blade passages, are quite complex, a high resolution scheme was used in order to achieve second-order accuracy (ANSYS, 2012).

\subsection{Turbulence Modeling}

The $k$ - $\omega$ Shear Stress Transport (SST) model was used to model the turbulence. The $k-\omega$ SST model is a two equation turbulence model combining the $k-\varepsilon$ and $k-\omega$ models. Flow separation in turbulent flow cannot be predicted accurately by the $k-\varepsilon$ model and the $k$ - $\omega$ model does not capture free-stream turbulence effects well. However, the $k-\omega$ SST model, which was developed by Menter (1994), combines the robust behaviors of the $k-\omega$ model in the near wall region and the free stream turbulence independence of the $k$ - $\varepsilon$ model in the outer region. A blending function is used to transition smoothly between the two models within the flow (ANSYS, 2012). In this way, the $k-\omega$ SST model has good performance in the near wall region, including separation prediction, and in the outer region as well. Therefore, the $k-\omega \mathrm{SST}$ model is suitable for solving turbomachinery flow problems, including for off-design operation where separation may be important.

$\mathrm{y}^{+}$is a non-dimensional wall distance, defined as:

$$
y^{+}=\frac{u_{*} y}{v}
$$

where $u_{*}$ is the friction velocity at the nearest wall, $y$ is the distance to the nearest 
wall and $v$ is the local kinematic viscosity of the fluid. It has been widely used in turbulence modeling to determine the proper size of the cells near the domain walls. For different turbulence models, the requirements for the $\mathrm{y}^{+}$value at the first node away from the wall are different. For the $k$ - $\omega$ SST model, the most reliable results are obtained if the value of $\mathrm{y}^{+}$at the nearest node to the wall is smaller than 1.0. Unfortunately, due to the fact that the effects of shroud tip leakage flow is simulated in the CFD model, the value of $\mathrm{y}^{+}$varies between 1.24 and 913.3 for the whole domain of the model. The highest values occur for only a small percentage of nodes and only in the shroud tip clearance area. The typical value of $\mathrm{y}^{+}$in blade, hub, shroud and tip clearance region are 30,45, 110 and 150, respectively. Finally, the option of automatic wall functions was chosen, which allows the $k$ - $\omega$ SST model to obtain good predictions even if the value of $\mathrm{y}^{+}$is significantly larger than 1.0 .

\subsection{Boundary Conditions}

The total pressure and total temperature are specified as the inlet boundary conditions along with the flow direction. The flow direction is estimated from the meanline analysis. Since the volute and nozzle are not included in the CFD model, the total pressure losses that are generated in the volute and nozzle area are not predicted in the CFD model. Thus, in order to better compare the results from the meanline analyses to the CFD results, a slightly lower value of inlet total pressure, $(10300 \mathrm{kPa})$, rather than the actual pressure at the design operating point, to account for the pressure losses from the volute to the nozzle outlet, as partly predicted by meanline analysis. The flow was assumed adiabatic from the volute inlet to the rotor inlet. Therefore, the total temperature boundary condition for the CFD model is the same as for the meanline analysis. 
The static pressure was specified as the outlet boundary condition. The outlet static pressure from meanline analysis was used to estimate the outlet static pressure in the CFD model. Also, because the static pressure may be different from hub to shroud due to the presence of swirl at the turbine rotor outlet, the average static pressure was used at the outlet boundary.

\subsection{Computational Model Setup}

Supercritical carbon dioxide $\left(\mathrm{S}-\mathrm{CO}_{2}\right)$ was used as the working fluid in the CFD model. As introduced in Chapter 2, when the state of the working fluid $\mathrm{S}^{-\mathrm{CO}_{2}}$ lies within the supercritical region, the behavior of $\mathrm{S}-\mathrm{CO}_{2}$ is different from ideal gas behavior. Thus, a Real Gas Properties (RGP) file, which was generated by PCA Engineers Limited for $\mathrm{S}-\mathrm{CO}_{2}$ fluid, was used for the CFD modeling.

The Reynolds number lies within the range of $10^{6} \sim 10^{7}$ for the whole domain. Thus, turbulent flow exists at both design and off-design operating points, and the model for transition from laminar to turbulent flow should not be necessary in the CFD model. Also, the total energy method was set in the heat transfer model to obtain the corresponding results such as the enthalpy drop that can be used to calculate the isentropic efficiency.

With regard to the reference frame, the flow in the areas from rotor blade hub to blade tip is solved in the rotating frame. The tip clearance area is within a non-rotating frame since the shroud is stationary. Due to the interaction of the non-rotating and rotating frames, the tip leakage flow is relatively complex. 


\subsubsection{Domain Geometry}

The rotor blade geometry used in the CFD analysis is based on the main geometric dimensions obtained using the meanline design point analysis. The detailed CFD geometry was then developed using the BladeGen software, which is a specialized, easy-to-use tool for 3-D design of rotating machinery components (ANSYS, 2010). However, in the meanline analysis, the relative flow angle at the trailing edge of the rotor blade was assumed equal to the metal angle, due to the lack of reliable data and correlations to estimate the deviation for radial turbine rotors. Therefore, as specified in the meanline analysis, in order to obtain zero swirl flow at the rotor outlet for the CFD analysis, the rotor outlet metal angle is refined using the CFD results from a series of tests.

The optimum number of rotor blades is 14 for the CU-BCL radial inflow turbine. The choice of blade number is based on Glassman's (1976) empirical equation. The geometry of the radial inflow turbine rotor and the rotor blade passages are presented in Figures 4.1 and 4.2 , respectively.

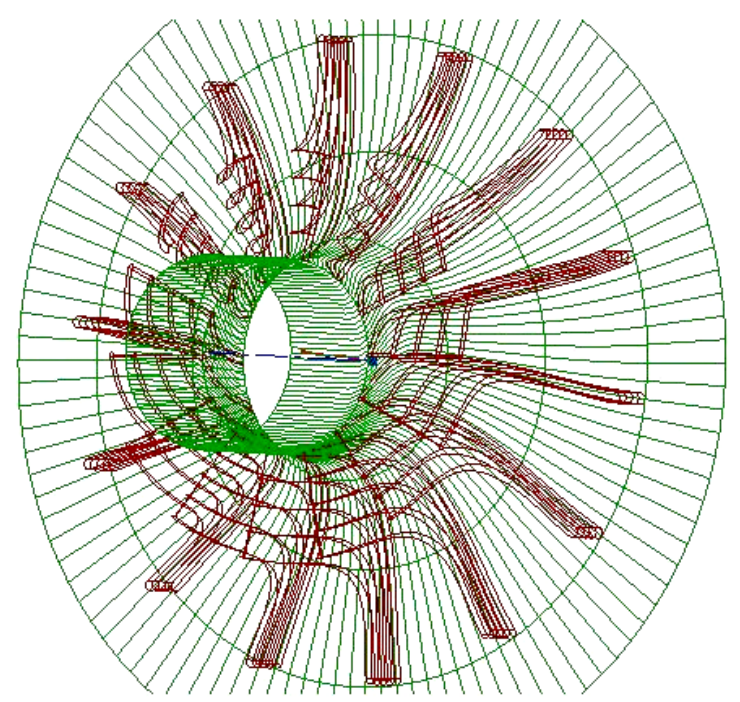

Figure 4.1: Geometry of Radial Inflow Turbine Rotors. 


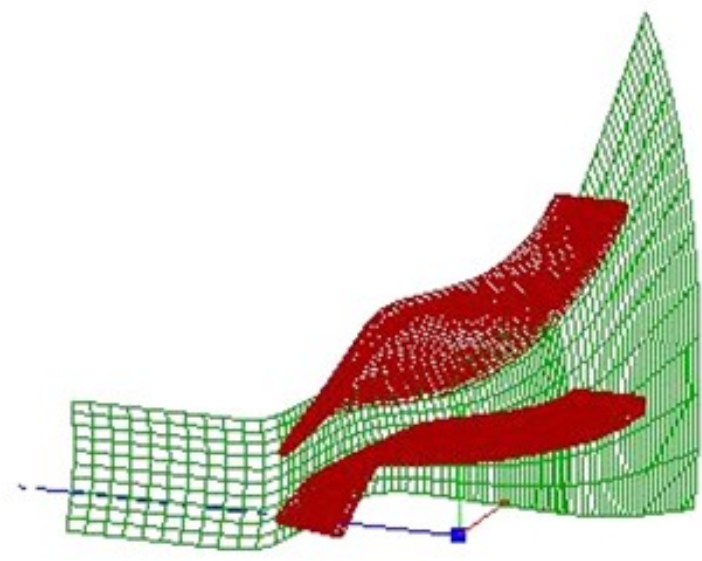

Figure 4.2: Geometry of Rotor Blade Passages.

As seen, two blade passages are presented in Figure 4.2. In view of the fact that the simulation of one rotor blade passage will give the same results as simulation of the full rotor, periodic boundary conditions were used during the simulation to take advantage of this. By doing this, only $1 / 14^{\text {th }}$ of the blade passages is simulated, minimizing the total size of the mesh and reducing the computational effort.

\subsubsection{Meshing Strategies}

As mentioned above, the rotor blade geometry was not fixed initially due to the changes of outlet blade metal angle. A structured mesh was suitable since it can keep the same mesh strategy for small changes of geometry and then the simulation results become more comparable. The benefit of using hexahedral meshes in turbomachinery modeling is that the mesh can be aligned relatively smoothly with the flow direction. At the same time, the numerical diffusion is reduced and the solution convergence becomes easier to obtain, as compared to using an unstructured mesh. Also, fewer meshing elements were necessary to fill the domain which reduces the computation effort (ANSYS, 2012). 
The hexahedral elements of the structured mesh were generated using ANSYS Turbogrid-v-14.5. The grid information near the shroud area and boundary layer of the blade is presented in Figure 4.3 and Figure 4.4, respectively.

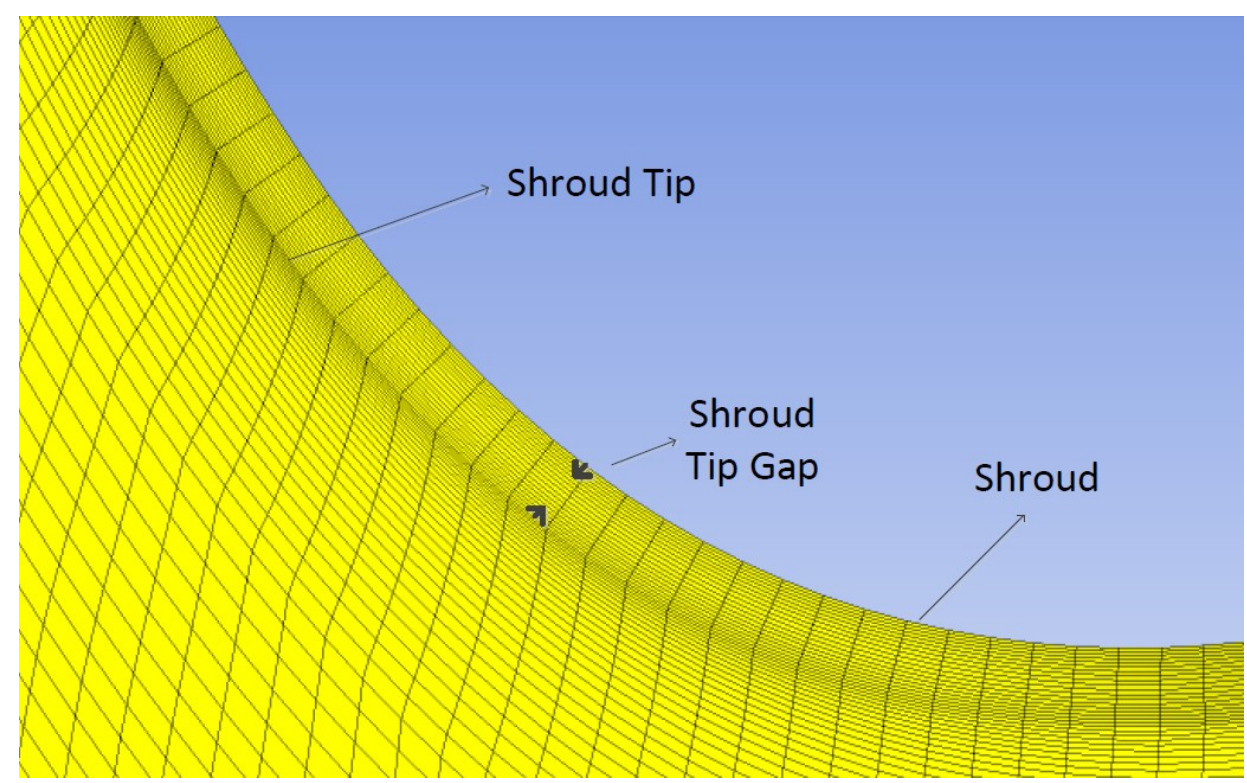

Figure 4.3: Grid Information at Shroud Area.

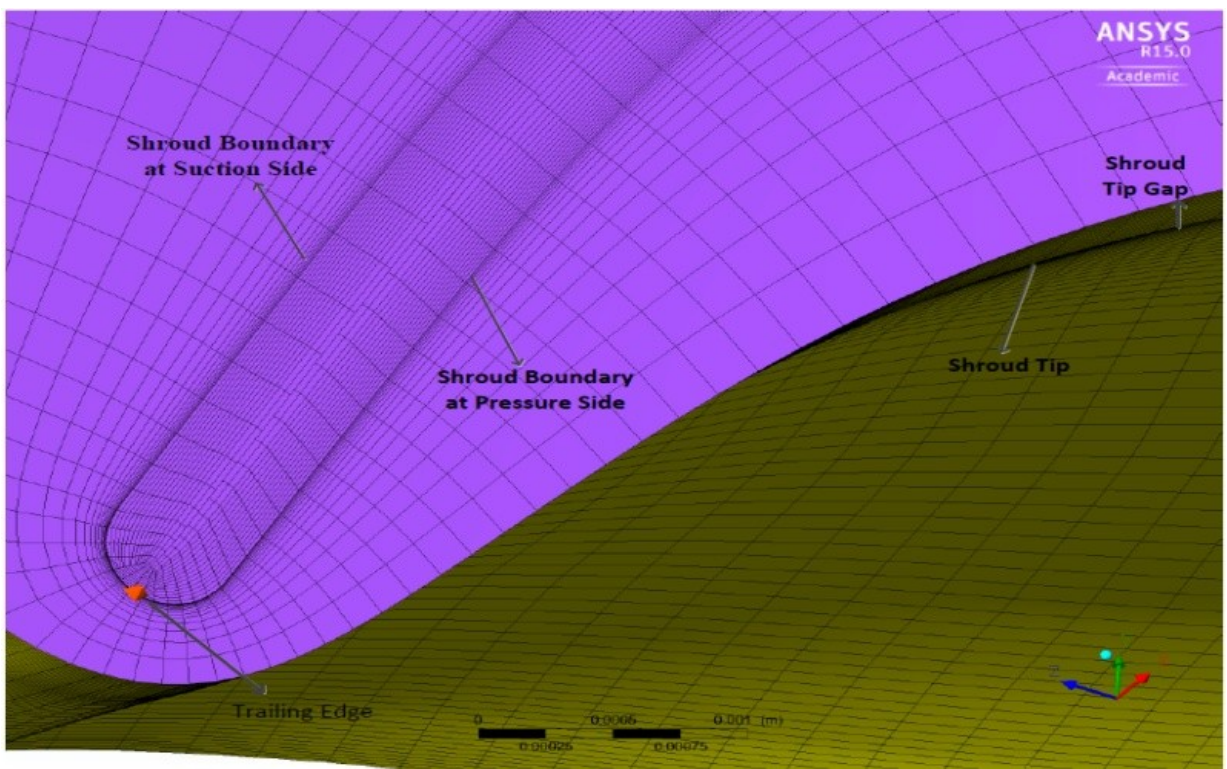

Figure 4.4: Grid Information at Blade Boundary Layer. 
As seen in Figure 4.3, in order to capture and solve the complex tip leakage flow between the shroud and shroud tip, the grid density at the shroud tip gap is high. Also, as shown in Figure 4.4, the grid density is increasing at the cells close to the boundary layer of blade.

If the effects of secondary flow and tip leakage flow are to be analyzed for radial inflow turbine rotor blades, this typical requires more than 500,000 nodes to allow detailed resolution (Baines, 2003). Therefore, a mesh with a total number of 535,226 nodes was generated. The data for grid quality is shown in Table 4.1 along with the requirements as specified in the ANSYS Turbogrid-v-14.5 manual:

\begin{tabular}{|c|c|c|c|}
\hline Mesh Measure & $\begin{array}{l}\text { Recommended } \\
\text { Values }\end{array}$ & $\begin{array}{l}\text { Obtained } \\
\text { Values }\end{array}$ & $\begin{array}{l}\text { \% Bad } \\
\text { (Outside } \\
\text { range) }\end{array}$ \\
\hline $\begin{array}{l}\text { Maximum Face Angle: the maximum angle between } \\
\text { edges of each face within an element }\end{array}$ & $<165^{\circ}$ & $\begin{array}{l}153^{\circ} \\
(\max )\end{array}$ & 0 \\
\hline $\begin{array}{l}\text { Minimum Face Angle: the minimum angle between } \\
\text { edges of each face within an element }\end{array}$ & $>15^{\circ}$ & $\begin{array}{l}28^{\circ} \\
(\min )\end{array}$ & 0 \\
\hline $\begin{array}{l}\text { Connectivity Number: the number of elements } \\
\text { connected to a single node }\end{array}$ & $<12$ & 10 & 0 \\
\hline $\begin{array}{l}\text { Maximum Element Volume Ratio: Ratio of largest to } \\
\text { smallest element volumes which surround by one node }\end{array}$ & $<2$ & $\begin{array}{c}15 \\
(\max )\end{array}$ & 1.3 \\
\hline Minimum Volume: the minimum volume of each cell & $>0$ & $\begin{array}{c}1.4 \mathrm{e}-15 \mathrm{~m}^{3} \\
(\mathrm{~min})\end{array}$ & 0 \\
\hline $\begin{array}{l}\text { Maximum Edge Length Ratio: the ratio of a node's } \\
\text { longest to shortest lengths }\end{array}$ & $<100$ & $\begin{array}{c}218 \\
(\max )\end{array}$ & 0.1 \\
\hline
\end{tabular}

Table 4.1 Data of Grid Quality. 
Although the grid quality did not fully meet the requirements in every location, the percentage of cells with poor quality is low.

\subsubsection{Grid Independence}

Even though the number of nodes and the quality of the grid are reasonable, a finer meshing should be performed to investigate whether the results from the CFD analysis are grid independent. Therefore, a mesh with $1,316,170$ nodes was also investigated. The computational process of the coarse and fine meshes are based on exactly the same boundary conditions and the differences for the results between the coarse and fine meshes are summarized in Table 4.2.

\begin{tabular}{|c|c|c|c|}
\hline Predicted Quantity & $\begin{array}{c}\text { Coarse Mesh } \\
(535,226 \text { Nodes })\end{array}$ & $\begin{array}{c}\text { Fine Mesh } \\
(1,316,170 \text { Nodes })\end{array}$ & Difference (\%) \\
\hline $\begin{array}{c}\text { Total-to-Static } \\
\text { Efficiency (\%) }\end{array}$ & 93.8 & 93.2 & 0.6 \\
\hline $\begin{array}{c}\text { Total-to-Total } \\
\text { Pressure Ratio }\end{array}$ & 1.3570 & 1.3568 & 0.015 \\
\hline Mass Flow Rate (kg/s) & 1.855 & 1.858 & 0.16 \\
\hline Output Power (W) & 85702 & 86013 & 0.36 \\
\hline $\begin{array}{c}\text { Maximum Mach } \\
\text { Number at Stage }\end{array}$ & 0.455 & 0.454 & 1.32 \\
\hline Stage Reaction & 0.538 & 0.540 & 0.37 \\
\hline
\end{tabular}

Table 4.2 Comparison between the Coarse and Fine Meshes.

As seen, the percentage difference of results between the coarse mesh and fine mesh are quite small. Therefore, when the penalty of about 2.5 times of longer CPU computation time for the fine mesh was considered, the coarse mesh was chosen to be used for the simulation process at all operating points. 


\subsubsection{Solution Convergence}

The criterion of solution convergence was determined by the residuals of the mass, momentum in $\mathrm{U}-\mathrm{V}-\mathrm{W}$ directions, energy and turbulence equations. The MAX normalized residuals method is more conservative than the root mean square (RMS) normalized residuals method. However, the values of MAX residuals may be large in localized areas of the grid (eg. where the mesh quality values are poor). These values may not be representative of the overall pattern of residuals in the solution. Therefore, the RMS residuals are generally used to judge convergence (MacIsaac, 2014). The results of RMS and MAX residuals at the design operating point simulation are plotted in Figures 4.5 (a) and (b) respectively. The solution technique is a time marching algorithm that starts from an initial (default) guess of the solution field, and "marches" the solution in time until the convergence criteria are met, thus arriving at the steady value. The time increments are effectively iterations. As seen, all of the solution convergence criteria in RMS residuals method are less than $10^{-6}$ after 800 timesteps. The residuals trends have been investigated for the simulation at the design point and the results from the residuals of $10^{-5}$ and $10^{-6}$ show that the resulting differences in efficiency and mass flow rate are smaller than $0.01 \%$. Thus, results based on the residual target of $10^{-6}$ are satisfactory for the design point. However, when the operating points are significantly different from the design point, the residuals increased, apparently due to strong secondary flows and flow separations inside the blade passages. The RMS residuals increased to $10^{-3}$, thus the accuracy of the simulation results decreased at the off-design operating points. 
(a)

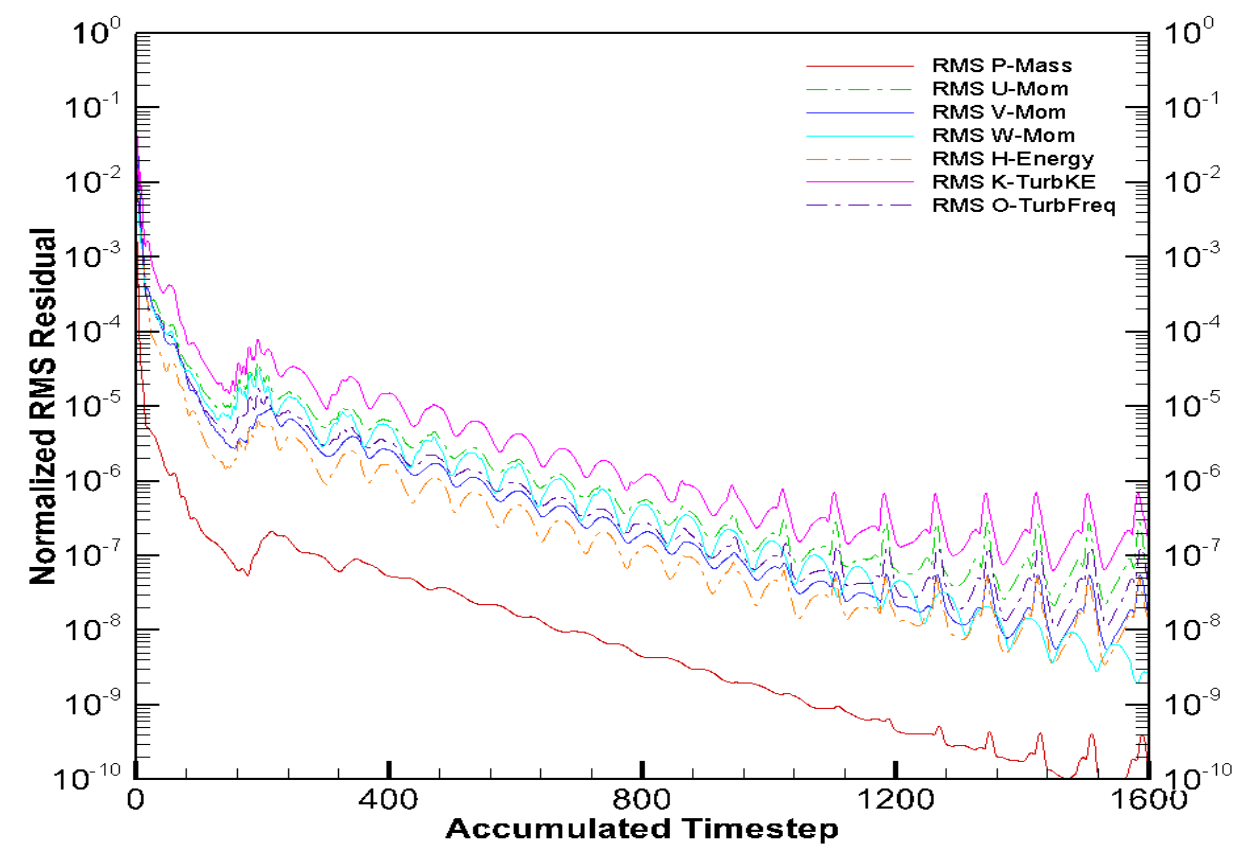

Figure 4.5 (a) Normalized RMS Residuals at Design Operating Point.

(b)

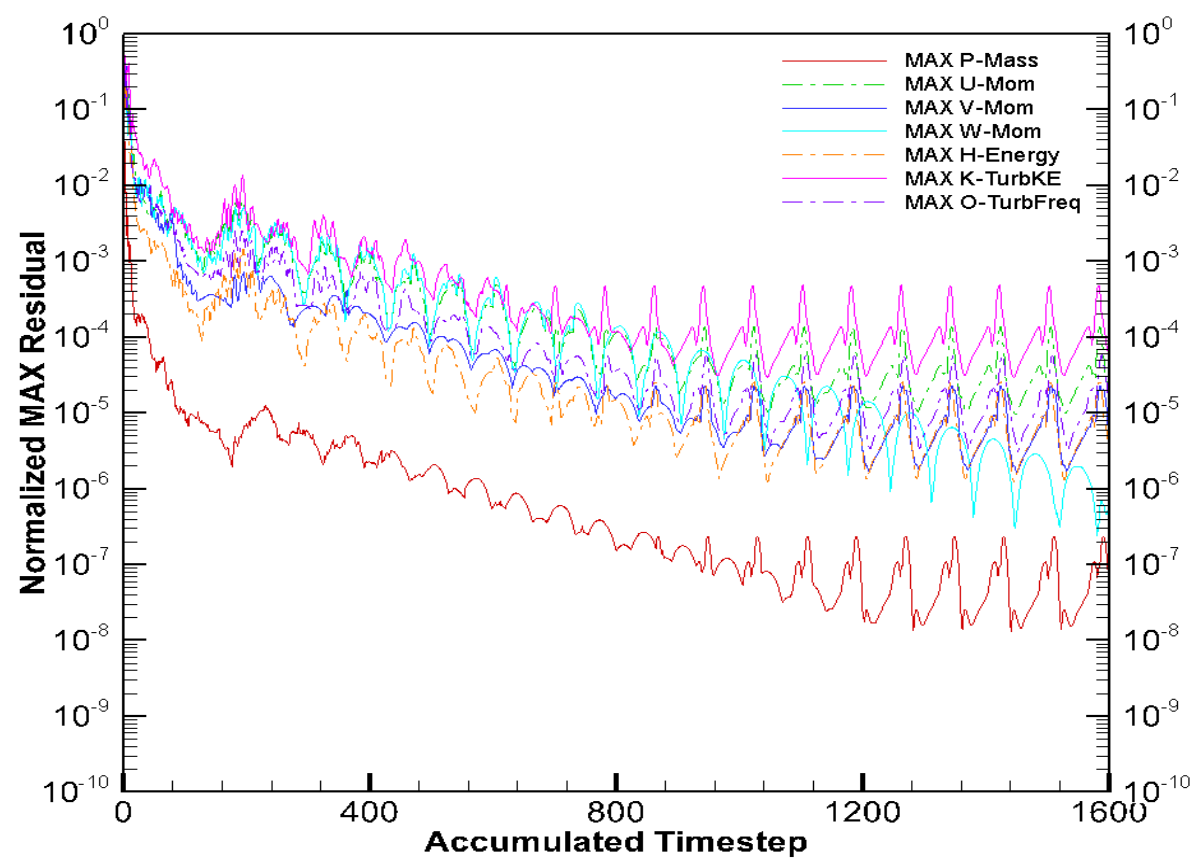

Figure 4.5 (b) Normalized MAX Residuals at Design Operating Point. 


\section{Chapter 5 Results and Discussion}

\subsection{Introduction}

This chapter presents the predictions for the CU-BCL radial inflow turbine at design and off-design operating points. These predictions are obtained from the meanline design code (RITMLD), the off-design meanline code (RITMLO), as well as from the ANSYS-CFX CFD code.

Section 5.2 gives the details about the stage geometry dimensions of the CU-BCL turbine. The velocity triangles and the estimated losses for the nozzle and rotor are described in this section as well. The CU-BCL turbine characteristics over the full operating range were generated by RITMLO after the turbine geometry had been confirmed. As the most important characteristics, the parameters of efficiency and corrected mass flow rate as a function of pressure ratio are presented in Section 5.3. In Section 5.4, the conditions of flow separation, secondary flow and entropy generation in the rotor blade passages at off-design operating points are presented. This detailed information was obtained by CFD analysis. Section 5.5 presents a comparison of the results between the meanline and CFD analyses.

\subsection{Results of Meanline Analysis at the Design Operating Point}

The overall objective of the meanline analysis is to design a reasonable geometry for the turbine and obtain the flow information at significant points in the stage. A reasonable meanline design should have efficiency close to the optimum value and other parameters should meet the requirements of the feasibility checks discussed in Section 3.3.2. The 
design operating point value for the CU-BCL turbine is shown in Table 5.1. The radial inflow turbine is one component of the CU-BCL turbomachinery arrangement. The overall design of the turbomachinery is ongoing, but a representative depiction is shown in Figure 5.1. The design is based on the turbo-alternator-compressor design used in the Sandia National Laboratories $\mathrm{S}-\mathrm{CO}_{2}$ test assembly (Pasch, 2012), and includes a centrifugal compressor, a radial inflow turbine, and a permanent magnet motor mounted on a shaft. The shaft is supported by bearings, and the rotating assembly is housed in a casing. RITMLD was used to obtain the meanline design at the design point.

\begin{tabular}{|c|c|}
\hline Working Fluid & Supercritical Carbon Dioxide \\
\hline Mass Flow Rate $(\mathrm{kg} / \mathrm{s})$ & 1.8 \\
\hline Rotational Speed $(\mathrm{RPM})$ & 80000 \\
\hline Turbine Inlet Total Temperature $(\mathrm{K})$ & 943 \\
\hline Turbine Inlet Total Pressure $(\mathrm{kPa})$ & 10692 \\
\hline Turbine Outlet Total Pressure $(\mathrm{kPa})$ & 7833.0 \\
\hline Output Power $(\mathrm{kW})$ & 84.076 \\
\hline
\end{tabular}

Table 5.1 Design Operating Point for the CU-BCL Radial Inflow Turbine.

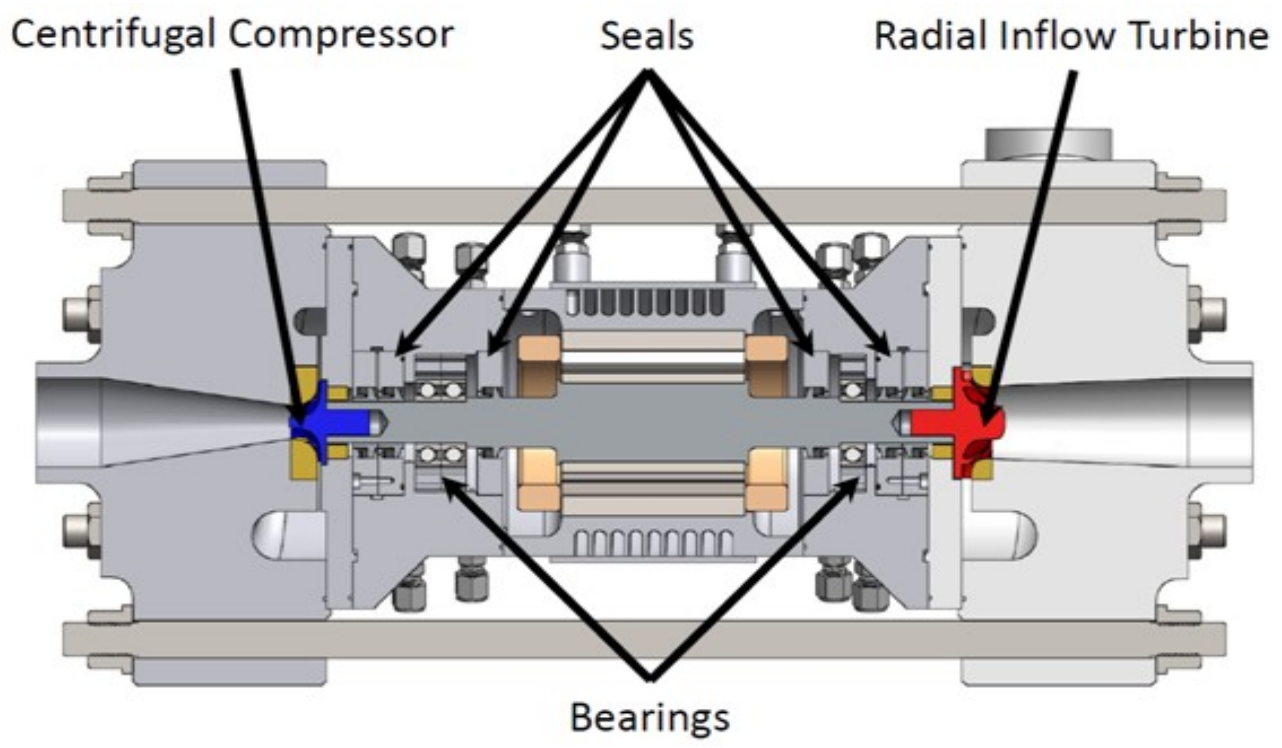

Figure 5.1 The CU-BCL Turbomachinery Arrangement (CU-BCL 2013-14 Design Team, 2014). 


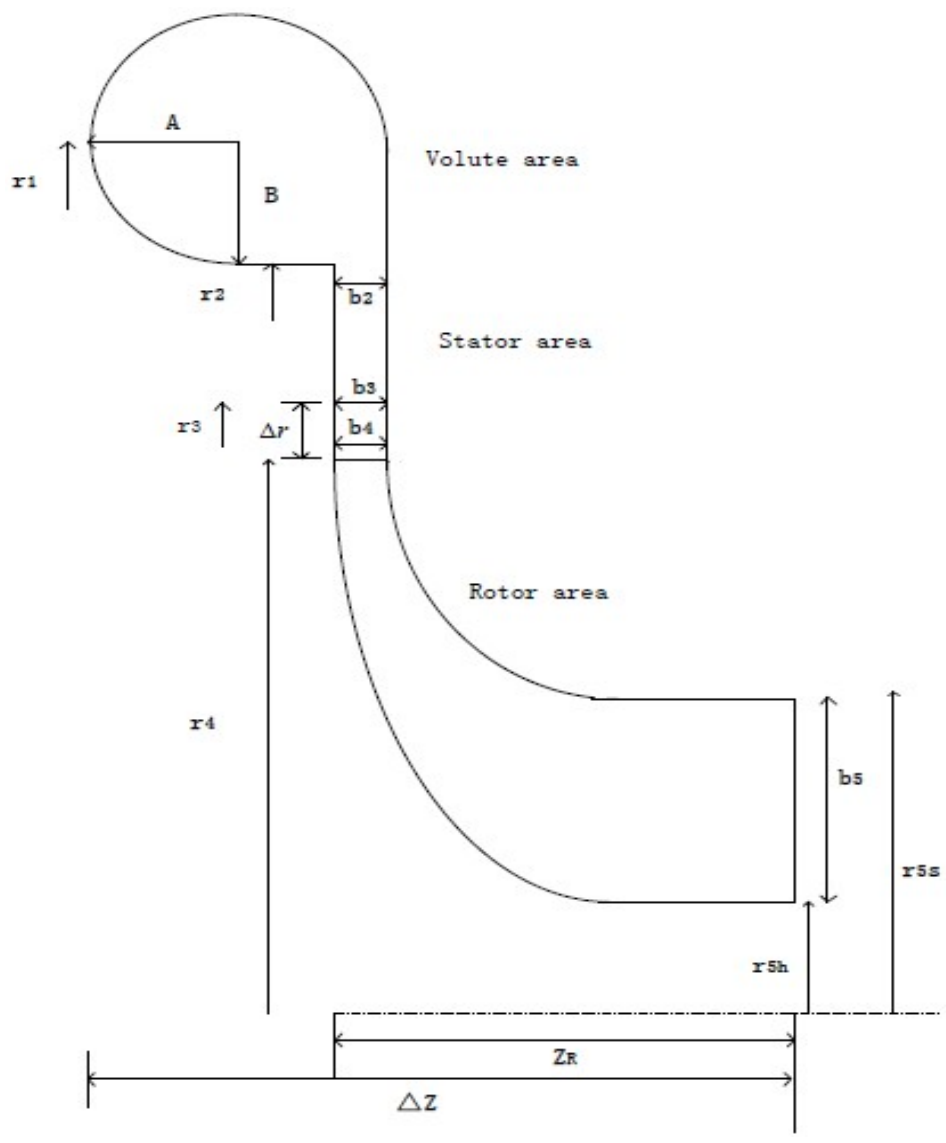

Figure 5.2 Nomenclature for Radial Inflow Turbine Stage Cross Section.

The nomenclature used for the turbine stage is summarized in Figure 5.2 and the corresponding symbols have been introduced in the earlier sections. As described in Section 3.3.1, the outlet total pressure in Table 5.1 is estimated based on an assumed efficiency and it will be updated along with the value of updated efficiency in the calculation process. The final stage dimensions for the CU-BCL radial inflow turbine are listed in Table 5.2. The values of rotor leading-edge thickness, $\mathrm{t}_{\text {leading, }}$, and trailing edge thickness, $t_{\text {trailing, }}$ and results for the rotor outlet mean blade pitch, $q_{5}$, and mean throat width, $o_{t}$, are given in Table 5.2 as well. 


\begin{tabular}{|c|c|c|c|c|c|c|}
\hline $\mathbf{A}(\mathbf{m})$ & $\mathbf{B}(\mathbf{m})$ & $\mathbf{r}_{\mathbf{1}}(\mathbf{m})$ & $\mathbf{r}_{\mathbf{2}}(\mathbf{m})$ & $\mathbf{b}_{\mathbf{2}}(\mathbf{m})$ & $\mathbf{r}_{\mathbf{3}}(\mathbf{m})$ & $\mathbf{b}_{\mathbf{3}}(\mathbf{m})$ \\
\hline 0.008732 & 0.008732 & 0.04375 & 0.03502 & 0.003950 & 0.02918 & 0.003950 \\
\hline$\Delta r(\mathbf{m})$ & $\mathbf{r}_{\mathbf{4}}(\mathbf{m})$ & $\mathbf{b}_{\mathbf{4}}(\mathbf{m})$ & $\mathbf{r}_{5 \mathbf{s}}(\mathbf{m})$ & $\mathbf{r}_{\mathbf{5 h}}(\mathbf{m})$ & $\mathbf{r}_{\mathbf{5}}(\mathbf{m})$ & $\mathbf{b}_{\mathbf{5}}(\mathbf{m})$ \\
\hline 0.0019 & 0.02728 & 0.00400 & 0.01724 & 0.008183 & 0.012711 & 0.009053 \\
\hline $\mathbf{r}_{\mathbf{m a x}}(\mathbf{m})$ & $\mathbf{q}_{\mathbf{5}}(\mathbf{m})$ & $\mathbf{0}_{\mathbf{5}}(\mathbf{m})$ & $\mathbf{t}_{\text {leading }}(\mathbf{m})$ & $\mathbf{t}_{\text {trailing }}(\mathbf{m})$ & $\mathbf{Z}_{\mathbf{R}}(\mathbf{m})$ & $\Delta Z(\mathbf{m})$ \\
\hline 0.052479 & 0.005704 & 0.002633 & 0.001091 & 0.000546 & 0.01358 & 0.02709 \\
\hline
\end{tabular}

Table 5.2 The CU-BCL Radial Inflow Turbine Stage Dimensions.

As described in Chapter 2, the velocity triangles at rotor inlet and outlet are the essential part for the meanline analysis since they determine the blade geometry and working fluid properties. Also, the relationship between the total and static condition of working fluid is connected by the corresponding velocity components. Figure 5.3 presents the velocity triangles at the design operating point of the CU-BCL radial inflow turbine.

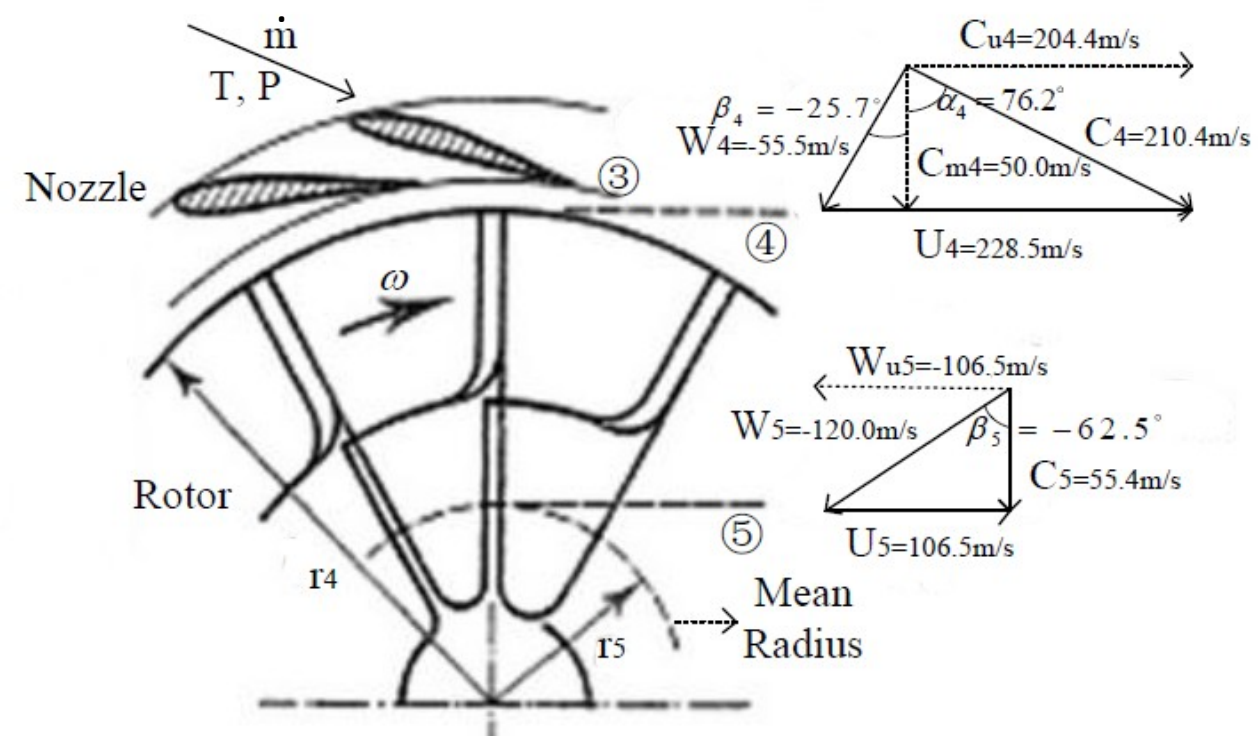

Figure 5.3 Velocity Triangles of the CU-BCL Radial Inflow Turbine at Design Operating Point (Adapted from Baskharone, 2006). 
As seen, the outlet flow direction has zero swirl. This was specified at the design point to decrease the exit energy losses and increase the stage efficiency. The effect of outlet swirl flow on the turbine stage can be seen from the Euler turbomachine equation:

$$
\Delta h_{0}=\frac{\dot{W}}{\dot{m}}=U_{4} C_{u 4}-U_{5} C_{u 5}
$$

For a given inlet flow $U_{4} C_{u 4}$ and mass flow rate $\dot{m}$, if the flow leaves with no swirl at rotor outlet, $C_{u 5}=0$, the kinetic energy in the outlet flow is minimized. If the flow leaves with some swirl in the same direction as the inlet swirl, the output power is decreased compared with the case of zero outlet swirl. At the same time, it leaves with higher kinetic energy in the outlet flow. By contrast, it will generate more output power than zero swirl if the flow leaves some swirl in the opposite direction to the inlet swirl. The disadvantage is that it will again leave with more kinetic energy in the outlet flow along with decreasing the efficiency. Thus, in order to obtain the best efficiency for a given output power, the zero swirl design strategy is the most effective.

The definitions of stage loading, $\psi$, and flow coefficients, $\phi$, are given in Equations 5.2 and 5.3, respectively, along with the results of CU-BCL radial inflow turbine at the design point:

$$
\begin{gathered}
\psi=\frac{\Delta h_{0}}{U_{4}^{2}} \simeq \frac{C_{u 4}}{U_{4}}=0.895 \\
\phi=\frac{C_{m 5}}{U_{4}}=0.243
\end{gathered}
$$

As discussed in Chapter 2, these two non-dimensional parameters can be used to judge 
the quality of the design. Figure 5.4 shows the correlation of stage loading and flow coefficients with the corresponding values of total-to-static efficiency of radial inflow turbines.

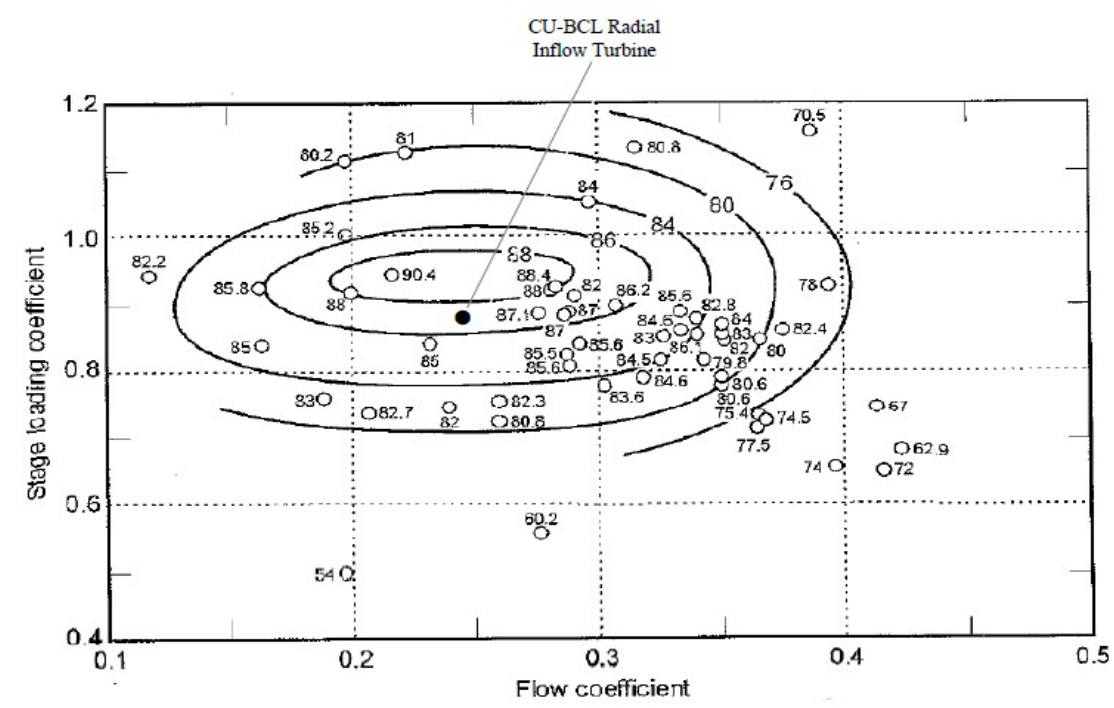

Figure 5.4 Correlation of Blade Loading and Flow Coefficients for Radial Inflow Turbines. Data Points and Contours Show Total to Static Efficiency (Chen and Baines, 1994).

As seen, the design point for the CU-BCL turbine is located in a range that is close to the optimum efficiency range.

Feasibility checks are incorporated in RITMLD, as described in Section 3.3. The reasonable ranges for the concerned parameters as recommended in the open literature, are discussed in Section 3.3. The results of feasibility checks for the CU-BCL radial inflow turbine are listed in Table 5.3, along with the recommended values. It shows that all of the concerned parameters of the turbine lie within the recommended ranges. 


\begin{tabular}{|c|c|c|}
\hline & CU-BCL Value & Recommended Value \\
\hline Incidence (deg) & -25.7 & $-20 \sim-40$ \\
\hline Maximum Mach Number & 0.44 & $<1.0$ \\
\hline $\mathrm{Z}_{\mathrm{R}} / \mathrm{b}_{4}$ & 3.40 & $>=1.5$ \\
\hline $\mathrm{C}_{\mathrm{m} 5} / \mathrm{U}_{4}$ & 0.24 & $0.2 \sim 0.4$ \\
\hline $\mathrm{r}_{\mathrm{s} 5} / \mathrm{r}_{4}$ & 0.63 & $<=0.78$ \\
\hline $\mathrm{C}_{\mathrm{m} 5} / \mathrm{C}_{\mathrm{m} 4}$ & 1.11 & $1.0 \sim 1.5$ \\
\hline Stage $\mathrm{Reaction}_{\mathrm{R}}(\mathrm{R})$ & 0.56 & $0.45 \sim 0.65$ \\
\hline
\end{tabular}

Table 5.3 Feasibility Checks for the Meanline Analysis of the CU-BCL Radial Inflow Turbine.

As described in Section 3.2, a loss correlation system is incorporated in RITMLD. Figure 5.5 presents the contribution of each loss category to the overall energy losses at the rotor section of the CU-BCL turbine. 


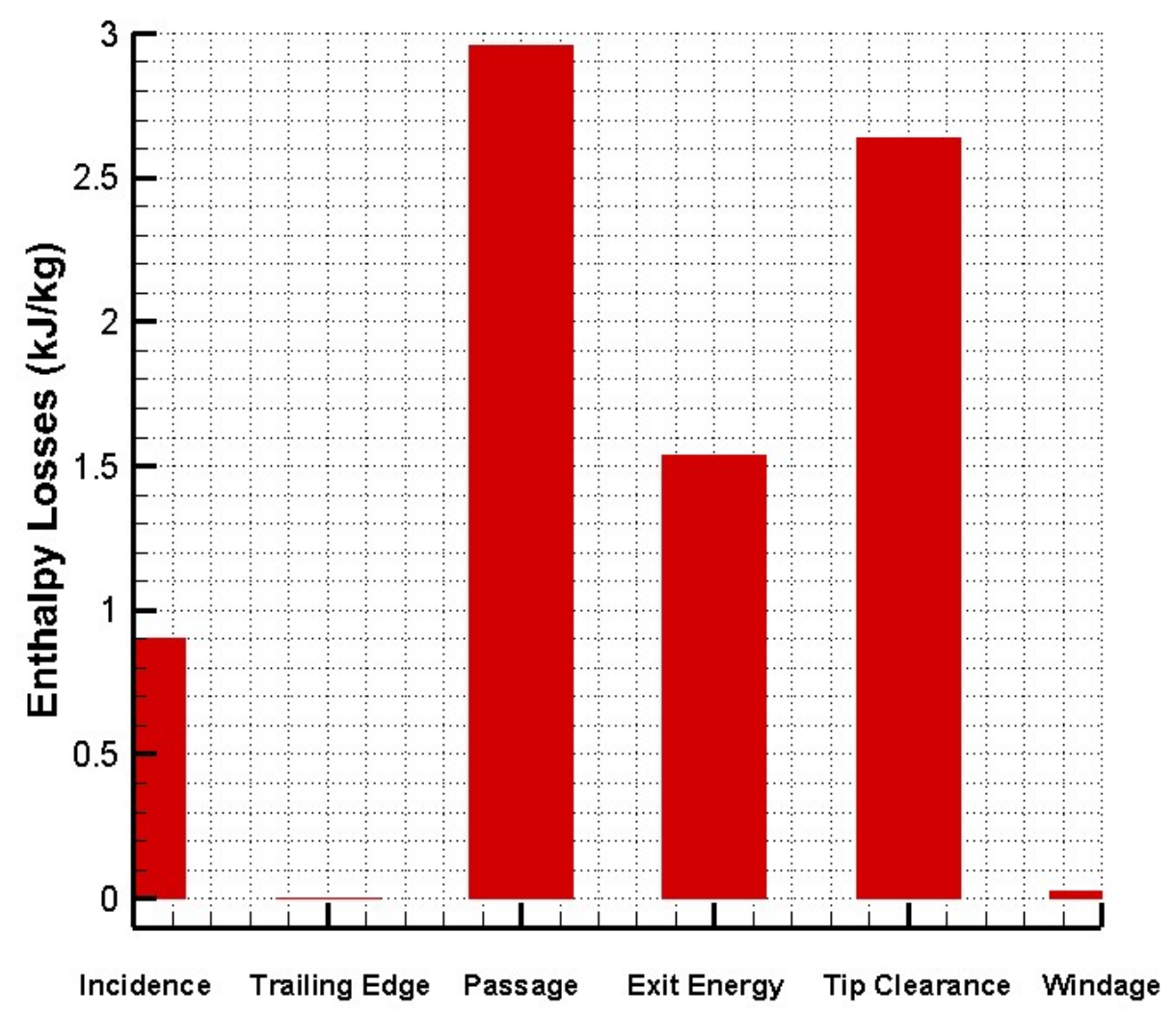

Figure 5.5 Distribution of Enthalpy Losses at the CU-BCL Radial Inflow Turbine Rotor.

Due to the highly complicated process in the rotor blade passage, separation can occur in a number of areas. The entropy generation inside the blade passages is mainly the result of the secondary flow mixing and flow separation. This was demonstrated in the CFD analysis. The tip clearance flow is a major factor in forming the secondary flow and triggering flow separation. Although there is relatively little separation in the rotor blade passages when the turbine runs at the design point, the loss correlations in meanline analysis indicate that the passage and tip clearance losses are the major contributors to the enthalpy losses, as shown in Figure 5.5. Section 5.4 presents the corresponding results from the CFD analysis. For the design point meanline analysis, the incidence and outlet zero swirl flow are specified by the designer. Thus the incidence loss and exit energy losses should be relatively low. However, as the machine runs at off-design operating points, the outlet fluid velocity may increase and the incidence deviates from the 
optimum value. Then, much higher enthalpy losses will be generated due to the incidence and exit energy losses process. For the calculation of total-to-static efficiency, the exit energy losses are needed to be included to account for the kinetic energy in the outlet flow. However, much of the kinetic energy in the outlet flow can be recovered if a diffuser exists at the downstream of rotor. Also, if the loss calculation process is based on the total-to-total efficiency, the exit energy losses cannot be counted toward the overall losses. Due to the fact that the major losses during the blade passages have been calculated by passage and tip clearance losses correlations, the trailing edge losses only account for the losses due to the effect of the sudden expansion from the rotor throat to a plane just downstream of the trailing edge (Baines, 2003). The results in Figure 5.5 indicate that the sudden expansion losses are negligible in design point for the CU-BCL turbine. For the windage losses, it does not relate to the passage flow directly but a frictional loss occurring on the back face of the turbine disk. Figure 5.5 shows that the windage losses are fairly small at the design point. Therefore, the trailing edge and windage losses only contribute a small fraction of the overall enthalpy losses, respectively. The results from RITMLO show that the percentages of enthalpy losses, which are generated from the trailing edge and windage losses process do not change markedly when the radial turbine is running at off-design operating points. As discussed in Section 3.2, Figure 3.1 was used to predict the losses generated by the nozzle. The comparison of nozzle and rotor enthalpy losses is presented in Figure 5.6. 


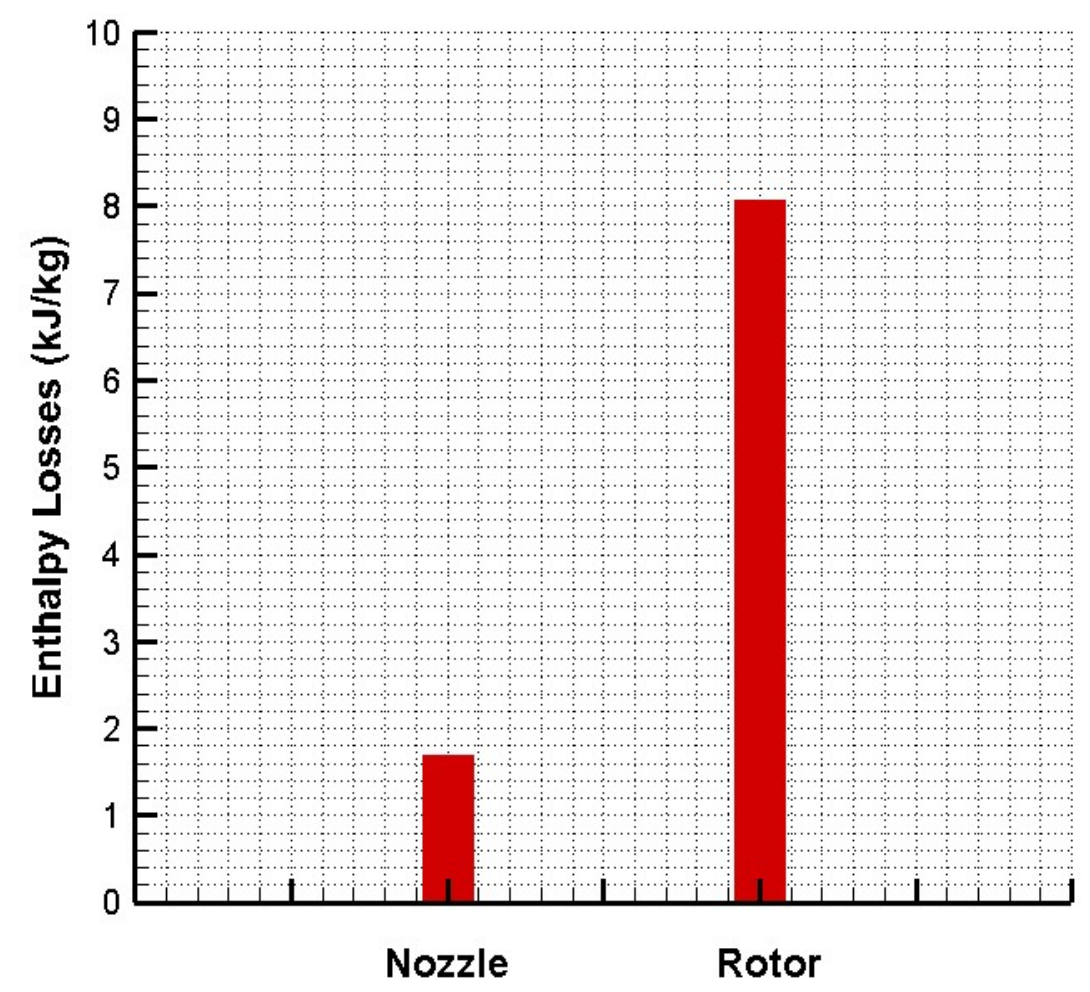

Figure 5.6 Comparison of Nozzle and Rotor Enthalpy Losses of the CU-BCL Radial Inflow Turbine.

Finally, the overall stage performance of the CU-BCL radial inflow turbine is summarized in Table 5.4. The number of rotor blades $\mathrm{N}_{\mathrm{R}}$ is presented in Table 5.4. Glassman (1976) introduced an empirical equation for the optimum number of radial inflow turbine rotor blades:

$$
N_{R}=\frac{\pi}{30}\left(110-\alpha_{4}\right) \tan \alpha_{4}
$$

and the number of rotor blades for the CU-BCL turbine is determined by Equation 5.4. The reasonability of the blade number is examined by the CFD analysis as well. Experience suggests that when the blade number was reduced below an acceptable level, flow separation easily occurs in the shroud-suction surface corner. As a result, the predicted rotor efficiency is reduced under the effect of too few blades (Baines, 2003). 
However, for the design point CFD analysis of the CU-BCL turbine, the flow field in the rotor blade passages gave good efficiency. Therefore, the number of rotor blades was confirmed after the designed turbine in meanline has been examined by the CFD analysis.

\begin{tabular}{|c|c|}
\hline Mass Flow Rate $(\mathrm{m}) \cdot(\mathrm{kg} / \mathrm{s})$ & 1.8 \\
\hline Rotational Speed $(\mathrm{N})(\mathrm{RPM})$ & 80000 \\
\hline Specific Speed $\left(\mathrm{n}_{\mathrm{s}}\right)$ & 0.456 \\
\hline Velocity Ratio $\left(\mathrm{v}_{\mathrm{s}}=\mathrm{U}_{4} / \mathrm{C}_{0 \mathrm{~S}}\right)$ & 0.68 \\
\hline Stage Loading Coefficient $(\psi)$ & 0.895 \\
\hline Flow Coefficient $(\phi)$ & 0.243 \\
\hline Total-to-Total Pressure Ratio $\left(\mathrm{PR}_{\mathrm{t}-\mathrm{t}}\right)$ & 1.364 \\
\hline Total-to-Static Pressure Ratio $\left(\mathrm{PR}_{\mathrm{t}-\mathrm{s}}\right)$ & 1.377 \\
\hline Output Power $(\mathrm{W})(\mathrm{KW})$ & 84.076 \\
\hline Total-to-Total Efficiency $\left(\eta_{t-t}\right)$ & 0.850 \\
\hline Total-to-Static Efficiency $\left(\eta_{t-s}\right)$ & 0.827 \\
\hline Enthalpy Losses at Rotor Section $(\mathrm{kJ} / \mathrm{kg})$ & 8.061 \\
\hline Enthalpy Losses at Nozzle Section $(\mathrm{kJ} / \mathrm{kg})$ & 1.694 \\
\hline Number of Rotor Blades $\left(\mathrm{N}_{\mathrm{R}}\right)$ & 14 \\
\hline
\end{tabular}

Table 5.4 Stage Performance of the CU-BCL Radial Inflow Turbine.

\subsection{CU-BCL Radial Inflow Turbine Characteristics from RITMLO}

The CU-BCL turbine characteristics over the full operating range were predicted by the off-design meanline code RITMLO. As described in Chapter 3, the calculation procedures in RITMLO are also based on real fluid properties. The characteristics of the 
CU-BCL turbine are presented as curves of total-to-static efficiency, total-to-total efficiency, corrected mass flow rate, rotor inlet relative flow angle, rotor outlet absolute flow angle, absolute Mach number at rotor inlet as a function of the total-to-total pressure ratio, for a range of constant rotational speeds.

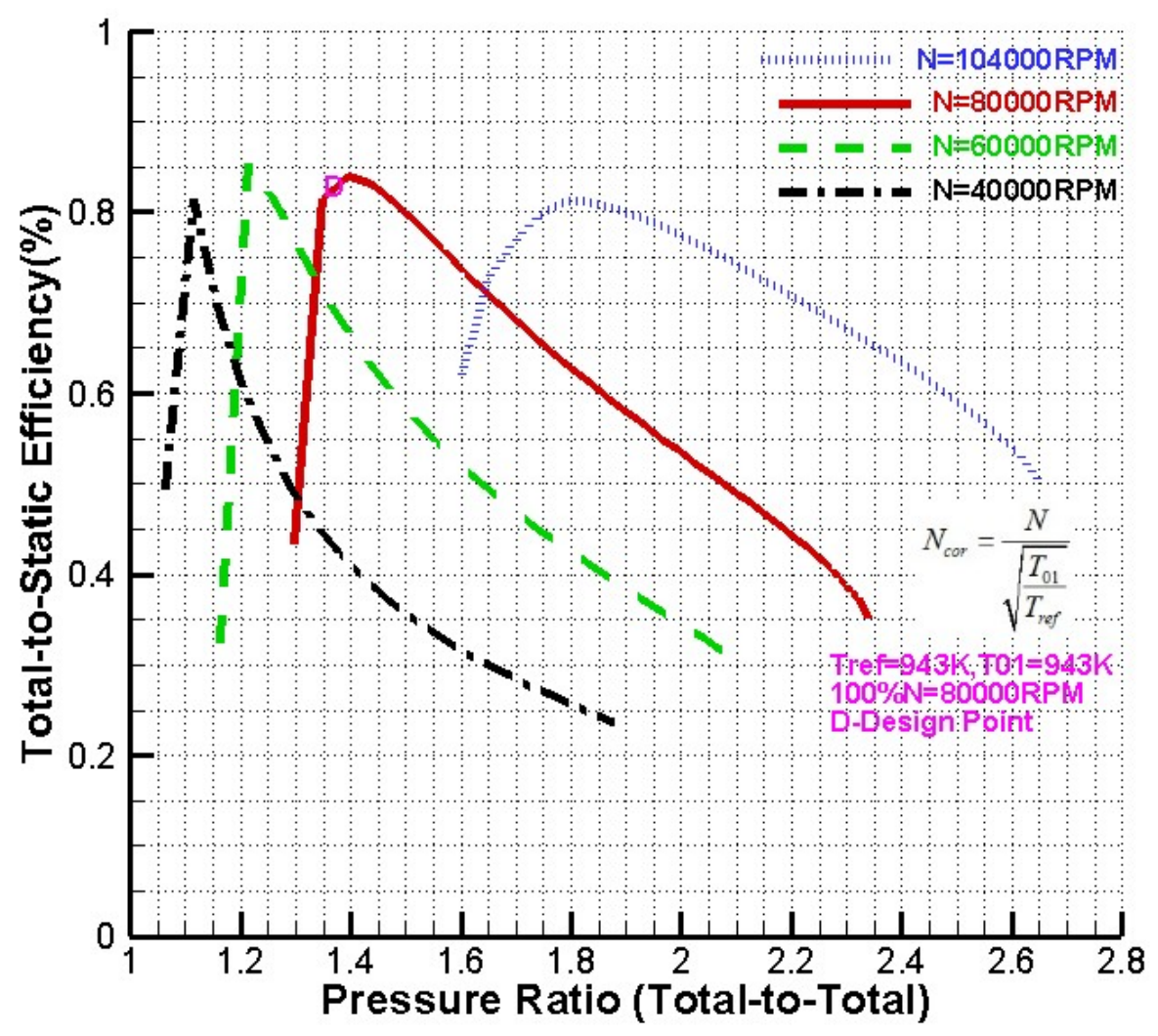

Figure 5.7 Characteristics of Total-to-Static Efficiency of the CU-BCL Radial Inflow Turbine.

Figure 5.7 presents the total-to-static efficiency as a function of the total-to-total pressure ratio and rotational speed. The capital " $D$ " represents the design point. The design point is also marked " $\mathrm{D}$ " on the following figures. In these figures, the capital "D" is locate at the curve of $\mathrm{N}=80000 \mathrm{RPM}$, which is predicted by RITMLO. In view of the fact that the calculation procedures are different between RITMLD and RITMLO, it may cause the round-off error during the calculation process and have a small effect on the results. Also, since the pressure ratio at the design point is not specified to calculate in 
RITMLO, the corresponding value of the capital " $\mathrm{D}$ " is read from the curve but not given from RITMLO directly. Therefore, a slight difference may exist between the results of RITMLD and RITMLO at the design point, but generally the difference is negligible. As presented in Table 5.4, the RITMLD predicted the total-to-static efficiency is 0.827 which is no different with the prediction of RITMLO. As seen, RITMLO predicts a smooth variation in efficiency, even for operating points significantly different from the design point. Figure 5.7 shows that as the rotational speed increases, the efficiency will be maintained at higher values for a wider operating range.

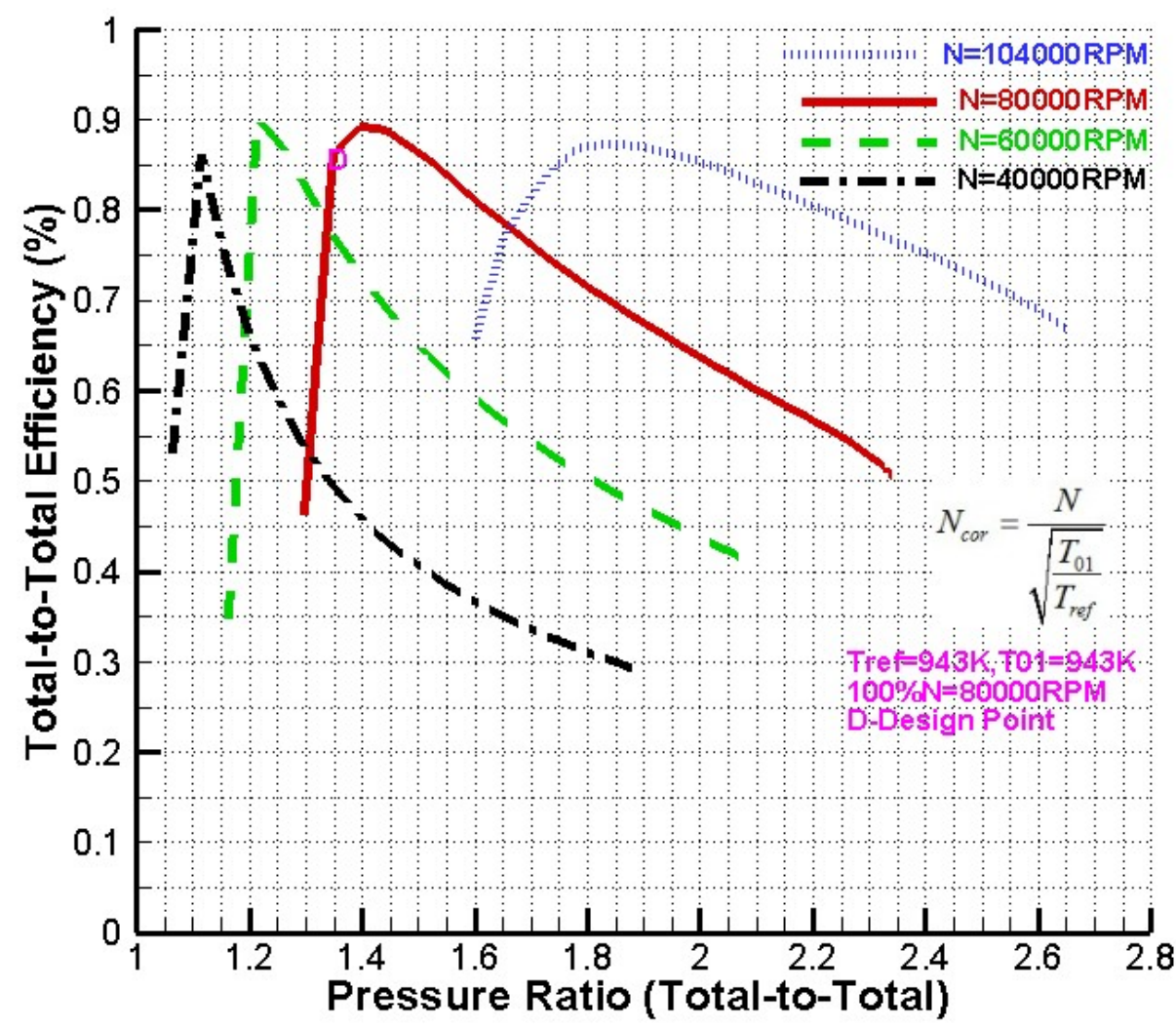

Figure 5.8 Characteristics of Total-to-Total Efficiency of the CU-BCL Radial Inflow Turbine.

Generally, total-to-static efficiency is used mainly in industrial gas turbines and steam turbines where it is not possible to recover the kinetic energy in the turbine outlet flow. However, for the CU-BCL design, a diffuser will exist immediately downstream of 
the turbine with other components in the rest of the circuit that introduce their own losses. Therefore, as presented in Figure 5.8, the characteristics of total-to-total efficiency of CU-BCL radial inflow turbine are more directly related to the plant thermal efficiency. As shown, except for the numerical difference, the general trend is the same between the total-to-total efficiency and total-to-static efficiency over the full operating range. It indicates that the kinetic energy in the outlet flow is not the reason that the total-to-static efficiency in Figure 5.7 varied more rapidly away from its peak value for the lower rotational speeds.

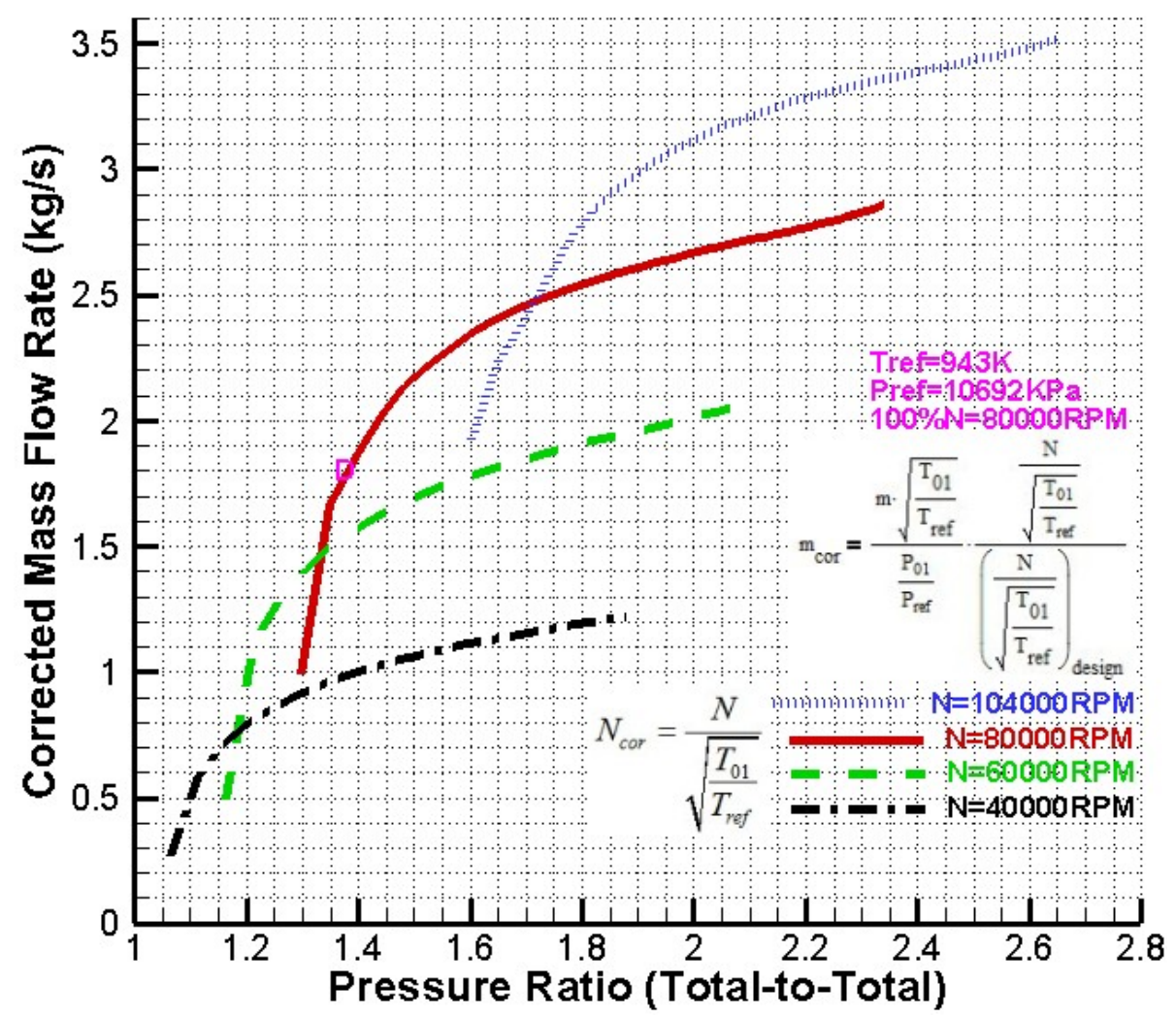

Figure 5.9 Corrected Mass Flow Rate of the CU-BCL Radial Inflow Turbine.

Figure 5.9 presents the corrected mass flow rate as a function of the total-to-total pressure ratio and rotational speed. The parameter of corrected mass flow rate includes the rotational speed as well. As shown, although a slowdown in mass flow rate growth is 
seen as the pressure ratio increases, choking, which would be shown by the mass flow parameter tending to a constant at high pressure ratio, is not seen to occur over the full operating range of the CU-BCL radial inflow turbine. Due to the fact that the choking is determined by the Mach number, the Mach number at the rotor inlet and outlet is examined in RITMLO as well. The results show that the highest Mach number at rotor inlet and outlet are 0.95 and 0.90 at full off-design points, respectively. A warning message will appear in the output file of RITMLO if choking $(\mathrm{M}>=1.0)$ is predicted.

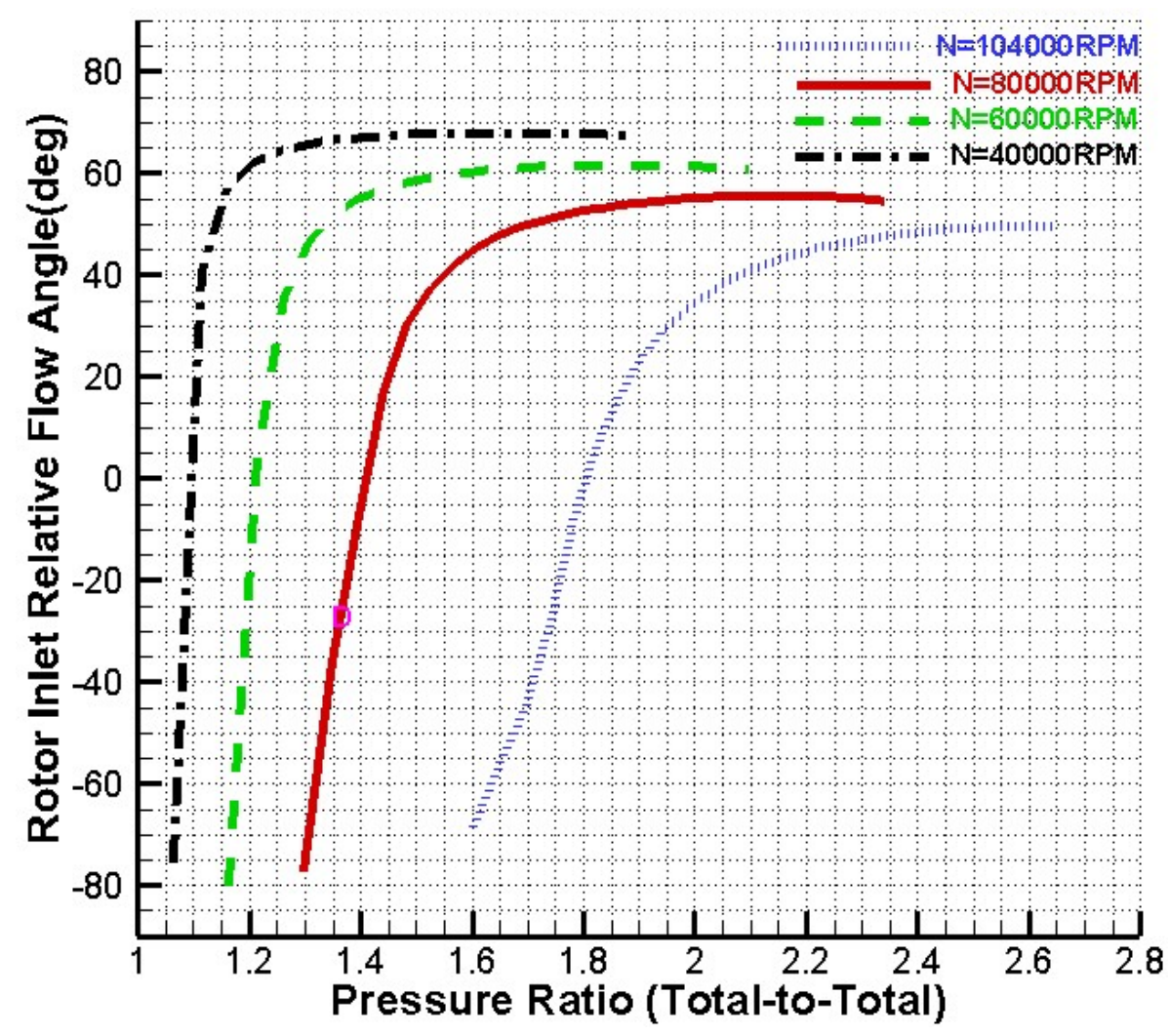

Figure 5.10 Characteristics of the Rotor Inlet Relative Flow Angle of the CU-BCL Radial Inflow Turbine.

Figure 5.10 presents the characteristics for the rotor inlet relative flow angle (incidence), $\beta_{4}$, versus the total-to-total pressure ratio and rotational speed. When the turbine runs at $\mathrm{N}=40000 \mathrm{RPM}$ and $\mathrm{N}=60000 \mathrm{RPM}$, the recommended range of incidence 
$(-20 \sim 40)$ is only obtained for a very limited range of pressure ratios. This is one of the reasons that the efficiency can be maintained at a higher value for a wider operating range when the machine is running at higher values of rotational speed. As discussed in Chapter 3, the range of the rotor inlet absolute flow angles, $\alpha_{4}$, is small and therefore this parameter is not presented.

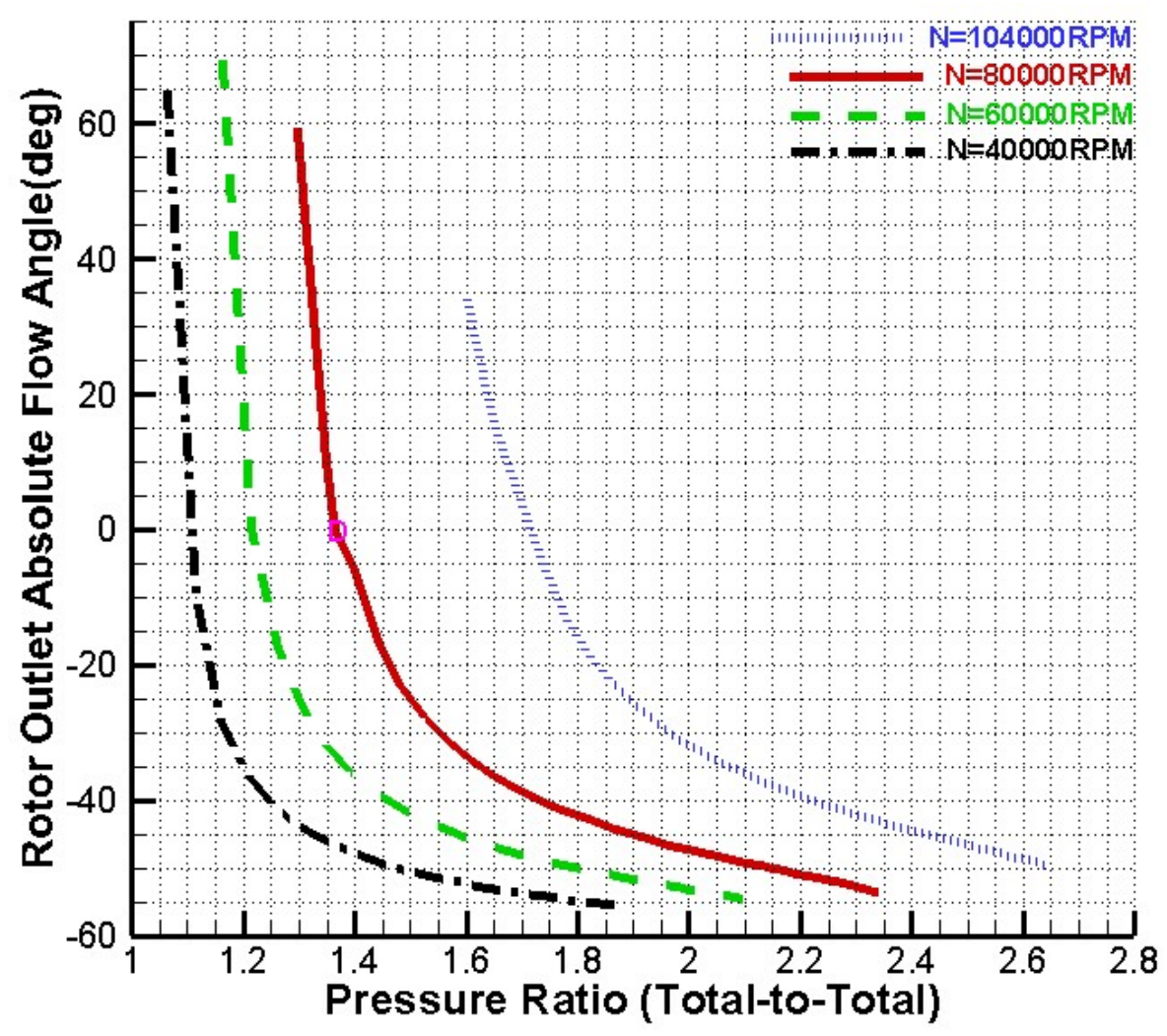

Figure 5.11 Characteristics of the Rotor Outlet Absolute Flow Angle of the CU-BCL Radial Inflow Turbine.

Figure 5.11 shows the rotor outlet absolute flow angle, $\alpha_{5}$, as a function of the total-to-total pressure ratio and rotational speed. As indicated, the design objective was to have zero swirl, and thus zero flow angle, in the turbine outlet flow. At N=40000 RPM and N=60000 RPM, the maximum value of outlet angle can be very large. At design and higher rotational speeds, the outlet swirl varies over a somewhat smaller range. 


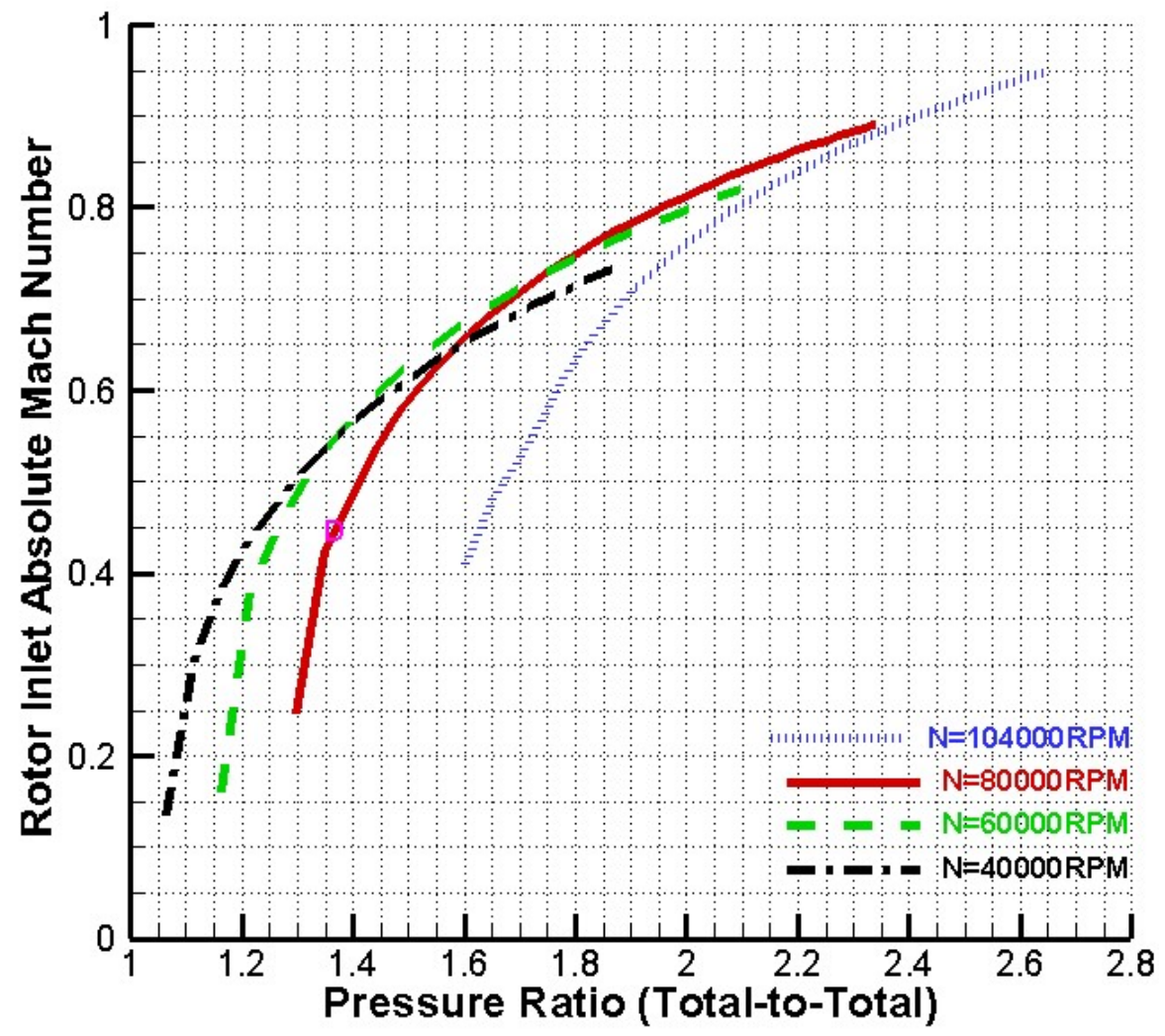

Figure 5.12 Characteristics of the Rotor Inlet Absolute Mach Number of the CU-BCL Radial Inflow Turbine.

Figure 5.12 shows the absolute Mach number at rotor inlet as a function of the total-to-total pressure ratio and rotational speed. The location of the maximum absolute Mach number is the rotor inlet since the flow was accelerated through the gap between the nozzle exit and rotor inlet. As seen, the maximum value of Mach number is not larger than 0.95 over the full operating range. This indicates that the turbine nozzles are not choked for the full operating range. 


\subsection{Result of CFD Analysis for the CU-BCL Radial Inflow Turbine}

\subsubsection{Introduction}

The characteristics of the CU-BCL radial inflow turbine over the full operating range have been predicted by the meanline analysis. A full viscous three-dimensional Computational Fluid Dynamics (CFD) method was then used to solve the complex flow in the rotor blade passages of the CU-BCL radial inflow turbine.

The results for the turbine running at the design and off-design operating points are presented in Sections 5.4.2 and 5.4.3, respectively. The predicted characteristics of the turbine based on the CFD analysis are then presented in Section 5.5. The results from meanline and CFD analyses are presented in the same figures. The objective is to evaluate the accuracy of the meanline predictions, particularly at off-design since that is a novel application of meanline analysis.

\subsubsection{Result of CFD Analysis at Design Operating Point}

The velocity magnitude and direction of the $\mathrm{S}-\mathrm{CO}_{2}$ working fluid in the rotor blade passages are presented in Figure 5.13. In order to identify the separation in the blade passages, the corresponding contour of entropy, as presented in Figure 5.14, needs to be examined simultaneously with Figure 5.13. The velocity streamlines in the blade passages are plotted in Figure 5.15, which is a better view to identify the secondary flow than Figure 5.13. 


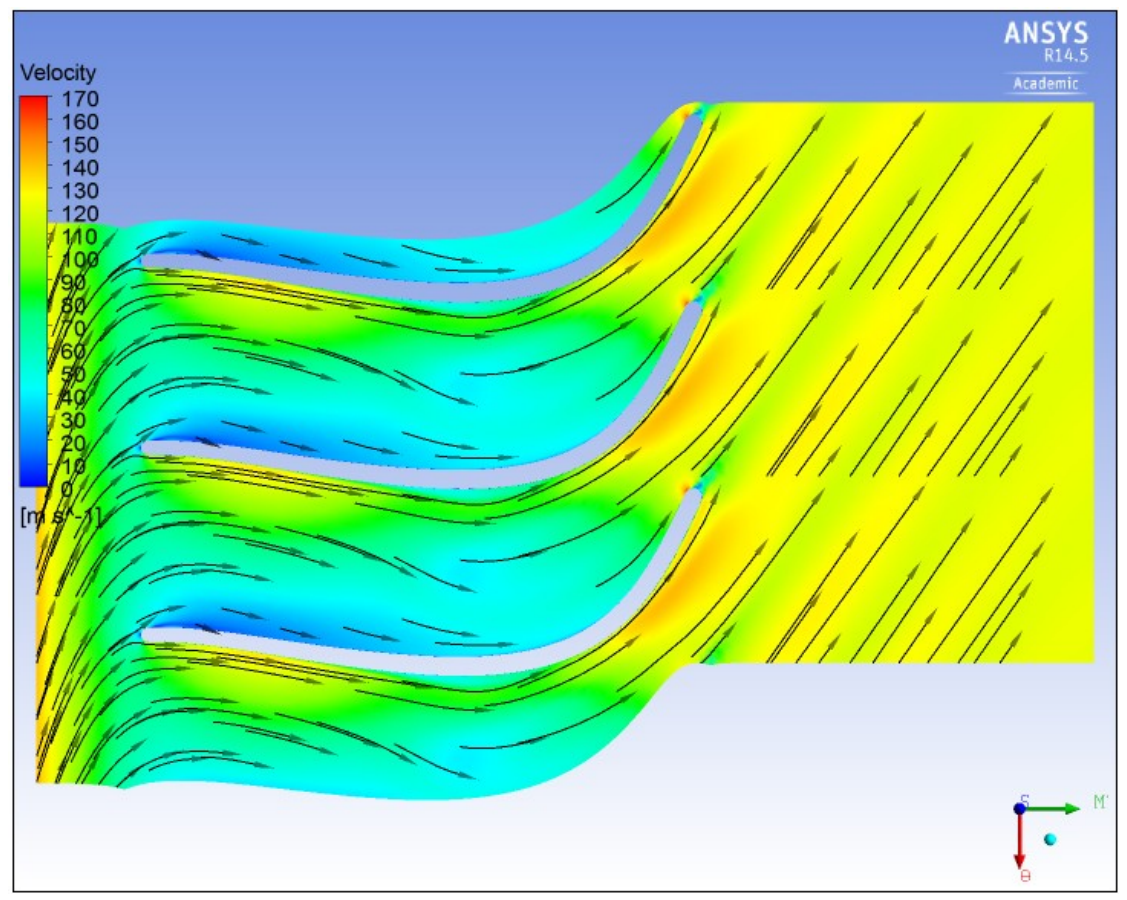

Figure 5.13 Velocity Vectors at 50\% Span of the CU-BCL Radial Inflow Turbine Rotor Blade Passages.

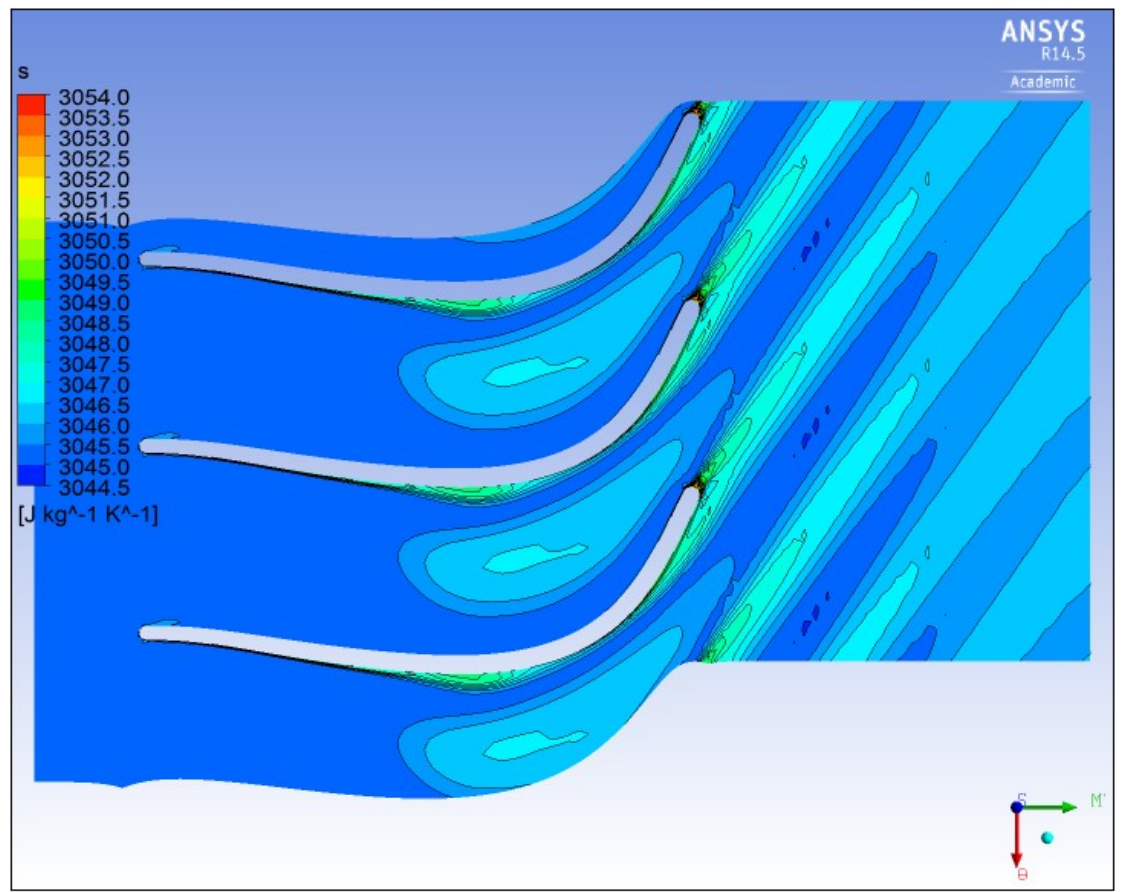

Figure 5.14 Contour of Entropy at 50\% Span of the CU-BCL Radial Inflow Turbine Rotor Blade Passages. 
Figure 5.13 indicates some boundary layer separation at the middle chord and near the trailing edge on the suction side. Also, it is supported by the corresponding entropy generation in Figure 5.14. Figure 5.14 presents a large patch of entropy in the middle of passage as well. This may be entropy that is generated in the tip leakage flow near the shroud wall and is being convected into the midspan region by spanwise fluid movement.

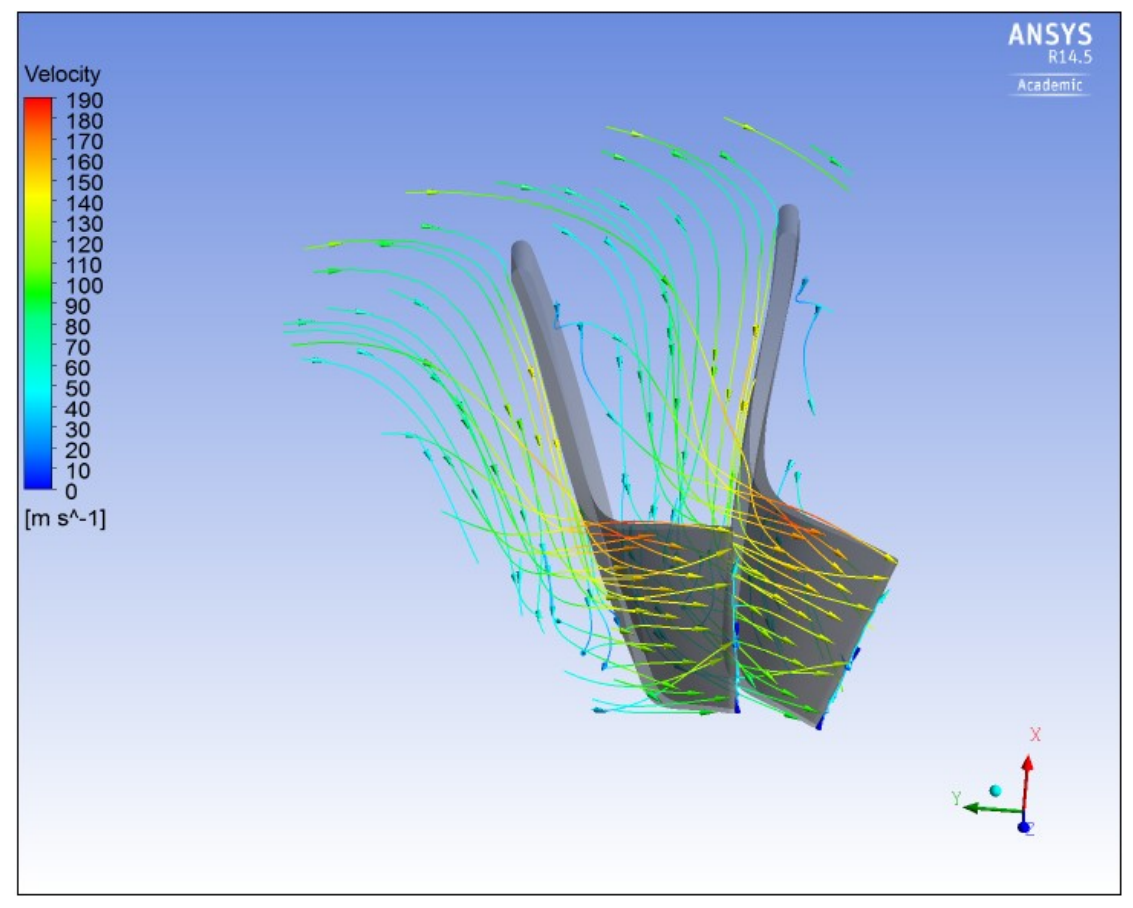

Figure 5.15 Velocity Streamlines at the CU-BCL Radial Inflow Turbine Rotor Blade Passages.

During the process of a turbine generating output power, the blades are developing lift and then a pressure difference exists between the blades. Thus, any fluid that has lower momentum than the core flow will be driven more strongly from the pressure side to the suction side of the passage and the secondary flow is formed in this process. As seen, plenty of signs of secondary flow in the blade passages are presented in Figure 5.15. 


\subsubsection{Result of CFD Analysis at Off-Design Operating Points}

CFD results for the turbine running at off-design pressure ratios and rotational speeds are presented in this section. The following includes results for the design rotational speed ( $\mathrm{N}=80000 \mathrm{RPM}$ ) but an off-design pressure ratio. In addition, results are predicted at two off-design rotational speeds, N=40000 RPM and N=104000 RPM.

In order to investigate the effect of incidence on the flow in the blade passages, the results of the turbine running at an off-design incidence are presented in Figures 5.16-5.18.

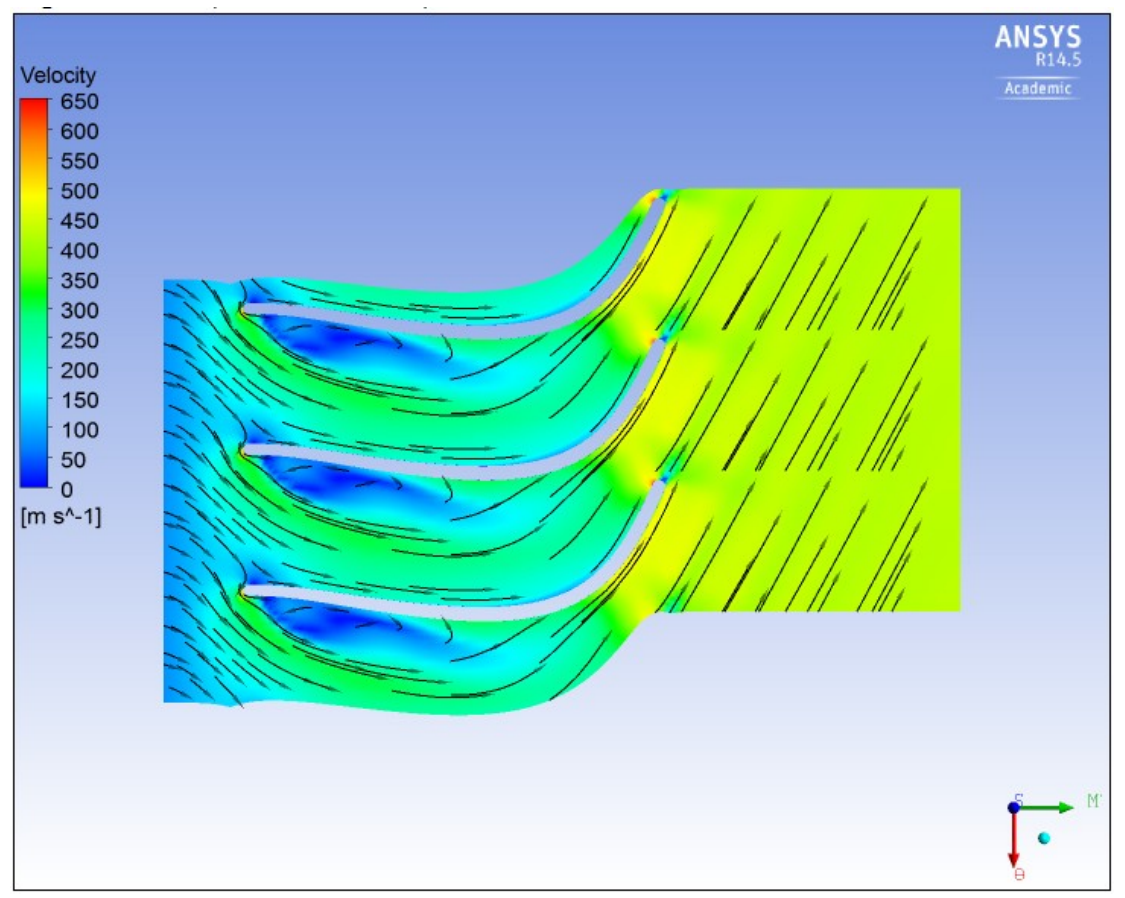

Figure 5.16 Velocity Vectors at 50\% Span of the CU-BCL Radial Inflow Turbine Rotor Blade Passages $(\mathrm{N}=80000, \mathrm{PR}=2.20)$. 


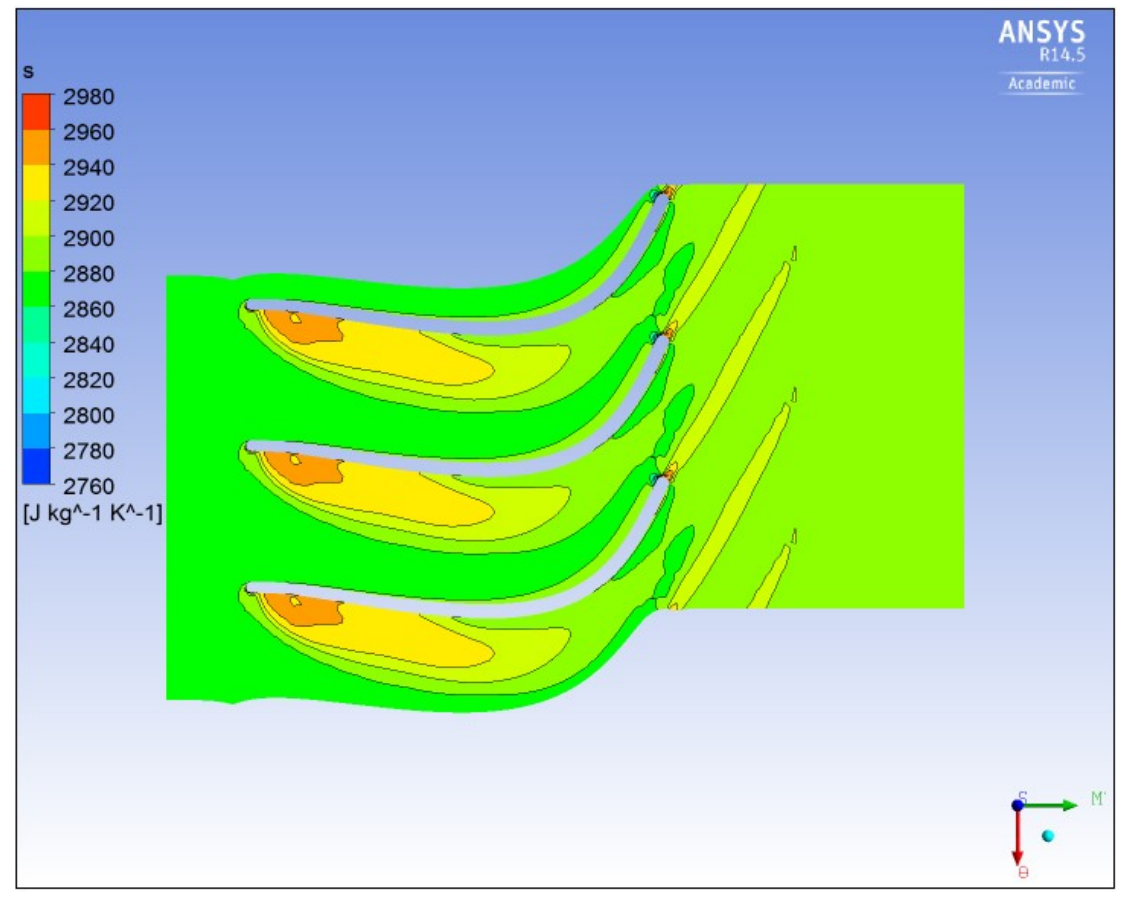

Figure 5.17 Contour of Entropy at 50\% Span of the CU-BCL Radial Inflow Turbine Rotor Blade Passages $(\mathrm{N}=80000, \mathrm{PR}=2.20)$.

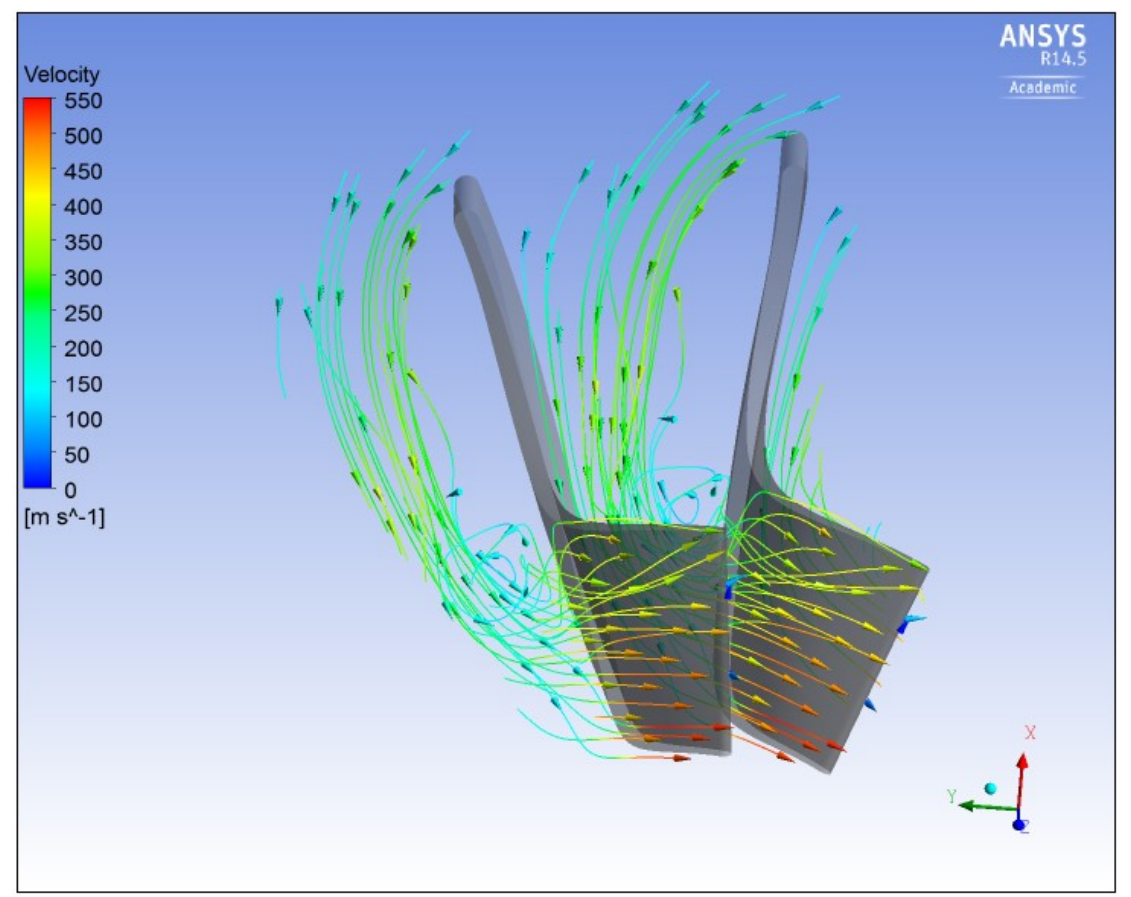

Figure 5.18 Velocity Streamlines at the CU-BCL Radial Inflow Turbine Rotor Blade Passages $(\mathrm{N}=80000, \mathrm{PR}=2.20)$. 
At the design point, the optimum incidence for radial inflow turbine lies within the range of $-20^{0}$ to $-40^{0}$. However, in Figures 5.16-5.18, the value of incidence is $+44^{0}$, which is significantly different from the design point value of $-26^{0}$. As seen, due to the effect of incidence, in Figures 5.16-5.18, a large region of leading edge separation along with corresponding entropy generation is predicted by the CFD analysis. The results indicate that incidence has a significance influence on the rotor passage flow. Therefore, for meanline analysis, a good correlation of incidence losses is essential to obtain reasonable predictions of off-design efficiency as well.

In order to examine the effect of rotational speed on the rotor passages flow, two off-design rotational speeds, N=40000 RPM and N=104000 RPM, were predicted by the CFD analysis. In view of the fact that the losses originating inside the blade passage, due to surface boundary layers, separations on the surfaces, secondary and tip-leakage losses are taken into account by the total-to-total efficiency, if the value of total-to-total efficiency at a particular off-design point is only a little lower than the value at design point, it would indicate that most of the change in total-to-static efficiency is due to the higher downstream kinetic energy, while the rotor passage flow is fairly well behaved. Thus, the predicted off-design pressure ratios for $\mathrm{N}=40000$ RPM and N=104000 RPM are both significantly different from the corresponding optimum efficiency to make the results more comparable. The results for $\mathrm{N}=40000$ RPM and $\mathrm{N}=104000$ RPM are presented in Figures 5.19-5.21 and Figures 5.22-5.24, respectively. 


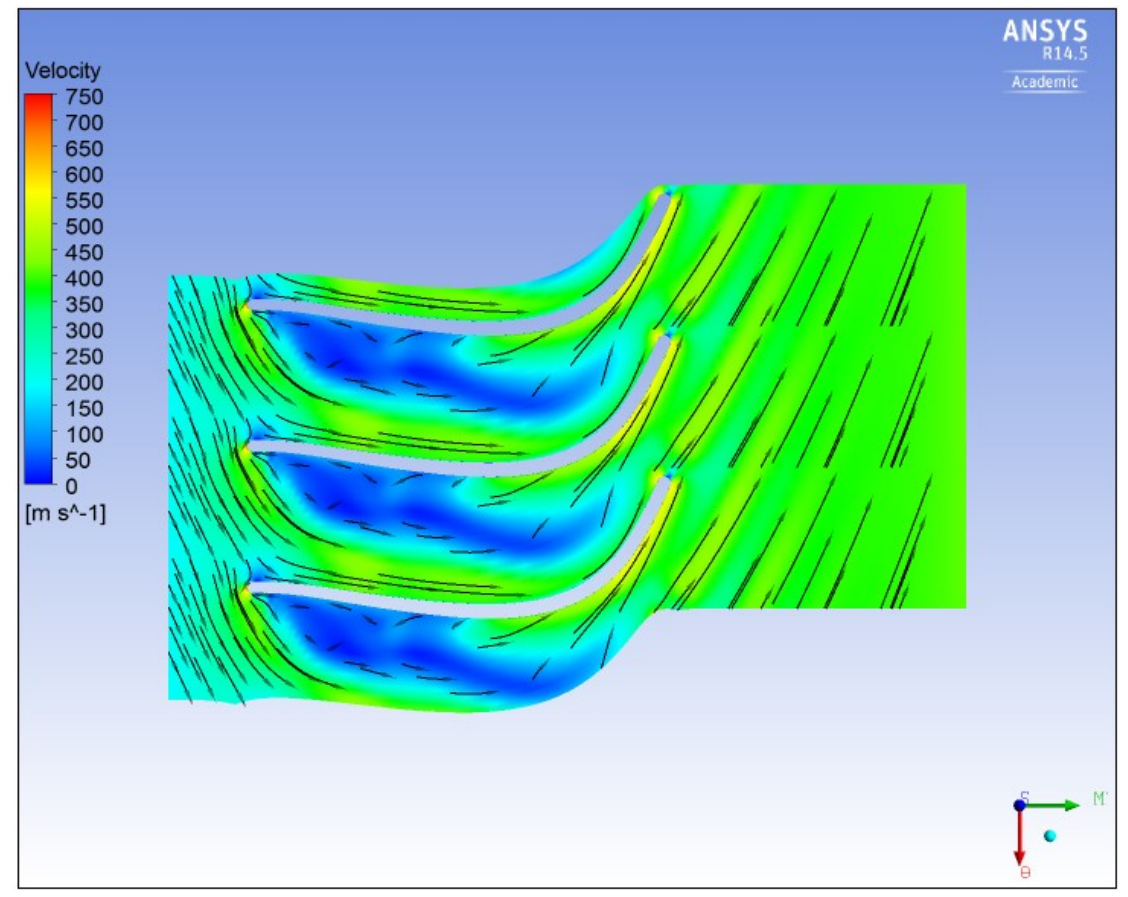

Figure 5.19 Velocity Vectors at 50\% Span of the CU-BCL Radial Inflow Turbine Rotor Blade Passages $(\mathrm{N}=40000, \mathrm{PR}=1.87)$.

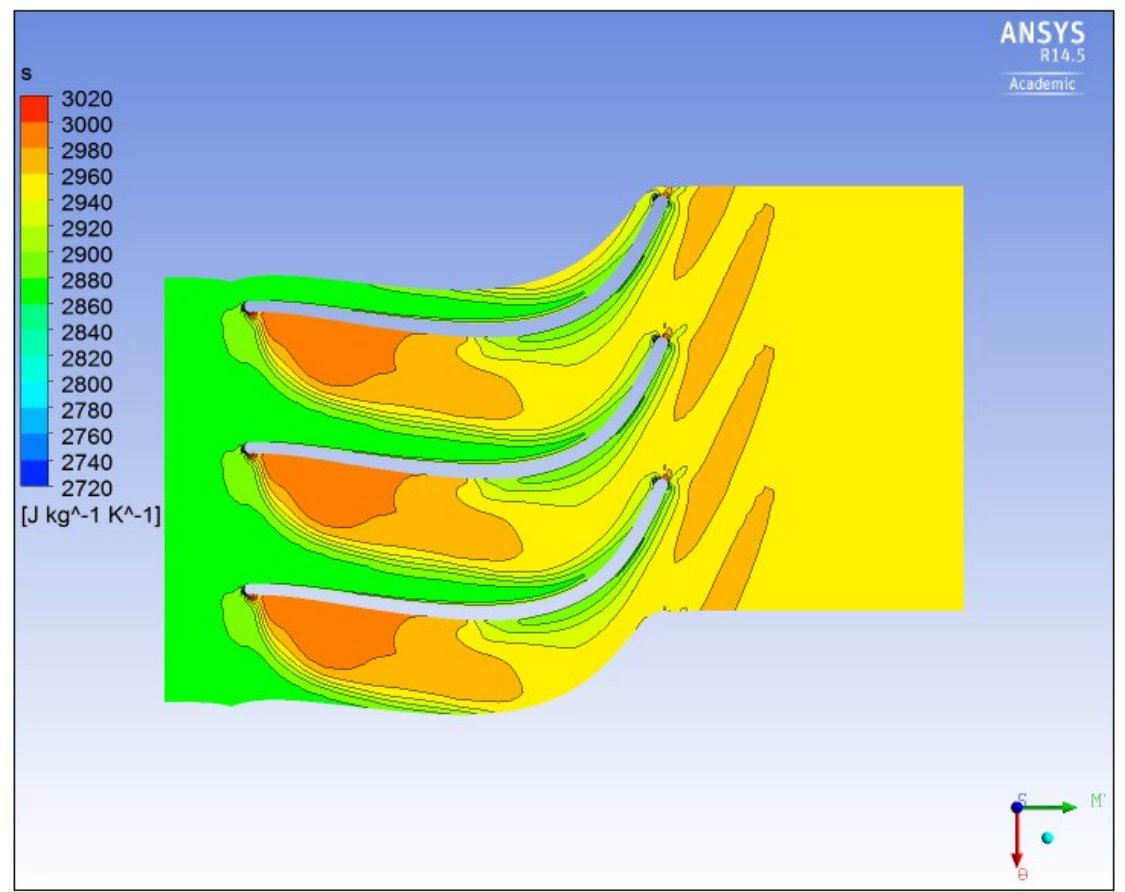

Figure 5.20 Contour of Entropy at 50\% Span of the CU-BCL Radial Inflow Turbine Rotor Blade Passages $(\mathrm{N}=40000, \mathrm{PR}=1.87)$. 


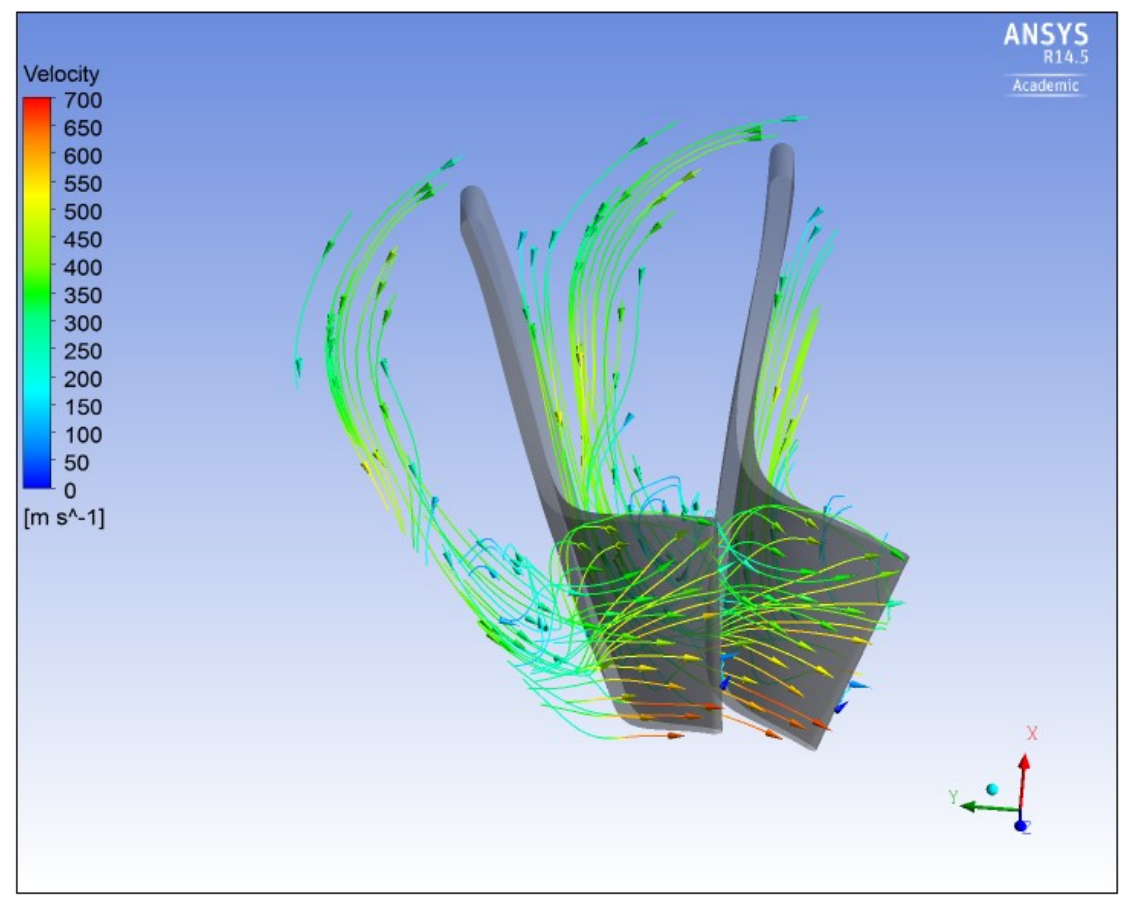

Figure 5.21 Velocity Streamlines at the CU-BCL Radial Inflow Turbine Rotor Blade Passages $(\mathrm{N}=40000, \mathrm{PR}=1.87)$.

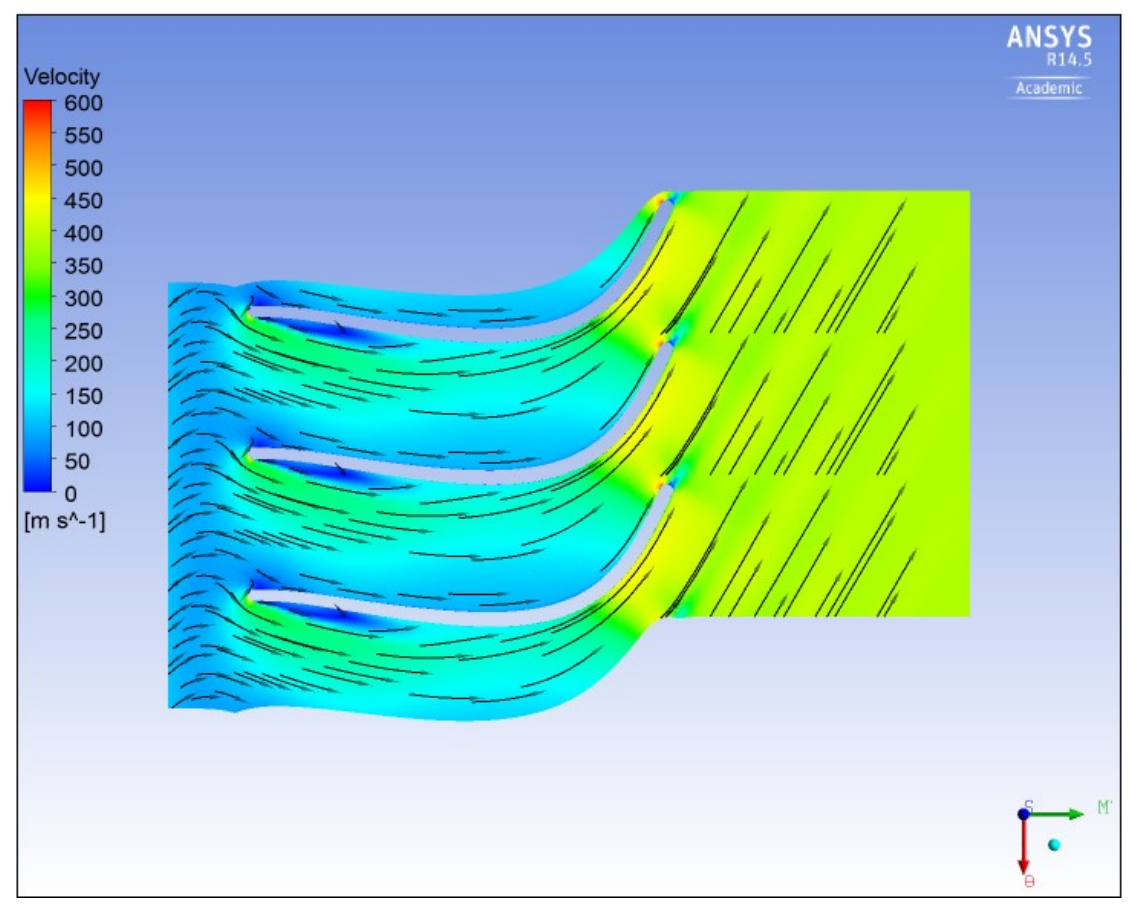

Figure 5.22 Velocity Vectors at 50\% Span of the CU-BCL Radial Inflow Turbine Rotor Blade Passages $(\mathrm{N}=104000, \mathrm{PR}=2.41)$. 


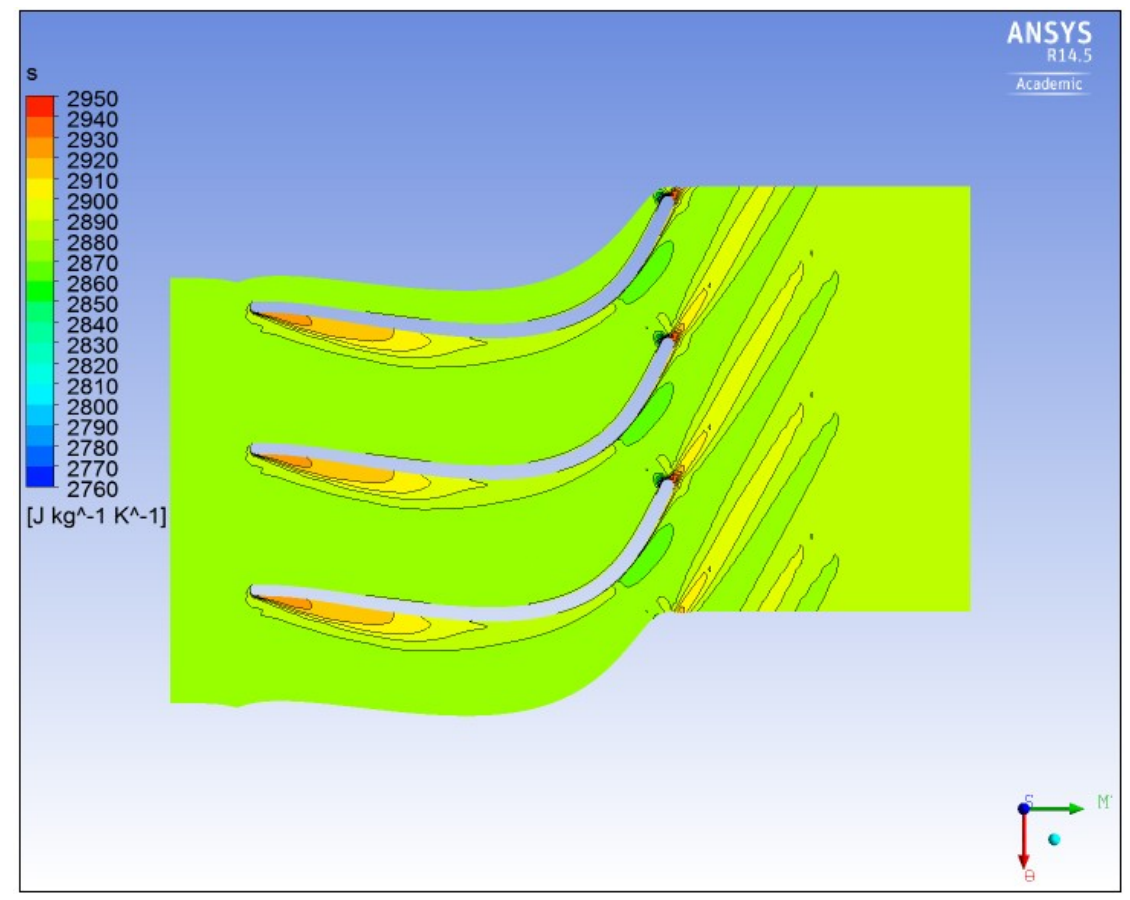

Figure 5.23 Contour of Entropy at 50\% Span of the CU-BCL Radial Inflow Turbine Rotor Blade Passages $(\mathrm{N}=104000, \mathrm{PR}=2.41)$.

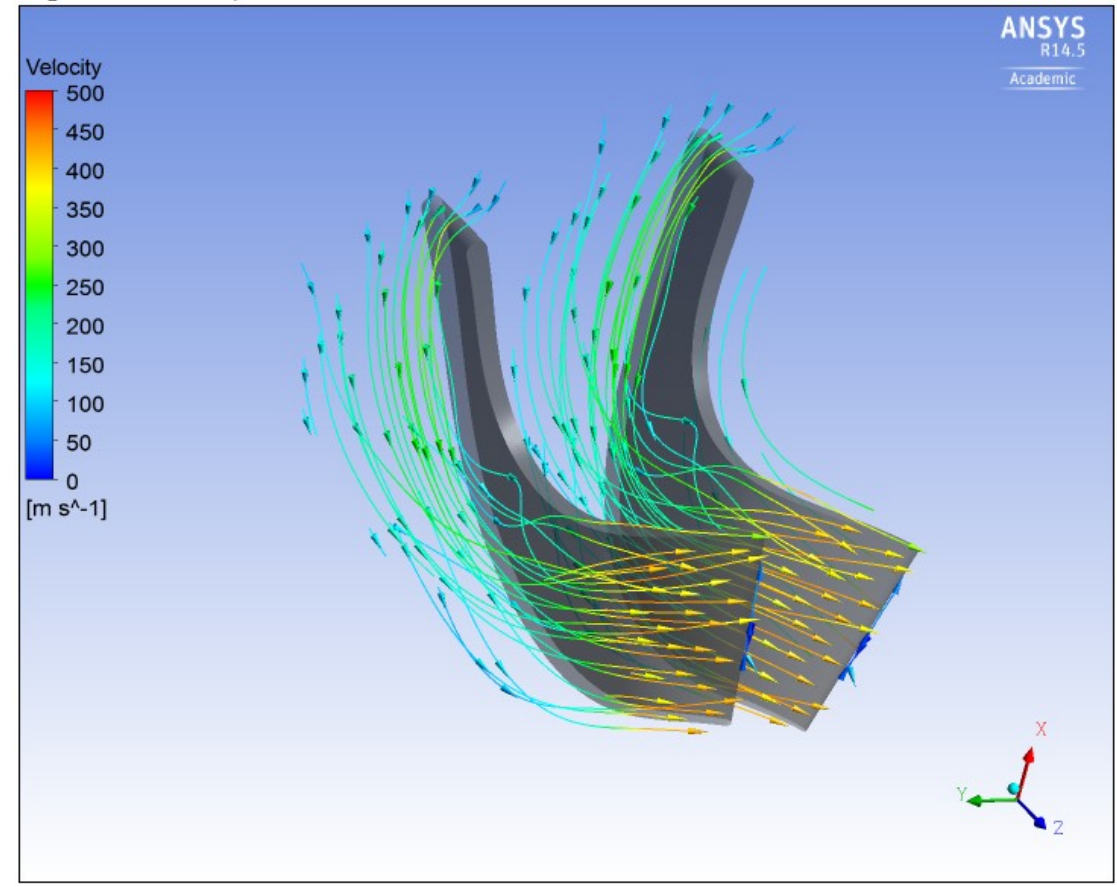

Figure 5.24 Velocity Streamlines at the CU-BCL Radial Inflow Turbine Rotor Blade Passages $(\mathrm{N}=104000, \mathrm{PR}=2.41)$. 
As seen, the flow field in the blade passages is well behaved for N=104000 RPM and the passage flow is very disordered for $\mathrm{N}=40000 \mathrm{RPM}$. Also, the predicted results in Figures 5.19-5.24 are supported by the CFD results quantitatively. For N=104000 RPM, the highest total-to-total efficiency is 0.975 and the result for the selected pressure ratio of 2.41 is 0.935 . At this off-design pressure ratio, the total-to-static efficiency is 0.765 . As discussed above, it indicates that the passage flow is fairly well behaved and the kinetic energy in the outlet flow has to account for most of the change in total-to-static efficiency. On the contrary, for $\mathrm{N}=40000$ RPM, the results of total-to-total efficiency and total-to-static efficiency at this off-design pressure ratio of 1.87 are 0.57 and 0.34 , respectively. The highest total-to-total efficiency for $\mathrm{N}=40000 \mathrm{RPM}$ is 0.88 . It means that losses in the rotor blade passages along with the downstream kinetic energy are taken into account by the total-to-static efficiency.

As the rotational speed varies, other relevant parameters at the rotor inlet are also changed. Thus, the differences between the results at $\mathrm{N}=104000 \mathrm{RPM}$ and $\mathrm{N}=40000$ RPM are also affected by changes in incidence or Mach number. To examine the reasons for the change of efficiency and the behavior of the passage flow, the corresponding conditions for these off-design points are summarized in Table 5.5 along with the machine design point for comparison.

\begin{tabular}{|c|c|c|c|c|c|}
\hline $\mathrm{N}(\mathrm{RPM})$ & $\mathrm{PR}_{\mathrm{t}-\mathrm{t}}$ & $\eta_{t-t}(\%)$ & $\eta_{t-s}(\%)$ & $i$ (degree) & $\mathrm{M}_{\text {4rel }}$ \\
\hline 80000 & 1.36 (design) & 97.2 & 93.8 & -25.7 & 0.14 \\
\hline 104000 & 1.63 (optimum) & 97.5 & 92.9 & -24.8 & 0.19 \\
\hline 104000 & 2.41 & 93.5 & 76.5 & 25.8 & 0.40 \\
\hline 40000 & 1.14 (optimum) & 88.3 & 81.1 & 38.1 & 0.17 \\
\hline 40000 & 1.87 & 57.0 & 34.1 & 59.1 & 0.75 \\
\hline
\end{tabular}

Table 5.5 Results Comparison of CFD Analysis at Design and Off-Design Points. 
In Table 5.5, $i$ and $\mathrm{M}_{4 \text { rel }}$ are the values of incidence and relative Mach number at rotor inlet respectively. For the off-design rotational speeds, the pressure ratios at which the corresponding optimum efficiencies occur are also indicated in the table, to compare with the chosen off-design points in Figures 5.19-5.24. As mentioned in Section 3.2.2, for radial inflow turbine, the optimum incidence is thought to lie within the range of $-20^{0}$ to $-40^{\circ}$. As seen in Table 5.5, the incidence for $\mathrm{N}=80000 \mathrm{RPM}, \mathrm{PR}_{\mathrm{t}-\mathrm{t}}=1.36$ and $\mathrm{N}=104000$ RPM, $P R_{t-t}=1.63$ are both within the optimum range. For the off-design points of $\mathrm{N}=104000 \mathrm{RPM}, \mathrm{PR}_{\mathrm{t}-\mathrm{t}}=2.41$ and $\mathrm{N}=40000 \mathrm{RPM}, \mathrm{PR}_{\mathrm{t}-\mathrm{t}}=1.87$, the values of incidence are $25.8^{0}$ and $59.1^{0}$, respectively. This is likely the reason that a much larger area that is occupied by the separations at $\mathrm{N}=40000 \mathrm{RPM}$ than $\mathrm{N}=104000$ RPM. Also, due to the large absolute value of incidence at $\mathrm{N}=40000 \mathrm{RPM}, \mathrm{PR}_{\mathrm{t}-\mathrm{t}}=1.87$, a large relative inlet Mach number, $\mathrm{M}_{4 \mathrm{rel}}$, is generated. Since the increasing of $\mathrm{M}_{4 \mathrm{rel}}$ will increase the losses generated at the leading edge and inside the blade passages, the efficiency is also affected and therefore the result of total-to-total efficiency is much lower than for $\mathrm{N}=104000$ RPM, $\mathrm{PR}_{\mathrm{t}-\mathrm{t}}=2.41$.

As presented in Table 5.5, for the lower rotational speed N=40000 RPM, even if the machine is operating at the optimum pressure ratio $\mathrm{PR}_{\mathrm{t}-\mathrm{t}}=1.14$, the incidence $\left(38.1^{0}\right)$ differs considerable from what is thought to be optimum. This may cause the large region of separation in the blade passage, as seen in Figure 5.25. The entropy contours at midspan are presented in Figure 5.26 and streamlines for the full rotor passage in Figure 5.27 . 


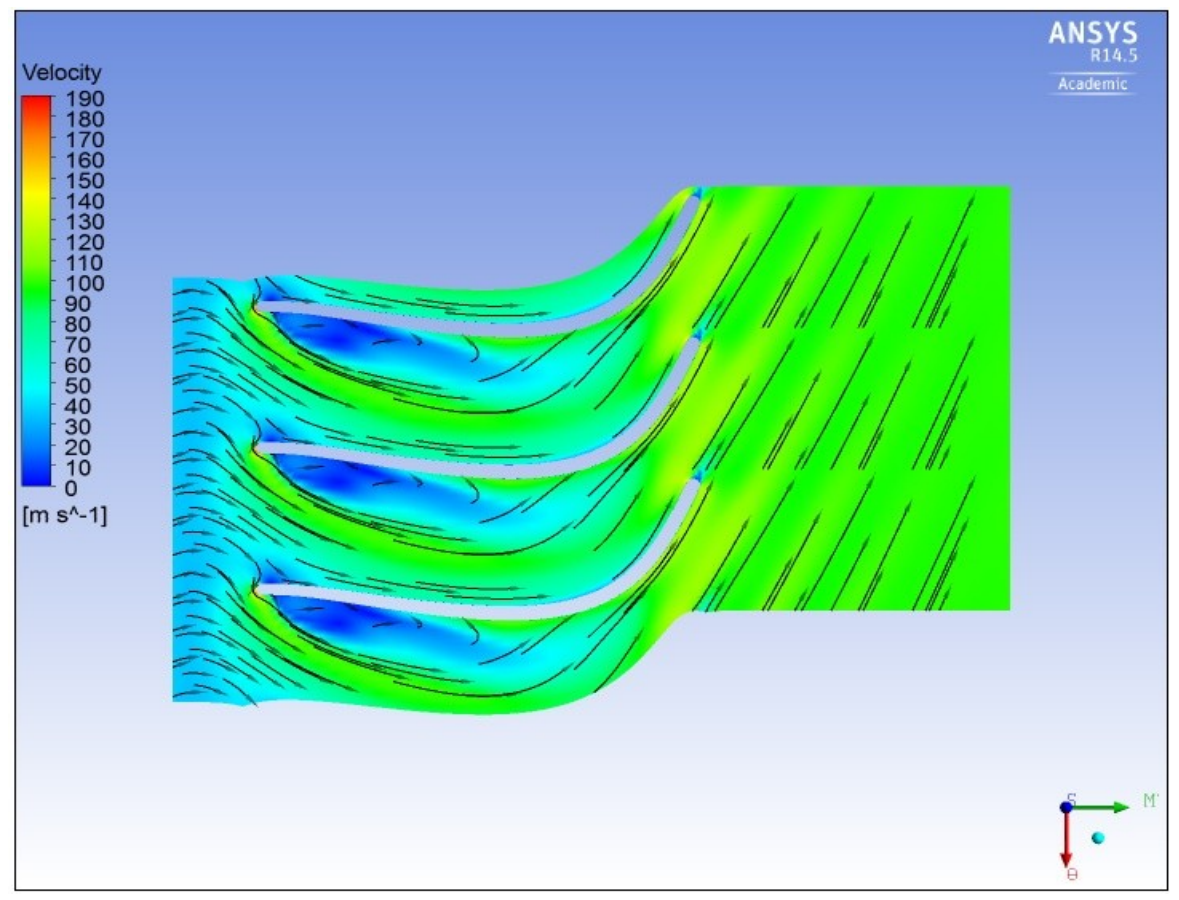

Figure 5.25 Velocity Vectors at 50\% Span of the CU-BCL Radial Inflow Turbine Rotor Blade Passages $(\mathrm{N}=40000, \mathrm{PR}=1.14)$.

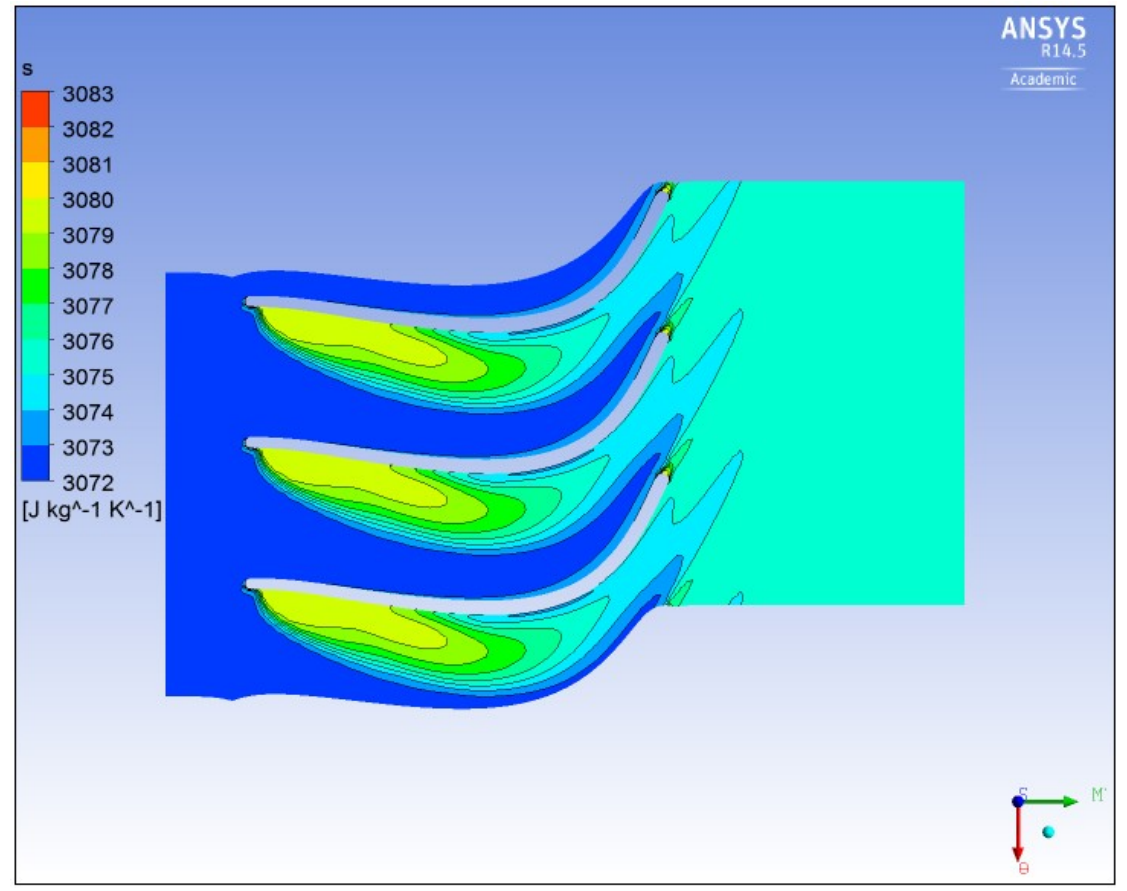

Figure 5.26 Contour of Entropy at 50\% Span of the CU-BCL Radial Inflow Turbine Rotor Blade Passages $(\mathrm{N}=40000, \mathrm{PR}=1.14)$. 


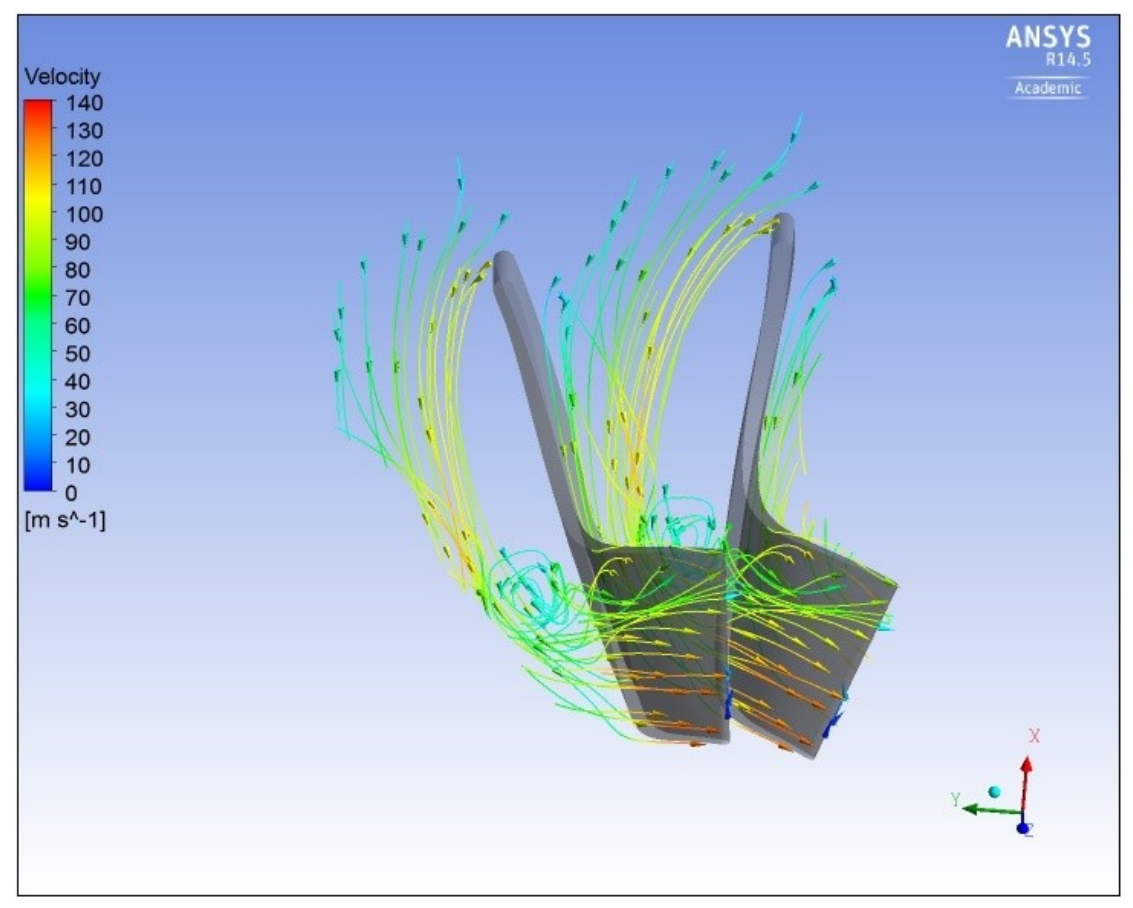

Figure 5.27 Velocity Streamlines at the CU-BCL Radial Inflow Turbine Rotor Blade Passages $(\mathrm{N}=40000, \mathrm{PR}=1.14)$.

From the CFD analysis, the values of total-to-total and total-to-static efficiency are 0.88 and 0.81 , respectively. This indicates that the losses originating inside the blade passages account for most of the change in total-to-static efficiency for this lower off-design rotational speed even at the optimum operating point.

\subsection{The Comparison of Results from Meanline and CFD Analyses}

This section compares the turbine characteristics at design and off-design operating points from the meanline and CFD analyses. The parameters that are chosen for comparison are ones that are available from both methods, although the three-dimensional CFD method can take into consideration more aspects of the flow. 


\subsubsection{The Comparison of Results from Meanline and CFD Analyses at Design Operating Points}

The CU-BCL turbine performance at the design operating point from the meanline and CFD analyses are presented in Table 5.6. All of the results from the CFD analysis are mass-averaged in CFX-Post and then presented in the following tables and figures.

\begin{tabular}{|c|c|c|}
\hline Parameter & Meanline Analysis & CFD \\
\hline Total-to-Total Efficiency, $\left(\eta_{t-t}\right)(\%)$ & 85.0 & 97.2 \\
\hline Total-to-Static Efficiency, $\left(\eta_{t-s}\right)(\%)$ & 82.7 & 93.8 \\
\hline Total-to-Total Pressure Ratio $\left(\mathrm{PR}_{\mathrm{t}-\mathrm{t}}\right)$ & 1.364 & 1.357 \\
\hline Output Power $(\dot{\mathrm{W}})(\mathrm{KW})$ & 84.076 & 85.702 \\
\hline Mass Flow Rate $(\dot{\mathrm{m}})(\mathrm{kg} / \mathrm{s})$ & 1.8 & 5.855 \\
\hline Rotor Outlet Absolute Flow Angle $\left(\alpha_{5}\right)(\mathrm{deg})$ & 0 & 0.127 \\
\hline Rotor Outlet Absolute Mach Number $\left(\mathrm{M}_{5}\right)$ & 0.121 & \\
\hline
\end{tabular}

Table 5.6 Results Comparison of Meanline and CFD Analyses at Design Operating Point $\left(\mathrm{N}=80000 \mathrm{RPM}, \dot{\mathrm{m}}=1.8 \mathrm{~kg} / \mathrm{s}, \mathrm{PR}_{\mathrm{t}-\mathrm{t}}=1.364\right)$.

As seen in Table 5.6, most of the results from the meanline and the CFD analyses are in reasonable agreement. With regard to the performance of efficiency predictions at the design operating point, the CFD prediction results are more than 10 percentage points higher than the meanline analysis. As will be shown later, the values of total-to-total and total-to-static efficiencies as were predicted by CFD analysis are always larger than the meanline analysis. Some possible reasons are proposed in the following to explain this.

Firstly, in view of the fact that the Reynolds number would not be larger than the

order of $10^{5}$ for the general working fluid, most of the loss correlations in meanline 103 
analysis are developed from the experimental and experience results which the corresponding Reynolds number lies within the order of $10^{4} \sim 10^{5}$. However, with regard to the fluid properties of $\mathrm{S}-\mathrm{CO}_{2}$, the $\mathrm{CU}-\mathrm{BCL}$ radial inflow turbine characteristics over the full operating range are based on the Reynolds number which lies within the order of $10^{6} \sim 10^{7}$. Due to the lack of corrected parameter for Reynolds number in the loss correlation system, it will cause errors in the efficiency predictions in meanline analysis. Thus, if the loss correlation system is based on the eligible order of Reynolds number for the working fluid $\mathrm{S}-\mathrm{CO}_{2}$, the results comparison between meanline and CFD analyses will become closer to the real situation.

Secondly, as introduced in Chapter 4, due to the lack of high quality data and correlations in the open literature to estimate the deviation for radial inflow turbine rotor blade in meanline analysis, the metal angle was assumed equal to the relative flow angle at rotor outlet in RITMLD and RITMLO. Thus, the rotor outlet metal angle is different between the meanline and CFD analysis and it can account for the different characteristics of efficiency predictions over the full operating range to some extent.

Finally, as described in Section 1.1, there are currently no experimental data against which to compare the meanline results. Thus, CFD analysis was used to compare and assess the meanline results. However, for the prediction of turbine efficiency, CFD analysis may not predict the absolute value accurately, even if the prediction of changes and trends are reliable by CFD analysis.

In order to achieve the objective of zero swirl flow at the rotor outlet as intended in RITMLD, the rotor outlet metal angles were varied in the CFD analysis until zero swirl was achieved over the full blade span. However, as the rotor outlet metal angle was modified in the CFD model, the prediction of the mass flow rate is varied as well. In 
order to match the value of the mass flow rate in the CFD analysis with design point in the meanline analysis, meanwhile, keep the outlet static pressure constant as the meanline analysis, the final choice of rotor outlet metal angle is a trade-off between the results of mass flow rate and outlet swirl. As presented in Table 5.6, the outlet swirl is $5.0^{\circ}$ and mass flow rate is $1.855 \mathrm{~kg} / \mathrm{s}$ for CFD analysis. The resulting metal and relative flow angles are given in Table 5.7.

\begin{tabular}{|c|c|c|c|}
\hline & Hub (deg) & Mid-Span (deg) & Shroud (deg) \\
\hline Metal Angle & -57 & -65 & -71 \\
\hline Flow Angle & -51 & -62.5 & -69 \\
\hline Deviation & 6 & 2.5 & 2 \\
\hline
\end{tabular}

Table 5.7 Deviation of the CU-BCL Radial Inflow Turbine Rotor Blade.

As seen, the deviation angle is large for the rotor blade near the hub and decreases towards the shroud. In view of the fact that the solidity relates to the deviation directly and the wrap angle changes the effective solidity of the blade passage by changing the effective chord length of the blade, the -20 degree wrap angle for the turbine rotor blade was chosen along with the outlet metal angle after a series of tests. Although the wrap angle is not used in the one-dimensional analysis, a correlation to predict deviation in meanline analysis could presumably be developed based on the solidity as one of the main correlating parameters.

\subsubsection{The Comparison of Results from Meanline and CFD Analyses at Off-Design Operating Points}

As presented in Section 5.4, the CU-BCL turbine characteristics over the full operating range were predicted by the CFD analysis as well as the meanline analysis. The characteristics for only a single rotational speed are present in the same figure to avoid 
clutter and make the comparisons more clear.

The characteristics of the CU-BCL radial inflow turbine running at the $\mathrm{N}=80000$ RPM are presented in this section. The results for off-design rotational speeds $(\mathrm{N}=40000$ RPM, N=60000 RPM, N=104000 RPM) are presented in Appendix E. Since the residuals in the CFX solutions will increase to as much as $10^{-3}$ when the operating points are significantly different from the design point, the accuracy of the CFD results decrease at these operating points. Also, due to the significant computational effort for the three-dimensional simulations, only five or six operation points were calculated in the CFD model for each rotational speed.

As discussed in Section 5.4.3, in the CFD analysis, the rotor passage flow is fairly well behaved at the higher rotational speed. It means that the total-to-total efficiency would not be much lower than the highest value at off-design points and the kinetic energy in the outlet flow is taken into account by the change in total-to-static efficiency. Thus, in order to investigate the effect of rotational speed on the rotor passage flow in meanline analysis, the results comparison of total-to-total efficiency and total-to-static efficiency between the meanline and CFD analyses are presented in Figures 5.28 and 5.29, respectively. 


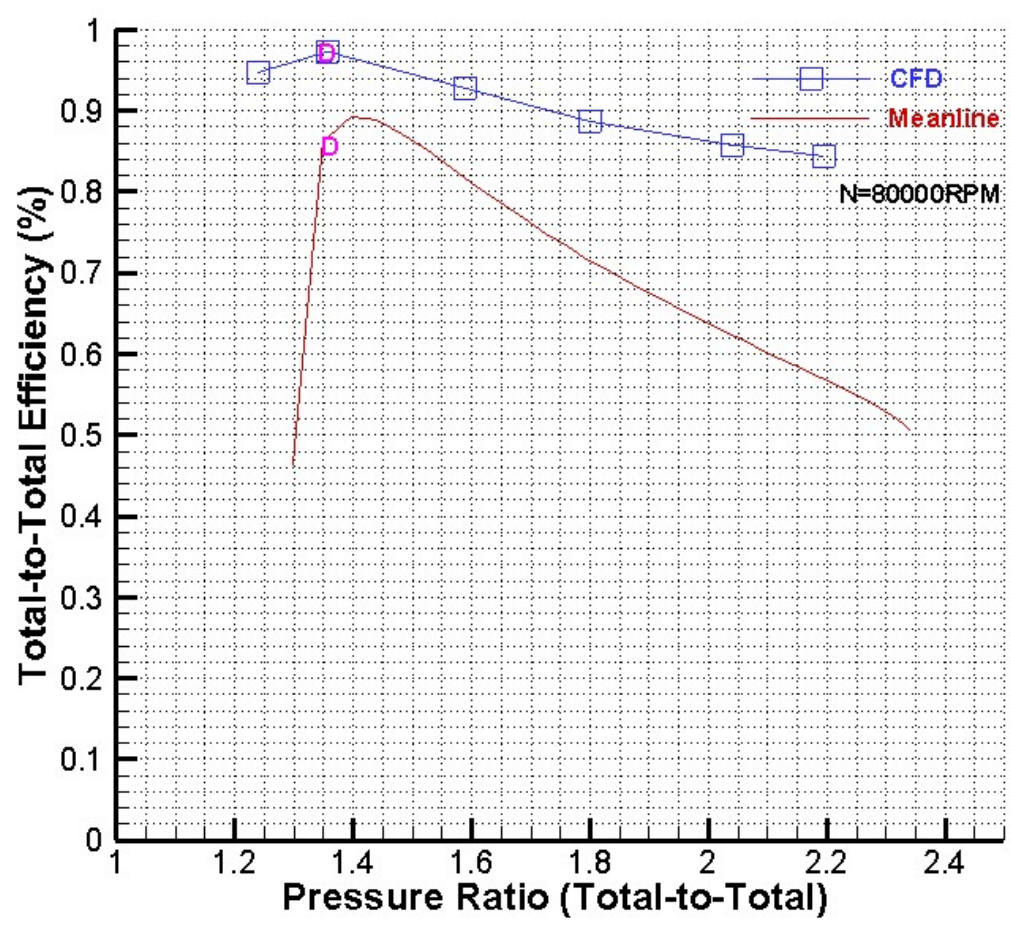

Figure 5.28 Results Comparison for Total-to-Total Efficiency between Meanline and CFD Analyses (N=80000 RPM).

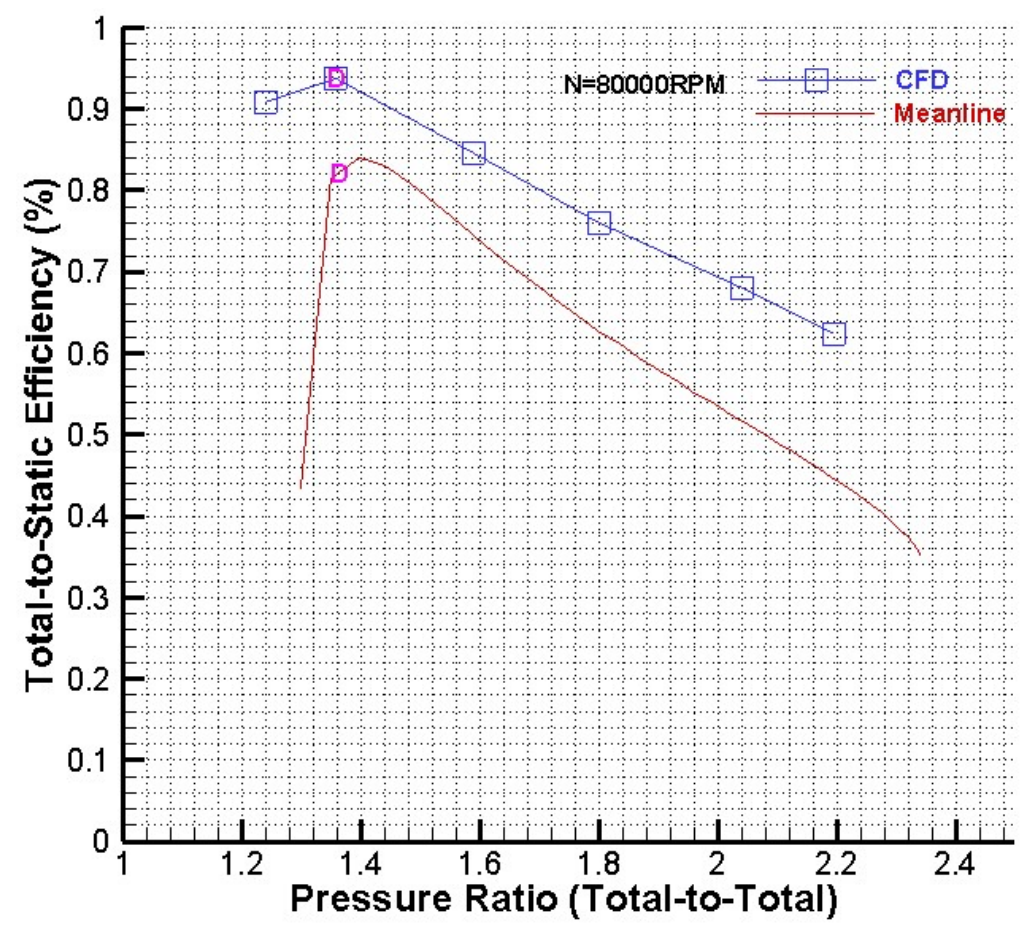

Figure 5.29 Results Comparison for Total-to-Static Efficiency between Meanline and CFD Analyses (N=80000 RPM). 
As seen in Figure 5.28, for the CFD analysis, the difference between the highest and lowest value of total-to-total efficiency is only about $10 \%$. However, in the meanline analysis, the differences in total-to-total efficiency are much larger. In Figure 5.29, the general trend of the total-to-static efficiency over the full operating range is similar between meanline and CFD curves. Furthermore, the results in Figures 5.28 and 5.29 are typical of the ones that are given for other rotational speeds in the Appendix E. These results indicate that the meanline loss correlations that account for the losses originating inside the blade passages are not as sensitive to the change of rotational speed and pressure ratio as the predictions in the CFD analysis. Also, as the machine is operating at off-design points, the extent of the separation in blade passages is sensitive to details of the machine aerodynamic design. These subtle effects are influenced by far more geometric and aerodynamic parameters than the few that are used in the off-design loss correlations. Therefore, due to the limited understanding of separation, secondary and tip-leakage losses for the corresponding radial inflow turbine loss correlations at off-design points, the predictions of rotor passage flow in the CFD analysis are expected to be more reliable than those from the meanline analysis.

Also, in Figures 5.28 and 5.29, as the pressure ratio increases, the differences in the predicted efficiencies become larger. As will be seen, the differences also increase for other parameters. For the CFD analysis, as the operating point significantly differs from the design operating point, the stronger secondary flow and more extensive separation in the blade passages presents greater challengers for both the turbulence model and the computation process. This causes growth of residuals and thus poorer convergence. Thus, as the pressure ratio differs more from the design point value, the accuracy of the CFD results are reduced. For meanline analysis, the only way that the meanline analysis can account for the stronger secondary flows and separations is through the loss correlations. However, as discussed above, these correlations are not as reliable as at the design point. 


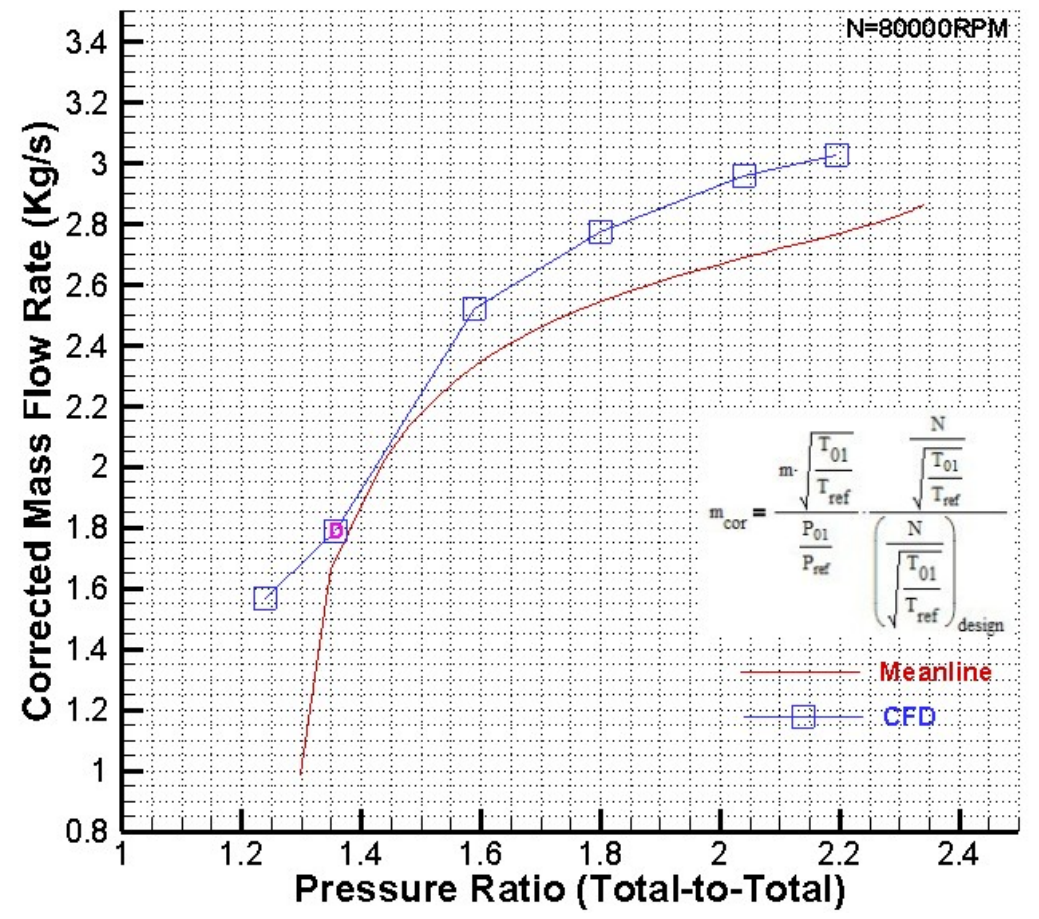

Figure 5.30 Results Comparison for Mass Flow Rate between Meanline and CFD Analyses $(\mathrm{N}=80000$ RPM).

As seen from Figure 5.30, at the design pressure ratio, the trend in corrected mass flow rate is very similar for the meanline and CFD curves. For both meanline and CFD analysis, no choking occurs at the highest off-design pressure ratios examined at $\mathrm{N}=80000$ RPM. However, as seen from the CFD prediction, a kink exists in this curve at low pressure ratio. As discussed above, the reason for this kink is that the poor convergence in the CFD analysis and therefore the result accuracy at this point is reduced. As with the prediction curves in Figures 5.28 and 5.29, the deviation between the meanline and CFD curves increases when the turbine is operating at larger pressure ratios. 


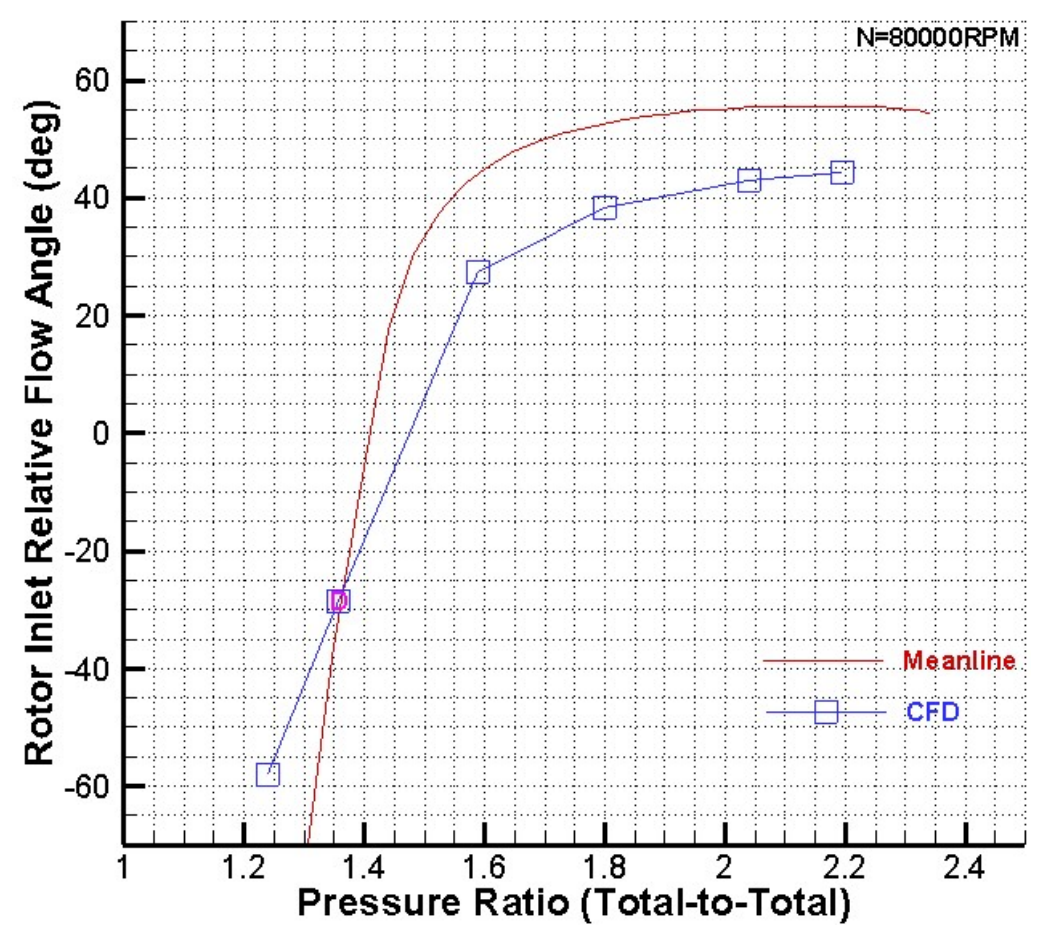

Figure 5.31 Results Comparison for Rotor Inlet Relative Flow Angle between Meanline and CFD Analyses (N=80000 RPM).

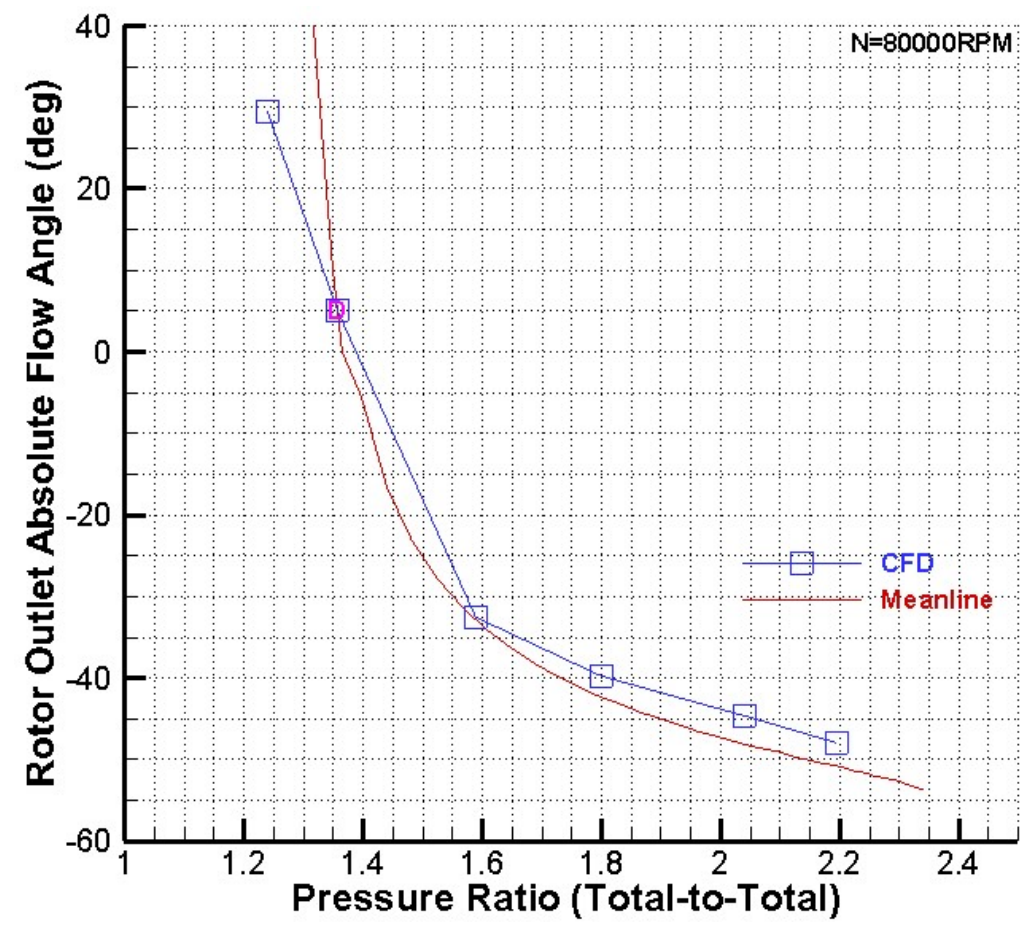

Figure 5.32 Results Comparison for Rotor Outlet Absolute Flow Angle between Meanline and CFD Analyses ( $\mathrm{N}=80000 \mathrm{RPM})$. 


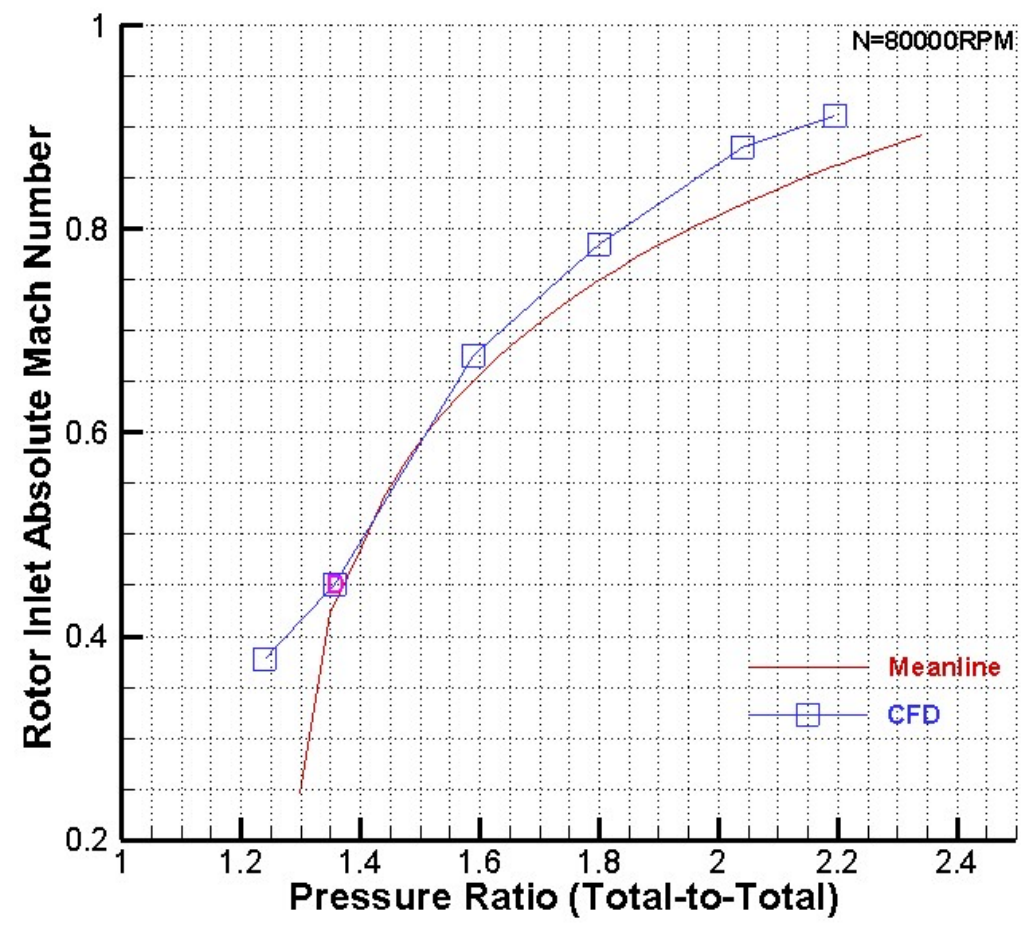

Figure 5.33 Results Comparison for Rotor Inlet Absolute Mach Number between Meanline and CFD Analyses ( $\mathrm{N}=80000 \mathrm{RPM})$.

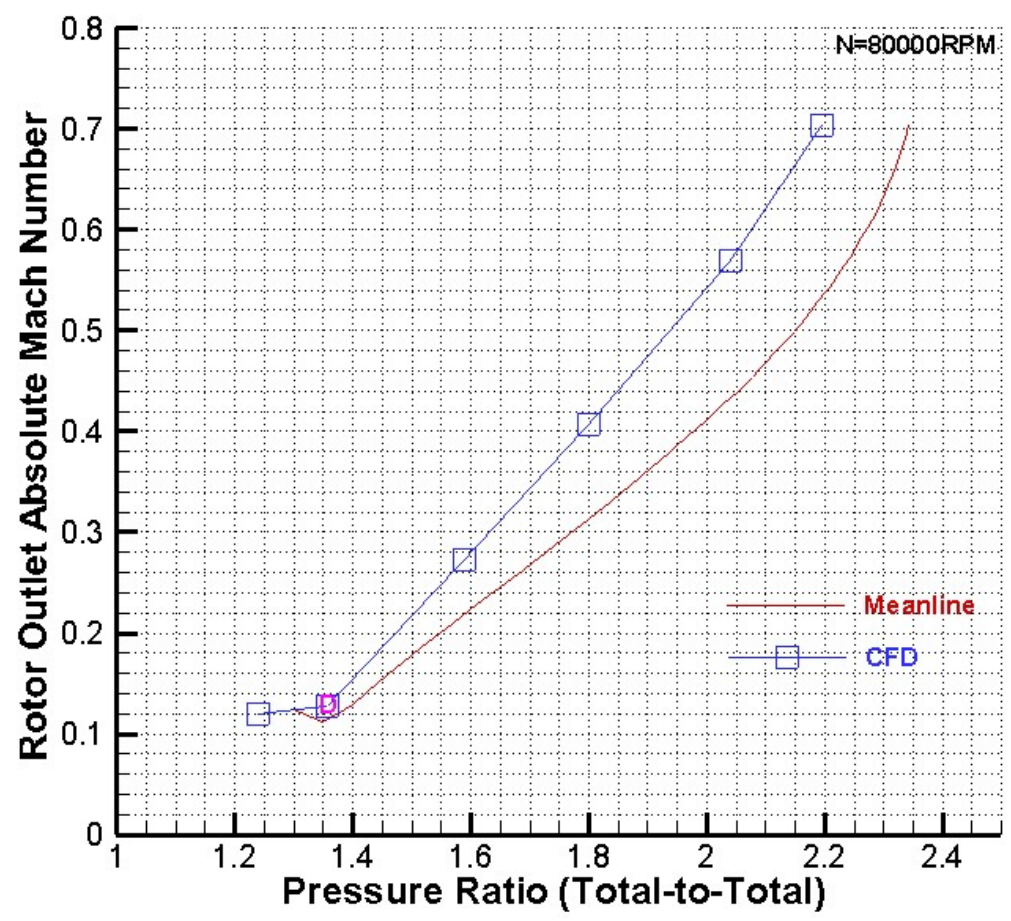

Figure 5.34 Results Comparison for Rotor Outlet Absolute Mach Number between Meanline and CFD Analyses ( $\mathrm{N}=80000 \mathrm{RPM})$. 
The prediction of rotor inlet relative flow angle, rotor outlet absolute flow angle, rotor inlet absolute Mach number and rotor outlet absolute Mach number are shown in Figures 5.31-5.34, respectively. Unlike the efficiency predictions in Figures 5.28 and 5.29, the results at design and off-design points are very similar between the meanline and CFD curves.

As seen in Figure 5.31, the result of rotor inlet relative flow angle (incidence), which is predicted by the meanline analysis, is always larger than the result in the CFD analysis. Since the rotor inlet relative velocity, $\mathrm{W}_{4}$, which is determined by the incidence at the velocity triangle, is an important parameter in the meanline loss correlations of incidence and passage, this will produce more losses in the prediction process of the meanline analysis. Thus, it is another reason to account for the difference increasing between meanline and CFD curves with the growth of total-to-total pressure ratios.

Figure 5.34 presents the results of comparisons between the rotor outlet absolute Mach number from the meanline and CFD analyses at N=80000 RPM. As seen, the value of outlet absolute Mach number predicted by CFD method is always larger than the results from RITMLO, especially at larger pressure ratios. However, since the outlet Mach numbers are different, this will cause the outlet total pressure, $\mathrm{P}_{05}$, at outlet boundary condition in the CFD analysis to be different from the value of $\mathrm{P}_{05}$ in the meanline analysis, at each corresponding pressure ratio. It indicates that the comparisons in the above figures are based on different inlet and outlet total pressure, even though the corresponding pressure ratio is the same.

All of the prediction characteristics of the CU-BCL radial inflow turbine operating at $\mathrm{N}=80000 \mathrm{RPM}$ from meanline and CFD analyses have been presented in the above figures. Similar comparisons can be found in Appendix E for N=40000 RPM, N=60000 RPM and N=104000 RPM. With regard to the different rotational speeds, the results 
comparisons between meanline and CFD analyses are similar to results for $\mathrm{N}=80000$ RPM.

From the results comparison between meanline and CFD analysis, it appears that the meanline codes RITMLD and RITMLO can give reasonable estimates of the overall radial inflow turbine characteristics at an early stage in the design. These characteristics can be used, for example, in the preliminary compressor-turbine matching calculations and for plant dynamic modeling. 


\section{Chapter 6 Conclusions and Recommendations}

\subsection{Conclusions}

This thesis focused on the development of the one-dimensional meanline and three-dimensional Computational Fluid Dynamics (CFD) analyses of a radial inflow turbine at design and off-design operating points. The methods were applied to the design of the CU-BCL radial inflow turbine. All of the codes used real fluid properties. The codes RITMLD (Radial Inflow Turbine Meanline Design Operating Point) and RITMLO (Radial Inflow Turbine Meanline Off-Design Operating Point) were developed for the purpose of preliminary design of radial inflow turbines and the estimation of their characteristics over the full operating range in a highly rapid way. The CFD calculations were mainly used to assess the accuracy of the simpler meanline calculations.

In order to investigate the losses originating in different locations of the turbine, a loss correlation system was incorporated in RITMLD and RITMLO. At the design operating point, the results from RITMLD show that the passage and tip clearance losses make more contributions to the overall losses compared with the other loss mechanisms of incidence, trailing edge, windage and exit energy. After RITMLD had converged to the specified performance, the main geometric dimensions of the turbine were known.

For the prediction of turbine characteristics at off-design points, the results from RITMLO show that the meanline off-design codes were able to predict successfully the turbine characteristics for a wide range of rotational speed and pressure ratio operating points. Generally, choking is possible to occur in turbine stage when machine runs at larger pressure ratios. However, although the function of choking prediction has been set 
in RITMLD and RITMLO, due to the design requirement of the CU-BCL, the maximum Mach number is only 0.44 at the design point and there is no hint to indicate that choking occurs during the full off-design points.

The complex flow in the rotor blade passages of the CU-BCL radial inflow turbine was solved by the CFD analysis. At the design rotational speed of $\mathrm{N}=80000 \mathrm{RPM}$, the CFD results indicate that incidence has a significance influence on the passage flow. If incidence deviates from the optimum point, flow separations are prone to occur at the leading edge. Also, for the lower rotational speed N=40000 RPM (50\% of design rotational speed), due to the incidence is significantly different from the optimum range $\left(-20^{0} \sim-40^{0}\right)$, there is still a large area that is occupied by the flow separations in the blade passages even if the turbine is running at the corresponding optimum pressure ratio.

The accuracy of the meanline calculations was assessed by the results comparison between meanline and CFD analyses. The results comparison for total-to-total and total-to-static efficiencies between the two analyses show that the meanline loss correlations overestimate the losses originating inside the blade passages compared to the CFD analysis. However, the general trends of predicted characteristics are fairly similar between meanline and CFD curves over the full operating range. It indicates that the meanline analysis is adequate for estimating the overall turbine characteristics at an early design stage.

The present work was motivated by the requirement to design radial inflow turbines for a closed-cycle gas turbine engine using $\mathrm{S}-\mathrm{CO}_{2}$ as the working fluid. The meanline analysis codes for the design and off-design points of radial inflow turbine have been developed in this thesis. The turbine characteristics over the full operating range were predicted by RITMLO and it has been assessed through the comparison between the meanline and CFD analyses. 


\subsection{Recommendations for Future Work}

The CU-BCL radial inflow turbine characteristics have been investigated by meanline and CFD analyses in this thesis. However, the volute and nozzle geometries were not included in the CFD analysis. Thus an investigation should be conducted to analyze the flow field in these components as well as to examine the effect of the complete turbine stage model on the characteristics over the full operating range. The results based on the complete CFD model should again be compared with the meanline analysis.

Although a loss correlation system has been incorporated with the meanline analysis, due to the limited understanding of losses originating inside the blade passages for off-design points, the accuracy of loss predictions for passage flow still need to be assessed and improved in the meanline analysis. As one of the losses originating inside the blade passages, tip leakage losses, is an important loss component in the meanline analysis. In order to examine the accuracy of this separated loss correlation, it would be useful to vary the tip clearance in the CFD analysis and see whether the change in efficiency is similar to that predicted by the meanline analysis. In any case, there is far less data available from off-design testing than for the design point and therefore there is a much greater challenge to develop a well-established loss correlation system to allow good predictions for the full range of off-design points. Also, since reliable loss correlations for nozzle and volute are not available in the open literature, the CFD model which includes the nozzles and volute geometry could be used as a potential approach to develop these loss correlations for meanline analysis.

As mentioned in Section 5.5, the deviation angle between the metal and flow angles at the turbine rotor outlet cannot currently be estimated in the meanline analysis. 
However, it may be possible to develop a correlation based on the solidity as one of the main correlating parameters to predict the deviation in the meanline analysis. Also, as discussed in Section 3.4.2, a general correlation to predict deviation at the outlet of radial turbine nozzle at off-design points has not been fully developed yet. Although the radial nozzle vanes are effectively the axial blade rows, due to the correlations for estimating deviation of axial stators are based on the direction of axial flow but not radial flow, some investigations are likely necessary to adapt the axial turbine correlations for use with radial nozzles. 


\section{References}

ANSYS, 2009, ANSYS TurboGrid Introduction.

ANSYS, 2010, ANSYS CFX-BladeGen Tutorials.

ANSYS, 2012, ANSYS CFX-Solver Modeling Guide.

Aungier, R. H., 2005, “Turbine Aerodynamics: Axial-Flow and Radial-Inflow Turbine Design and Analysis," The American Society of Mechanical Engineers Press, New York.

Balje, O. E., 1952, "A Contribution to the Problem of Designing Radial Turbomachines," Transactions of the ASME, Vol. 74, pp.451.

Balje, O. E., 1981, “Turbomachines, A Guide to Design, Selection and Theory,” Wiley, New York.

Baskharone, E. A., 2006, "Principles of Turbomachinery in Air-Breathing Engines," Cambridge University Press, Cambridge.

Chen, H. and Baines, N.C., 1994, "The Aerodynamics Loading of Radial and Mixed Flow Turbines," International Journal of Mechanical Sciences 36:63-79.

CU-BCL 2013-14 Design Team, 2014, Carleton University. 
Daily, J. W. and Nece, R. E., 1960, "Chamber Dimension Effects on Induced Flow and Frictional Resistance of Enclosed Rotating Discs," Transactions ASME Journal Basic Eng 82:217-232.

Dambach, R., Hodson, H. P. and Huntsman, I., 1998, "An Experimental Study of Tip Clearance Flow in Radial Inflow Turbine," ASME Paper No.98-GT-467.

Futral, S. M., Wasserbauer, C. A., 1965, "Off-Design Performance Prediction with Experimental Verification for a Radial-Inflow Turbine," NASA TN D-2621.

Futral, S. M. and Holeski, D. E., 1970, "Experimental Performance Evaluation of a 4.59-Inch Radial Inflow Turbine with and without Splitter Blades,” NASA TN D-7015.

Ghosh, S. K., Sahoo, R. K. and Sarangi, S, K., 2011, "Mathematical Analysis for Off-Design Performance of Cryogenic Turboexpander Trans," ASME Journal of Fluids Eng 133(3), p, 031001.

Glassman, A. J., 1976, "Computer Program for Design and Analysis of Radial Inflow Turbines," NASA TN 8164.

Glassman, A. J., 1995, “Enhanced Analysis and User's Manual for Radial Inflow Turbine Conceptual Design Code RTD,” NASA, Contractor Report No.195454.

Holman, J.P., 1988, “Thermodynamics, 4th Edition,” Mc Graw-Hill, New York. 
Krylov, Y. P. and Spunde, Y. A., 1963, “About the Influence of the Clearance Between the Working Blades and Housing of a Radial Turbine on its Exponent," USAF Foreign Technology Division Translation FTD-MT-67-15.

MacIsaac, 2014, Ph.D Thesis, Carleton University.

Menter, F. R., 1994, “Two-Equation Eddy-Viscosity Turbulence Models for Engineering Applications," AIAA Journal, Vol. 32, No. 8, pp. 1598-1605.

Moustapha, H., Zelesky, M.F., Baines, N.C. and Japikse, D., 2003, "Axial and Radial Turbines," Chapters 7-9, Concepts NREC, White River Junction.

NIST, 2014, "NIST Chemistry WbrBook, The proper Citation of the NIST Wbrbook," http://webbook.nist.gov/cgi/cbook/cgi?Contrib=, accessed March 30,2014.

Pasch, J., Conboy, T., Feming, D. and Rochau, G., "Supercritical CO2 Recompression Brayton Cycle: Completed Assembly Description," Sandia Report SAND2012-9546, Sandia National Laboratories, October 2012.

Rodgers, C., 1968, “A Cycle Analysis Technique for Small Gas Turbines,” Proceedings Institution of Mechanical Engineers 183 (3N).

Rohlik, H. E., 1968, "Analytical Determination of Radial Inflow Turbine Design Geometry for Maximum Efficiency,” NASA TN D-4384. 
Sjolander, S. A., 2013, "Turbomachinery Supplementary Course Notes," Carleton University, pp 3.28.

Span, R. and Wagner, W., 1994, "A New Equation of State for Carbon Dioxide Covering the Fluid Region from the Triple-Point Temperature to $1100 \mathrm{~K}$ at Pressures up to 800 MPa,” The Journal of Physical Chemistry, Vol. 25, No. 6.

Spraker, W. A., 1987, "Contour Clearance Losses in Radial Inflow Turbines for Turbocharges," ASME Paper No 87-ICE-52.

Suhrmann, J. F., Peitsch, D., Gugan, M., Heuer, T. and Tomm, U., 2010, "Validation and Development of Loss Models for Small Size Radial Turbines," Proceedings of ASME Turbo Expo 2010: Paper No. GT2010-22666.

Taylor, L. T., 1996, “Supercritical Fluid Extraction,” John Wiley \& Sons, Inc, New York.

Ventura, C.A.M., Jacobs, P.A., Rowlands, A.S., Petrie-Repar, P., Sauret, E.,2012, "Preliminary Design and Performance Estimation of Radial Inflow Turbines: An Automated Approach,” ASME Journal of Fluids Eng 134(3), p, 031102.

Wallace, F. J., 1958, "Theoretical Assessment of the Performance Characteristics of a Radial Inflow Turbine," Proceedings Institution of Mechanical Engineers 172: 931-42.

Wasserbauer, C. A. and Glassman, A. J., 1975, "FORTRAN Program for Predicting the Off-Design Performance of Radial Inflow Turbines,” NASA TN-8063. 
Watanabe, I., Ariga, I. and Mashimo, T., 1971, "Effect of Dimensional Parameters of Impellers on Performance Characteristics of a Radial Inflow Turbine," Transactions ASME Journ Eng for Power 93:81-102.

Woolley, N. H. and Hatton, A. P., 1973, "Viscous Flow in Radial Turbomachine Blade Passages," Institution of Mechanical Engineers, IMechE Conference Proceedings 1973-3.

Yeo, J. H. and Baines, N. C., 1990, "Pulsating Flow Behavior in a Twin-Entry Vaneless Radial Inflow Turbine in Turbocharging and Turbochargers," Institution of Mechanical Engineers pp113-22. 


\section{Appendix A}

\section{A.1 RITMLD Input File Format}

\begin{tabular}{|c|c|c|c|}
\hline $\begin{array}{c}\text { Line } \\
\text { Number }\end{array}$ & Input Data & Type & Comments \\
\hline 1 & $\begin{array}{l}\text { Working Fluid Option: } \\
\text { Air } \\
\text { Carbon Dioxide } \\
\text { Argon }\end{array}$ & INTEGER & $\begin{array}{l}\text { Real working fluid selection. "1" } \\
\text { represents that this fluid was } \\
\text { chosen as the working fluid. " } 0 \text { " } \\
\text { represents that this fluid not } \\
\text { currently being used }\end{array}$ \\
\hline 2 & $\dot{\mathrm{m}}(\mathrm{kg} / \mathrm{s})$ & $\begin{array}{c}\text { FLOATING } \\
\text { POINT } \\
\end{array}$ & Mass flow rate of turbine stage \\
\hline 3 & $\mathrm{~N}(\mathrm{RPM})$ & $\begin{array}{l}\text { FLOATING } \\
\text { POINT }\end{array}$ & Rotational Speed of turbine stage \\
\hline 4 & $\mathrm{~T}_{01}(\mathrm{~K})$ & $\begin{array}{l}\text { FLOATING } \\
\text { POINT }\end{array}$ & $\begin{array}{l}\text { Total Temperature at the inlet } \\
\text { condition of turbine stage }\end{array}$ \\
\hline 5 & $\mathrm{P}_{01}(\mathrm{KPa})$ & $\begin{array}{c}\text { FLOATING } \\
\text { POINT } \\
\end{array}$ & $\begin{array}{l}\text { Total Pressure at the inlet } \\
\text { condition of turbine stage }\end{array}$ \\
\hline 6 & $\mathrm{~T}_{05}(\mathrm{~K})$ & $\begin{array}{l}\text { FLOATING } \\
\text { POINT }\end{array}$ & $\begin{array}{l}\text { Total Temperature at the outlet } \\
\text { condition of turbine stage }\end{array}$ \\
\hline 7 & $\mathrm{P}_{05}(\mathrm{KPa})$ & $\begin{array}{c}\text { FLOATING } \\
\text { POINT }\end{array}$ & $\begin{array}{l}\text { Total Pressure at the outlet } \\
\text { condition of turbine stage }\end{array}$ \\
\hline 8 & $\mathrm{P}_{5}(\mathrm{KPa})$ & $\begin{array}{l}\text { FLOATING } \\
\text { POINT }\end{array}$ & $\begin{array}{l}\text { Static Pressure at the outlet } \\
\text { condition of turbine stage }\end{array}$ \\
\hline 9 & $\dot{\mathrm{W}}(\mathrm{KW})$ & $\begin{array}{l}\text { FLOATING } \\
\text { POINT } \\
\end{array}$ & Output power of turbine stage \\
\hline 10 & $v_{s}$ & $\begin{array}{l}\text { FLOATING } \\
\text { POINT } \\
\end{array}$ & Velocity ratio of turbine stage \\
\hline 11 & $\psi$ & $\begin{array}{c}\text { FLOATING } \\
\text { POINT } \\
\end{array}$ & $\begin{array}{c}\text { Stage loading coefficient of } \\
\text { turbine stage }\end{array}$ \\
\hline 12 & $\phi$ & $\begin{array}{l}\text { FLOATING } \\
\text { POINT } \\
\end{array}$ & Flow coefficient of turbine stage \\
\hline 13 & $\varepsilon_{a}(\mathrm{~m})$ & $\begin{array}{c}\text { FLOATING } \\
\text { POINT } \\
\end{array}$ & Axial clearance \\
\hline 14 & $\varepsilon_{r}(\mathrm{~m})$ & $\begin{array}{c}\text { FLOATING } \\
\text { POINT }\end{array}$ & Radial clearance \\
\hline
\end{tabular}




\begin{tabular}{|c|c|c|c|}
\hline 15 & $\varepsilon_{b}(\mathrm{~m})$ & $\begin{array}{c}\text { FLOATING } \\
\text { POINT }\end{array}$ & Back face clearance \\
\hline 16 & $t_{\text {trailing }}(\mathrm{m})$ & $\begin{array}{l}\text { FLOATING } \\
\text { POINT }\end{array}$ & $\begin{array}{l}\text { Trailing edge thickness of turbine } \\
\text { rotor blade }\end{array}$ \\
\hline 17 & $N_{R}$ & $\begin{array}{c}\text { FLOATING } \\
\text { POINT }\end{array}$ & Number of rotor blades \\
\hline 18 & iVelocity Ratio & INTEGER & $\begin{array}{l}\text { If the value of velocity ratio has } \\
\text { been set by user, input "1", if not, } \\
\text { input "0" }\end{array}$ \\
\hline 19 & icoefficient & INTEGER & $\begin{array}{l}\text { If the value of stage loading and } \\
\text { flow coefficient has been set by } \\
\text { user, input " } 1 \text { ", if not, input " } 0 \text { " }\end{array}$ \\
\hline 20 & iOutlet Total Pressure & INTEGER & $\begin{array}{l}\text { If the outlet total pressure was } \\
\text { used as the outlet condition, input } \\
\text { "1", if not, input "0" }\end{array}$ \\
\hline 21 & iOutlet Static Pressure & INTEGER & $\begin{array}{l}\text { If the outlet static pressure was } \\
\text { used as the outlet condition, input } \\
\text { "1", if not, input "0" }\end{array}$ \\
\hline 22 & iNumber of Rotor Blades & INTEGER & $\begin{array}{l}\text { If the number of rotor bades has } \\
\text { been set by user, input "1", if not, } \\
\text { input "0" }\end{array}$ \\
\hline 23 & iAxial Clearance & INTEGER & $\begin{array}{l}\text { If the value of axial clearance has } \\
\text { been set by user, input "1", if not, } \\
\text { input "0" }\end{array}$ \\
\hline 24 & iRadial Clearance & INTEGER & $\begin{array}{l}\text { If the value of radial clearance has } \\
\text { been set by user, input "1", if not, } \\
\text { input "0" }\end{array}$ \\
\hline 25 & iBackface Clearance & INTEGER & $\begin{array}{c}\text { If the value of back face clearance } \\
\text { has been set by user, input "1", if } \\
\text { not, input " } 0 \text { " }\end{array}$ \\
\hline 26 & iTrailing Edge Thickness & INTEGER & $\begin{array}{l}\text { If the value of trailing edge } \\
\text { thickness has been set by user, } \\
\text { input "1", if not, input "0" }\end{array}$ \\
\hline
\end{tabular}




\section{A.2 User Manual of RITMLD}

RITMLD can be used for the radial inflow turbine preliminary design based on the real fluid property. User needs to input the value of mass flow rate, rotational speed, inlet total temperature, inlet total pressure at least. After that, user needs to input the parameter for the outlet condition. The information of the outlet condition can be combined by output power and outlet static pressure. However, if the user only has one parameter for outlet condition such as outlet total pressure (i.e. pressure ratio) or outlet total temperature (i.e. output power), the user may specify one of it and estimate another parameter based on an assumed efficiency. For example, the output power is specified and the outlet total pressure is estimated from an assumed efficiency. The estimated parameters of efficiency and outlet pressure ratio will be updated in RITMLD until reaching convergence. For the velocity ratio, user can input zero and RITMD can estimate it based on the Aungier's correlation or select a value to input (always between 0.6-0.7) to pursue the optimum efficiency of turbine. Since the velocity ratio relates with the result of incidence, the choice of velocity ratio have to make sure that the incidence

lies within the optimum range of $-20^{0} \sim-40^{0}$. For the parameters of stage loading, flow coefficient, axial clearance, radial clearance, back face clearance, trailing edge thickness and number of rotor blades, user can input reasonable values for these parameters or input zero and therefore RITMLD will calculate it. 


\section{A.3 Example of Input Files for RITMLD}

\section{Example 1}

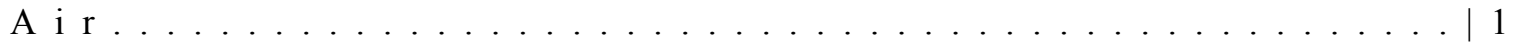

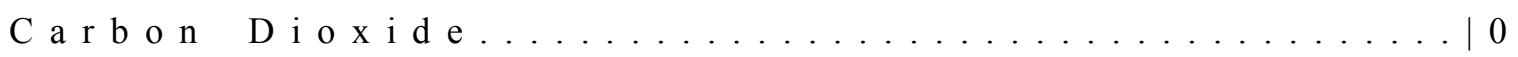

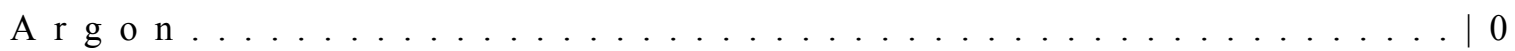

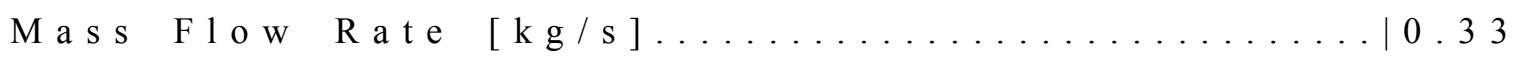

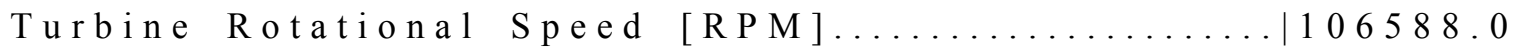

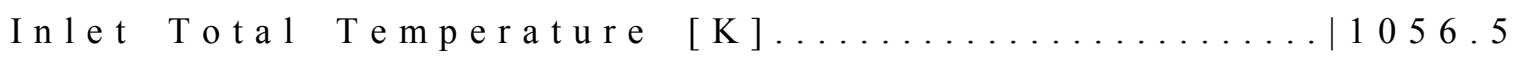

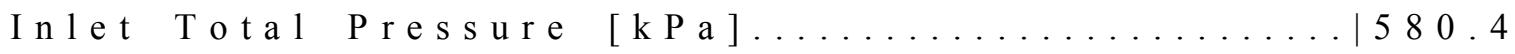

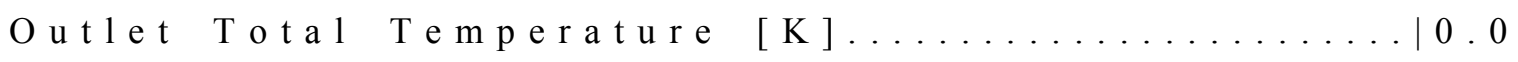

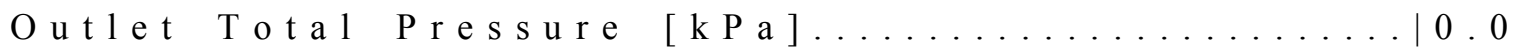

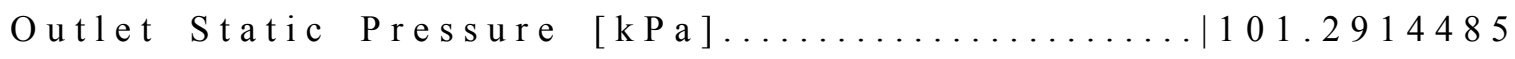

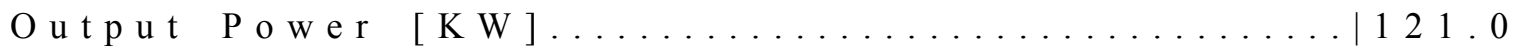

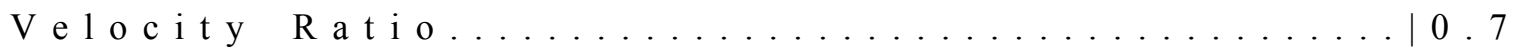

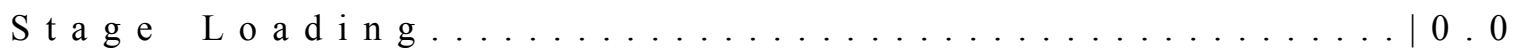

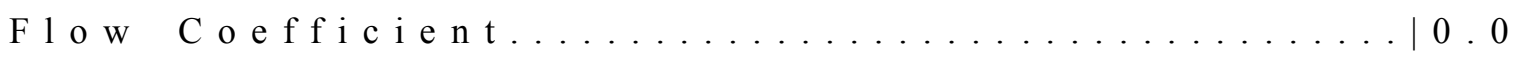

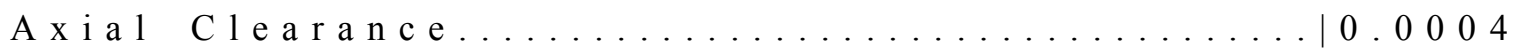

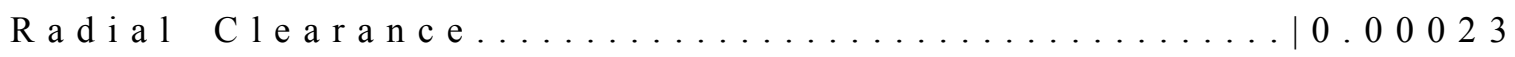

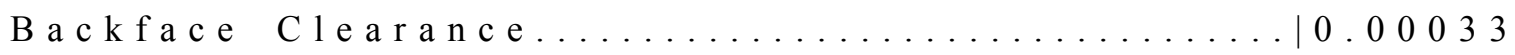

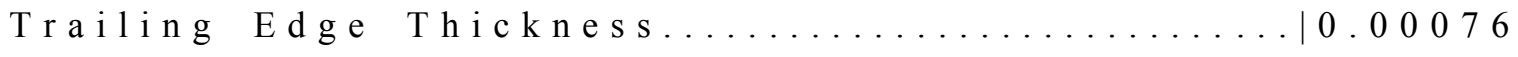

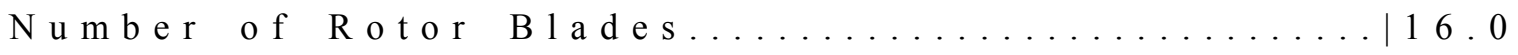

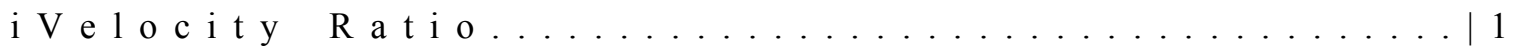

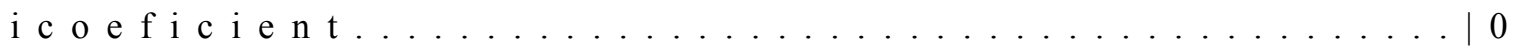

i Outlet Total Pressure $[\mathrm{kPa}] \ldots \ldots \ldots \ldots \ldots \ldots \ldots \ldots \ldots$

i O utlet $\mathrm{Static} P \mathrm{Pessure}[\mathrm{kPa}] \ldots \ldots \ldots \ldots \ldots \ldots \ldots \ldots$

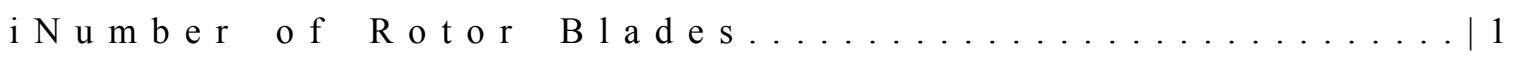

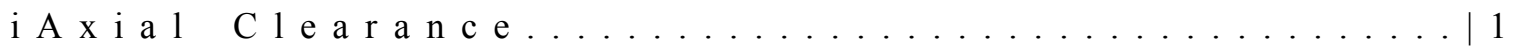

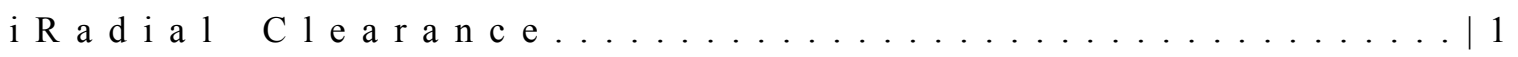

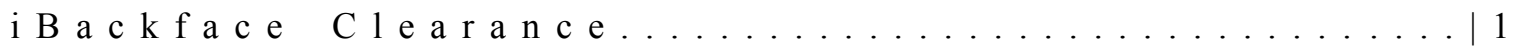

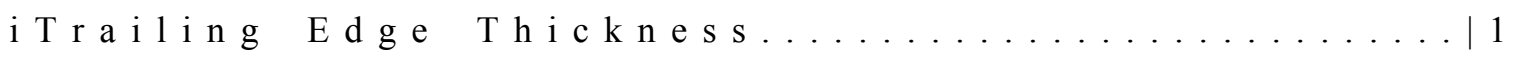




\section{Example 2}

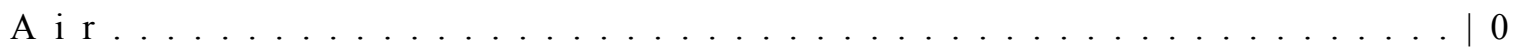

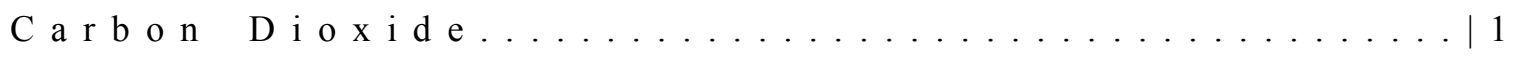

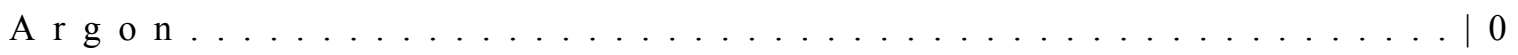

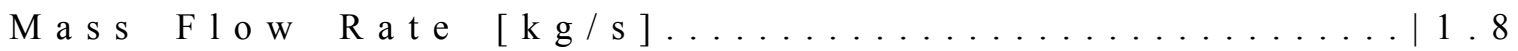

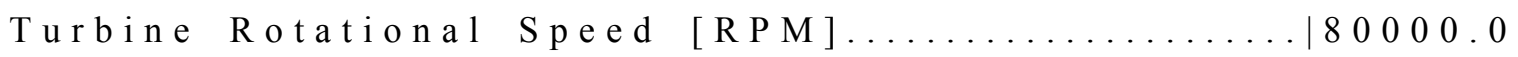

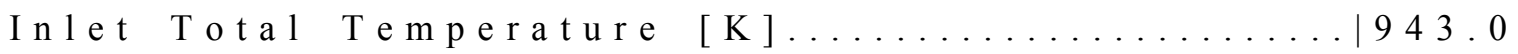

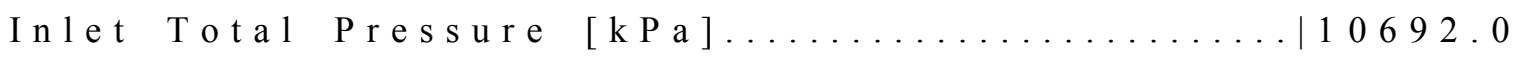

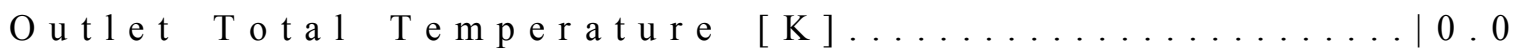

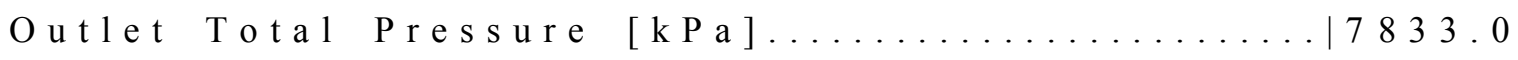

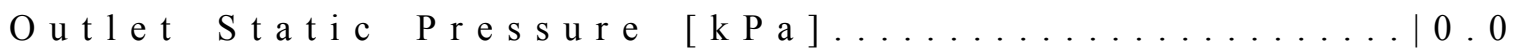

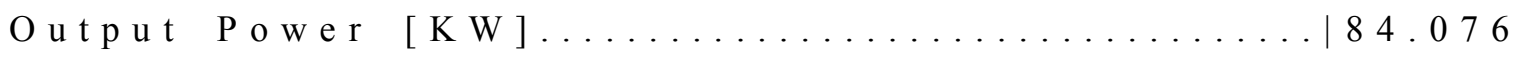

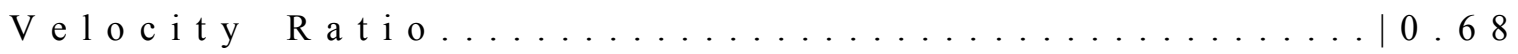

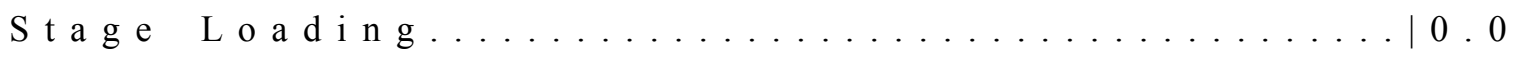

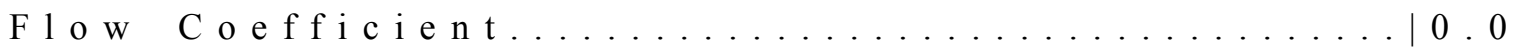

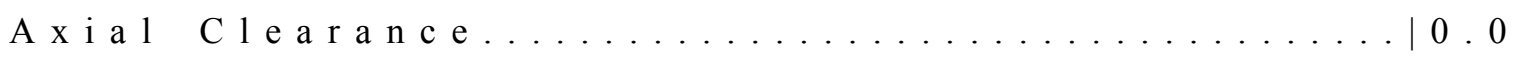

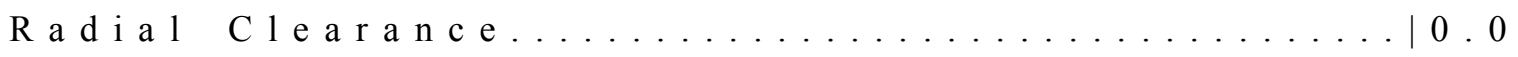

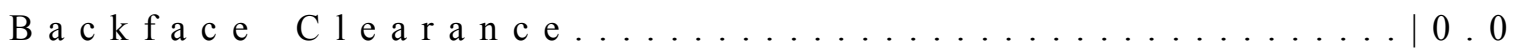

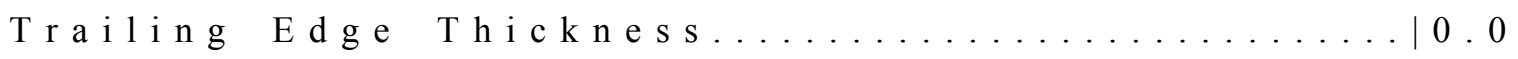

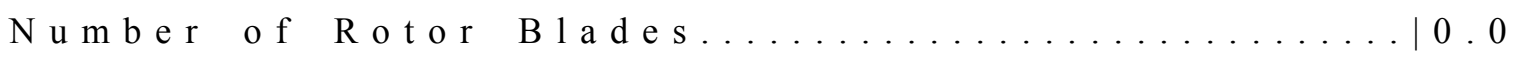

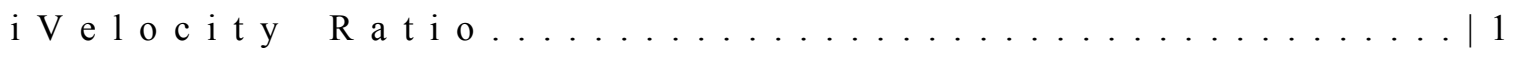

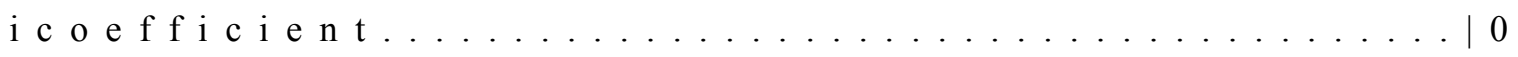

$\mathrm{iOutlet}$ Total Pressure $[\mathrm{kPa}] \ldots \ldots \ldots \ldots \ldots \ldots \ldots \ldots \ldots \ldots$

$\mathrm{iOutlet} \mathrm{Stat}$ i $\mathrm{Pressure}[\mathrm{kPa}] \ldots \ldots \ldots \ldots \ldots \ldots \ldots \ldots$

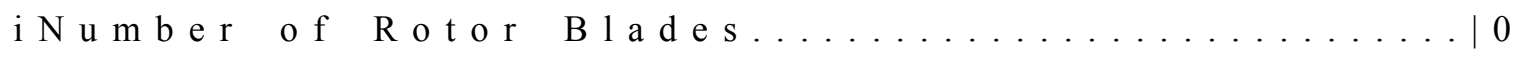

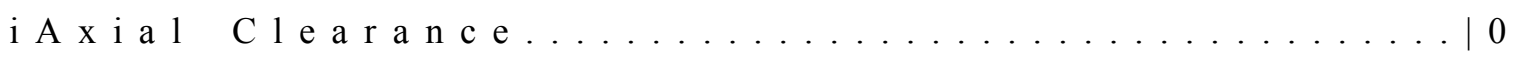

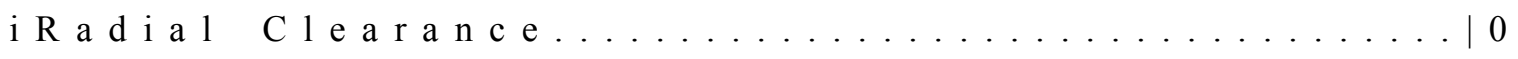

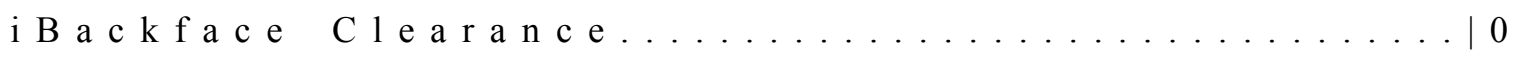

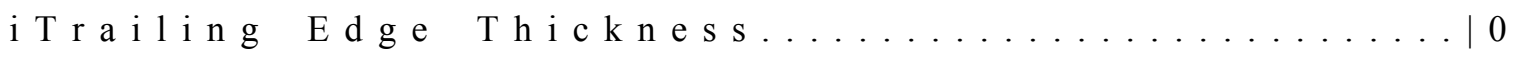




\section{Example 3}

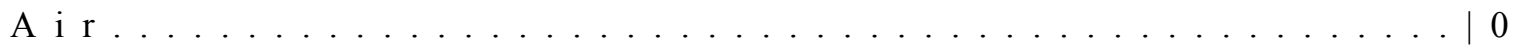

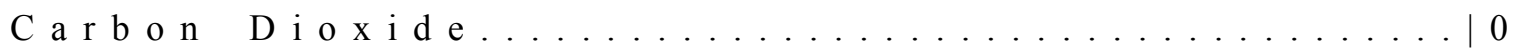

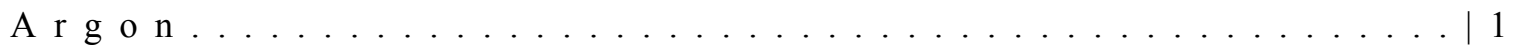

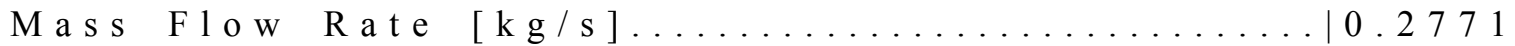

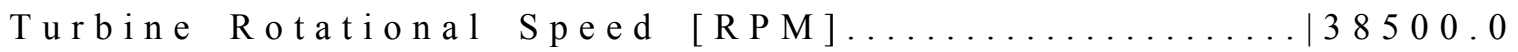

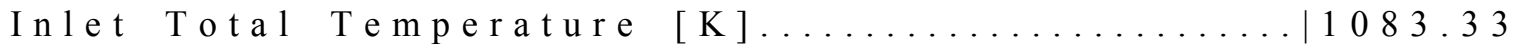

Inlet Total Pressure $[\mathrm{kPa}] \ldots \ldots \ldots \ldots \ldots \ldots \ldots \ldots \ldots \ldots \ldots \ldots \ldots 1 . \ldots \ldots 1$

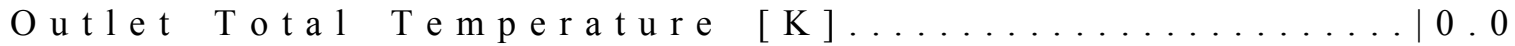

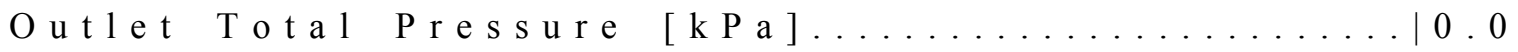

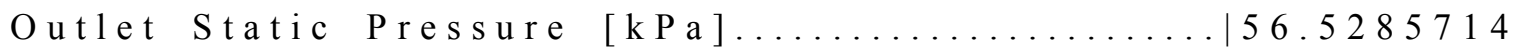

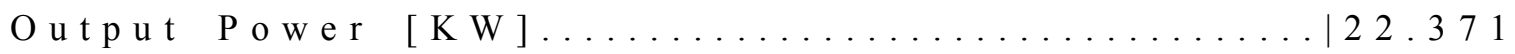

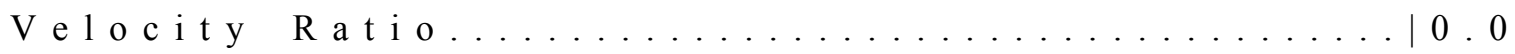

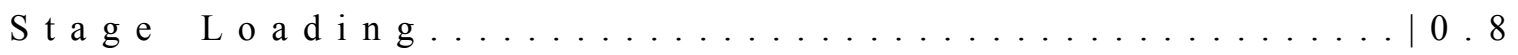

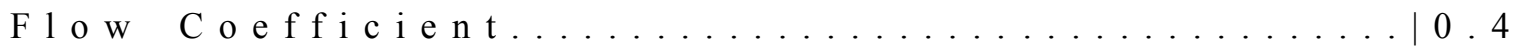

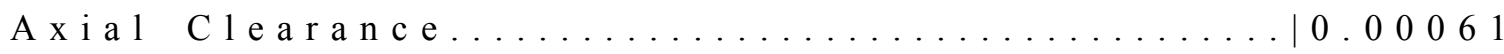

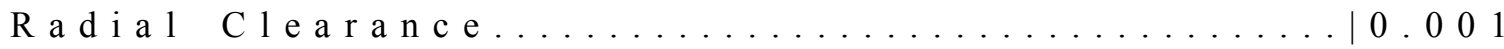

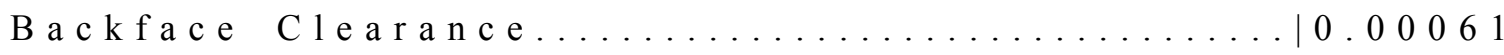

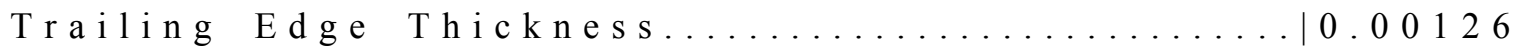

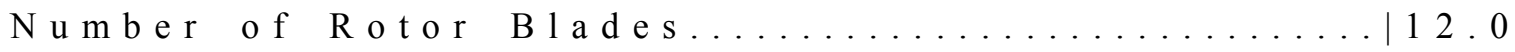

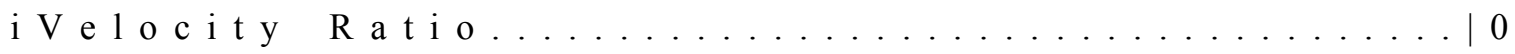

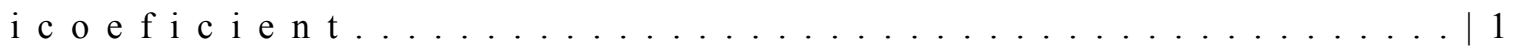

i O u t l e t Tota 1 Press ure $[\mathrm{kPa}] \ldots \ldots \ldots \ldots \ldots \ldots \ldots \ldots$

i O ut let $\mathrm{Static} P \mathrm{Pessure}[\mathrm{kPa}] \ldots \ldots \ldots \ldots \ldots \ldots \ldots \ldots$

i $\mathrm{Number}$ of $\mathrm{Rot}$ or $\mathrm{Bl}$ a d e $\mathrm{m} \ldots \ldots \ldots \ldots \ldots \ldots \ldots \ldots \ldots \ldots$

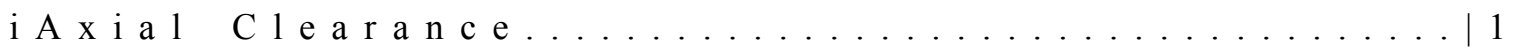

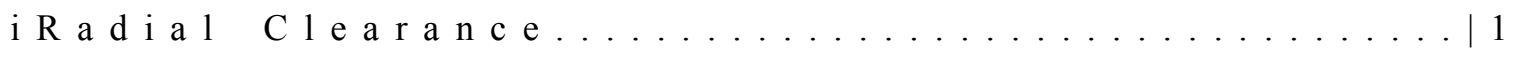

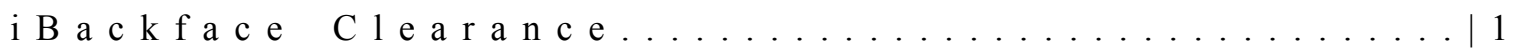

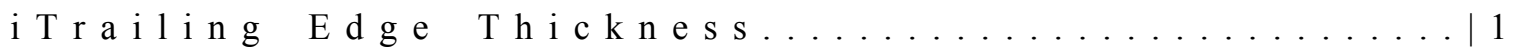

Note 1: For the "i" items, if user has inputted the value to the corresponding parameters, " 1 " is necessary to be inputted for the corresponding " $i$ " items.

Note 2: Except for the choice of working fluid and "i" items, the value of other parameters are real number, please do not forget add ".0" to the corresponding parameters even for the integral number. 


\section{Appendix B}

\section{B.1 RITMLO Input File Format}

\begin{tabular}{|c|c|c|c|}
\hline $\begin{array}{c}\text { Line } \\
\text { Number }\end{array}$ & Input Data & Type & Comments \\
\hline 1 & PR & $\begin{array}{l}\text { FLOATING } \\
\text { POINT }\end{array}$ & $\begin{array}{c}\text { Total-to-Static pressure ratio of } \\
\text { turbine stage }\end{array}$ \\
\hline 2 & $\mathrm{~N}(\mathrm{RPM})$ & $\begin{array}{c}\text { FLOATING } \\
\text { POINT }\end{array}$ & Rotational Speed of turbine stage \\
\hline 3 & $\mathrm{~T}_{01}(\mathrm{~K})$ & $\begin{array}{c}\text { FLOATING } \\
\text { POINT }\end{array}$ & $\begin{array}{c}\text { Total Temperature at the inlet } \\
\text { condition of turbine stage }\end{array}$ \\
\hline 4 & $\mathrm{P}_{5}(\mathrm{KPa})$ & $\begin{array}{l}\text { FLOATING } \\
\text { POINT }\end{array}$ & $\begin{array}{l}\text { Static Pressure at the outlet } \\
\text { condition of turbine stage }\end{array}$ \\
\hline 5 & $\mathrm{r}_{1}(\mathrm{~m})$ & $\begin{array}{c}\text { FLOATING } \\
\text { POINT }\end{array}$ & Inlet radius of volute \\
\hline 6 & $\mathrm{~A}(\mathrm{~m})$ & $\begin{array}{c}\text { FLOATING } \\
\text { POINT }\end{array}$ & Ellipse axial semiaxis \\
\hline 7 & $A_{1}\left(m^{2}\right)$ & $\begin{array}{c}\text { FLOATING } \\
\text { POINT }\end{array}$ & Volute area \\
\hline 8 & $\mathrm{r}_{2}(\mathrm{~m})$ & $\begin{array}{c}\text { FLOATING } \\
\text { POINT }\end{array}$ & Inlet radius of nozzle \\
\hline 9 & $\mathrm{~b}_{2}(\mathrm{~m})$ & $\begin{array}{c}\text { FLOATING } \\
\text { POINT }\end{array}$ & Inlet passage width of nozzle \\
\hline 10 & $\mathrm{r}_{3}(\mathrm{~m})$ & $\begin{array}{l}\text { FLOATING } \\
\text { POINT }\end{array}$ & Outlet radius of nozzle \\
\hline 11 & $\mathrm{~b}_{3}(\mathrm{~m})$ & $\begin{array}{l}\text { FLOATING } \\
\text { POINT }\end{array}$ & Outlet passage width of nozzle \\
\hline 12 & $\mathrm{r}_{4}(\mathrm{~m})$ & $\begin{array}{l}\text { FLOATING } \\
\text { POINT }\end{array}$ & Inlet radius of rotor \\
\hline 13 & $\mathrm{~b}_{4}(\mathrm{~m})$ & $\begin{array}{c}\text { FLOATING } \\
\text { POINT }\end{array}$ & Inlet passage width of rotor \\
\hline 14 & $t_{\text {leading }}(\mathrm{m})$ & $\begin{array}{l}\text { FLOATING } \\
\text { POINT }\end{array}$ & $\begin{array}{l}\text { Leading edge thickness of turbine } \\
\text { rotor blade }\end{array}$ \\
\hline 15 & $\mathrm{r}_{5}(\mathrm{~m})$ & $\begin{array}{l}\text { FLOATING } \\
\text { POINT }\end{array}$ & Mean radius of rotor outlet \\
\hline 16 & $\mathrm{r}_{\mathrm{h} 5}(\mathrm{~m})$ & $\begin{array}{c}\text { FLOATING } \\
\text { POINT }\end{array}$ & Hub radius of rotor outlet \\
\hline
\end{tabular}




\begin{tabular}{|c|c|c|c|}
\hline 17 & $r_{s 5}(m)$ & $\begin{array}{l}\text { FLOATING } \\
\text { POINT }\end{array}$ & Shroud radius of rotor outlet \\
\hline 18 & $\mathrm{~b}_{5}(\mathrm{~m})$ & $\begin{array}{l}\text { FLOATING } \\
\text { POINT }\end{array}$ & Outlet passage width of rotor \\
\hline 19 & $t_{\text {trailing }}(\mathrm{m})$ & $\begin{array}{l}\text { FLOATING } \\
\text { POINT }\end{array}$ & $\begin{array}{l}\text { Trailing edge thickness of turbine } \\
\text { rotor blade }\end{array}$ \\
\hline 20 & $\mathrm{~A}_{5}\left(\mathrm{~m}^{2}\right)$ & $\begin{array}{l}\text { FLOATING } \\
\text { POINT }\end{array}$ & Rotor outlet area \\
\hline 21 & $\beta_{4 \_ \text {optimum }}(\mathrm{deg})$ & $\begin{array}{l}\text { FLOATING } \\
\text { POINT }\end{array}$ & Value of optimum incidence angle \\
\hline 22 & $\beta_{5}(\mathrm{deg})$ & $\begin{array}{l}\text { FLOATING } \\
\text { POINT }\end{array}$ & $\begin{array}{c}\text { Value of rotor outlet metal angle } \\
\text { (assume that equal to relative flow } \\
\text { angle) }\end{array}$ \\
\hline 23 & $\mathrm{q}_{5}(\mathrm{~m})$ & $\begin{array}{c}\text { FLOATING } \\
\text { POINT }\end{array}$ & Rotor outlet mean blade pitch \\
\hline 24 & $o_{5}(\mathrm{~m})$ & $\begin{array}{l}\text { FLOATING } \\
\text { POINT }\end{array}$ & Rotor outlet mean throat width \\
\hline 25 & $Z_{R}(\mathrm{~m})$ & $\begin{array}{l}\text { FLOATING } \\
\text { POINT }\end{array}$ & Axial length of turbine rotor \\
\hline 26 & $r_{\max }(\mathrm{m})$ & $\begin{array}{l}\text { FLOATING } \\
\text { POINT }\end{array}$ & Turbine Stage maximum radius \\
\hline 27 & $\Delta Z(\mathrm{~m})$ & $\begin{array}{c}\text { FLOATING } \\
\text { POINT } \\
\end{array}$ & $\begin{array}{c}\text { Turbine Stage maximum axial } \\
\text { length }\end{array}$ \\
\hline 28 & $N_{R}$ & $\begin{array}{l}\text { FLOATING } \\
\text { POINT }\end{array}$ & Number of rotor blades \\
\hline
\end{tabular}




\section{B.2 Example of Input Files for RITMLO}

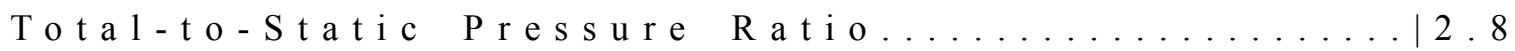

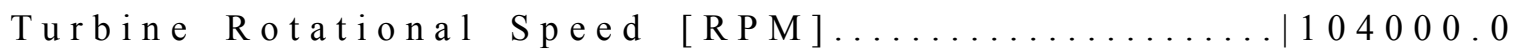

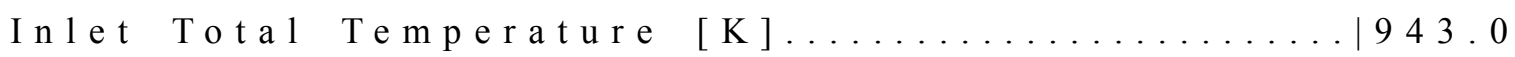

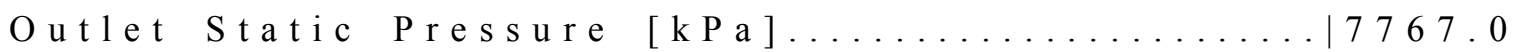

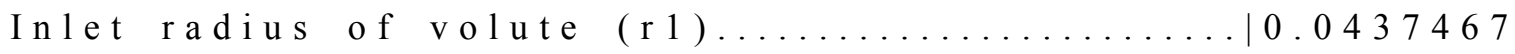

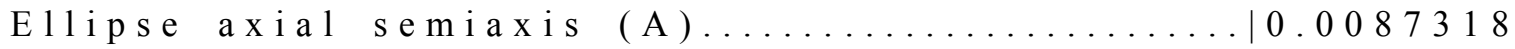

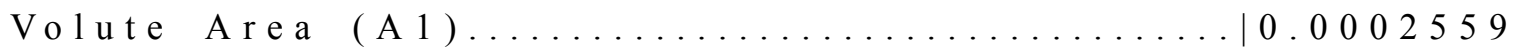

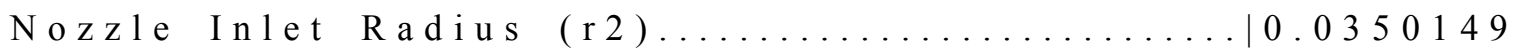

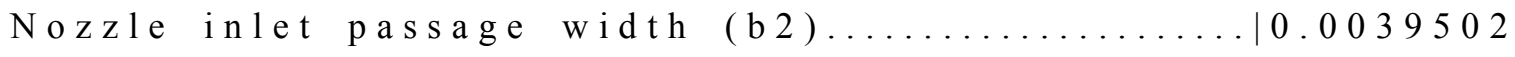

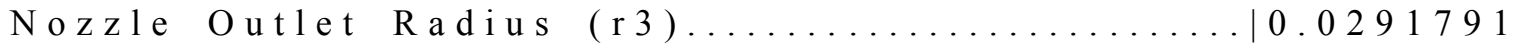

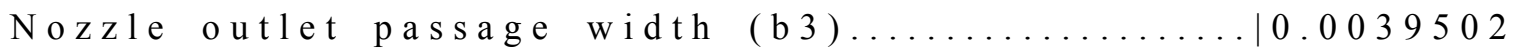

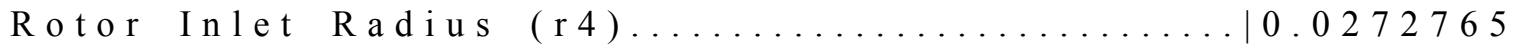

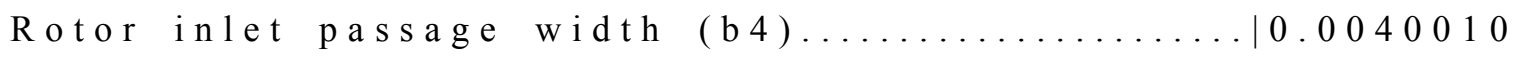

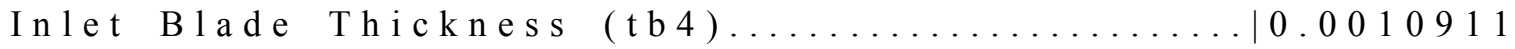

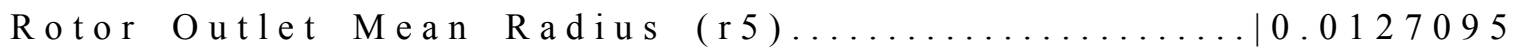

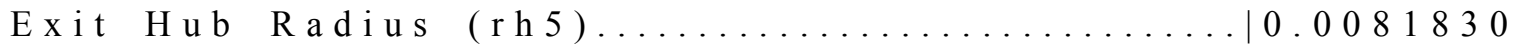

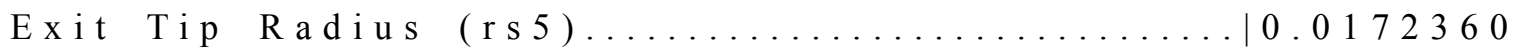

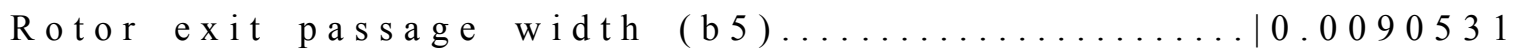

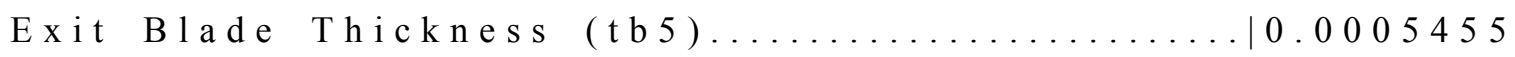

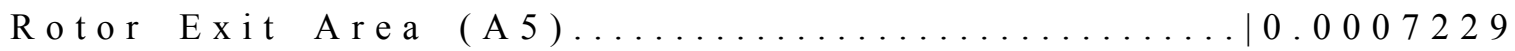

Optimum incidence Angle (beta4)Sjolander's definition|-25.7250585

Relative Flow Angle (beta5) Aungier's definition (angle between $\mathrm{W}_{5}$ and $\mathrm{W}_{\mathrm{u} 5}$ )...... -27.4955078

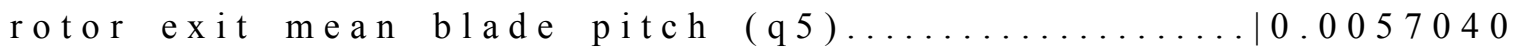

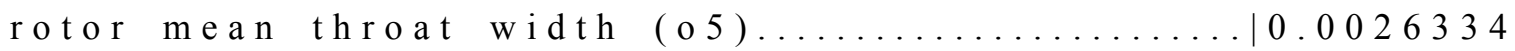

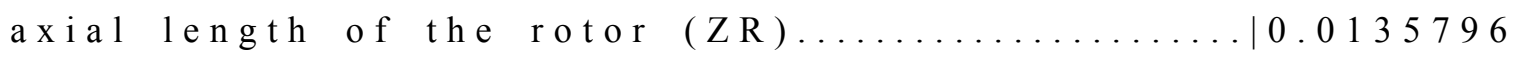

maximum radius of the stage $($ Rmax $) \ldots \ldots \ldots \ldots \ldots \ldots .0 .0524785$

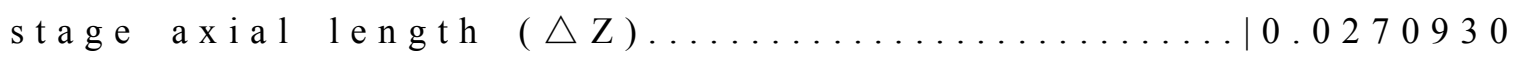

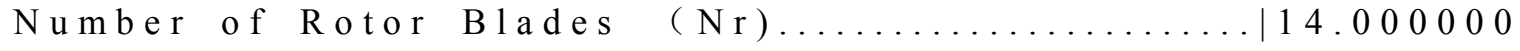




\title{
Appendix C Output File of RITMLD
}

\author{
(Based on the Example 2 of Input File)
}

Specific Data For Machine

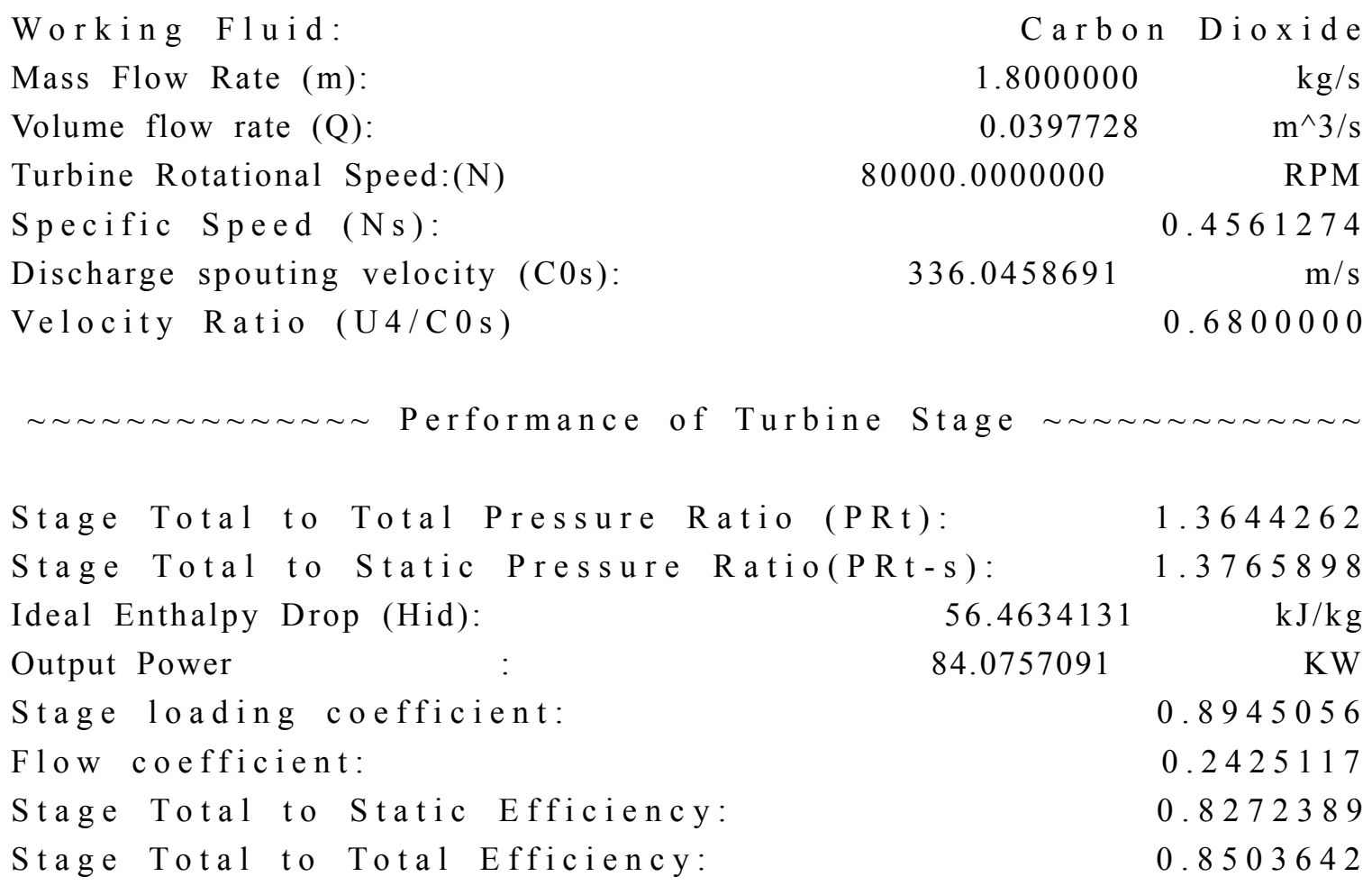

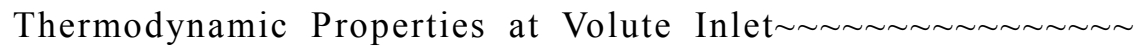

Total Temperature (T01): $\quad 943.0000000 \quad \mathrm{~K}$

Total Pressure (P01): $\quad 10692.0000000 \quad \mathrm{KPa}$

Total Enthalpy (H01): $\quad 1189.5501486 \quad \mathrm{~kJ} / \mathrm{kg}$

Total Entropy (S01): $\quad 3.0377869 \quad \mathrm{~kJ} / \mathrm{kg}-\mathrm{K}$

Total Density (rho1): $\quad 58.7621505 \quad \mathrm{~kg} / \mathrm{m}^{\wedge} 3$

Static Enthalpy (H1): $\quad 1181.8746218 \quad \mathrm{~kJ} / \mathrm{kg}$

Static Entropy (S1): $\quad 3.0377869 \quad \mathrm{~kJ} / \mathrm{kg}-\mathrm{K}$

Static Density (rh1): $\quad 56.7742139 \quad \mathrm{~kg} / \mathrm{m}^{\wedge} 3$

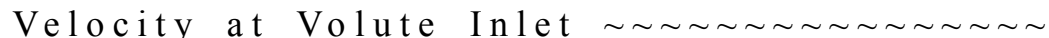

Absolute velocity at the volute inlet: $\quad 123.8993687 \quad \mathrm{~m}$ 
$\sim \sim \sim \sim \sim \sim \sim \sim \sim \sim \sim \sim \sim \sim \sim$ G e o metry of Volute

Inlet radius of volute ( 1$)$ :

$0.0437467 \mathrm{~m}$

Volute Area (A1):

0.0002559

$\mathrm{m}^{\wedge} 3$

Ellipse Axial semiaxis (A):

0.0087318

$\mathrm{m}$

Ellipse Radial semiaxis (B):

0.0087318

$\mathrm{m}$

volute aspect ratio (AR):

1.0000000

Thermodynamic Properties at Nozzle Inlet

Total Enthalpy (H02):

1189.5501486

$\mathrm{kJ} / \mathrm{kg}$

Total Entropy (S02):

3.0377869

$\mathrm{kJ} / \mathrm{kg}-\mathrm{K}$

Static Enthalpy (H2):

1176.8729598

$\mathrm{kJ} / \mathrm{kg}$

Static Entropy (S2):

3.0377869

$\mathrm{kJ} / \mathrm{kg}-\mathrm{K}$

Static Density (rh2):

55.5055990

$\mathrm{kg} / \mathrm{m}^{\wedge} 3$

Velocity Triangle at Nozzle Inlet

Nozzle Inlet Blade Speed (U2):

293.3401818

$\mathrm{m} / \mathrm{s}$

Absolute Tangential Velocity (Cu2):

154.7965019

$\mathrm{m} / \mathrm{s}$

meridional velocity $(\mathrm{Cm} 2)$ :

37.3151522

$\mathrm{m} / \mathrm{s}$

Absolute Velocity (C2):

159.2305800

$\mathrm{m} / \mathrm{s}$

Nozzle Inlet Flow Angle (Alpha2):

76.4468875

deg

Relative Tangential Velocity (Wu2):

$-138.5436799$

$\mathrm{m} / \mathrm{s}$

Relative Absolute Velocity (W2):

143.4809110

$\mathrm{m} / \mathrm{s}$

Relative Flow Angle (beta2):

$-74.9257550$

$\operatorname{deg}$

Thermodynamic Properties at Nozzle Outlet

Total Enthalpy (H03):

Total Entropy (S03):

Total Pressure (P03):

Static Enthalpy (H3):

Static Entropy (S3):

Static Density (rh3):

$\begin{array}{rr}1189.5501486 & \mathrm{~kJ} / \mathrm{kg} \\ 3.0403900 & \mathrm{~kJ} / \mathrm{kg}-\mathrm{K} \\ 10548.6984212 & \mathrm{kPa} \\ 1170.2012078 & \mathrm{~kJ} / \mathrm{kg} \\ 3.0403900 & \mathrm{~kJ} / \mathrm{kg}-\mathrm{K} \\ 53.1400319 & \mathrm{~kg} / \mathrm{m}^{\wedge} 3\end{array}$

Outlet

244.4501418

$\mathrm{m} / \mathrm{s}$

191.0767036

$\mathrm{m} / \mathrm{s}$

46.7715178

$\mathrm{m} / \mathrm{s}$ 
Absolute Velocity (C3):

Nozzle Outlet Flow Angle (Alpha3):

Relative Tangential Velocity (Wu3):

Relative Absolute Velocity (W3):

Relative Flow Angle (beta3):
196.7177712

$\mathrm{m} / \mathrm{s}$

76.2456588

$-53.3734382$

70.9668852

$-48.7716902$ deg

$\mathrm{m} / \mathrm{s}$

$\mathrm{m} / \mathrm{s}$

$\operatorname{deg}$

$\sim \sim \sim \sim \sim \sim \sim \sim$ Mach Number at Nozzle Inlet and Outlet

Absolute Mach number at nozzle inlet(aM2):

0.3363922

Relative Mach number at nozzle inlet(rM2):

0.3031192

Absolute Mach number at nozzle outlet(aM3):

0.4157812

Relative Mach number at nozzle outlet(rM3):

0.1499951

$\sim \sim \sim \sim \sim \sim \sim \sim \sim \sim \sim \sim \sim \sim \sim$ G e o metry of $\mathrm{Nozzle}$

Nozzle Inlet Radius (r2):

$0.0350149 \quad \mathrm{~m}$

Nozzle inlet passage width (b2):

0.0039502

$\mathrm{m}$

Nozzle Outlet Radius (r3):

0.0291791

$\mathrm{m}$

Nozzle outlet passage width (b3):

0.0039502

$\mathrm{m}$

ratio of nozzle throat width to blade pitch:

0.2377595

Thermodynamic Properties at Rotor Inlet

Total Enthalpy ( $\mathrm{H} 04)$ :

Total Entropy (S04):

Total Pressure (P04):

Static Enthalpy (H4):

Static Entropy (S4):

Static Density (rh4):

$\begin{array}{rr}1189.5501486 & \mathrm{~kJ} / \mathrm{kg} \\ 3.0403900 & \mathrm{~kJ} / \mathrm{kg}-\mathrm{K} \\ 10548.6984212 & \mathrm{kPa} \\ 1167.4078433 & \mathrm{~kJ} / \mathrm{kg} \\ 3.0403900 & \mathrm{~kJ} / \mathrm{kg}-\mathrm{K} \\ 52.4645749 & \mathrm{~kg} / \mathrm{m}^{\wedge} 3\end{array}$

Velocity Triangle at Rotor Inlet

Rotor Inlet Blade Speed (U4):

Absolutr Tangential Velocity ( $\mathrm{Cu} 4)$ :

meridional velocity ( $\mathrm{Cm} 4)$ :

Rotor Inlet Flow Angle (Alpha4):

Absolute Velocity (C4):

Relative Tangential Velocity (Wu4):

Relative Absolute Velocity (W4):

Relative Flow Angle (beta4):

228.5111910

204.4045505

$\mathrm{m} / \mathrm{s}$

50.0338916

$\mathrm{m} / \mathrm{s}$

76.2456588

$\mathrm{m} / \mathrm{s}$

210.4390899

deg

$-24.1066405$

$\mathrm{m} / \mathrm{s}$

55.5384590

$\mathrm{m} / \mathrm{s}$

$-25.7250585$

$\mathrm{m} / \mathrm{s}$

deg

1.1075818 
Total Enthalpy (H05):

$\begin{array}{cr}1142.8414213 & \mathrm{~kJ} / \mathrm{kg} \\ 903.8020931 & \mathrm{~K} \\ 7836.2613464 & \mathrm{kPa} \\ 3.0469292 & \mathrm{~kJ} / \mathrm{kg}-\mathrm{K} \\ 45.2571050 & \mathrm{~kg} / \mathrm{m}^{\wedge} 3\end{array}$

Total Temperature (T05):

45.2571050

$\mathrm{kg} / \mathrm{m}^{\wedge} 3$

Static Enthalpy (H5):

$\begin{array}{rr}1141.3059199 & \mathrm{~kJ} / \mathrm{kg} \\ 902.5124022 & \mathrm{~K} \\ 7767.0197689 & \mathrm{kPa} \\ 3.0469292 & \mathrm{~kJ} / \mathrm{kg}-\mathrm{K} \\ 44.9292480 & \mathrm{~kg} / \mathrm{m}^{\wedge} 3\end{array}$

Static Temperature (T5):

Static Pressure (P5):

Static Entropy (S5):

44.9292480

$\mathrm{kg} / \mathrm{m}^{\wedge} 3$

Static Density (rh5):

Velocity Triangle at Rotor Outlet

Rotor Outlet Blade Speed (U5):

Absolute Tangential Velocity (Cu5):

meridional velocity (Cm5):

Absolute Velocity (C5):

Rotor Outlet Flow Angle (Alpha5):

Relative Tangential Velocity (Wu5):

Relative Absolute Velocity (W5):

Relative Flow Angle (beta5):

Rotor Deviation Angle (beta_deviation):

Rotor Outlet Blade Angle (beta5_blade):

$\begin{array}{rl}106.4747326 & \mathrm{~m} / \mathrm{s} \\ 0.0000000 & \mathrm{~m} / \mathrm{s} \\ 55.4166294 & \mathrm{~m} / \mathrm{s} \\ 55.4166294 & \mathrm{~m} / \mathrm{s} \\ 0.0000000 & \mathrm{deg} \\ 106.4747326 & \mathrm{~m} / \mathrm{s} \\ 120.0327934 & \mathrm{~m} / \mathrm{s} \\ -62.5044922 & \mathrm{deg} \\ -5.6999998 & \mathrm{deg} \\ -68.2044920 & \mathrm{deg}\end{array}$

Velocity Triangle at Rotor Shoulder Outlet

Rotor Outlet Shoulder Blade Speed (U5s):

144.4162345

$\mathrm{m} / \mathrm{s}$

Absolute Shoulder Tangential Velocity(Cu5s):

0.0000000

$\mathrm{m} / \mathrm{s}$

meridional Shoulder velocity (Cm5s):

55.4196868

$\mathrm{m} / \mathrm{s}$

Absolute Shoulder Velocity (C5s):

55.4196868

$\mathrm{m} / \mathrm{s}$

Rotor Outlet Shoulder Flow Angle (Alpha5s):

0.0000000

deg

144.4162345

$\mathrm{m} / \mathrm{s}$

Relative Shoulder Absolute Velocity (W5s):

154.6848101

$\mathrm{m} / \mathrm{s}$

Relative Shoulder Flow Angle (beta5s):

$-69.0057104$

deg 
Rotor Outlet Hub Blade Speed (U5h):

$68.5540844 \mathrm{~m} / \mathrm{s}$

Absolute Hub Tangential Velocity(Cu5h):

0.0000000

$\mathrm{m} / \mathrm{s}$

meridional Hub velocity $(\mathrm{Cm} 5 \mathrm{~h})$ :

$55.4196868 \mathrm{~m} / \mathrm{s}$

Absolute Hub Velocity (C5h):

$55.4196868 \mathrm{~m} / \mathrm{s}$

Rotor Outlet Hub Flow Angle (Alpha5h):

$0.0000000 \quad \mathrm{deg}$

Relative Hub Tangential Velocity(Wu5h):

$68.5540844 \mathrm{~m} / \mathrm{s}$

Relative Hub Absolute Velocity (W5h):

$88.1532993 \mathrm{~m} / \mathrm{s}$

Relative Hub Flow Angle (beta5h):

$-51.0476412$

deg

Mach Number at Nozzle Inlet and Outlet

Absolute Mach number at rotor inlet(aM4):

0.4447825

Relative Mach number at rotor inlet(rM4):

0.1173857

Absolute Mach number at rotor outlet(aM5):

0.1205348

Relative Mach number at rotor outlet(rM5):

0.2610791

$\sim \sim \sim \sim \sim \sim \sim \sim \sim \sim \sim \sim \sim \sim \sim$ G e o metry of Rotor

Rotor Inlet Radius (r4):

$0.0272765 \quad \mathrm{~m}$

Rotor inlet passage width (b4):

0.0040010

$\mathrm{m}$

Exit Hub Radius (rh5):

0.0081830

$\mathrm{m}$

Exit Tip Radius (rs5):

0.0172360

$\mathrm{m}$

Rotor Outlet Mean Radius (r5):

0.0127095

$\mathrm{m}$

Rotor exit passage width (b5):

0.0090531

$\mathrm{m}$

Rotor Exit Area (A5):

0.0007229

$\mathrm{m}^{\wedge} 3$

Inlet Blade Thickness (tb4):

0.0010911

$\mathrm{m}$

Exit Blade Thickness (tb5):

0.0005455

$\mathrm{m}$

rotor exit mean blade pitch (q5):

$0.0057040 \mathrm{~m}$

rotor mean throat width (o5):

$0.0026334 \mathrm{~m}$

axial length of the rotor $(\mathrm{Zr})$ :

0.0135796

$\mathrm{m}$

Axial Clearance:

$0.0003000 \mathrm{~m}$

Radial Clearance:

$0.0004527 \mathrm{~m}$

Back Face Clearance:

0.0003000

$\mathrm{m}$

Number of Rotor Blades:

14.0000000 


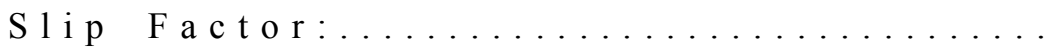

0.8503607

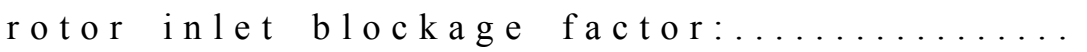

0.9010678

$\mathrm{Zr} / \mathrm{b} 4(\mathrm{recommended}>1.5): \ldots \ldots \ldots \ldots \ldots \ldots$

3.3940119

$\mathrm{Cm} 5 / \mathrm{U} 4(\mathrm{recommended} 0.2-0.4): \ldots \ldots \ldots \ldots \ldots$

0.2425117

$\mathrm{rs} 5 / \mathrm{r} 4(\mathrm{recommended}<=0.78): \ldots \ldots \ldots \ldots \ldots \ldots$

0.6318995

$\mathrm{Cm} 5 / \mathrm{Cm} 4(\mathrm{recommended} 1-1.5): \ldots \ldots \ldots \ldots \ldots \ldots$

1. 1075818

Stage Reaction R(recommended 0.45-0.65):....

0.5588233

$\sim \sim \sim \sim \sim \sim \sim \sim \sim \sim \sim \sim \sim \sim \sim \mathrm{St}$ a g e $\mathrm{G}$ e o m e t r y

maximum radius of the stage $(R \max )$ :

0.0524785

$\mathrm{m}$

stage axial length

$(\Delta \mathrm{Z})$ :

0.0270930

$\mathrm{m}$

Radius of curvature

(Rc_curvature):

0.0135796

$\mathrm{m}$

\section{Rotor Enthalpy Losses}

Incidence Losses:

Trailing edge Losses:

$\begin{array}{rr}0.9034374 & \mathrm{~kJ} / \mathrm{kg} \\ 0.0019114 & \mathrm{~kJ} / \mathrm{kg} \\ 2.9567838 & \mathrm{~kJ} / \mathrm{kg} \\ 1.5355014 & \mathrm{~kJ} / \mathrm{kg} \\ 2.6378358 & \mathrm{~kJ} / \mathrm{kg} \\ 0.0253117 & \mathrm{~kJ} / \mathrm{kg} \\ 8.0607815 & \mathrm{~kJ} / \mathrm{kg}\end{array}$

Passage Losses:

Exit Energy Losses:

Tip Clearance Losses:

8.0607815

$\mathrm{kJ} / \mathrm{kg}$

Enthalpy losses generated by rotor:

Nozzle Enthalpy Losses

Enthalpy losses generated by Nozzle:

1.6939024

$\mathrm{kJ} / \mathrm{kg}$

Total Enthalpy Losses: 


\section{Appendix D}

\section{D.1 Rotor Design Procedures in RITMLD}

Discharge spouting velocity:

$C_{0 s}=\sqrt{2 \Delta H_{i d}}$

D. 1

Rotor inlet tip blade speed:

$$
U_{4}=v_{s} C_{0 s}
$$

D.2

Tangential component of absolute velocity at rotor inlet: $\quad C_{u 4}=\frac{U_{4} \eta_{t-s}}{2 v_{s}{ }^{2}} \quad$ D.3

Inlet absolute flow angle (Aungier, 2005): $\quad \alpha_{4}=90^{\circ}-\left(10.8^{\circ}+14.2 n_{s}{ }^{2}\right) \quad$ D.4

Meridional component of absolute velocity at rotor inlet: $\quad C_{m 4}=\frac{C_{u 4}}{\tan \alpha_{4}} \quad$ D.5

Absolute velocity at rotor inlet: $\quad C_{4}=\sqrt{\left(C_{u 4}\right)^{2}+\left(C_{m 4}\right)^{2}} \quad$ D.6

Tangential component of relative velocity at rotor inlet: $\quad W_{u 4}=C_{u 4}-U_{4} \quad$ D.7

Relative velocity at rotor inlet:

$$
W_{4}=\sqrt{\left(W_{u 4}\right)^{2}+\left(W_{m 4}\right)^{2}}
$$

D.8

Meridional component of relative velocity at rotor inlet:

$$
W_{m 4}=C_{m 4}
$$

D.9 
Relative flow angle at rotor inlet: $\quad \beta_{4}=\arctan \left(\frac{W_{u 4}}{W_{m 4}}\right)$

The direction of $\beta_{4}$ in Equation D.10 is determined by the direction of $W_{u 4}$ in Equation D.7. Generally, in order to achieve the optimum incidence, the direction of $\beta_{4}$ is opposite to the rotational speed.

The velocity triangle at rotor inlet has been determined by the above equations. The geometry dimensions of rotor inlet section are obtained by the following steps.

Rotor inlet tip radius:

$$
r_{4}=\frac{U_{4}}{\omega}
$$

Static enthalpy at rotor inlet: $\quad H_{4}=H_{04}-\frac{1}{2} C_{4}^{2}$

D. 12

where $H_{04}$ is the total enthalpy at rotor inlet. Since there is no heat transfer and work from the volute inlet to the rotor inlet, the value of $H_{04}$ is equal to the total enthalpy at the stage inlet, $H_{01}$. The value of $H_{01}$ is obtained by REFPROP based on the parameters of stage inlet total temperature and pressure.

Total pressure at rotor inlet: $\quad P_{04}=P_{01}-\rho_{01} \cdot \Delta H_{i d} \cdot \frac{1-\eta_{t-s}}{4}$ D.13

where $\rho_{01}$ is the total enthalpy of working fluid at turbine stage inlet. Equation D.13 was introduced by Aungier (2005) to estimate the total pressure loss in the flow process from volute inlet to the rotor inlet. Based on the value of total pressure and total enthalpy 
at rotor inlet, REFPROP is called and then the entropy $s_{4}$ at rotor inlet is returned by REFPROP. The static density $\rho_{4}$ at rotor inlet can be returned by REFPROP based on the static enthalpy $H_{4}$ and entropy $s_{4}$.

Rotor inlet blade height: $\quad b_{4}=\frac{m}{2 \pi r_{4} \rho_{4} C_{m 4}} \quad$ D.14

Rotor leading edge thickness (Aungier, 2005): $\quad t_{\text {leading }}=0.04 \cdot r_{4} \quad$ D.15

Thus, the geometry dimensions and velocity triangle at rotor inlet have been determined. Unlike the design process for the rotor inlet section, the hub and tip radius at rotor outlet need to be determined first and then all of the necessary components for the outlet velocity triangle can be obtained.

Hub radius at rotor outlet:

$$
r_{h 5}=0.3 \cdot r_{4}
$$

D.16

The value of 0.3 in Equation D.16 is based on the recommendation of Baines (2003). The condition of blade crowding at the hub can be avoided if the Baines's recommendation is followed.

Rotor trailing edge thickness (Aungier, 2005): $\quad t_{\text {trailing }}=0.02 \cdot r_{4} \quad$ D.17

Ratio of $C_{m 5}$ to $C_{m 4}$ (Aungier, 2005): $\quad \Gamma=1+5\left(\frac{b_{4}}{r_{4}}\right)^{2} \quad$ D.18

Meridional component of absolute velocity at rotor outlet: $\quad C_{m 5}=\Gamma \cdot C_{m 4} \quad$ D.19 
The exit flow is assumed to have zero swirl at the meanline at the design operating point. Thus:

Absolute velocity at rotor inlet:

$$
C_{5}=C_{m 5}
$$

Static enthalpy at rotor outlet:

$$
H_{5}=H_{05}-\frac{1}{2} C_{5}^{2}
$$

where $H_{05}$ is the total enthalpy at rotor outlet. Its value was returned by REFPROP based on the state of outlet total temperature and total pressure. Then, the static density of working fluid at rotor outlet $\rho_{5}$ is obtained by the same method as described above for $\rho_{4}$.

Area of rotor outlet (from mass conservation equation): $\quad A_{5}=\frac{m}{\rho_{5} \cdot C_{m 5}} \quad$ D.22

Shroud radius at rotor outlet:

$$
r_{s 5}=\sqrt{\frac{A_{5}}{\pi}+\left(r_{h 5}\right)^{2}}
$$

Mean radius at rotor outlet:

$$
r_{5}=\frac{r_{h 5}+r_{s 5}}{2}
$$

Rotor outlet blade height:

$$
b_{5}=r_{s 5}-r_{h 5}
$$

D. 25

Blade speed at rotor outlet:

$$
U_{5}=r_{5} \cdot \omega
$$

D.26 
Meridional component of relative velocity at rotor outlet:

$$
W_{m 5}=C_{m 5}
$$

Tangential component of relative velocity at rotor outlet: $\quad W_{u 5}=-U_{5} \quad$ D.28

Relative velocity at rotor outlet: $\quad W_{5}=\sqrt{\left(W_{m 5}\right)^{2}+\left(W_{u 5}\right)^{2}}$

D. 29

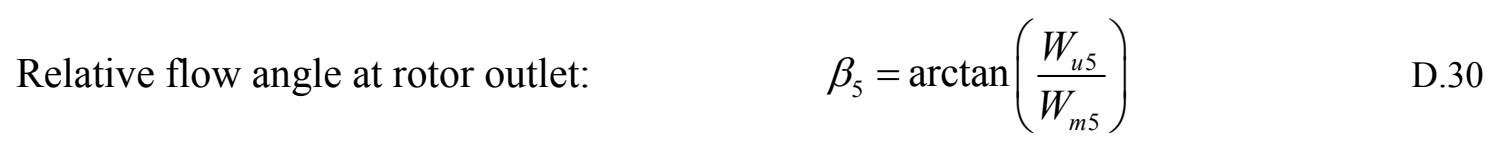

Thus the components of the velocity triangle and basic dimensions at the rotor outlet have been obtained.

Glassman (1976) introduced an empirical equation for the optimum number of radial inflow turbine rotor blades:

$$
N_{R}=\frac{\pi}{30}\left(110-\alpha_{4}\right) \tan \alpha_{4}
$$

Then the rotor outlet mean blade pitch $q_{5}$ and mean throat width $o_{t}$ can be determined from:

$$
q_{5}=\frac{2 \pi r_{5}}{N_{R}}
$$

and

$$
o_{t}=\frac{q_{5} C_{m 5}}{W_{5}} \text { (Aungier, 2005) }
$$


Also, Aungier (2005) introduced an equation to estimate the axial length of the rotor:

$$
Z_{R}=1.5\left(r_{s 5}-r_{h 5}\right)
$$

\section{D.2 Nozzle Design Procedures in RITMLD}

Tangential component of absolute velocity at nozzle outlet: $\quad C_{u 3}=C_{u 4} \frac{r_{4}}{r_{3}} \quad$ D. 35

Meridional component of absolute velocity at nozzle outlet: $\quad C_{m 3}=\frac{C_{u 3}}{\tan \alpha_{3}} \quad$ D.36

where $\alpha_{3}$ is the absolute flow angle at the nozzle outlet. The value of $\alpha_{3}$ is assumed equal to the blade angle $\beta_{3}$ and the rotor inlet absolute flow angle $\alpha_{4}$.
Absolute velocity at nozzle outlet:
$C_{3}=\sqrt{\left(C_{u 3}\right)^{2}+\left(C_{m 3}\right)^{2}}$
D. 37

Because the nozzle inlet conditions are unknown, an approximate equation suggested by Aungier (2005) is used to estimate the meridional component of absolute velocity at nozzle inlet. The inlet absolute flow angle is assumed to be equal to the inlet blade angle as well. Aungier suggested that the ratio of nozzle inlet to outlet radius lies between 1.1 and 1.7. In RITMLD, a default value is set to 1.2 and the user can adjust it through the codes based on design requirements. 
Meridional component of absolute velocity at nozzle inlet: $\quad C_{m 2} \approx C_{m 3} \frac{r_{3}}{r_{2}} \quad$ D.38

Tangential component of absolute velocity at nozzle inlet: $C_{u 2}=C_{m 2} \tan \alpha_{2} \quad$ D.39
Absolute velocity at nozzle inlet:
$C_{2}=\sqrt{\left(C_{u 2}\right)^{2}+\left(C_{m 2}\right)^{2}}$
D. 40

Although the velocity triangles at nozzle inlet and outlet are determined, the inlet velocity triangle is based on an approximate value of $C_{m 2}$. Thus, an iterative process based on the conservation of mass flow was necessary to obtain an accurate value of $C_{m 2}$.

Static enthalpy at nozzle inlet: $\quad H_{2}=H_{02}-\frac{1}{2} C_{2}^{2}$

where $H_{02}$ is the total enthalpy at the nozzle inlet.

Update meridional component of absolute velocity at nozzle inlet:

$$
C_{m 2}=\frac{m}{2 \pi r_{2} \rho_{2} b_{2}}
$$

where $\rho_{2}$ is the static density of working fluid at the nozzle inlet and it is obtained from REFPROP based on the static enthalpy $H_{2}$ and entropy $s_{2}$ which was assumed to be equal to the entropy at volute inlet $s_{1}$. The updated $C_{m 2}$ is used iteratively in Equations D.39 and D.40 until the results converge. 


\section{D.3 Volute Design Procedures in RITMLD}

The design of an external volute is an iterative process. The volute inlet velocity is calculated by conservation of angular momentum from:

$$
C_{1}=\frac{C_{u 2} \cdot r_{2}}{r_{1}}
$$

where $r_{1}$ is the radius of volute inlet and it was assumed $r_{1}=r_{2}$ initially.

Static enthalpy at volute inlet:

$$
H_{1}=H_{01}-\frac{1}{2} C_{1}^{2}
$$

Volute passage area:

$$
A_{1}=\frac{m}{C_{1} \rho_{1}}
$$

where $\rho_{1}$ is the static density of the working fluid at volute inlet, as obtained from REFPROP based on the state of static enthalpy $H_{1}$ and entropy $s_{1}$. An isentropic process was assumed when flow through the volute, then the thermodynamic parameters of working fluid at volute section is based on the turbine stage inlet total pressure $\mathrm{P}_{01}$ and total temperature $\mathrm{T}_{01}$. The volute area and the mean radius of the external volute can be expressed by Equations D.46 and D.47,

$$
\begin{gathered}
A_{1}=\left(\frac{3}{4} \pi+1\right) A B \\
r_{1}=r_{2}+B
\end{gathered}
$$


where A and B are the ellipse axial and radial semiaxis respectively. The ratio of the ellipse axial semiaxis to radial semiaxis is the volute aspect ratio ( $A R=A / B)$. Generally, the aspect ratio $\mathrm{AR}$ is equal to one for external volutes. Therefore, the value of $\mathrm{A}$ and $\mathrm{B}$ can be solved after the aspect ratio was specified and then a new estimation value of $r_{1}$ is obtained. This process will be repeated until the result of $r_{1}$ reaches convergence. Therefore, when the preliminary volute design is completed, the maximum radius and the axial length of the stage can be expressed by:

$$
\begin{array}{cr}
r_{\text {max }}=r_{1}+B & \text { D. } 48 \\
\Delta Z=Z_{R}-b_{3}+2 A & \text { D. } 49
\end{array}
$$

where $r_{\max }$ and $\Delta Z$ refer to the stage maximum radius and maximum axial length respectively. 


\section{Appendix E Results Comparison for Off-Design Rotational Speed between Meanline and CFD Analyses}

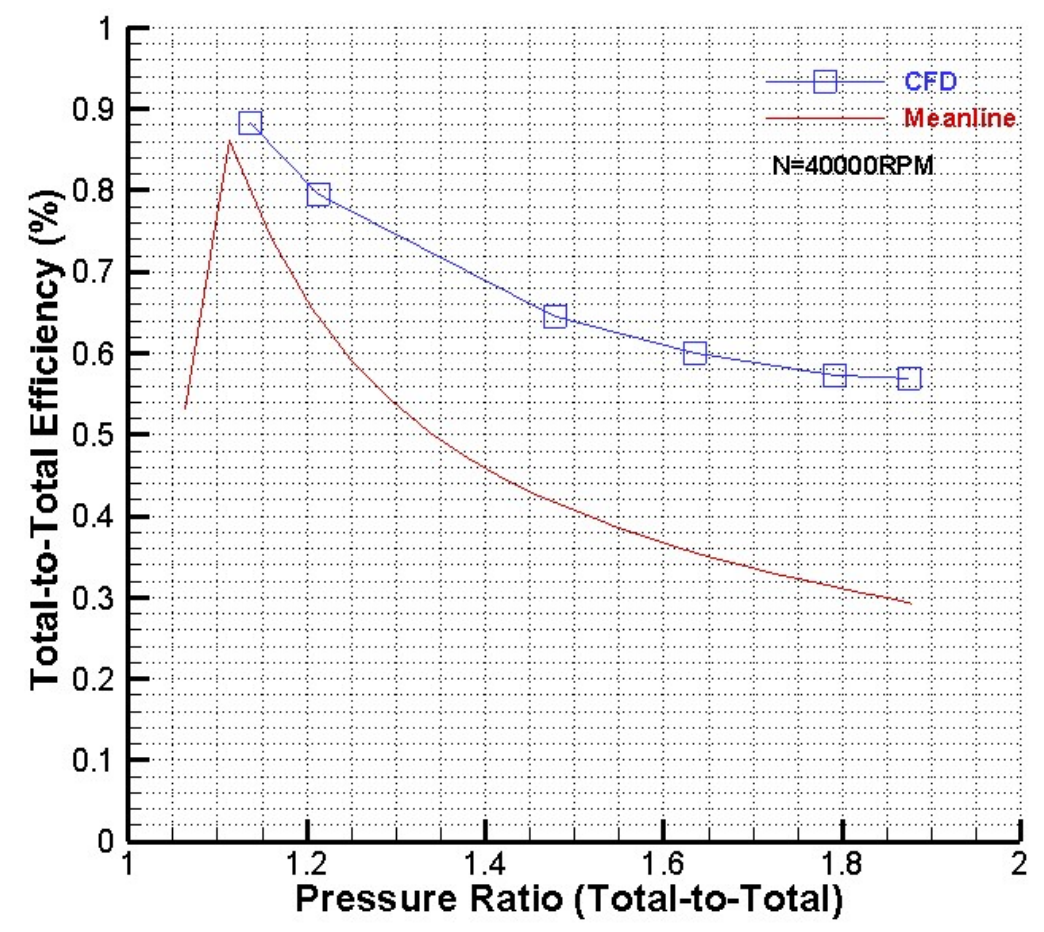

Figure E-1 Results Comparison for Total-to-Total Efficiency between Meanline and CFD Analyses (N=40000 RPM). 


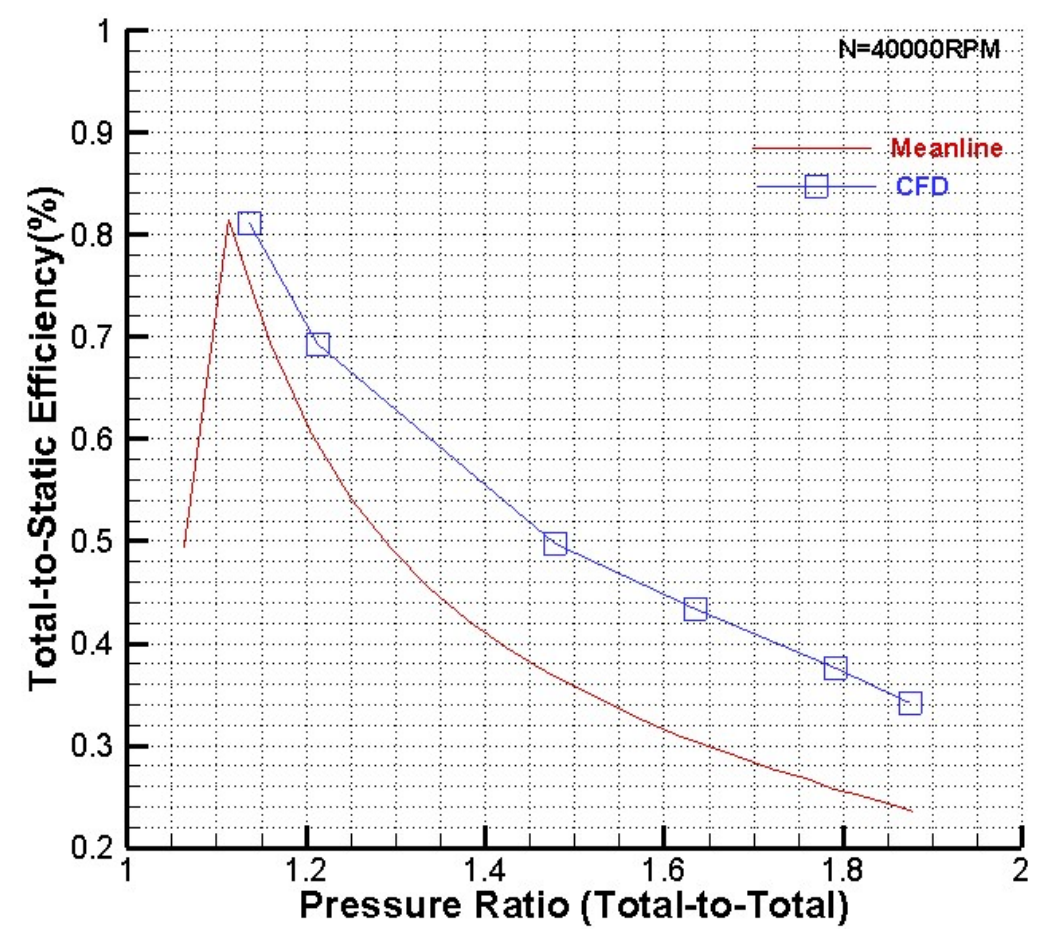

Figure E-2 Results Comparison for Total-to-Static Efficiency between Meanline and CFD Analyses (N=40000 RPM).

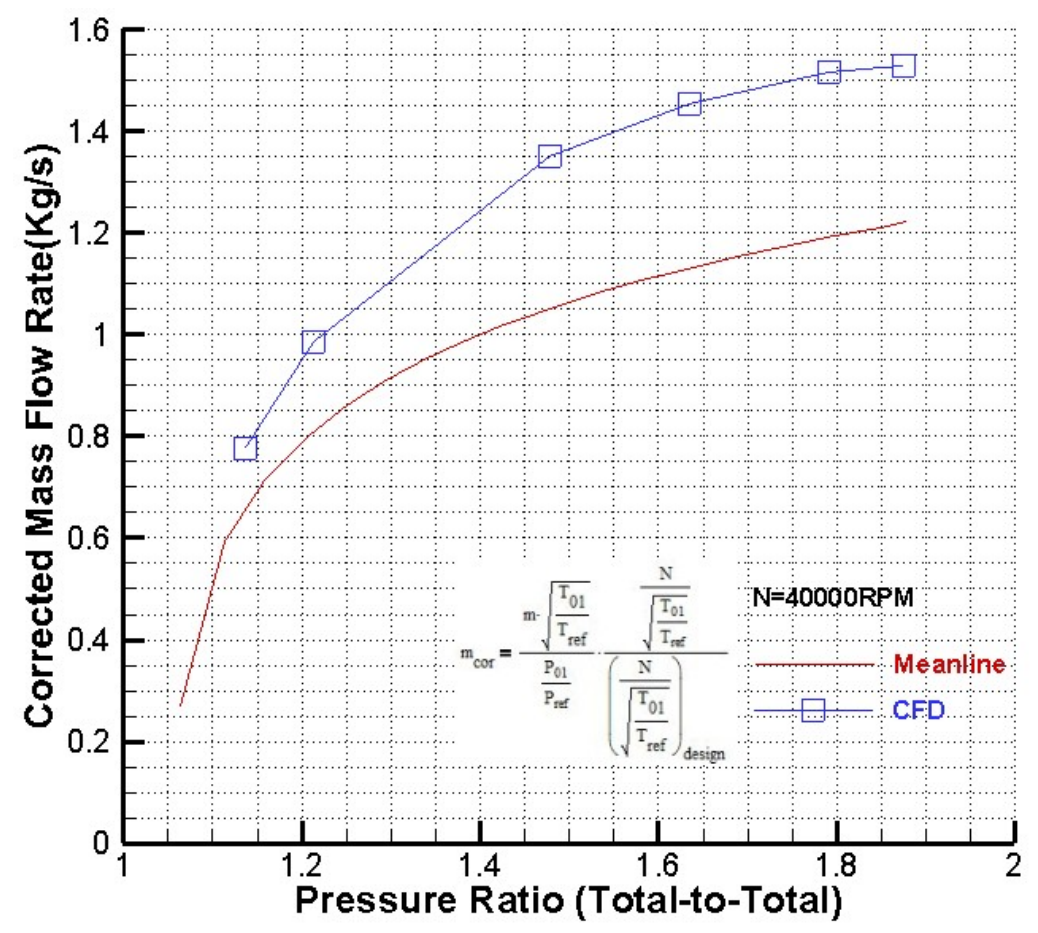

Figure E-3 Results Comparison for Mass Flow Rate between Meanline and CFD Analyses $(\mathrm{N}=40000$ RPM). 


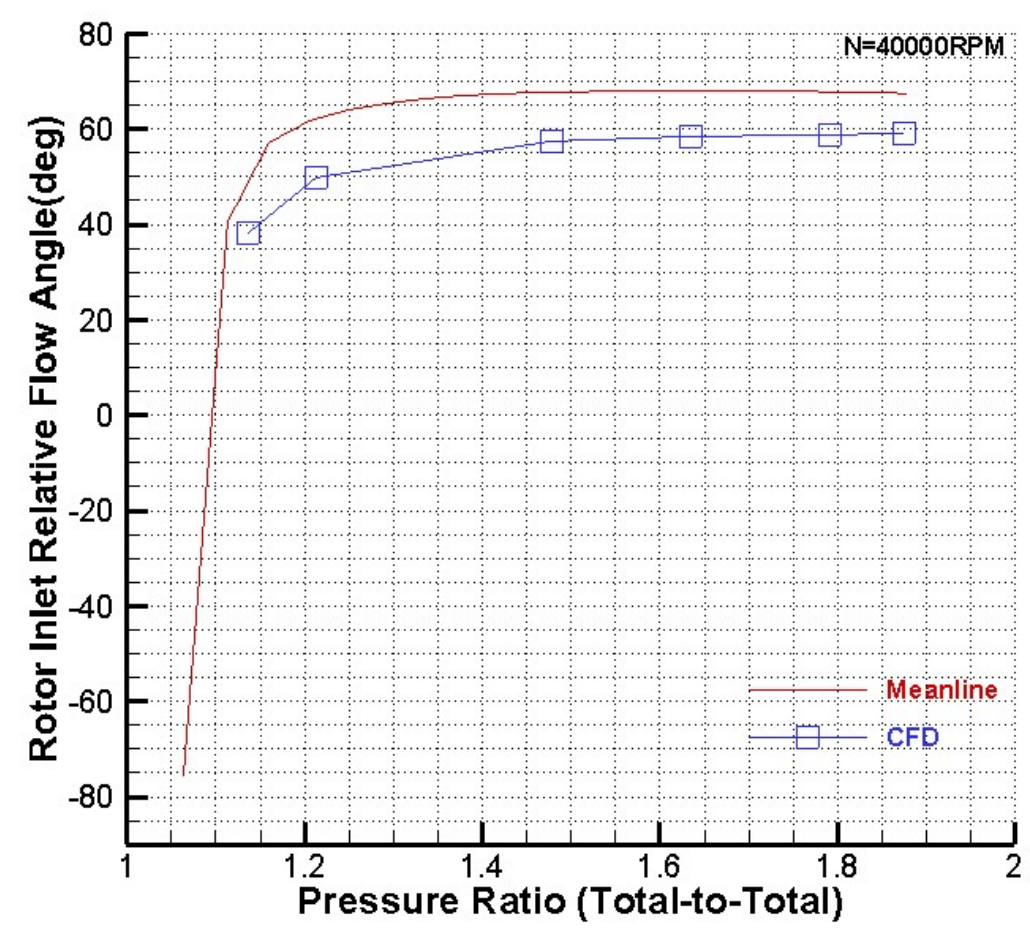

Figure E-4 Results Comparison for Rotor Inlet Relative Flow Angle between Meanline and CFD Analyses (N=40000 RPM).

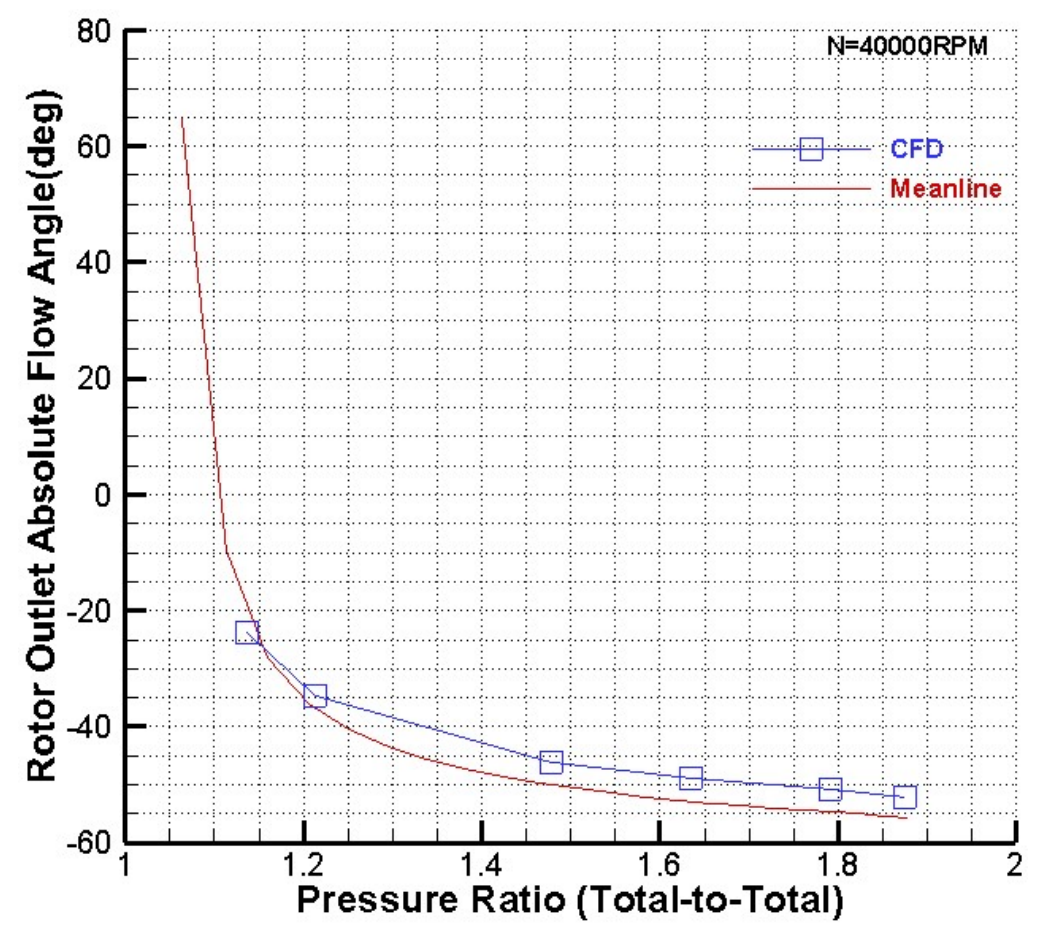

Figure E-5 Results Comparison for Rotor Outlet Absolute Flow Angle between Meanline and CFD Analyses ( $\mathrm{N}=40000 \mathrm{RPM})$. 


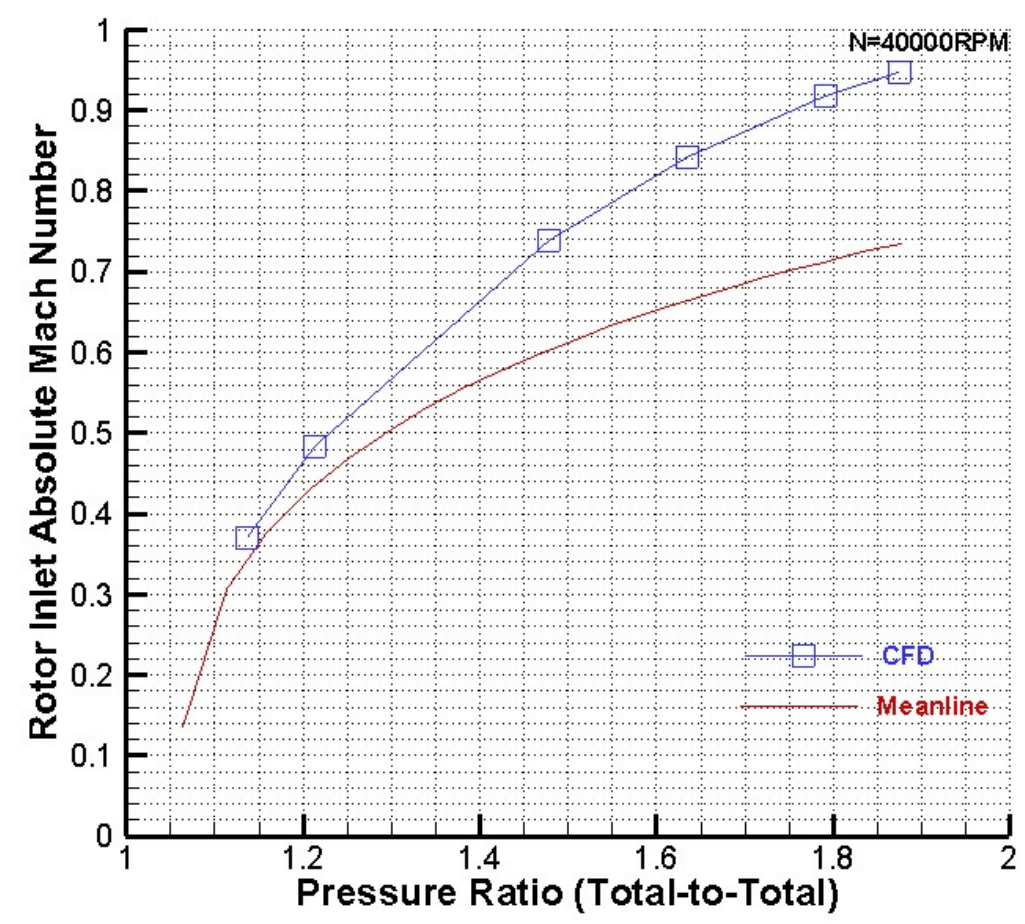

Figure E-6 Results Comparison for Rotor Inlet Absolute Mach Number between Meanline and CFD Analyses ( $\mathrm{N}=40000 \mathrm{RPM})$.

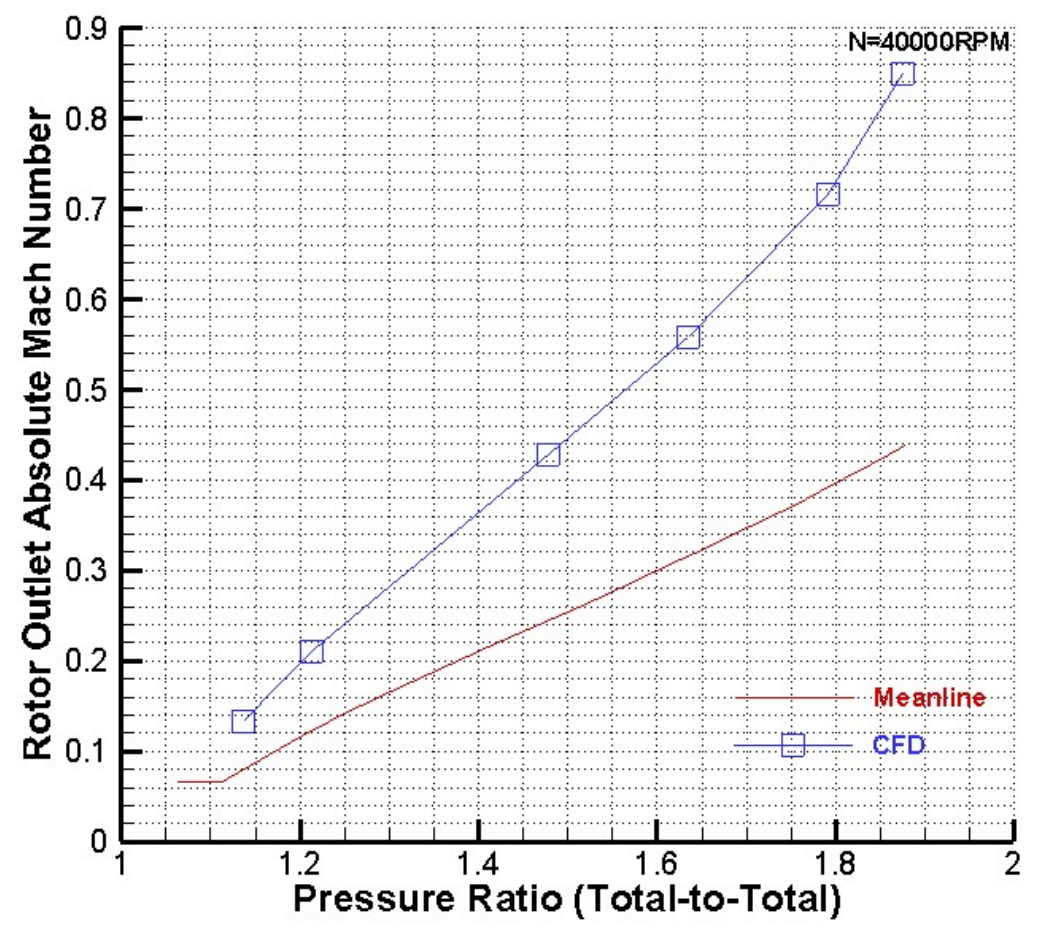

Figure E-7 Results Comparison for Rotor Outlet Absolute Mach Number between Meanline and CFD Analyses ( $\mathrm{N}=40000 \mathrm{RPM})$. 


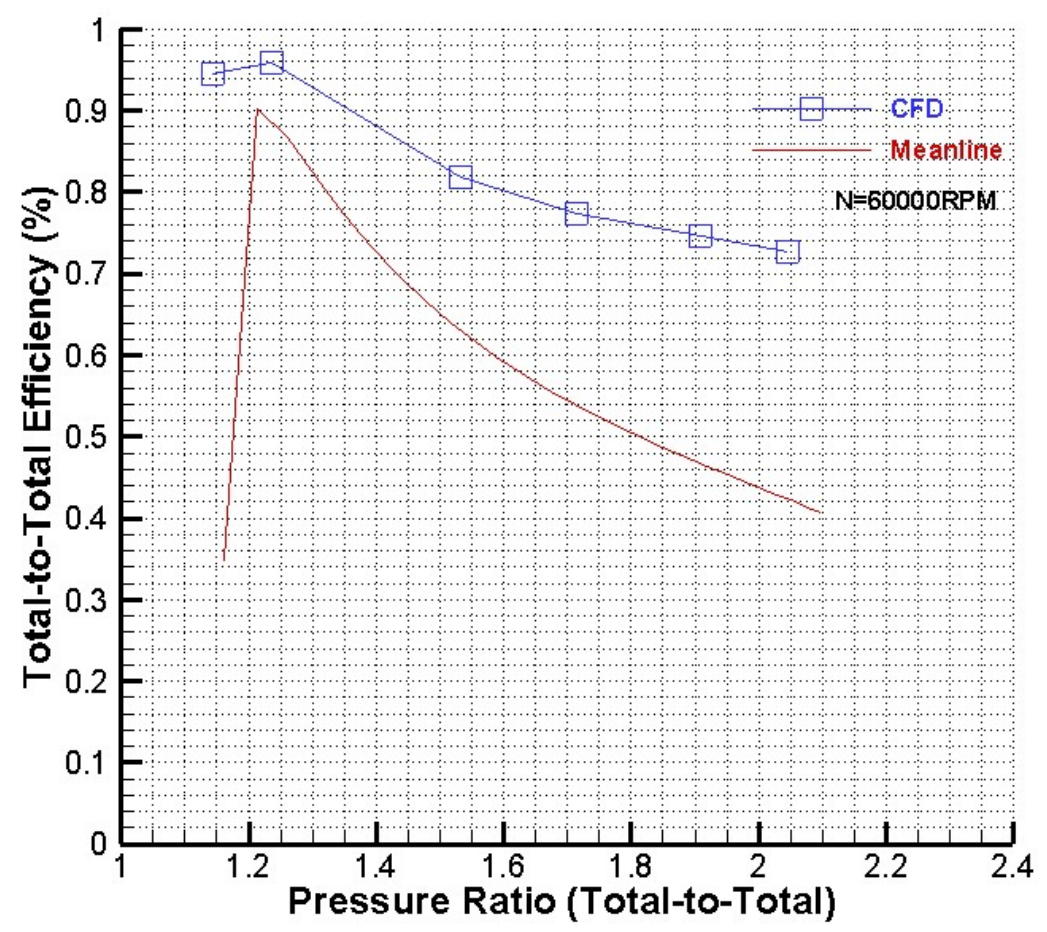

Figure E-8 Results Comparison for Total-to-Total Efficiency between Meanline and CFD Analyses (N=60000 RPM).

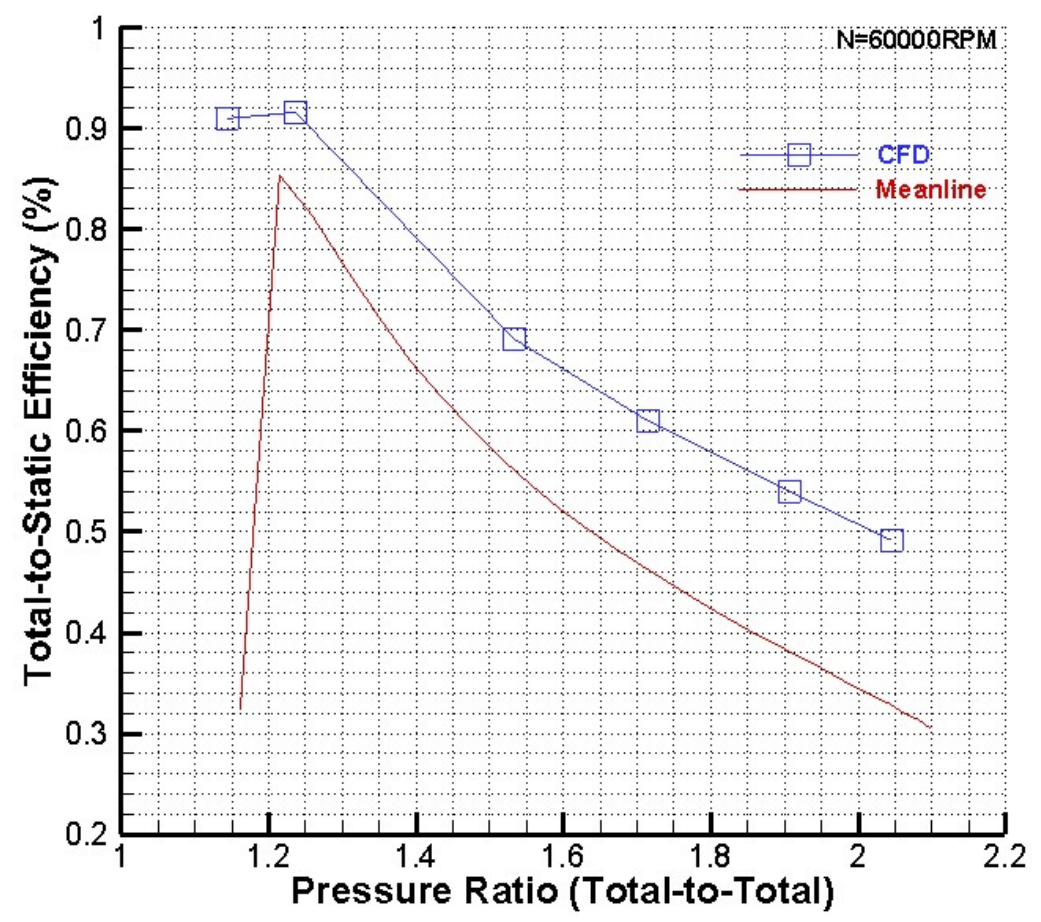

Figure E-9 Results Comparison for Total-to-Static Efficiency between Meanline and CFD Analyses (N=60000 RPM). 


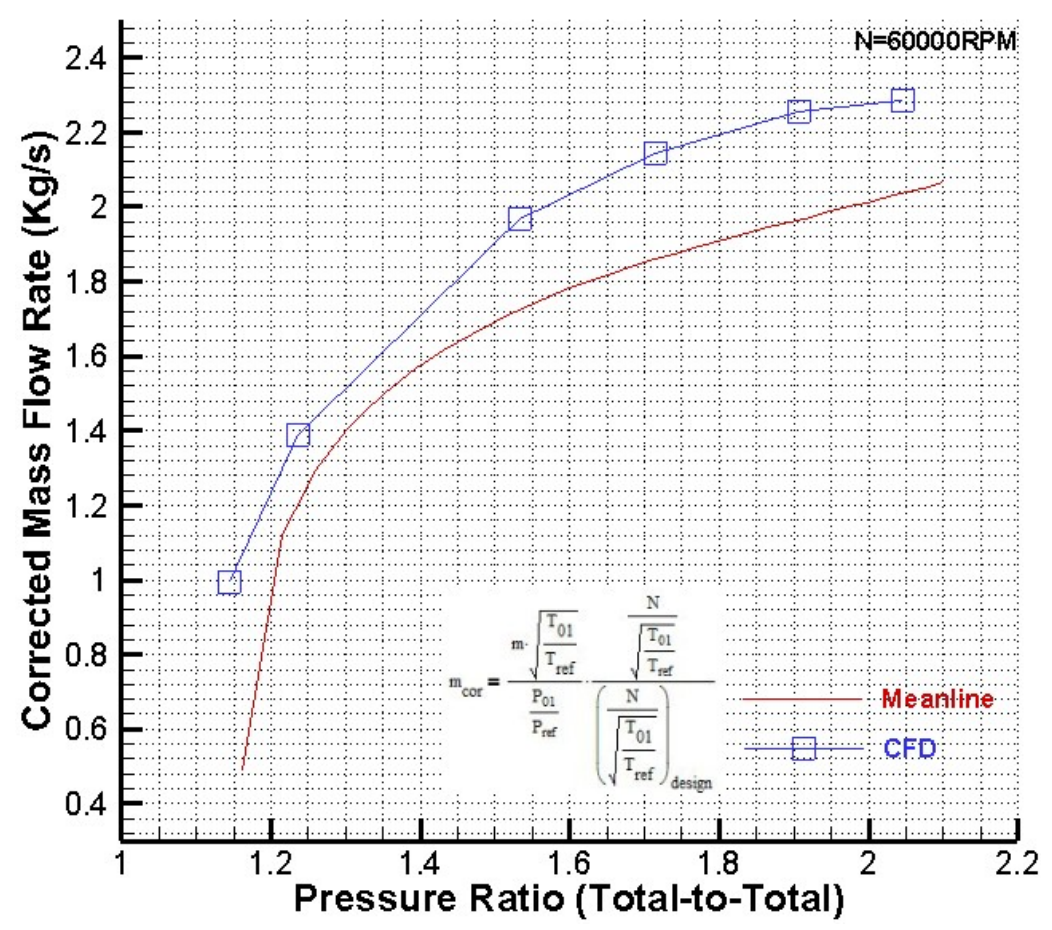

Figure E-10 Results Comparison for Mass Flow Rate between Meanline and CFD Analyses $(\mathrm{N}=60000 \mathrm{RPM})$.

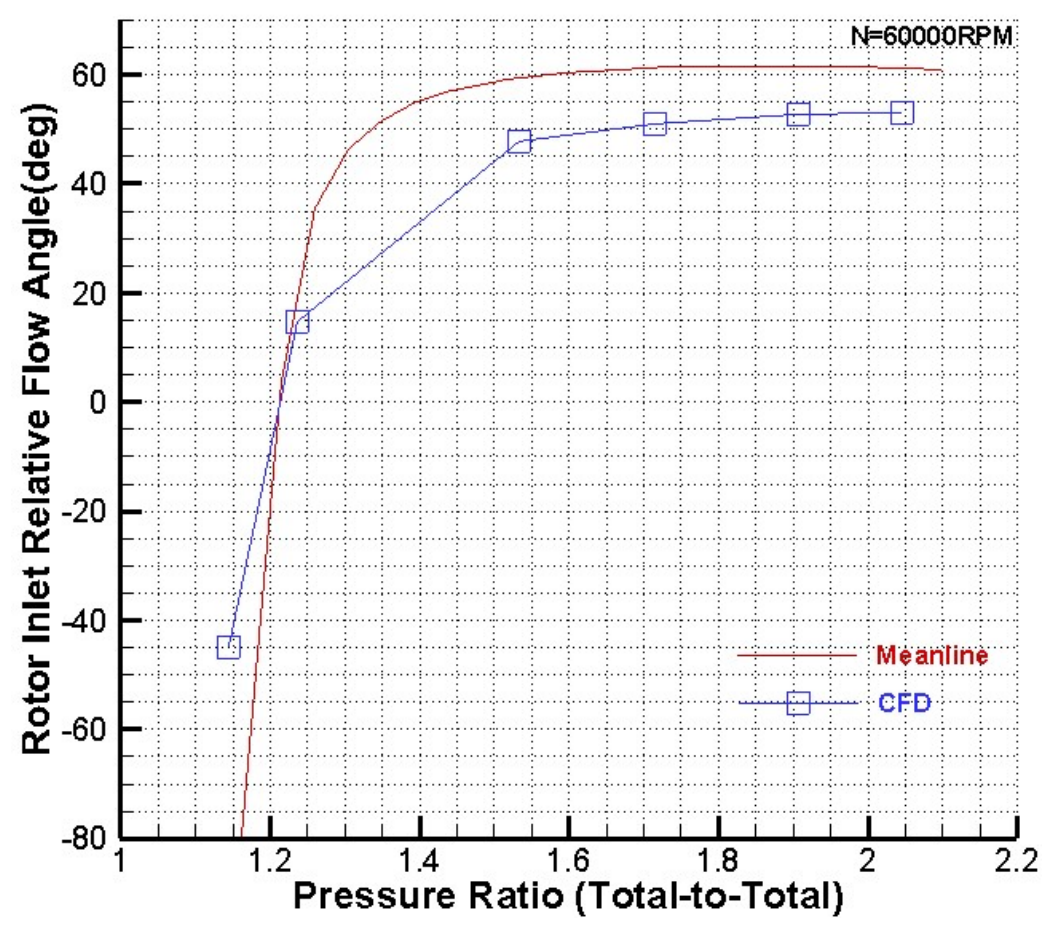

Figure E-11 Results Comparison for Rotor Inlet Relative Flow Angle between Meanline and CFD Analyses ( $\mathrm{N}=60000 \mathrm{RPM})$. 


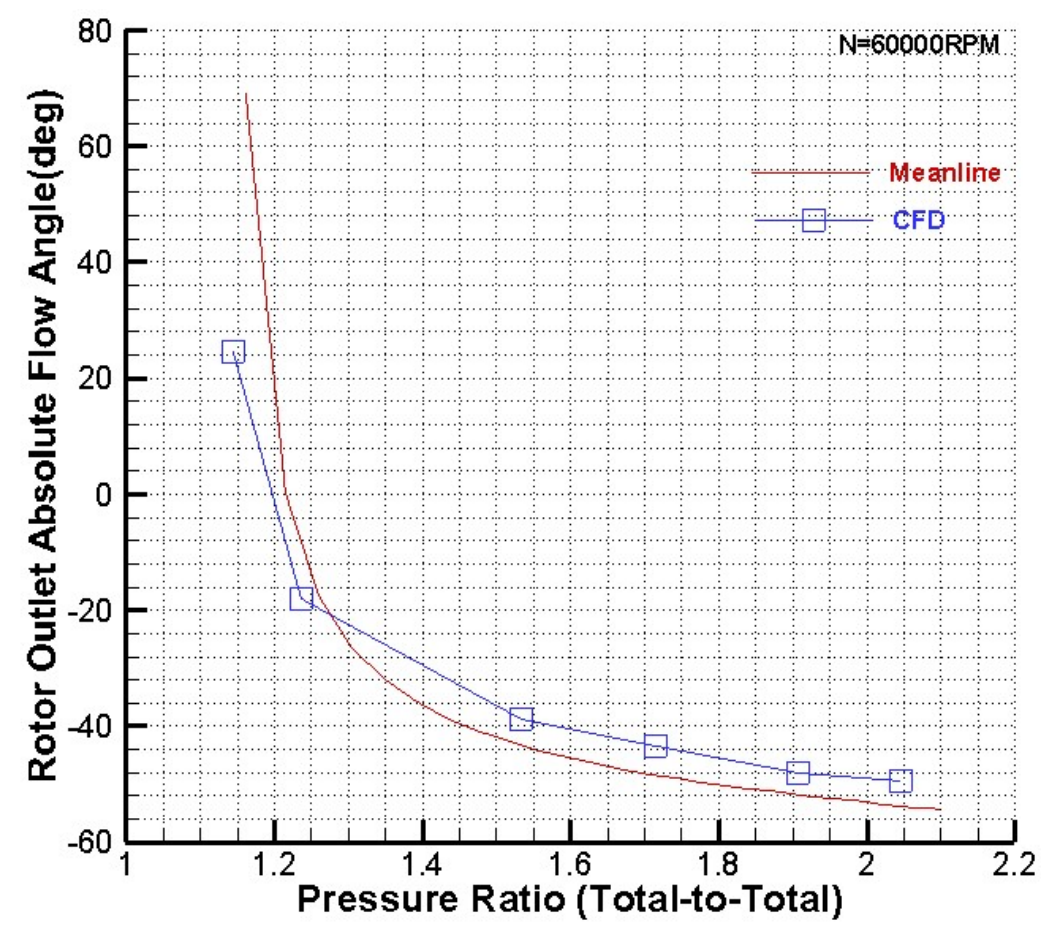

Figure E-12 Results Comparison for Rotor Outlet Absolute Flow Angle between Meanline and CFD Analyses ( $\mathrm{N}=60000 \mathrm{RPM})$.

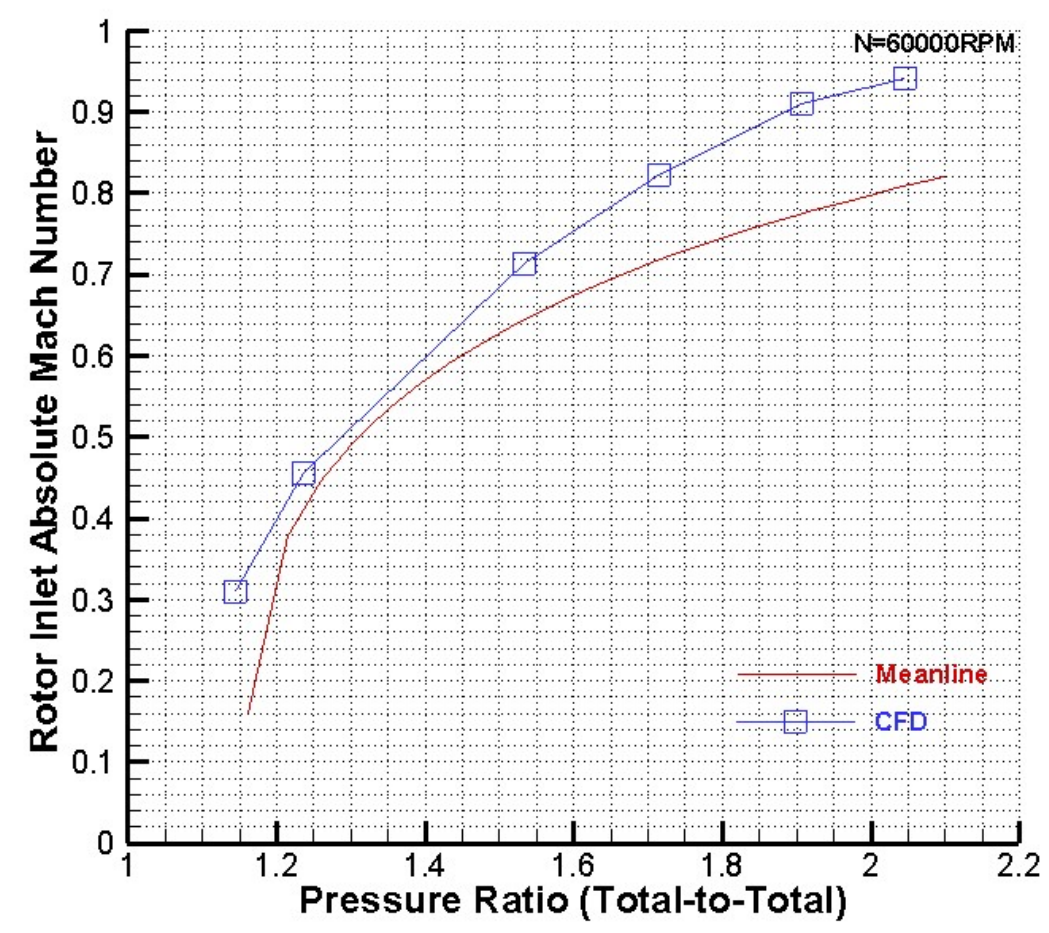

Figure E-13 Results Comparison for Rotor Inlet Absolute Mach Number between Meanline and CFD Analyses ( $\mathrm{N}=60000 \mathrm{RPM})$. 


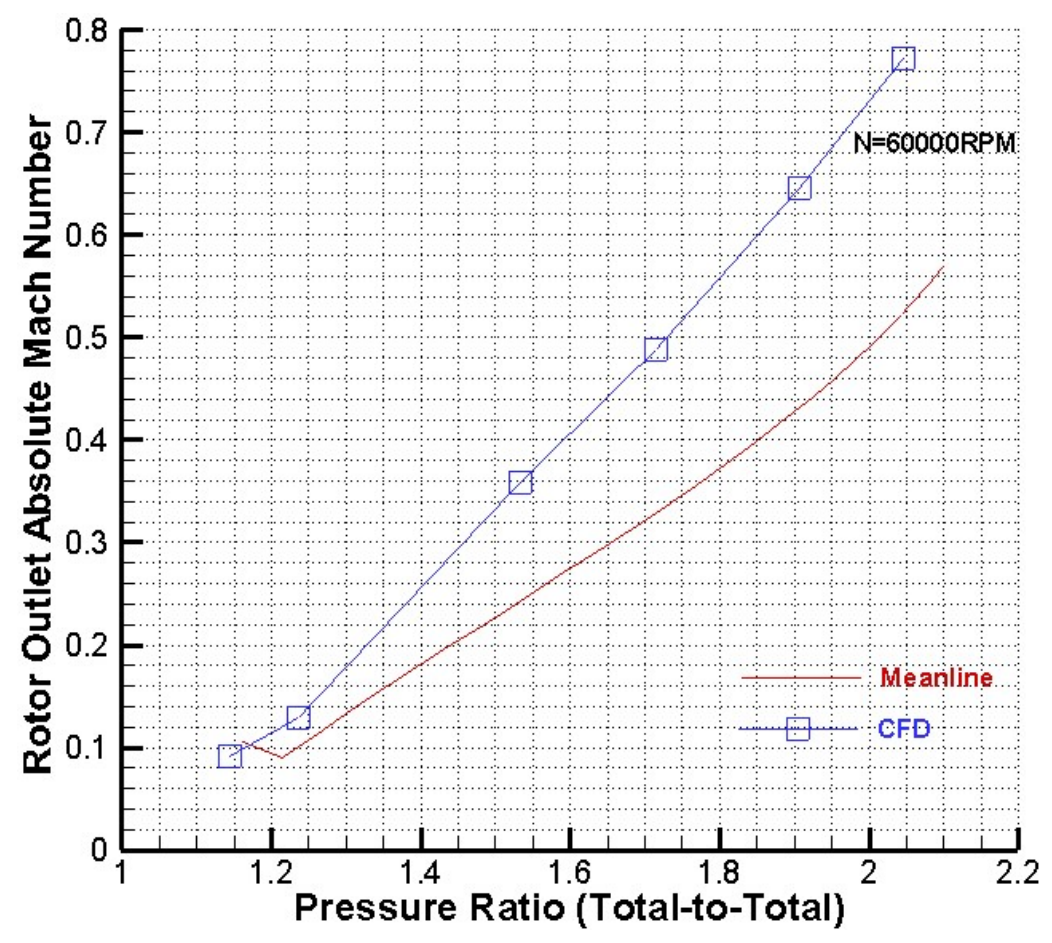

Figure E-14 Results Comparison for Rotor Outlet Absolute Mach Number between Meanline and CFD Analyses ( $\mathrm{N}=60000 \mathrm{RPM})$.

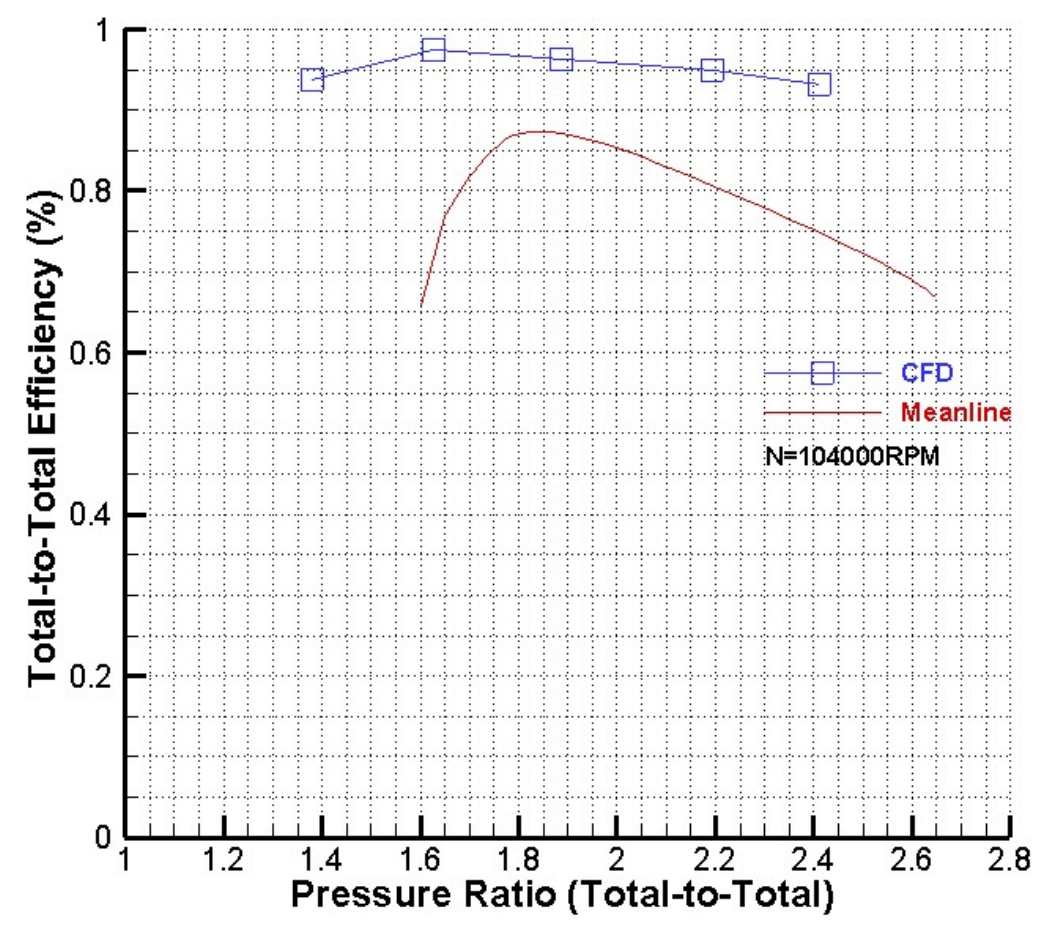

Figure E-15 Results Comparison for Total-to-Total Efficiency between Meanline and CFD Analyses (N=104000 RPM). 


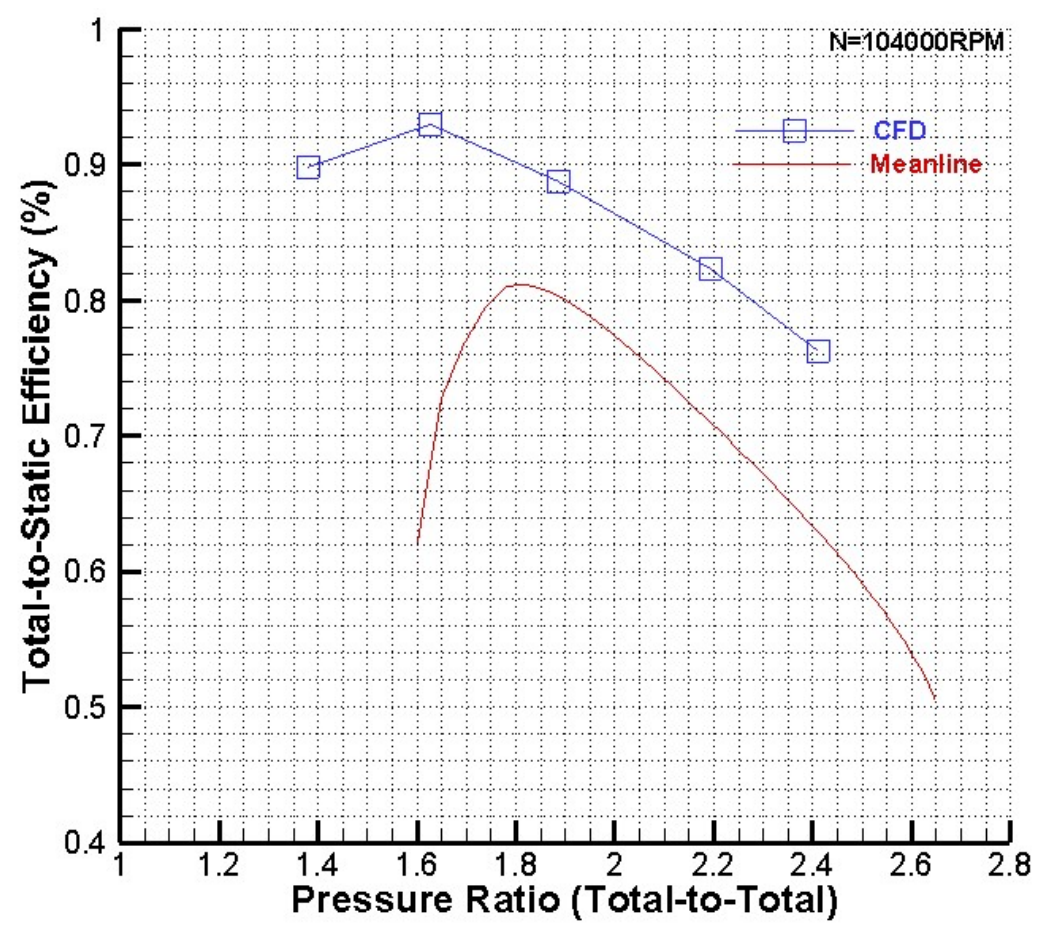

Figure E-16 Results Comparison for Total-to-Static Efficiency between Meanline and CFD Analyses (N=104000 RPM).

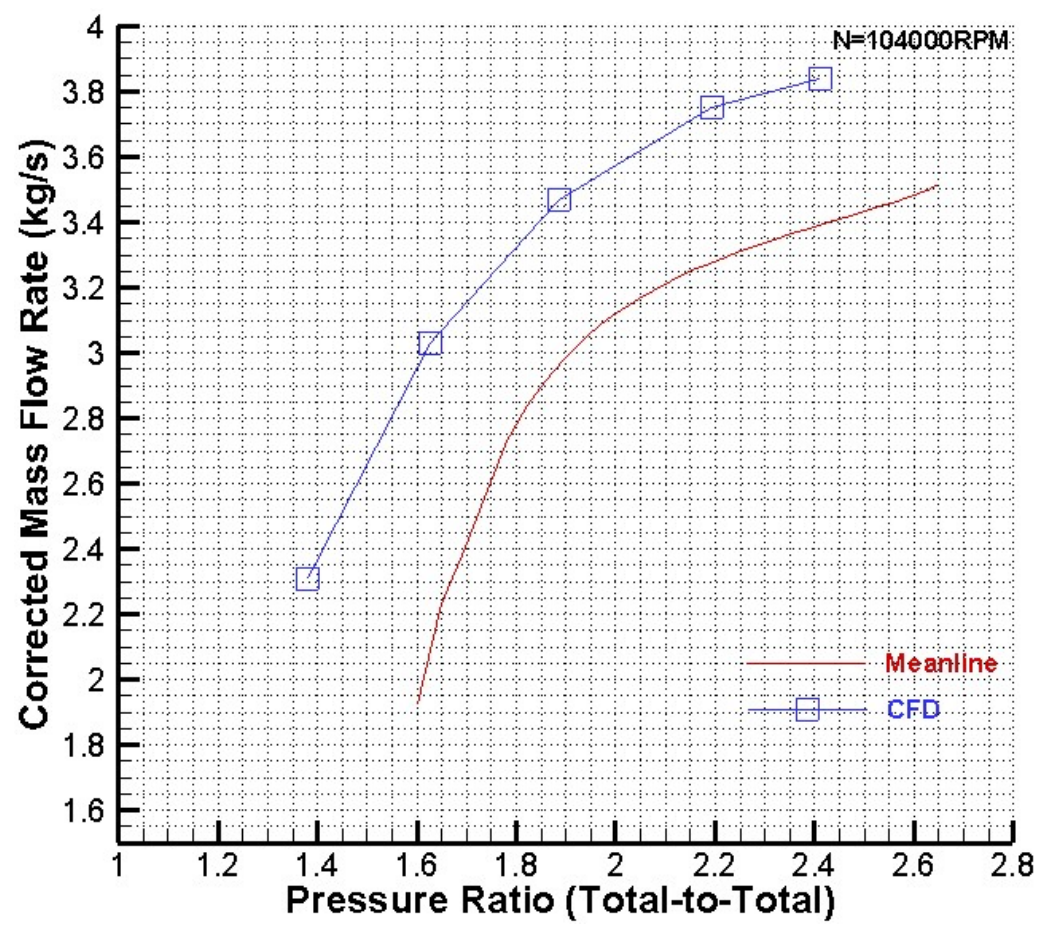

Figure E-17 Results Comparison for Mass Flow Rate between Meanline and CFD Analyses $(\mathrm{N}=104000$ RPM). 


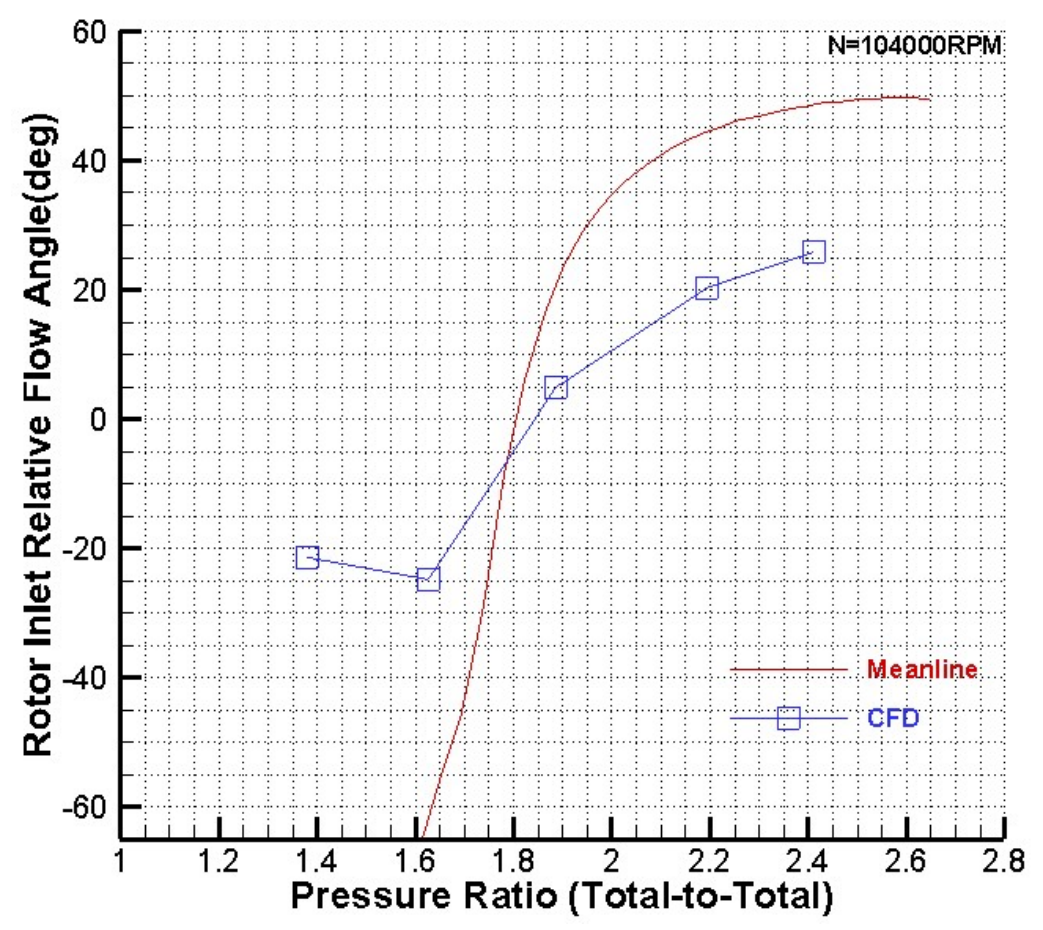

Figure E-18 Results Comparison for Rotor Inlet Relative Flow Angle between Meanline and CFD Analyses (N=104000 RPM).

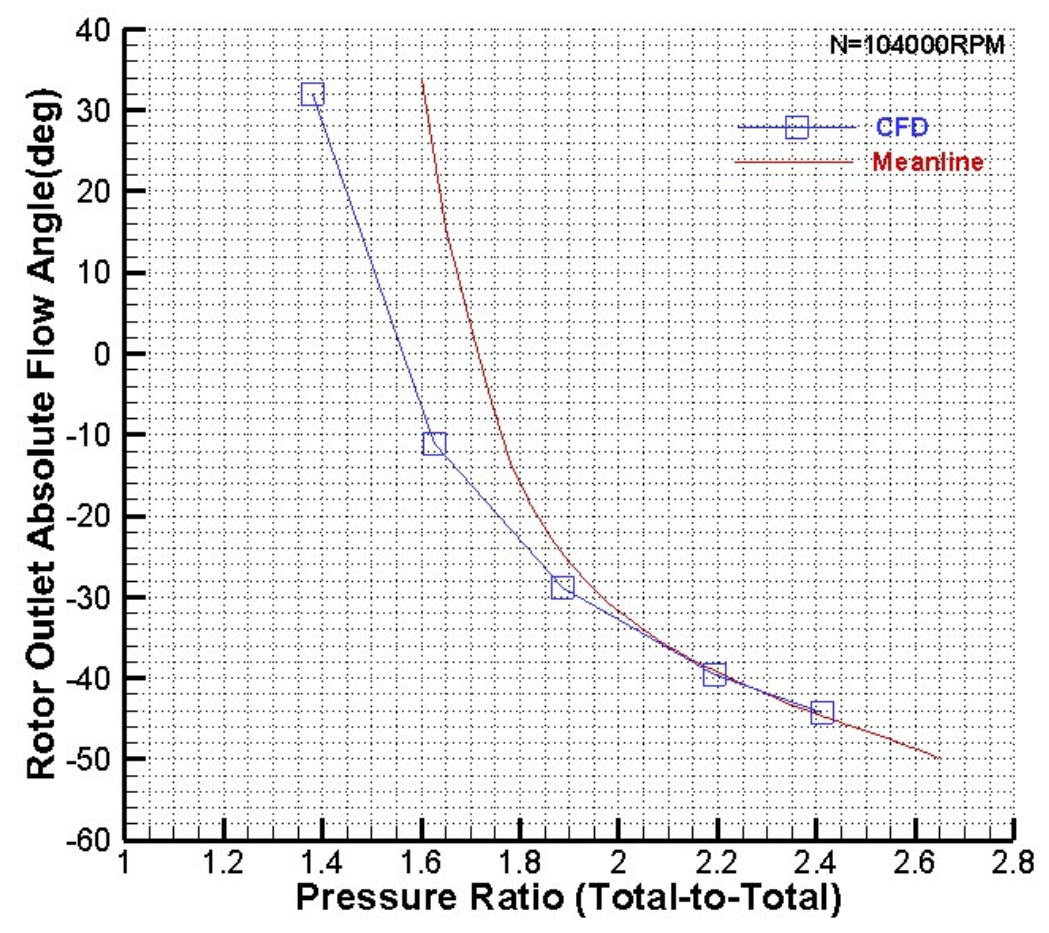

Figure E-19 Results Comparison for Rotor Outlet Absolute Flow Angle between Meanline and CFD Analyses ( $\mathrm{N}=104000 \mathrm{RPM})$. 


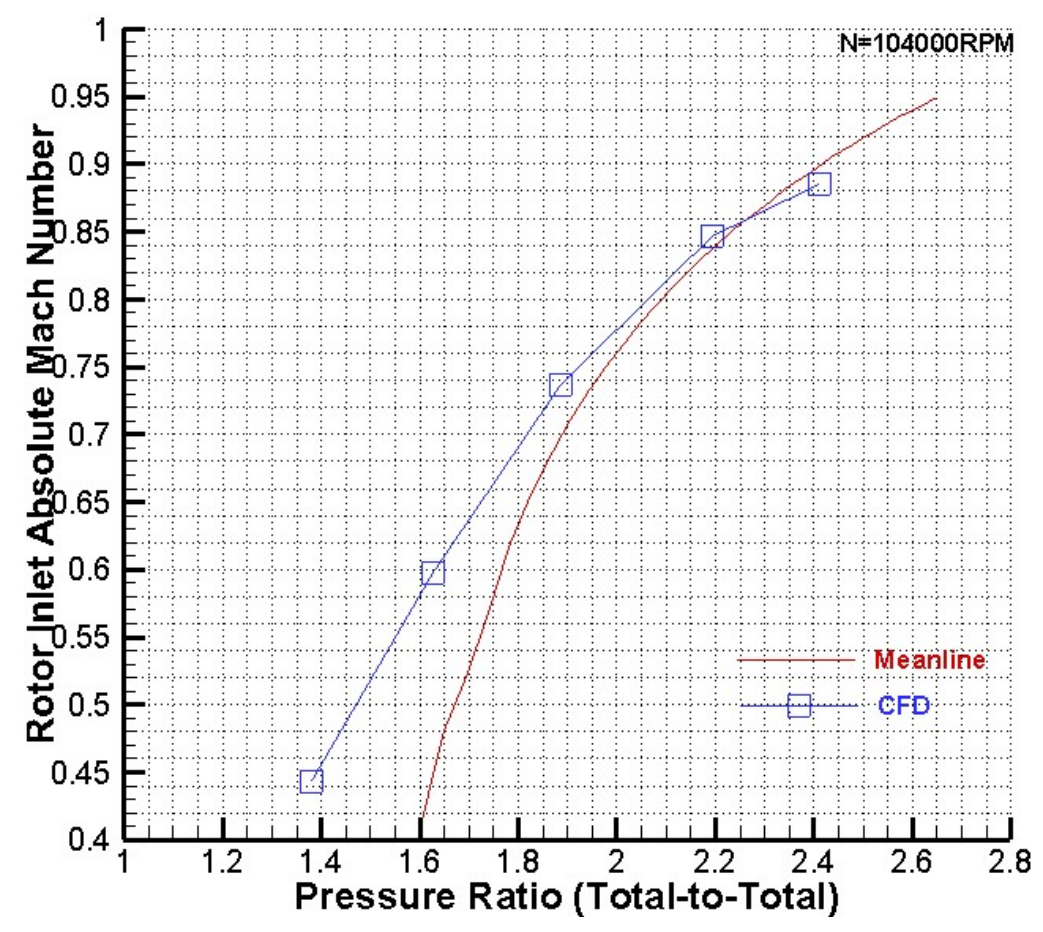

Figure E-20 Results Comparison for Rotor Inlet Absolute Mach Number between Meanline and CFD Analyses ( $\mathrm{N}=104000 \mathrm{RPM}$ ).

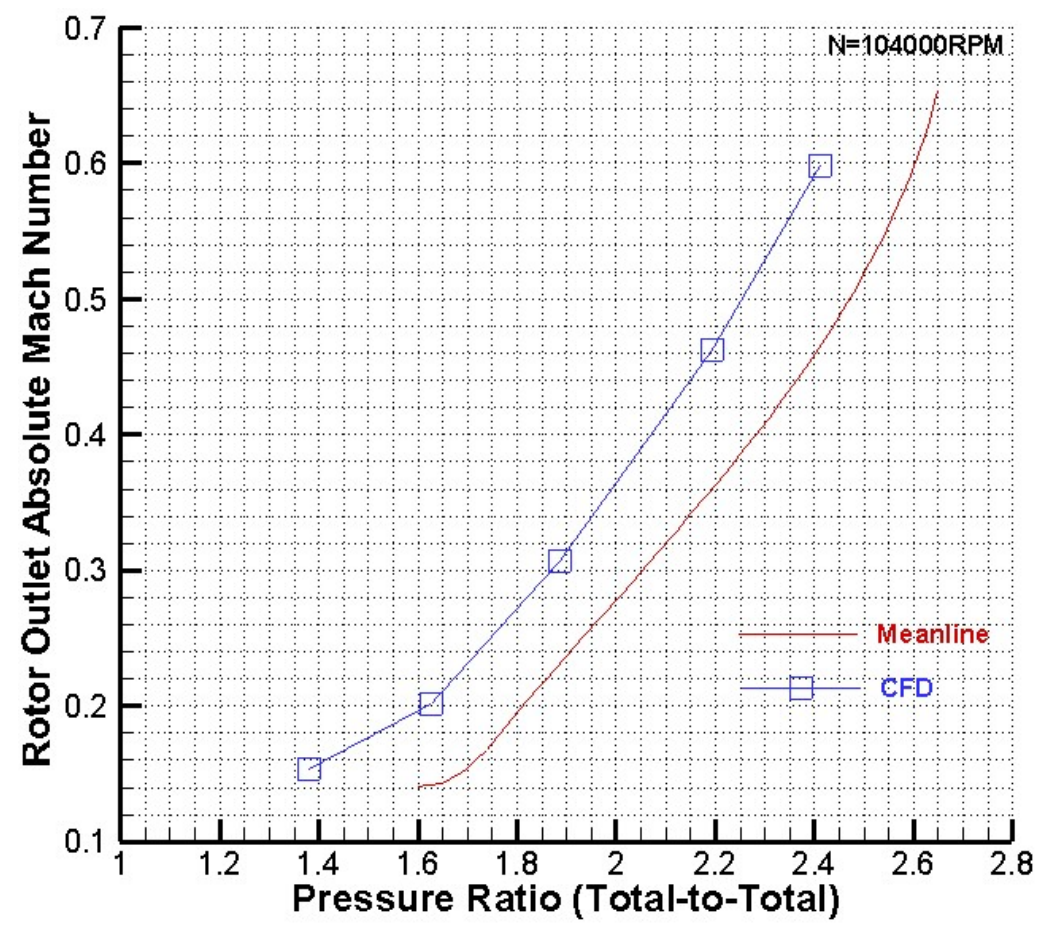

Figure E-21 Results Comparison for Rotor Outlet Absolute Mach Number between Meanline and CFD Analyses ( $\mathrm{N}=104000 \mathrm{RPM}$ ). 